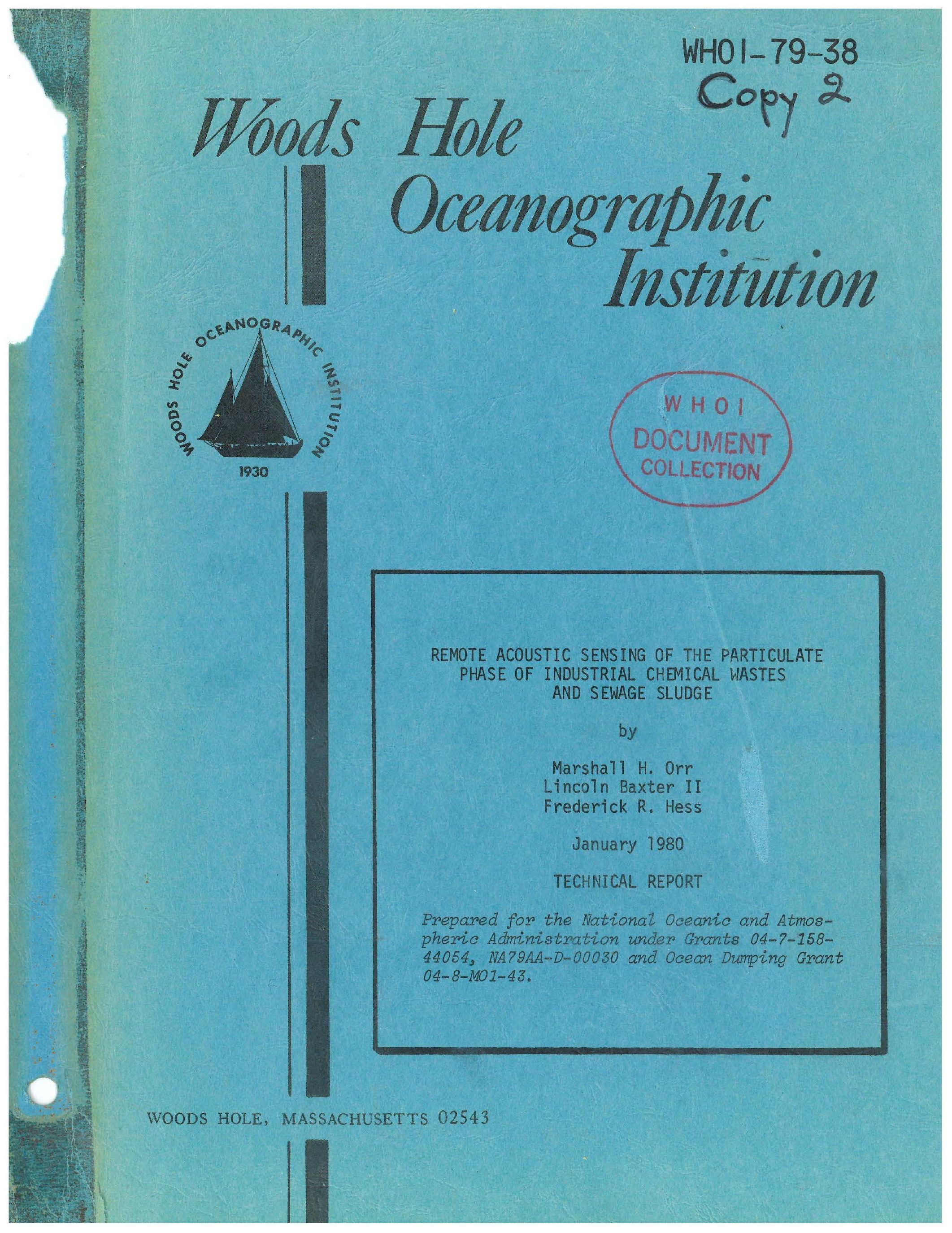


WHOI $-79-38$

FINAL REPORT FOR THE YEAR 1978

\title{
REMOTE ACOUSTIC SENSING OF THE PARTICULATE \\ PHASE OF INDUSTRIAL CHEMICAL WASTES AND SEWAGE SLUDGE: \\ REPORT ON THE SEASONAL VARIABILITY OF \\ THE DISPERSION OF THE PARTICULATE PHASE \\ AS OBSERVED FROM THREE CRUISES: JULY 1977 , JANUARY-FEBRUARY 1978, AND APRIL 1978.
}

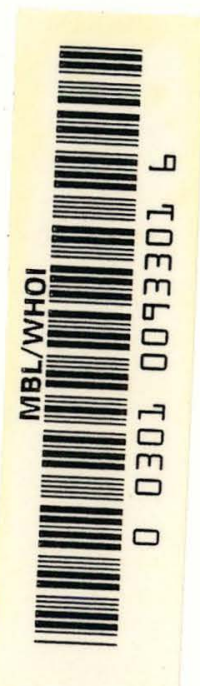

by

\begin{abstract}
Marshall R. Orr Lincoln Baxter II
\end{abstract} Frederick R. Hess

\author{
WOODS HOLE OCEANOGRAPHIC INSTITUTION \\ Woods Hole, Massachusetts 02543 \\ January 1980
}

\section{TECHNICAL REPORT}

Prepared for the National Oceanic and Atmospheric Administration under Grants 04-7-158-44054, NA79AA-D-00030 and Ocean Dumping Grant 04-8-M01-43.

Reproduction in whole or in part is permitted for any purposed of the United States Govermment. This report should be cited as: Woods Hole Oceanographic Institution Technical Report WHOI-79-38.

Approved for DistributionEal \& deyo 
I. Introduction I

II. Description of Acoustic System 2

A. Design Requirements 2

B. System Philosophy 3

C. System Layout 4

II. Discussion of the Oceanic Conditions Which Have 11

$\begin{array}{ll}\text { Existed at DWD } 106 \text { as a Function of Season } & \\ \text { A. Water Properties } & 11\end{array}$

B. Internal Waves: Their Effect on the Position of 13 Isopycnals and Chemical Sampling Procedures

$\begin{array}{ll}\text { IV. Ships Operations } & 16\end{array}$

V. Dispersion of the Particulates as a Function of 19 Season

A. Edge Moor Waste 19

1. Summertime Conditions 20

2. Wintertime Conditions 28

3. Springtime Conditions 30

4. Analysis of Analog Signal Amplitude vs. Time 31 to Indicate Dispersion Rates of the Plume

B. Grasselli Waste 34

1. Wintertime Conditions 34

2. Summertime Conditions 36

3. Analysis of Analog Signal Amplitudes vs. Time 39 to Determine Dispersion Rates of the Plume

VI. Dispersion of the Sewage Sludge and the Effects of

Pharmaceutical Waste Disposal on the Acoustic Backscattering as Observed During One Season

A. Sewage Sludge

B. Pharmaceutical Waste 44

VII. Discussion of Some Model Considerations: The Necessary 46 Supportive Physical Oceanographic Data Needed to Support or Test the Models

VIII. Conclusions 
INDEX (cont.)

$\begin{array}{ll}\text { Figure Captions } & 57\end{array}$

$\begin{array}{ll}\text { Figures } & 67\end{array}$

$\begin{array}{ll}\text { List of Tables } & 139\end{array}$

Tables 140 


\section{Abstract}

The seasonal variability of the dispersion of the particulate phase of industrial chemical waste has been studied with acoustic backscattering techniques at Deep Water Dumpsite 106 (DWD 106). The vertical dispersion of the particulates has been found to be strongly dependent on the depth of the mixed layer and the magnitude of the density gradient associated with the seasonal thermocline. The horizontal dispersion of the particulates as a function of depth has been found to be strongly dependent on the shear present in the water column. Entire waste plumes have been found to be advected out of the dumpsite in less than 24 hours when the area is occupied by a warm core ring.

Simple calculations based upon Stoke's law are presented to reveal the impact of variable oceanic density structure on the sink rate of particles and to indicate the need for incorporating these considerations into numerical models.

A short discussion is presented on (I) the need to make field measurements on the magnitude of both turbulence and shear in the water column and (2) the need to incorporate shear an 1 turbulencedependent calculations for the sink rates of particles into those numerical models which may be used to predict the particulate and effluent dispersion rates at DWD 106. 


\section{Introduction}

High-frequency acoustic backscattering systems ${ }^{1}$ (Figure I) are being used at Deep Water Dumpsite 106 (DWD 106) to study the vertical and horizontal dispersion of particles which are associated with or are formed during the release of industrial chemical waste and sewage sludge.

This report discusses the results of three cruises which occurred during winter, spring, and summertime oceanic conditions at DWD 106. The report is divided into eight sections. These include an engineering description of the acoustic system used during the cruises, a description of the seasonal variability of the dispersion of the particulates associated with the duPont Edge Moor waste and the duPont Grasselli waste, a discussion of the dispersion of sewage sludge during summer oceanic conditions, the impact on the water column of a pharmaceutical waste disposal observed during the spring, and a discussion of the implications which the acoustic data has on any consideration for predictive models of waste dispersion in the ocean.

Three data sets, which were acquired in July 1977, January-February 1978, and April 1978, will be presented by waste type and season. The sets will be intercompared, with specific attention being focused on the differences in dispersion characteristics which have been detected as a function of varying water conditions. Overlay maps showing the time development in the horizontal plane of the particulate plumes, graphic acoustic records showing the vertical distribution of the particulates, and analog acoustic signals indicating the change in amplitude of the volume reverberation levels, hence, the particulate concentrations as a function of time, will be presented. 
II. Description of the Acoustic System

A high-performance acoustic backscattering system (Figure 1) has been developed at the Woods Hole Oceanographic Institution for the study of particulate distributions and fluid processes in the ocean. The design requirements, engineering philosophy, and layout of the system are discussed below.

\section{A. Design Requirement}

Preliminary investigation ${ }^{1,2}$ (Orr, 1977) into the possible use of a multi-frequency, high resolution acoustic backscattering system for observation of the particulate phase of industrial chemical waste dispersion and fluid processes in the ocean led to the establishment of the system design criteria. These investigations, using available, commercially produced, and improvised equipment, proved that the particulate phase of chemical wastes as well as sediment burdens in the water column could be investigated acoustically. From these tests, it became obvious that the two major design goals for a single package system were wide operating frequency range and the widest possible system dynamic range. In order to be capable of high discrete target resolution as well as low level volume scattering detection, variable pulse widths from a few cycles to several tens of cycles irrespective of operating frequency were specified. Control of the pulse amplitude was also specified to permit short range studies to be made without unnecessary reverberation and to allow the observer to optimize the received signal for a particular range. 
B. System Philosophy

$\underline{\text { Receiver }}$

The initial acoustic investigations ${ }^{1,2}$ had indicated that the receiver should incorporate analog signal processing and digital control of appropriate functions.

The design criteria specified were:

(1) The receiver should be easily tuned to a wide range of frequencies ( $10 \mathrm{kHz}$ to $>600 \mathrm{kHz}$ ) and all channels should be interchangeable.

(2) Digital control should be included for repeatability.

(3) Receiver bandwidths should be made constant and repeatable from one operating frequency to another.

(4) Receiver blanking and signal gating should be provided.

(5) Some form of repeatable time-variable-gain (TVG) should be incorporated into the system.

All of the foregoing virtually mandated the use of a superheterodyne receiver. This receiver type allows:

(1) Tuning by digital control if a synthesizer is used for the local oscillator.

(2) Uniformity of response at different frequencies with the use of intermediate frequency (IF) filters.

(3) Overall system gain which is readily adjusted and has good stability.

(4) Any frequency within the design range to be received with equal facility. 


\section{Transmitter}

To be compatible with the receiver specifications, the transmitter was required to operate over the same frequency range (10 to $>600 \mathrm{kHz}$ ). The need for repeatability in performance also demanded synthesizer control. The criteria of variable pulse width, i.e., the number of cycles transmitted, dictated the use of digital control. The low duty cycle of this acoustic system, typically less than one or two percent, allowed the generation of high pulse power in a small physical package.

Recorder and Control

The system was designed to provide the timing, gating, and drive signals necessary for the control of a graphic recorder (EPC 4600)

\section{Transducers}

A set of transducers and associated tow-body was necessary. Due to theoretical considerations, the $200 \mathrm{kHz}$ transducer was specified to have a beamwidth on the order of one degree, while at the lower frequencies (20 and $37 \mathrm{kHz}$ ), beamwidths of 15 and 6 degrees respectively were dictated by the space available in the tow body.

\section{System Layout}

The system layout was divided into three main components exclusive of the recorder. These components were mounted in a Nuclear Instrumentation Module (NIM) rack (Figure 2). One NIM 
rack contains the necessary number of components to operate at two separate frequencies.

The three principal main-frame components are (1) clock and timing control chassis (CTC) (Figure 3), (2) the receiver (RCVR) (Figure 4), and (3) the transmitter (XMTR) (Figure 5). All of the system power is provided by modular power supplies mounted on the NIM main-frame.

(1) Main-frame. Commercially available power supply modules provide the following power: $+5 \mathrm{~V},-25 \mathrm{~V},+12 \mathrm{~V}$, and $-12 \mathrm{~V}$, all of which are bussed to each module and are available on internal terminal strips for external access.

The main-frame rear apron mounts the fuses as well as the I/O connections to the system.

(2) Clock and Timing Control Chassis (CTC). This module (Figure 3 ) is comprised of a master crystal oscillator and associated count-down circuitry which generates all system control signals. Signals available from the CTC chassis are as follows:

(a) IRIG Clock. An IRIG B format time code is generated and consists of a $\mathrm{BCD}$ time code amplitude modulated on a $1 \mathrm{kHz}$ sine wave. The signal is suitable for direct recording on magnetic tape recorders and is available from the rear apron.

(b) Recorder Clock. An 800 pulse-per-sweep, TTL level pulse train suitable for providing external drive signal to the EPC recorder is generated and is accessible from both the front panel and the rear apron. 
(c) Key. Two lines, "Ø1 Key" and "Ø2 Key" are available. These lines provide TTL, positive-going pulses of approximately two micro-seconds duration at the beginning of each recording interval. They are internally wired to the appropriate transmitter through the module back connectors as well as being available on the front panel for convenience in synchronizing oscilloscope displays. Two flashing red LED's are provided on the panel to give a visual indication of the system operation.

(d) Receive Enable. A signal, internally wired through back connectors, enables each receiver for its selected portion of the system sweep cycle and conversely disables each receiver when the other is enabled.

(e) TVG Ramps. Zero to +10 volt ramps are internally connected to each receiver. One ramp is linear and the other rises as $t^{2}$. The ramps are used as control inputs to multipliers in the receivers. The ramps alternate between channel one and channel two, and increase from 0 to $+10 \mathrm{~V}$ for each receive enable period. Slopes vary with sweep split (see split scan loths below) such that the channel gain goes to maximum at the end of each scan segment, irrespective of the split used.

Front panel controls on the CTC module are as follows:

Set Day. A thumbwheel switch allows the setting of the day of the year or any 3-digit number into the day position of IRIG time code.

Set Time. The "hours" switch advances the clock (and display) at a one step/second rate. The "minutes" switch advances minutes 
at a one step/second rate. The "hold" switch stops the clock and allows restarting at 00 seconds upon release.

Speed. A programmed divider chain provides the proper drive frequency to the EPC recorder corresponding to the sweep speed set on this switch.

Split Scan 10ths. A thumbwheel switch selects the fraction of the sweep on which the channel two transmitter is keyed and the channel two receiver enabled. If the switch is set to zero, channel one is disabled.

Sync Receptable. A TTL pulse is accepted at the sync receptacle from the EPC recorder key pulse output. The pulse synchronizes the recorder sweep to the keying of the transmitter. The circuit is active when the push-button above the jack is pressed.

(3) Receiver. The function of the receiver front panel controls and connectors (Figure 4) is described:

(a) Frequency. A four-gang thumbwheel switch sets the operating frequency of the receiver and transmitter. The frequency is settable in $100 \mathrm{~Hz}$ increments $(0.1 \mathrm{kHz})$. An internal adder circuit adds 455.0 to the number entered and uses the sum to program the synthesizer card for the local oscillator injection frequency .

(b) RCVR Bandwidth. A single section thumbwheel switch provides a parallel BCD signal to CMOS multiplexer I/C's which select one of eight ceramic IF filters. (Note digits 9 and 0 select filter zero and one respectively.) The filter 
selection is as follows:

\begin{tabular}{cc} 
Digit & Bandwidth $(3 \mathrm{db})$ \\
\cline { 2 - 2 } 0 & $35 \mathrm{kHz}$ \\
1 & 30 \\
2 & 26 \\
3 & 20 \\
4 & 16 \\
5 & 12 \\
6 & 8 \\
7 & 6 \\
8 & 35 (repeat 0$)$ \\
9 & 30 (repeat 1$)$
\end{tabular}

(c) Manual Gain Control. A 10-turn potentiometer sets the system gain when the spreading ON/OFF switch is in the OFF position. The manual gain control operates by providing a 0 to IOV adjustable level to the multiplier in place of the TVG ramp signals.

(d) Spreading ON/OFF. This switch is used to select whether one of the TVG voltage ramps or the adjustable voltage level from the manual gain control is applied to the multiplier.

(e) Spreading $I I N-I / R^{2}$. This switch selects whether the linear or $t^{2}$ voltage ramp is applied to the multiplier for partial compensation of the acoustic spreading losses.

(f) Post Detection Amplifiers. A five-position switch which sets the dc amplifier gain applied to output of the superheterodyne receiver after simple diode detection and $100 \mathrm{\mu} \mathrm{sec}$ integration is provided for each gain range of the receiver. An OFFSET screwdriver adjustment below each gain switch provides convenient adjustment of the dc amplifier offset voltage.

(g) Output HI-MED-LO. Output jacks from the receiver provide signals whose gains differ by $30 \mathrm{db}$ (LO-MED) and $10 \mathrm{db}$ (MED-HI) assuming equal settings of the past detection amplifiers. The output signal is a positive voltage level from the detector which 
is applied to the past detection dc amplifier and a subsequent relay which is keyed by the receiver enable signal. A $10 \mathrm{k}$ ohm output resistor prevents accidental overload and makes for simple mixing of both receiver outputs with a single resistor to ground. These outputs are also available on the rear apron of the NIM rack.

(h) $\mathrm{v}^{2} / 10$. This pair of jacks (IN and OUT) provide a voltage squaring capability. The output is equal to the input voltage squared times 0.1 , and is useful up to approximately two volts peak input signal.

(i) Testpoints. The $+5,+12,-12,+25$, local oscillator (LO) test points provide convenient access for checking power supply voltage and proper operation of the local oscillator synthesizer.

(4) Transmitter. The front panel controls and connectors of the transmitter (Figure 5) are described below:

(a) Pulse width. A two-section thumbwheel switch selects the number of cycles in each transmitted burst. The programmed cycle counter compares the number set to the running count of output and stops when they are equal.

(b) Range. A three-position switch sets the synthesizer frequency range to a proper decade (not necessary on receiver because added $455 \mathrm{kHz}$ keeps output always in same decade). The range control is necessary to obtain full four-digit frequency control.

(c) Output. An XL-type jack provides a 2-phase TTL square wave burst to the power amplifier. Both phases are low during receive time.

(d) Frequency. This control is located on the receiver module. The transmitter is slaved to the receiver frequency. 
(5) Pre-Amplifier Control and Junction Panel. This panel (Figure 6) contains power distribution as well as signal connections from and to the acoustic fish. Remote switching allows the selection of the proper pre-amplifier gain setting relays contained in the pre-amplifier housing in the acoustic fish.

(a) Pre-Amplifier Gain. A four-position switch remotely controls the gain of the pre-amplifiex by means of reed relays. (The pre-amplifiers, tuning networks, and transmit/receive (T/R) diodes are in a small housing in the transducer tow body.) Depending on environmental conditions, the pre-amplifier gain is varied from 20 to $50 \mathrm{db}$.

(b) Line Amplifier. A $20 \mathrm{db}$ line amplifier is provided in the junction panel to augment the pre-amplifier gain. A front panel bypass switch is provided.

(6) Transmitter Power Amplifiers. Two power amplifiers (Figure 7), one for each channel, are provided. Each is capable of approximately 1200 watt pulse output at 2\% duty cycle over the entire frequency range of the system. A commercial power supply comprises an integral part of the amplifier assembly. It serves as a control of the power output by means of varying the supply voltage to the output stage. 
III. Description of the Oceanic Conditions Which Have Existed at DWD 106 as a Function of Season

A. Water Properties - Densities, Currents, and Turbulence

The water properties ${ }^{3}$ encountered at DWD 106 which is located

over the continental slope (Figure 8) are known to change considerably

as a function of time. This is a result of the daily and seasonal

variability of the thermal heating of the mixed layer, the frequency

and intensity of atmospheric storms and cold fronts, the influxes of

both shelf and slope water, and/or the passage of warm core rings

through the immediate vicinity. The late spring and summer months

find increasing thermal heating of the water column and a decrease

in both the intensity and the frequency of atmospheric disturbances.

These circumstances cause formation of seasonal thermocline and an

associated pycnocline, which can act as an effective barrier to vertical

mixing of the water column. Shears of variable magnitude and direction

are expected throughout the water column. The pycnocline can capture

or slow the descent of nearly neutrally buoyant particles which may

fall from the mixed layer over a period of time. Shear can cause

horizontal advection of the particles. In addition, shear instabilities may be generated which can cause periodic and spatially isolated mixing events $^{1,4,5,6}$.

Interleaving layers of shelf and slope water could occur at any time of the year. Warm core rings can intrude into a fraction of the dumpsite area or encompass the entire dumpsite at any time. Associated with the warm core rings is a clockwise circulation of the water column which can be in excess of $1 \mathrm{~m} / \mathrm{s}$ and also significant shear as this circulation has a strong vertical gradient. The warm core rings 
can rapidly advect the near surface waters of the dumpsite outside its boundaries. The warm core rings have been observed and estimated to be within the dumpsite boundaries for $20 \%$ of the year ${ }^{3}$. Three of the five cruises on which the acoustic systems have been deployed have found warm core rings affecting a portion of the waste disposal area. Only the two 1978 cruises have occurred when no warm core rings were present in the dumpsite.

Though storms are less common in the summer, hurricanes or occasional cold fronts can disturb the summer thermocline and increase the mixed layer depth to as much as four times that normally found. After such a mixing event, the gradient of the pycnocline below the mixed layer may be weaker than that normally encountered during the summer season.

Wintertime water conditions are characterized by a well-mixed water column which can reach depths in excess of $180 \mathrm{~m}$. The temperature gradient and pycnocline found at the base of the mixed layer is considerably smaller than during the summer months. As a result of the deeper mixed layer and the lack of a strong pycnocline to impede the descent of nearly neutrally buoyant particles, it should be anticipated that the winter water conditions may permit a more rapid vertical mixing of the particulate phase of the chemical waste than conditions occurring during the late spring, summer, and early fall months.

As an example of the differences in the water column between summer, winter, and spring conditions, the temperature, salinity (where available), and density $\left(\sigma_{\tau}\right)$ plots of the upper $200 \mathrm{~m}$ of the water column within DWD 106 are presented (Figures 9, 10, and 
11). The largest density gradients have been found to occur in the summertime and have a magnitude of $0.0014 \mathrm{~g} / \mathrm{cm}^{3}$ in $10 \mathrm{~m}$. The density gradients which occur during the winter months have had a magnitude of $0.00005 \mathrm{~g} / \mathrm{cm}^{3}$ in $15 \mathrm{~m}$ (see Figure 10b); those in the spring are .0004 in $27 \mathrm{~m}$ (see Figure 11b).

B. Internal Waves: Their Effect on the Position of Isopycnals and Chemical Sampling Procedures

Acoustic backscattering data (Figure 12) recorded during the July 1977 study of a duPont Edge Moor acid iron dump detected an internal wave group of a type occasionally encountered with the high frequency acoustic backscattering systems. The trochoidal shape of the lower two reflecting horizons is the result of an internal wave that caused vertical displacement of the pycnocline. The heavy acoustic backscattering associated with the pycnocline is caused by particles originating from the acid iron dump. The data was obtained 8 hours after the release of the waste field. From this graphic record, one realizes that occasional XBT's or CTD's (sampling periods greater than 5 minutes) do not allow a complete description of the water column and that during chemical sampling close attention must be paid to the vertical variability of the water column caused by internal wavefields or interleaving water masses if meaningful interpretations of chemical data obtained from the water column are to be made. Specifically (Figure 12), if water samples were taken from the water column at a depth of $20 \mathrm{~m}$ at 2327 and then at 2328, distinctly different concentrations of iron would have been detected, indicating to the casual observer 
that the waste field had terminated when in actuality it had been vertically displaced by the internal wave field.

As Figure 12 is the first of a number of grey scale acoustic records that will be presented in this report, it should be noted that the darkness of the record at a given point in time and depth is dependent on the pressure amplitude of the reflected sound from that depth. Time increases from left to right and the depth scale is noted from the top to the bottom of the record. For a constant particle concentration as a function of depth, the intensity of the reflected sound will decrease with increasing depth because of attenuation and transmission loss. The TVG in the acoustic system can partially compensate for transmission loss, but not attenuation loss. In Figure 12, the gain was on a manual setting, not varying with time and hence not compensated for transmission loss. The darkness at a given depth of any area that is not totally black is roughly proportional to the square root of the number of particles at that depth. Equal gray scales at different depths do not imply that the particle concentration is the same at those depths when manual gain is used.

The acoustic record (Figure 12) was created in the following manner: A short (200 kHz) acoustic pulse was projected downward perpendicular to the water surface every $1 / 4$ second. The acoustic energy reflected by the waste particles distributed throughout the water column was detected, amplified, and then plotted with a graphic recorder. The graphic recorder displays a gray level proportional to the reflected signal level from the transducer depth (usually 1-2 $\mathrm{m}$ below the surface) to the maximum depth 
plotted. The display shows many backscattered signals as a function of time and allows the eye to discern variations in gray scale as a function of time and interpret the records in terms of the presence or absence of congregations of particulate or other scattering sources in the water column. In Figure 12, there is a dark area at the top of the chart from 0 to 7.5 meters depth where the reflected acoustic signal's amplitude overloads the system amplifiers. The two dark layers on the record and below the $7.5 \mathrm{~m}$ depth (the first quite dark, the second lighter) outline the pycnoclines and, in this case, the suspended particle field's distribution.

The direction of propagation and wavelength of these internal waves could be estimated because the ship, moving at a constant speed of about 4 knots, changed course by approximately $150^{\circ}$ shortly after the initial transit through the internal wave and crossed through the same wave packet about an hour after the first passage. Using this data and the two-fluid theory of internal waves $^{7}$, a wave period of about 20 minutes is calculated. 
IV. Ships Operations

The three experiments to trace the dispersion of the particulate phase of industrial chemical waste at DWD 106 were performed in July 1977, January-February 1978, and April 1978. The wastes were dumped from barges towed by tugs. The number of participating research vessels and the details of each experiment varied. The distinctions between the three experiments are now drawn.

During the July 1977 cruise, two research vessels (NOAA ship PEIRCE and NOAA ship ALBATROSS IV) were employed to gather data. During the January-February 1978 cruise, the ALBATROSS IV was available. In April 1978, the research vessel was the NOAA ship MT. MITCHELL。

In July 1977, the NOAA ship PEIRCE was used as a roving vessel to collect acoustic data in an attempt to determine both the horizontal and vertical dispersion of the particulate phase of the sewage sludge and the duPont acid iron wastes which were independently released at the dumpsite. The NOAA ship ALBATROSS IV was used to obtain biological, chemical, and acoustic data from outside and inside the waste plume. The PEIRCE had a Loran $\mathrm{C}$ data logging and plotting system which was in a development stage. The plotting system did not work, thus precise live-time navigation of the ship's position was not available. The logging section of the computer program was modified during the early stages of the cruise such that the ship"s position as a function of time could be plotted onshore to aid in the data reduction. The charts presented in this report are a synthesis of the automatically-logged PEIRCE Loran $\mathrm{C}$ and hand-logged ALBATROSS IV Loran C positions. The 
position of drogues released during the experiment by ALBATROSS IV and PEIRCE were logged by hand on ALBATROSS IV and PEIRCE during part of the experiment and are plotted on charts presented in this report.

The January-February 1978 DWD 106 cruise aboard the ALBATROSS IV monitored an acid iron waste disposal for 18 hours. Due to threatening weather conditions, two additional and unanticipated disposal operations were performed (one duPont Edge Moor waste, the other duPont Grasselli waste) and were acoustically monitored at the end of the experiment period. The acoustic data set obtained during these unanticipated dumps provided confirmation of the interpretation of the acoustic records obtained upon first arriving at DWD 106 in the immediate vicinity of and prior to the primary acid iron waste disposal of February 2. A Grasselli waste release had occurred on January 31, 1978, and it was thought that the particulate phase of this dump was being acoustically detected on February 1, 1978. The nature of the acoustic backscattering records obtained prior to the primary acid iron waste and those of the Grasselli event monitored on February 5, 1978 were very similar. Loran C positions were handlogged during this cruise. Charts were plotted from the digitized log sheets by NOAA and WHOI. Only one drogue was released during the experiment. It was not possible to log its position after launch due to sea surface clutter on the radar display.

The April 1978 cruise aboard the NOAA ship MT. MITCHELL had a primary purpose of attempting to find a duPont acid iron waste plume which had been released prior to the ships arrival at DWD 106 and to monitor a duPont Grasselli waste dump with both the acoustic 
system and a multiport water sampling system ${ }^{8}$ developed at WHOI $^{9}$. The Grasselli waste had been dyed with rhodamine WT to monitor the spread of the effluent phase of the waste field. During the latter portion of this cruise (April 1978), pharmaceutical waste was released at the dumpsite. An effect of the release on the biology of the water column was monitored by the acoustic system. During this cruise, navigational data was provided by a Loran C live-time plotting and data logging system which was available aboard the MT. MITCHELI. Charts presented for this cruise were plotted by NOAA from the navigational data base developed during the operation. No drogue data was available. 
V. Dispersion of the Particulates as a Function of Season

In the following two sections, the dispersion properties of the particulate phase of the duPont Edge Moor and the duPont Grasselli waste will be described as a function of season. As the dispersion properties of the Grasselli wastes for the summer

months have been previously described ${ }^{1,10}$, only spring and winter data will be presented in detail here. The separate discussions will be followed by a short intercomparison of the differing dispersion properties of the particulates of the two wastes.

A. Description of duPont Acid Iron Dispersion as a Function of Season

The seasonal variability of the dispersion of the particulate phase of the duPont Edge Moor acid iron waste will be discussed. The Edge Moor waste has been acoustically monitored in the summer (July 1977, NOAA ships PEIRCE and ALBATROSS IV), the winter (JanuaryFebruary 1978, NOAA ship ALBATROSS IV), and spring (April 1978, NOAA ship MT. MITCHELL). The summer data was obtained with $20 \mathrm{kHz}$ and $200 \mathrm{kHz}$ acoustic systems (PEIRCE) and 39 and $200 \mathrm{kHz}$ systems (ALBATROSS IV). The wintertime and springtime data were obtained with 20 and 200 $\mathrm{kHz}$ acoustic systems.

The seasonal variability of the water properties at DWD 106 has been discussed in Section III. One should recall that summertime conditions in the absence of occasional large storms are characterized by a shallow mixed layer ( 10-15 $\mathrm{m}$ ) and an associated large gradient in the pycnocline (Figure $9 \mathrm{~b}$ ), that wintertime conditions are characterized by a deep mixed layer ( $160-180 \mathrm{~m}$ ) and a small gradient in the pycnocline (Figure 10b), and that springtime 
conditions during the case studied found a mixed layer of fresh water over warm salty water and a moderate gradient in the pycnocline (Figure 11b).

The variation of the vertical dispersion properties of the Edge Moor acid iron waste as a function of season are represented in acoustic records displayed in Figures 12-21. Figures 12-18 are for summer conditions, Figures 19-20 are for winter conditions, and Figure 21 is for springtime conditions.

1. Summertime Conditions. The summertime data was taken while a warm core ring was present at DWD 106. The NOAA ship PEIRCE was used as a roving vessel to detect waste advection and dispersion. The NOAA ship ALBATROSS was used as a chemical and acoustic sampling vessel and was to remain primarily in the waste plume. A series of XBT records taken during the time interval that the waste was being tracked appears on the right side of Figure 9a; representative temperature, salinity, and $\sigma_{\tau}$ vs. depth curves are presented in Figure 9b. During the acoustic and chemical sampling of the waste plume, the ring advected the waste material $35^{\prime}$ in longitude over a period of 27 hours (Figure 22). Without drogues in the water to mark the approximate position of the waste field, it would have been quite difficult to maintain contact. The relative positions of the two drogues released by the PEIRCE and ALBATROSS IV during the acid iron waste disposal are shown for the later stages of the investigation in Figure 23. The vector between the drogues did not rotate or change greatly in length over this 10-hour period. The distance between the drogues was $\sim 1.5$ to $1.7 \mathrm{mi}$ and the 
orientation was $\sim 142^{\circ}$. The barge dump line was along the course of $333^{\circ}\left(153^{\circ}\right)$. The drogues were released independently from the ALBATROSS IV and the PEIRCE, about 25 minutes apart. Using the positions at release and assuming that the ships, drogues, and wastes were being advected together, the initial separation of the drogues was calculated to be $1.14 \mathrm{~nm}$ and the alignment angle was $147^{\circ}$. The data indicates a nominal amount of rotation of the drogues, but some separation in distance with time $(\sim .6 \mathrm{~nm}$ over a 27-hour period). The widths of the plume calculated from the acoustics data assume a plume alignment of $145^{\circ}$ during the latter stages of the cruise.

A selected portion of the acoustic records obtained during the cruise is presented in Figures 12-18. They reveal that the base of the summertime mixed layer was a barrier to the vertical dispersion of a portion of the particulate phase of the acid iron waste. The PEIRCE records (Figures 13 and 16-18) do not highlight the particulates originating from the acid iron dump as well as the ALBATROSS IV data (Figures 12, 14, and 15). This was due to difficulties encountered with the acoustic system aboard the PEIRCE during the experiment. In case of shipboard equipment failure, most of the PEIRCE data was recorded on analog mag tape during the experiments such that it could be played back and analyzed in the laboratory. The recording techniques chosen were to direct-record the data. The high pass cut-off of the direct-record magnetic tape channels prevented the recording of the broad envelopes in the signal during the passage of the acoustic system through heavily concentrated sections of the particulate 
plume. A significant amount of information concerning the particle concentration levels was contained in the envelope. FM recording techniques which do not have the high pass cut-off problems associated with the direct-recording techniques have been adopted since the July 1977 cruise. The recorded magnetic tape signals will be digitized once a small computer which is being prepared for this purpose is brought on line in an attempt to extract the particulate concentration variability of the dupont waste plume as a function of time. The ALBATROSS data was not analog recorded due to the failure of a borrowed tape recorder.

In Figure 13, both the $20 \mathrm{kHz}$ and the $200 \mathrm{kHz}$ acoustic records, which were obtained simultaneously aboard the PEIRCE and within 4 minutes of the passage of the barge, show that the waste field was distributed throughout the mixed layer which had its base near the $15 \mathrm{~m}$ depth markers. The mixed layer base is outlined by the light diffuse scattering areas in both the 20 and $200 \mathrm{kHz}$ records. Each of the records (Figures 14, 15, 16, 17, 12, and 18 in order of increasing time following the dump) indicates that the particles from the waste field were captured or slowed in their descent by the pycnocline at the base of the mixed layer. An exception to this statement appears in data collected aboard the ALBATROSS IV (Figure 15). In the area of the time marker $1645 \mathrm{z} \pm 4$ minutes, $\sim 1$ hour after the waste release, a narrow scattering area with an inverted $\mathrm{V}$-shape indicated that the particles had penetrated the mixed layer base to a depth in excess of 60 meters. It is thought that either the mass of particles accumulating at the mixed layer base became concentrated enough to sink through it, or the 
acoustic transducers passed over particles which had penetrated the mixed layer during the chemical waste release. Figure 15 also shows a typical example at $\sim 1632$ z of a heavy concentration of waste particles which had accumulated at and near the mixed layer base. Figures 16, 17, and 18 (data collected aboard the PEIRCE) are skewed. The graphic recorder dedicated to the acoustic system failed. The shipboard graphic recorder was used but could not be synchronized with the acoustic system. The depth scale starts at zero at the upper edge of the first dark line in each section of the display. These figures (Figures 16, 17, and 18) also reveal that the particulate distributions detected aboard the PEIRCE remained concentrated in the top 15 meters of the water column and undergo vertical displacement by internal wave fields.

Figure 12 (ALBATROSS data) was discussed in section III B. This acoustic record shows the particulate phase of the waste field concentrated on the pycnocline and being vertically displaced by the passage of an internal wave packet. During the acquisition of this section of the acoustic data, water samples were taken from depths near 15 meters. Trace metal analysis (D. Kester and R. Mukherji, pers. comm.) of the samples found high iron content from the same depths as the maximum acoustic backscattering levels and lower concentrations when the acoustic scatterers were vertically displaced toward the surface by the internal wave field.

The width and depth of particulates in the Edge Moor plume as a function of time are plotted in Figures 24 and 25 and are listed in Table I. The depth data includes measurements from 
both PEIRCE and ALBATROSS IV, while the width data is dominantly from PEIRCE because ALBATROSS IV usually remained drifting within the plume and did not have the navigational capabilities of the PEIRCE .

Aside from one section of data which detected particles at $\sim 40$ meters in depth, the particulate phase of the waste was found in the top 15 to 30 meters of the water column during the $\sim 26$ hours of waste field detection. As seen in the acoustic records, in particular Figure 12, the particles were not evenly distributed through the top 30 meters of the water column but were concentrated near high gradients in the pycnocline. Estimates of the width of the plume are more difficult than the depths due to the necessity of combining the acoustic data, ship navigation data, and drogue position data, i.e., an estimate of the waste plume angular orientation to the original ship track and the track of the monitoring vessel. The drogue data obtained during the experiment indicated a small rotation in the drogue alignment. The initial alignment, $\sim 1110 \mathrm{z}$, July 26,1977 , was about $155^{\circ}\left(330^{\circ}\right)$. The alignment at $1345 \mathrm{Z}$, July 27, 1977, 26 hours later, was about $142^{\circ}\left(322^{\circ}\right)$. Except for the first several hours of the experiment when only the original alignment was available, the majority of the widths of the plume presented in Table I B and Figure 24 have been calculated using the alignment of $142^{\circ}$. Only the data calculated for ship crossing of the plume at angles $>15^{\circ}$ are presented to eliminate error in the estimated width due to uncertainty in the plume orientation. The plume width was determined by noting the beginning and ending of an acoustic scattering layer 
at a particular depth which was usually in the 7 to 30 meter range for this experiment.

All of the plume widths displayed in Figure 24 and in each similar display have been corrected for advection of the water mass relative to the ship's speed through the water as a function of direction of motion. The widths reported are the widest observed acoustically, irrespective of depth. The width of the acid iron particulate plume studied during this experiment increased from $\sim 100$ meters to a width of 1000-1300 meters over the 26-hour period. There were occasions when both the PEIRCE and the ALBATROSS detected heavy particulate scattering for distances in excess of 4000 meters. There was one occasion when the ALBATROSS IV, while approaching the area of last detection of the plume from the southwest (Figure 22), detected an area of increased acoustic scattering of about 9-10 km in width 1530$1620 \mathrm{z}$ prior to entering the heavy scattering areas detected by the PEIRCE. This heavy scattering area can possibly be explained as the detection of a portion of the plume created during the southerly leg of the barge track (1540-1700 Z, July 26, 1977) noted on Figure 22. Without chemical data, this interpretation cannot be either dismissed or accepted. The character of the detected plume was, however, the same as observed throughout the experiment.

The widths of the acoustically detected plume are wider (375-1500 $\mathrm{m}$ and occasionally $\sim 4000 \mathrm{~m}$ ) than those anticipated from the interpretation of both chemical data and satellite imagery (Thomas O'Connor, NOAA Ocean Dumping Office, pers. Comm.). 
The acoustic records have been carefully scrutinized, although there are a few sections which are questionable until the playback of the analog magnetic tape records is completed. On the whole the calculated widths appear to be justified. The acoustic data is detecting scattering surfaces in the depth range of 7 to 30 meters. A mechanism which is responsible for the increased widths observed by acoustic backscattering as compared to the chemistry and satellite imagery is the following: During the study of a sewage sludge dump two days prior to the acid iron waste disposal, a shear in the water column had been noted (Figure 53) at a depth between 12 and 17 meters. Plotting the ship's track $\left(225^{\circ}\right.$ for the first crossing, 27 minutes after disposal; $60^{\circ}$ for the second crossing, 48 minutes after disposal) during the observations and overlaying the direction of the particle motion indicated that a shear was present with a component to the east. Thus, although the particles in the first 10 meters of the water column may have been moving together with small increase in plume width, any particles falling into the shear zone would be advected away, creating an acoustic backscattering plume with a larger width than the near-surface plume. The water speed in the shear area has been estimated from available navigation and the acoustic records (Figure 53) to have a component velocity of $26 \mathrm{~m} / \mathrm{min}$ in an east-northeast direction $\left(\sim 50^{\circ}\right)$. If this component of the flow speed remained constant over a 26-hour period, the particulate plume in the depth zone $(12-17 \mathrm{~m})$ could have become $\sim 4000$ meters in width assuming particles were available from the upper 10 meters of the water column and continuously sank 
into the high shear zone. The plume width figures above are not far from some of the plume widths determined from the acoustic data. A schematic of the situation encountered at DWD 106 during the experiment period showing the direction of shear, the motion of the PEIRCE while acquiring the data, the initial estimate of the direction of plume growth in the high $(12-17 \mathrm{~m})$ flow region, and the possible plume growth in the 12 to 17 meter depth range over a 24-hour period is displayed in Figure 54. As can be seen from the navigation data, the magnitude of the component of shear in the orthogonal direction to that calculated above cannot be determined. The widths of the plumes of sewage sludge which revealed the shear are listed in the figure, uncorrected for mean advective current and corrected using estimated mean current (1.75 kts) from the easterly motion of the surface sewage sludge. The true value of both the plume width as a function of time and the true mean current lies somewhere between the limits set. The importance of accurately determining mean current and shear in the water column on a continuous basis and over finite slabs of the water column ( $\sim 2 \mathrm{~m}$ in thickness) such that the acoustic and chemical records can be interpreted properly for plume widths should be apparent from the above estimates.

In summary, the acoustic detection of the particulate phase of the Edge Moor acid iron waste during summer months shows that particles accumulated in regions of high density gradient are distributed throughout the mixed layer and occasionally penetrate the areas of high density gradient to depths on the order of 40 to 60 meters. The width of the acoustically detected plume was 
estimated to be on the order of 1000 to 1500 meters and occasionally 4000 meters approximately 26 hours after the chemical waste release. Assuming an initial plume depth of 15 meters, an initial width of 15 meters, and a final width and depth of 1500 meters and 15 meters respectively, one calculates possible dilution of the waste field of $\sim 100$ in a 28-hour period after the initial mixing of the waste field into the barge's wake. This number is good only if uniform mixing is assumed. The particles observed acoustically were not uniformly distributed but were layered. The initial sink rate of the waste field shortly after release was $\sim 1$ to $3 \mathrm{~m} / \mathrm{s}$. The sink rate decreased rapidly in a time period of $\sim 20 \mathrm{~m}$, indicating that the waste field quickly lost its vertical momentum.

\section{Wintertime Conditions. Wintertime acoustic data} on the dispersion of the duPont Edge Moor acid iron waste was obtained during January and February of 1978. The NOAA ship ALBATROSS IV was used during the cruise. The mixed layer depth was between 100 and 180 meters. A sequence of XBT's obtained between February 1 and 6, 1978 indicates the variability of the thermal structure (Fiqure 10a). A representative temperature, salinity, and $\sigma_{\tau}$ curve vs. depth is also presented (Figure 10b). The winter density gradient is small as compared to the summertime conditions (compare Figure $10 \mathrm{~b}$ to Figure 9b). Figures 19 ( $\mathrm{a}$ and $\mathrm{b}$ ) and 20 are representative of the $200 \mathrm{kHz}$ acoustic records obtained during the cruise. A 0 to 180 meter depth display range was used during the experiment. During the first 10 minutes of data acquisition (Figure 19a), manual gain was used; otherwise all the data presented was obtained with $1 / x$ time varying gain compensation. 
Figure 26 plots the approximate track of the waste disposal barge, the subsequent track of the ALBATROSS IV, and indicates those positions under which the particulate plume of the acid iron waste field was detected. The width and depth of the detected waste field as a function of time are plotted in Figures 27 and 28, respectively. Most of the data was taken with a ship speed of about $1.5 \mathrm{~m} / \mathrm{s}$. The plume width was calculated by using ship speeds determined from a doppler speed log and by estimating the ship's course angle to the original barge track. The uncertainty in the width of the plume increases with time because all information obtained aboard the ship was in the Eulerian reference frame. No drogue data or expendable shear probes were available to measure the rotational or translational motion of the water.

The patchy spatial character of the duPont acid iron waste plume is well-represented in Figures 19 ( $a$ and $b$ ). The particulates were distributed in the vertical in patches over a distance of $\sim 120$ meters and were distributed in the horizontal by less than 400 meters, usually around 100 meters (see Figures 27 and 28). The depth data presented spans a 17-hour period while the width data spans a 13-hour period. There was often a large area of diffuse scattering associated with the distinctly patchy structure in the top 30 or 50 meters of the water column which appeared to be related to the waste field. The material was more deeply dispersed than during the summertime conditions discussed earlier, and the width of the plume was narrower than in the summer months (see Figures 24 and 27). 
The sink rate was calculated after the release time to be 1.1 to $1.7 \mathrm{~m} / \mathrm{min}$ (see Table $I-A$ ), with an exception of 3.9 to $5.8 \mathrm{~m} / \mathrm{s}$ (see Table I-A). The particles appeared to maintain the fall speed of 1.1 to $1.7 \mathrm{~m} / \mathrm{min}$ through the water for periods up to 20 minutes following the waste release. The averaged sink rate was reduced to $.28 \mathrm{~m} / \mathrm{min}$ approximately $180 \mathrm{~m}$ after the initial release. As this number is an average sink rate calculated from the initial time of introduction of the waste material into the water, it indicates that the vertical momentum of the particles has been dissipated.

\section{Springtime Conditions. A release of dupont acid} iron waste occurred (April 7, 1978) during the April 1978 MT. MITCHELI cruise. An attempt was made to acoustically locate the plume approximately 3 hours after its release from the barge. The temperature history of the water column during the cruise is presented in Figure $11 \mathrm{la}$ and $\mathrm{a} T, \mathrm{~S}$, and $\sigma_{\tau}$ plot is presented in Figure 11b. Intercomparing the winter (Figure 10b), spring (Figure 11b) and summertime (Figure 9b) $\sigma_{\tau}$ contours indicates that the near-surface density gradient during the springtime was of intermediate magnitude $\left(.00012 \mathrm{~g} / \mathrm{cm}^{3}\right.$ in $\left.45 \mathrm{~m}\right)$. The respective ship and barge tracks are presented in Figure 29. Only one crossing of the area gave any acoustic indication (Figure 21) of the presence of the particulate phase of the acid iron waste. The acoustic record shows an apparent plume in the 67-82 meter depth range. The data set is too meager to warrent further comment. 
4. Analysis of Analog Signal Amplitudes vs. Time Following a Waste Release to Determine the Dispersion Rates of the Particulate Plumes.

The grey scale acoustic records presented in the previous sections were created by aligning the detected backscattered energy of many acoustic signals. The acoustic signals were also recorded on analog magnetic tape so that the signal intensity could be analyzed. In the long wavelength limit, Rayleigh backscattering theory $^{11}$ predicts that the backscattered acoustic signal intensity is proportional to the total number of particles in a scattering volume. Thus, the recorded acoustic signals should allow the determination of the rate at which the particulate phase of the waste is dispersing in the vertical and horizontal. An IMSAI 8080 microcomputer is presently being brought on-line for automatic digital analysis of the signal levels as a function of time. In the absence of the digital processing capability, analog acoustic signal records obtained from backscattering from acid iron waste and recorded during the January-February 1978 cruise are presented (see Figures 30-32) to indicate the type of information which can be extracted from them.

Figure 30 displays 28 acoustic signals played back from a magnetic tape and recorded on light sensitive paper with a fibre optics recorder. Each signal displays the backscattered acoustic signal levels which were received from a water column 187.5 meters in depth. A signal was recorded every half-second. Except for signals 10-17 which reveal particulates formed from the acid iron waste in the first 15 meters of the water column (see the signal envelope arrow 1, pulse 11), the individual and discrete pulses 
distributed throughout the water column are representative of the normal background signal levels from the ocean (see bracket on pulse 6). To detect the particulates formed from the chemical waste release, one must be able to differentiate their signals from background levels by such features as changes in the signal envelope or by signal amplitude enhancement.

The ship's speed was about $1.5 \mathrm{~m} / \mathrm{s}$ during the experiment. Therefore, the small near-surface waste plume, pulses 10-17, was approximately 5.2 meters in width. The section of the gray scale graphic record which was created from these analog signals has been displayed in Figure 19. This small section of waste is pointed to in the figure with arrow "S".

Figure 31 presents another set of analog signals. In this case, the dominant feature is the signal caused by acoustic backscattering from a plume of waste in the depth range $\sim 70$ to 110 meters. Again, this is a section of data graphically displayed in Figure 19 (see arrow "D"). Note the variable signal level within the plume. A factor of 25 or more variability in the particle concentration can be inferred from the signal. The width of the plume is about 25 meters. The $200 \mathrm{kHz}$ transducer used during the experiment had a beamwidth of $1.4^{\circ}$, which allows a horizontal resolution of 2.4 meters at a range of 100 meters. The vertical resolution is pulse width-dependent and for this experiment was on the order of $30 \mathrm{~cm}$. With a ship speed of 1.5 to $2 \mathrm{~m} / \mathrm{s}$ and assuming no rapid angular motion of the fish such that the beam would sense a varying water column, the same section of the plume is partially sampled at least twice at a depth of 
100 meters. Those sections of the plume signal which are flattopped (see arrow "1") indicate that the backscattered signal was large enough to saturate the electronics at the gain settings used for this recording.

Figure 32 presents a display similar to Figures 30 and 31. The advance speed of the fibre optics recorder which generated the records in Figures 30 and 31 was slowed so that a large number of analog signals could be displayed. The near-surface plume (arrow "S") discussed in Figure 30, and the deeper plume (arrow "D") discussed in Figure 31 are pointed out. The ship was in an area of distributed waste as evidenced by the occasionally increased signal level in the depth ranges $\sim 1$ to 150 meters. Note the larger number of discrete scatterers in the top 50 meters of the water column on the right center of the figure (bracket) as compared to the increased gray scale levels in the same area in Figure 19.

The patchy nature of the acid iron waste which was mentioned earlier is again apparent. The difficulty of both sampling the plume with water samplers or finding and crossing the same plume several hours later to obtain acoustic backscattering levels to determine the rate of dispersion of the particles should be apparent.

In an attempt to estimate the dispersion rate of the particles in a patchy plume under winter conditions, the analog signals of several hours of data have been played back as in Figure 30. The signal amplitude, hence the change in particle concentration, was not found to decrease significantly. As a result, no firm estimate 
of particle dispersion rates may be made until the signals are A-to-D converted and integrated over the appropriate depths with a computer.

B. Description of duPont Grasselli Plant Waste Dispersion as a Function of Season

The dispersion of the duPont Grasselli plant waste during summertime oceanic conditions has been previously discussed ${ }^{1,10}$. In review, the conclusions $\mathrm{drawn}^{1,10}$ were that the particles were found to reside in the mixed layer for extended periods with enhanced concentrations on the pycnoclines. Some penetration of the particles through the seasonal thermocline was noted and should be anticipated if Stoke's law for particle settling is considered. The summertime acoustic records obtained when the Grasselli particles were distributed throughout the stably stratified layer near the surface were similar in appearance to the laboratory tank data which have been presented in Turner's ${ }^{12}$ discussions on the interaction of a stably stratified two-layer fluid system. The qualitative dispersion properties of duPont Grasselli waste during winter and springtime oceanic conditions will be presented in the following sections.

1. Wintertime Conditions. The acoustic character and dispersion properties of duPont Grasselli plant waste during wintertime oceanic conditions were studied for two separate dumps, one which occurred on January 31, 1978 and is thought to have been acoustically detected (see Figure 33) nearly 40 hours after the release, and a second which occurred on February 5, 1978 and was observed for a few hours (see Figures 34-36). Both of the 
winter studies were opportunistic, as the waste happened to be released in the immediate vicinity of an acid iron waste dump track which was being studied during the cruise. The physical properties of the water at DWD 106 in winter conditions have been discussed in sub-section A (see Figures 10a and 10b). The dominant character of the water is a deep mixed layer and a weak $\sigma_{\tau}$ gradient at its base.

A disposal of duPont Grasselli plant waste occurred on January 31, 1978, prior to the arrival of the NOAA ship ALBATROSS IV at DWD 106. The particulates from the dump were acoustically detected several times after arrival of the ALBATROSS IV. The acoustic records of the waste field detected on February 2, 1978 (see Figure 33) were similar in nature to that observed on several occasions. This scattering pattern is similar to that detected on February 5, shortly after another Grasselli plant dump (see Figures 34-36). All the acoustic records were characterized by particles distributed in bands throughout the water column. After the initial release, the scatterers do not appear to settle rapidly out of the water column.

The estimated width and depth of the Grasselli plume as a function of time after release are plotted respectively in Figures 37 and 38. The calculated sink rates for the winter event on February 5 are listed in Table II. The initial sink rate is ح 10-20 minutes following release). The barge tracks, ship tracks, and positions at which waste fields are identified as either Grasselli or Edge Moor acid iron waste are plotted in Figure 39 for the February 5, 1978 waste releases. As can be seen from 
the chart, both Grasselli and Edge Moor acid iron waste were disposed of in the same area.

The winter data indicates that the particulate phase of the Grasselli waste is distributed shortly after release throughout the mixed layer, 0-60 or more. Little vertical displacement following the initial descent was observed. Due to limited navigation capabilities aboard the ALBATROSS IV, the estimated widths of the plume (Figure 37) after 4 hours should be regarded with suspicion. The analog data for the Grasselli waste has been played back using a fibre optics graphics recorder in an attempt to determine the dispersion rates of the particulates. Although a factor of 10 variability in the signal amplitude was noted from one waste patch to another, there was no consistent decline in the signal level over the observation period. The data will be reanalyzed digitally once the IMSAI 8080 computer system mentioned earlier is on-line to look for finer effects than those which are discernable on the fibre optics paper.

2. Springtime Conditions. A cruise to DWD 106 aboard the NOAA ship MT. MITCHELI in April 1978 was undertaken to study the dispersion of duPont Grasselli waste during springtime oceanic conditions. The waste had been dyed with rhodamine WT dye and was to be tracked both with the dye for the effluent phase of the waste and with acoustics for the particulate phase. A multiport water sampling system provided water for the flow-through fluorometers used aboard the MT. MITCHELL; in addition, surface bucket samples and Niskin water bottle samples were obtained for fluorometric analysis. The ports of the multiport sampler covered 
a. 6 meter range at 1 meter intervals ${ }^{9}$, and were placed at a depth which corresponded to the maximum acoustic backscattering levels. The configuration of the water sampler is outlined in Figure 40. The ports which take in the water are placed below the pump housing which holds a pressure transducer for depth readout, a temperature transducer, and six water pumps. The towing characteristics of the intake ports are not experimentally documented. It is anticipated that, as the system is towed through the water, the intake ports may flare to the rear and not sample a 6 meter vertical section of the water. All of the multiport data which is presented here assumes that a 6 meter vertical section of the water has been sampled. The barge track and ship track, as well as those positions at which the Grasselli waste was detected acoustically are plotted on the chart in Figure 41. The time lapse history of the depth of the water sampler, the depth of the detected dye, the depth of the Grasselli waste as detected acoustically, and the estimated width of the Grasselli waste are plotted in Figures 42, 43, 44, and 45 respectively. The sink rates calculated for the Grasselii waste during this springtime experiment are listed in Table II. Representative acoustic records indicating the vertical and horizontal extent of the particulate plume are displayed in Figures 46-48. The dye data has been tabulated in this report so the water sampler depth and acoustic backscattering depth could be correlated. Interpretation of the physical significance of the dye data rests with J. Bisagni and/or T. O'Connor. The acoustic data will be discussed in detail below. 
The physical oceanographic data obtained during the cruise was not high resolution in the vertical, as the onboard STD failed. The $\sigma_{\tau}$ plot fabricated from XBT and salinity bottle data (Figure 11b) indicated an isopycnal water column to a depth of 50 meters. The acoustic records (Figures 46-48), however, revealed multiple scattering surfaces starting at a depth of 15 meters. These multiple scattering layers are normally correlated with increases in the gradient of the pycnocline. The course scale of the available physical oceanographic data is useless for either predicting the fate of the waste or estimating the vertical distribution of the waste field.

As is revealed in Figures 46 and 47 , the particle field from the Grasselli release became distributed through the first 15 meters of the water column and, as can be seen in Figure 47 , $1312 \mathrm{Z}$, formed a dense scattering layer up to 6 meters thick at the boundary whose depth varied from 7 to 15 meters (see Figure 47, arrow 1). Note that the horizontal width of the plume of material at 15 meters depth is wider than that at the surface, and there are regions of heavy particle concentration and regions of lighter concentration.

The acoustic backscattering data for springtime conditions found the vertical descent of the particles to be limited by what is interpreted to be a gradient in the pycnocline, which was at a depth in the vicinity of 15 meters. See Figures 45-48 for an indication of the variability of the pycnocline depth. The estimated initial sink speed of the particulates was about $.3 \mathrm{~m} / \mathrm{min}$ and was maintained for a period of time on the order of 30 minutes. 
The horizontal width of the waste plume was depth-dependent, being the widest at the base of the mixed layer. The width of the plume 14 hours after the waste release was found to be between 200 and 400 meters. Intercomparison of the acoustic records with the dye data obtained from the multiport water sampling system, i.e., Figure 43 compared with Figures 46-48, indicates that the dye samples were found near the base of the first acoustic scattering surface and were generally correlated to the areas of high levels of acoustic backscattering.

3. Analysis of the Analog Acoustic Signal Amplitudes vs. Time to Determine Dispersion Rates of the Grasselli Plume.

The analog acoustic signals recorded on magnetic tape during these experiments have been played back through a fibre optics recorder as described in Section A-3. The signal levels between those initially detected at the beginning of the dump and those detected some 14 hours after the dump have been intercompared.

The signals do not show a large enough decrease in amplitude over the time period nor were they proper in time response to allow reliable estimates of the dispersion of the particle using manual integration techniques such as can be accomplished with planemeters. The signals will be digitized and integrated by computer to allow an estimate of dispersion.

C. Intercomparison of the Differing Dispersion Properties of the Edge Moor and Grasselli Particulate Waste Fields

Comparing the winter, spring, and available summer acoustic data for the Grasselli and acid iron wastes reveals that: 
1. Acid iron waste sinks faster ( 5-10 times) than the Grasselli in the initial 30 minutes after the waste release. The sink speeds appear to be independent of season.

2. During winter conditions (deep mixed layer) the acid iron sinks further and appears to remain clustered, especially the deeper portions, in dense scattering patches which do not show rapid dispersion when detected acoustically.

3. During winter conditions, the Grasselli waste is distributed more uniformly in the vertical than the acid iron waste. It does tend to form dense scattering layers in the vicinity of the base of the mixed layer.

4. The vertical distribution of acoustic scattering from both the Grasselli and acid iron particulates is severely limited if large gradients in the density structure are encountered. Small scale measurements ( $<1$ meter) of the density structure are needed during these experiments to either predict where the waste fields may be captured or to aid in the interpretation of the acoustics data.

5. The horizontal dispersion of the waste field is variable depending upon oceanic conditions. In an ocean with little apparent shear, the width of the plume will expand from 15 meters to 400-500 meters in a time span on the order of 20-30 hours. In an ocean with shear present, a section of the plume may expand from 15 meters to 4500 meters, as discussed in the Edge Moor summer data. The width is depth-dependent in the acoustic records. When shear is present, as in the case of the July 1977 cruise, the acoustic data indicates plume widths in 
the high shear zone to be $\sim 4000$ meters. The plume widths compared favorably with the estimated values calculated from the estimated fluid flow speed in the high shear zone. 
VI. Dispersion of Sewage Sludge in Summertime and the Effects of Pharmaceutical Waste on Natural Acoustic Backscattering During Spring Conditions

A. Sewage Sludge Dispersion in the Summer

Acoustic monitoring of the dispersion of a sewage sludge waste plume occurred from the 23 rd to the 25 th of July, 1977. DWD 106 was occupied by a warm core ring at the time of the experiment. The advective influence of the ring on the released material is evident in Figure 49. The barge dump line and the track of the NOAA ships PEIRCE and ALBATROSS IV are plotted (Figure 49) during the time the waste material was studied. The temperature, salinity, and $\sigma_{\tau}$ profiles (see Figure 9b) for the water column have been discussed earlier. The calculated width and depth of the plume as a function of time during the experiment period are plotted in Figures 50 and 51 . The sink speed and plume width and depth as a function of time are listed in Table III.

Figures 52, 53, and 55-61 present graphic acoustic records which show the vertical and horizontal distribution of the waste over a 20-hour period following its release. The early dispersion of the sewage plume was monitored by the NOAA ship PEIRCE, which repeatedly crossed the disposal barge wake following the release of the sludge (see Figures 52 and 53). The early crossings detected dense clouds of material in the first 10 meters (Figure 52). Later crossings (Figure 53) found the material penetrating the pycnocline at depths of about 18 and 24 meters. The first crossing (Figure 53) detected some of the waste at a depth in 
excess of 50 meters (arrow 1). The presence and effect of shear on the horizontal transport of the waste material is evident during both of the passes on the waste plume in Figure 53. The results of the shear on the dispersion of a waste plume have been discussed at the end of Section V A and are outlined in Figure 54. The sewage sludge plume was found to be distributed throughout the first 22 meters of the water column with the acoustic system aboard the NOAA ship ALBATROSS IV. The expanded depth scale used on the ALBATROSS IV acoustic graphic recorder (Figure 55) shows a concentration of the particles near the high gradient in the pycnocline at $\sim 15$ meters depth. The distribution of particles within the plume is revealed in the time span from 2105-2106 where a $6 \mathrm{db}$ reduction in the acoustic system gain resulted in a graphic record which outlined the heaviest particle concentrations. Figures 56-61 show the sewage sludge plume as detected over an 11.5-hour time span by both the PEIRCE and the ALBATROSS IV. These fiqures emphasize the tendency for the waste to lie in scattering layers in the vicinity of gradients in the density structure. Figure 61 is a section of an acoustic record which shows patches of acoustic scattering which appear to be sinking through the areas of high scattering to depths in the vicinity of 35-60 meters. The record suggests that the density structure in the immediate area could not support the mass of particles which had accumulated on it.

The acoustic records suggest that the sewage sludge particle distribution differentiates shortlv after disposal, i.e.. some particles penetrate the seasonal thermocline shortly 
after release, trose in the high shear zone are separated in the horizontal from the surface plume, and surface plume particles appear to slowly sink and collect in layers associated with high density gradients over extended periods of time with small groups penetrating the layers in patchy formation. The penetration of the groups of particles suggests that the buoyancy associated with the gradients in the pycnocline could no longer support them. Those areas where the sewage waste was acoustically detected have been outlined in Figure 49 for the duration of the experiment. The sewage sludge penetrated to a greater depth than the acid iron plume previously described, which was studied two days later.

B. Effects of a Pharmaceutical Waste Disposal on Natural Acoustic Backscattering During Springtime Conditions

A pharmaceutical waste disposal occurred during the April 1978 cruise. The wake of the barge which was slowly releasing the pharmaceutical waste was crossed twice with the towed acoustic backscattering system. The first crossing (see Figure 62) occurred at an unknown time interval after the passage of the disposal barge. The angle of the ship to the barge track was uncertain. Evidence of the effects of the waste (in the first 15 meters of depth) on the local uniformly distributed biological acoustic backscatterers is revealed by a region of $\sim 12$ meters depth and $\sim 450$ meters in width which was nearly devoid of acoustic backscattering. The depression in the acoustic backscattering levels may have been caused either by an avoidance reaction by the biological scatterers or a more serious reaction such as death or physical impairment. 
A second crossing of the pharmaceutical waste plume with the acoustic systems at a distance of $.6 \mathrm{~nm}$ behind the barge and less than 8 minutes after its passage detected only a dense plume caused by the tug's and barge's turbulent wake (see Figure 63). The effluent material apparently had not mixed with a large enough volume of water to cause a detectable avoidance reaction by the biological scatterers. Without a redundant data set, the strongest statement concerning the interaction of the biological acoustic backscatterers with the pharmaceutical is that they avoid, either by choice or physical impairment, the contaminated section of the water column, and in doing so they nicely outline the waste plume. 
VII. Discussion of Some Model Considerations and the Necessary Physical Oceanographic Data Needed to Support the Interpretation of the Acoustic Data or Test Oceanographic Dispersion Models

\section{Density Effects}

As an indication of the impact which small density changes may have on the sink rate of small particles in quiescent water, consider the simple case of a sphere. Stoke's Law (good for a heavy sphere in a light fluid), which allows one to calculate the sink speed of a sphere ${ }^{13}$ in a water column without turbulence, is written as:

$$
v=\frac{2 g r^{2}\left(\rho_{1}-\rho_{2}\right)}{9 n}
$$

$\eta$ is the viscosity of water $=1.0019 \times 10^{-2} \frac{\text { dyne-sec }}{\mathrm{cm}^{2}}$ (poise) (at $20^{\circ} \mathrm{C}$ ) ( $n$ varies from $1.7921 \times 10^{-2}$ at $0^{\circ} \mathrm{C}$ to $17840 \times 10^{-2}$ at $31^{\circ} \mathrm{C}$ ) $r$ is the radius of the sphere $\rho_{1}$ is the density of the sphere $\rho_{2}$ is the density of the medium $g$ is the gravitational acceleration $u$ is the sink speed of a sphere

Table IV summarizes the result of a calculation of the sink speed of a sphere of $.1 \mathrm{~cm}$ radius $(1000 \mu)$ and density of $1.03 \mathrm{~g} / \mathrm{cm}^{3}$ as a function of sea water density. As can be seen, the sink rate can vary from $46.9 \mathrm{~m} / \mathrm{hr}$ in water of density $1.024 \mathrm{~g} / \mathrm{cm}^{3}$ to $23 \mathrm{~m} / \mathrm{hr}$ 
in water of density $1.027 \mathrm{~g} / \mathrm{cm}^{3}$. Particles of $100 \mu$ radius will sink 100 times slower, or $.469 \mathrm{~m} / \mathrm{hr}$ and $.23 \mathrm{~m} / \mathrm{hr}$ in water of density $1.024 \mathrm{~g} / \mathrm{cm}^{3}$ and $1.027 \mathrm{~g} / \mathrm{cm}^{3}$ respectively. For this ideal case, small variation in particle size and water density as a function of depth will cause large changes in particle sink rates. Density gradients will thus cause the accumulation of particles in their vicinity due to their ability to slow the descent of the particles. This has been remotely sensed previous$1 y^{1,2,14,15}$ and during the acoustic backscattering experiments described in this report. To date, the size distribution and density distribution of the particles formed upon the release of chemical wastes have not been determined by other investigators involved in the DWD 106 experiments. Also, the variation of the density or size of particulates as a function of the density, temperature, and salinity of the water in which they are formed is not known. Simple predictive models concerning the separation of the particulate phase of the waste field by size, density, and depth in quiescent sea water need the above information if they are to be applied to the dispersion problem. In addition, models which predict the rate of fall of particles or mixing of effluent in a quiescent ocean need to incorporate detailed CTD measurements (less than $50 \mathrm{~cm}$ resolution) as a function of season to accurately describe the density field, hence both the effluent and particulate distributions as a function of time and depth. It is well known that density gradients are effective in decreasing the vertical dispersion rates of the water column. 
Diffusion Coefficients, Turbulence, and Prediction

Vertical and horizontal diffusion coefficients in the ocean have been measured by a large number of scientists. The results have been tabularized by Koh and $\mathrm{Chang}^{6}$, and range from less than $10^{-1}$ to $10^{8} \mathrm{~cm}^{2} / \mathrm{s}$. This range of coefficients is much too wide to be useful in prediction unless it can be narrowed by specification of the oceanographic conditions, e.g., wind stress, depth of mixed layer, or steps in the pycnocline and thermal heating, which exist for each dispersion range.

The development of predictive models concerning the vertical dispersion of particles and effluents in the upper $100 \mathrm{~m}$ of the ocean requires a knowledge of the size, density, and sink rates in a quiescent water column as outlined above, and an understanding of the effects that convective and turbulent flow fields which exist in and below the mixed layer have on particle sink rates. In addition, the shear of the water column must be measured to account for horizontal mixing as is apparent from the data presented in this report and as described by Bowden ${ }^{16}$. Routine drogue measurements are not suitable for this task. Instrumentation such as the doppler acoustic current meter, which can profile the shear of the ocean over multiple layers, are needed. The rate of sink of particles as alluded to above is affected by the magnitude of the turbulence encountered. Simple empirical models which predict the distribution of particles by size in turbulent river channel flow have been developed ${ }^{17} \cdot$ Csanady $^{18}$ has recently commented on the suitability of using similar tech- 
niques to understand the turbulent interfacial layers which exist in the ocean at the base of the mixed layer. These models, which are based on the diffusion equation, could be applied to the mixed layer of the ocean provided the nature of the turbulent flow fields encountered in the ocean's mixed layer are known. Measurements of the statistical nature of the turbulence associated with the oceanic mixed layer as a function of thermal exchange, sea state, and wind stress do not exist; they are needed.

An attempt to bring together those individuals currently interested in the study of the oceanic mixed layer has confirmed the lack of the experimental data sets which are necessary to test existing mathematical models and to differentiate between the various proposed mechanisms of entrainment at the base of the mixed layer ${ }^{19}$. Only recently, for instance, has strong evidence for the existence of large scale shear instabilities at the base of the mixed layer been substantiated for the oceanic environment ${ }^{4}$, although they had been projected to exist in the ocean from data obtained in Loch Ness by Thorpe ${ }^{5}$. Small scale instabilities have been known to exist for some time from the experiments of Woods ${ }^{20}$.

To develop a reliable predictive capability of the dispersion rates of the particulate or effluent phase of industrial chemical waste released at DWD 106, basic measurements concerning the fine scale of the density structure of the water column over several years as a function of season and atmospheric forcing events must be made, the seasonal variations in convective and turbulent mixing 
must be measured, the statistical properties of the turbulent field measured, and the physical characteristics (density, shape, size) of the particles formed at or released within the dump must be determined. Once these types of measurements are performed, an experimental data base for testing predictive models of mixing rates as a function of season, sea state, thermal exchange, and atmospheric forcing events will exist.

The following example illustrates one type of mixing process which appears to exist at the DWD 106 experiment area.

An event which appeared to be a Kelvin-Helmholtz shear instability was observed (Figure 64 ) with the acoustic systems during the passage of an atmospheric front, and has been previously described ${ }^{1,2,4}$. A flow-through fluorometer was also used on the ship and recorded an increase in dye concentration at a depth of $10 \mathrm{~m}$ following the observation of the mixing event. If vertical mixing at the dumpsite is assumed to be an event limited in time and geographic distribution followed by a period of little or no vertical mixing, the vertical diffusion coefficient over the mixing period and distance may be calculated. This coefficient will be higher than a long-term average, and gives an order of magnitude of the vertical diffusion coefficient during the mixing events but not over a lengthy time period or geographic section of the immediate ocean. To calculate the vertical diffusion coefficient, the water column is divided into two slabs, one $6 \mathrm{~m}$ thick, the other $4 \mathrm{~m}$ thick (Figure 65), with an initial estimated dye concentration of $3.8 \mathrm{ppb}$ in the upper slab and $1 \mathrm{ppb}$ in the lower slab. The final concentration of the dye after the mixing 
event was assumed to be uniformly distributed over $15 \mathrm{~m}$ of the ocean with a value of $2.7 \mathrm{ppb}$. It is thought that the mixing may have occurred in a time period of 5 to 15 minutes. Using a simple model for the diffusion of a finite sized cloud ${ }^{21}$, the vertical diffusion coefficient is found to lie between 190 and $60 \mathrm{~cm}^{2} / \mathrm{s}$ for the 5 minute and 15 minute mixing times respectively. As the mixing event identified here was detected from a moving ship, it was distributed over a horizontal distance, and one cannot be certain that the increase in dye concentration at $10 \mathrm{~m}$ can be entirely attributed to the mixing event. The difficulty of making process-oriented diffusion measurements in the ocean is well known. 
VIII. Conclusions

The seasonal dependence of the dispersion of the particulate phase of duPont acid iron and Grasselli industrial chemical waste has been remotely sensed with high frequency acoustic backscattering systems. In addition, sewage sludge and the effects of pharmaceutical wastes on the scatterers in the water column have been independently observed during summer and springtime water conditions respectively.

The dominant theme in the seasonal data is that the particles in the waste field were strongly affected by the presence of pycnoclines. During summer and springtime water conditions, the particles from the chemical waste are trapped within and near the base of the mixed layer (depth $10-30 \mathrm{~m}$ ) for significant periods of time. Some particles do penetrate the mixed layer base. During the winter months, the particles were observed to remain distributed throughout the mixed layer (depth to $180 \mathrm{~m}$ ) in diffuse and/or dense clouds for extended periods of time. Analog acoustic signals were presented which revealed the patchy nature of the chemical waste particle waste plumes in the vertical, in the horizontal, and internally.

A sewage sludge waste field was monitored in the summer during well stratified water conditions. Although there was penetration of pycnocline associated with the base of the mixed layer shortly after the sludge disposal, there was a large concentration of particles at the base of the mixed layer which was acoustically detected for an extended period. 
A crossing of a pharmaceutical waste disposal track revealed that a section of the water column had become nearly completely void of acoustic backscatterers (Figure 62). The data indicated that the biota which is considered to cause a significant portion of the backscattering in the upper few 10's of meters had left the area of pharmaceutical contamination either by decision or death.

The importance of determining the density structure in detail and as a function of season and in response to a variety of meteorological conditions, the statistical nature of the turbulent flow field, the shear present in the water column, and the size and density distribution of the particles released or formed at the dumpsite has been emphasized. The nature of the turbulent flow and its effects in retaining particles in suspension as compared to particle settling in quiescent water should be studied. Each of these measurements and studies is needed to provide a baseline data set for the testing and guidance of the development of the numerical models which are needed to predict the rate of vertical and horizontal dispersion and advection of the particulate and effluent phase of the chemical waste fields. 


\section{Acknowledgements}

The authors acknowledge the contributions of the following individuals during construction, maintenance, installation, and data acquisition: Brian Bardsley, Donald Crowell, James Doutt, William Kucharski. Stanley Bergstrom put extensive time and energy into preparing the charts, figures, and playing back of much of the analog recordings of the data. Susan Smith has patiently prepared the manuscript. 
Bibliography

1. Orr, M. H. and Hess, F. R., (1978), Remote Acoustic Monitoring of Industrial Chemical Waste Released at Deep Water Dumpsite 106, J. Geophys. Res., 83, 6145-6154.

2. Orr, M. H. and Hess, F. R., (1978), Remote Acoustic Monitoring of Natural Suspensate Distributions, Active Suspensate Resuspension, and Slope Shelf Water Intrusions, J. Geophys. Res., 83, 4062-4068.

3. Baseline Report of Environmental Conditions in Deep Water Dumpsite 106, NOAA Dumpsite Evaluation Report 77-1, U.S. Department of Commerce, National Oceanic and Atmospheric Administration, Rockville, MD, June 1977.

4. Hess, F. R. and Orr, M. H., (1978), Remote Sensing of Near Surface Oceanic Mixing Processes, EOS, Transactions, Am. Geophys. Union, 59 .

5. Thorpe, S. A., (1978), The Near Surface Ocean Mixing Layer in Stable Heating Conditions, J. Geophys. Res., 83, 2875-2885.

6. Koh, R. C. Y. and Chang, Y. C., (1973), Mathematical Model for Barged Ocean Disposal of Wastes, EPA-660/2-73-029, Office of Research and Development, U.S. Environmental Protection Agency, Washington, D.C. 20460.

7. Thorpe, S. A., (1968), On the Shape of Progressive Internal Waves, Phil. Trans. R. Soc. Lond. A., 263, 563-614.

8. Kester, D. R., Hittenger, R. C., and Mukherji, R., (1978), Effect of Acid Iron Waste Disposal on Transition and Heavy Metals at Deep Water Dumpsite 106, Ist International Ocean Dumping Symposium Volume, University of Rhode Island.

9. Winget, C. L., (1979), Design and Construction of a Multiport Seawater Sampling System, Woods Hole Technical Memorandum 79-1 (in preparation).

10. Orr, M. H., (1977), Acoustic Detection of the Particulate Phase of Industrial Chemical Waste Released at DWD 106, Final Report Submitted to the Ocean Dumping Program of the National Oceanic and Atmospheric Administration.

11. Morse, P. M. and Ingard, K. U., (1968), Theoretical Acoustics, (Chapter 8), McGraw-Hill Book Company, New York, NY.

12. Turner, J. S., (1973), Buoyancy Effects in Fluids, (Chapter 9), Cambridge University Press. 
13. Condon, E. U. and Odishaw, H., (1967), Handbook of Physics, (Chapter 3, p. 48), McGraw-Hill Book Company, New York, NY.

14. Proni, J. R., Newman, F. C., Rona, P. C., Drake, D. E., Berkberian, G. A., Lauter, C. A., and Sellers, R. L., (1976), On the use of acoustics for studying suspended oceanic sediment and for determining the onset of the shallow thermocline, Deep Sea Research, 23, 831-327.

15. Proni, J. R., Newman, F. C., and Sellers, R. L., (1976), Acoustic Tracking of Ocean-Dumped Sewage Sludge, Science, 193, 1005-1007.

16. Bowden, K. F., (1965), Horizontal mixing in the sea due to a shearing current, J. Fluid Mech., 21, 83-95.

17. Raudkivi, A. J., (1976), Loose Boundary Layer Hydraulics, 2nd edition, Pergamon Press, New York, NY.

18. Csanady, G. T., (1978), Turbulent Interface Layers, J. Geophys. Res., 83, 2329-2342.

19. Knauss, E. B., (1977), Modelling and Prediction of the Upper Layers of the Ocean, Pergamon Press, New York, NY.

20. Woods, J. D. and Wiley, R. L. (1972), Billow Turbulence and Ocean Macrostructure, Deep Sea Research, 19, 87-121.

21. Csanady, G. T., (1973), Turbulent Diffusion in the Environment, D. Reidel Publishing Company, Boston, MA. 


\section{Figure Captions}

Figure 1 High Frequency Acoustic Backscattering System Configured for 4-Channel Operation

Figure 2 Main Frame - Dual Channel High Frequency Acoustic Backscattering System Mounted in Nuclear Instrumentation Module Rack

Figure $3 \quad$ Clock and Timing Control Chassis

Figure 4 Receiver Module

Figure 5 Transmitter

Figure $6 \quad$ Preamplifier Control and Junction Panel

Figure $7 \quad$ Power Supply with Dual Channel Transmitter Power Amplifier

Figure 8 Chart of the United States Continental Shelf off New York and New Jersey Showing the Location of Deep Water Dumpsite 106

Figure 9a Expendable Bathythermograph Traces Taken at DWD 106 in July 1977

Figure 9b Temperature, Salinity, and Potential Density at DWD 106 in July 1977 from ALBATROSS IV. Station 6, July 24, 1977, $1940 \mathrm{z}$.

Figure 10a Expendable Bathythermograph Traces at DWD 106 in February 1978.

Figure 10b Temperature, Salinity, and Potential Density at DWD 106 in February 1978 from ALBATROSS IV. Station 2, February $1,1978,2236$.

Figure 1la Expendable Bathythermograph Traces at DWD 106 in April 1978

Figure 1lb Temperature, Salinity, and Potential Density at DWD 106 in April 1978 from MT. MITCHELI. Station 3 on April 8, 1978 at 0715 z

Figure 12 Edge Moor acid iron waste on July 26, 1977. The waste is riding on an internal wave 480 minutes after passage of the disposal barge. This gray scale record was made by the $200 \mathrm{kHz}$ high frequency acoustic backscattering system carried on the ALBATROSS IV. Denser scattering areas indicate greater concentrations of scattering particles, hence the particulate phase of the chemical waste. Note that there are two scattering layers on the left-hand side of the figure, indicating that the particles of waste are slowly settling through one density gradient to another. 
Figure 13 Edge Moor acid iron waste detected on July 26, 1977 by the 20 and $200 \mathrm{kHz}$ acoustic systems 4 minutes after the passage of the disposal barge. This record was made by the acoustic system carried on the PEIRCE.

Figure 14 Edge Moor acid iron waste detected about 15 minutes after the passage of the barge. This record was made at $200 \mathrm{kHz}$ by the acoustic system carried on the ALBATROSS IV. The ALBATROSS IV was taking chemical samples and remaining in the plume. Most of the scattering was in the 7.5-15 m depth range. Some material was seen in the $22 \mathrm{~m}$ depth range. The heaviest scattering was seen from 1520-1530 as tendrils in the 7.5 to $15 \mathrm{~m}$ depth region (see arrows).

Figure 15 Edge Moor acid iron waste detected on July 26, 1977 about 50 minutes after the passage of the barge. This record was made at $200 \mathrm{kHz}$ by the acoustic system carried on the ALBATROSS IV. The patchy nature of the particulates is evident, especially in the 1630-1633 Z time frame. Note the area of deep penetration of the waste field, 20-75 m (see bracket).

Figure 16. Edge Moor acid iron waste detected by the acoustic system aboard the PEIRCE on July 26, 1977 at $\sim 2130 \mathrm{Z}$, or $\sim 7$ hours after the chemical waste release. Note the plume's limited depth of penetration and the formation of the heavy scattering layers at the base of the seasonal mixed layer. The ship left the area of heaviest waste concentration at $\sim 2134$, then reversed course and proceeded back into the plume.

Figure 17 Edge Moor acid iron waste detected by the acoustic system aboard the PEIRCE on July 27, 1977 at $\sim 0335 \mathrm{Z}$, or $\sim 13$ hours after the chemical waste release. The area of heaviest particle concentration extended from $0334 \mathrm{z}$ to $0338 \mathrm{z}$. The layering of the particulate phase of the waste is noteworthy, as well as the extent of the waste field. A large amplitude, short period internal wave field occurs near $0344 \mathrm{z}$. Both the 20 and $200 \mathrm{kHz}$ data sets are displayed.

Figure 18 Edge Moor acid iron waste detected by the acoustic system aboard the PEIRCE on July 27, 1977 at $~ 1635 \mathrm{Z}$, or $\sim 26$ hours after the chemical waste release. The system gain used to obtain the graphic record was less than the gain used to create the records displayed in the previous two figures. As a result, only the heaviest scattering areas or densest plume areas are highlighted on the record. The thin scattered line which is most pronounced from 1640-1644 on the $200 \mathrm{kHz}$ section of the record would have appeared as the heavier scattering layers shown in the previous records if higher system gain had been used. Both the 20 and $200 \mathrm{kHz}$ records are displayed. 
Figure 19a $200 \mathrm{kHz}$ records of Edge Moor acid iron waste dispersion as detected during wintertime conditions. Edge Moor acid iron waste detected on February 2, 1978 at 19 minutes and less after passage of the barge. The 200 $\mathrm{kHz}$ high frequency acoustic backscattering system is used first at constant gain and then with gain proportional to depth. The dominant feature of the records is the patchy structure of the waste field and the depth of penetration of the waste field (see arrow $\mathrm{D})$. The arrows $\mathrm{S}$ and $\mathrm{D}$ are discussed in relation to Figures 30-32.

Figure 19b Edge Moor acid iron waste detected on February 2, 1978 at about 180 minutes and less after passage of barge. The $200 \mathrm{kHz}$ acoustic system is used with gain proportional to depth. The waste field is again very patchy in nature. The variable gray level near the bottom of the record was caused by a motion of the acoustic fish due to the ship's response to the seas.

Figure 20 A $200 \mathrm{kHz}$ record of a duPont acid iron waste plume as detected on February 2, 1978 at 2005z, 6.6 hours after release. In this case, the waste plume does not reveal the patchy structure observed in the previous figures. The material is distributed through the first $82 \mathrm{~m}$ of the water column.

Figure 21 Edge Moor acid iron waste detected on April 7, 1978 at about 180 minutes after the passage of the barge. The $200 \mathrm{kHz}$ acoustic system is used with $1 / \mathrm{r}$ time varying gain. No chemical data wereobtained for this plume.

Figure 22 Chart of the tracks of the disposal barge, the PEIRCE, and the ALBATROSS IV on July 26 and 27, 1977 during the disposal and tracking of Edge Moor acid iron waste. The areas where waste was detected are shown by heavy lines flanking the ship's tracks.

Figure 23 A plot of drogue positions indicating the Lagrangian motion of the surface water on July 27, 1977 after the disposal of Edge Moor acid iron waste. The drogues were originally placed in the plume on July 26, 1977, but their positions were not continuously monitored until the 27 th.

Figure 24 Width of July 26, 1977 acid iron plume as a function of time after release as monitored from the PEIRCE. The ship's crossing angle to the alignment direction of the drogues is noted adjacent to each width. The width was calculated for any portion of the subsurface plume which was detected without regard to the plume depth. The majority of the detected plumes were in the 15-30 $\mathrm{m}$ depth range. 
Figure 25 Depth of penetration of the acid iron particulate plume as a function of time following release on July 26, 1977. Data collected from aboard both the PEIRCE and ALBATROSS has been combined to form the figure.

Figure 26 A chart of the tracks of the waste disposal barge and the ALBATROSS IV on February 2 and 3, 1978 during the disposal of the Edge Moor acid iron waste. The areas where waste was detected are shown by symbols placed beside the ALBATROSS IV tracks.

Figure 27 Width of the Edge Moor acid iron waste plume in February 1978 as a function of time elapsed since release from the barge.

Figure 28 The depth of penetration of the Edge Moor acid iron waste plume in February 1978 as a function of time elapsed since release from the barge.

Figure 29 A chart of tracks of the barge and the MT. MITCHELL on April 7, 1978 during disposal of Edge Moor acid iron waste. The position of the only acoustic backscattering event which was considered to be a plume is indicated.

Figure 30 Amplitude records of returns from 28 successive 200 $\mathrm{kHz}$ pulses of the high frequency acoustic backscattering system. The pulse repetition rate was 2 per second. Each trace represents the receiver output for 0.25 seconds after emission of the pulse. The returns correspond to a depth range of 0 to $180 \mathrm{~m}$. Deflections caused by reflections from accumulations of waste particles at depths between 4 and $12 \mathrm{~m}$ are indicated as near surface plumes (see arrow 1). The bracket indicates the character of the background acoustic signals.

Figure 31 Amplitude records of returns from another 28 successive acoustic pulses, 1 minute 20 seconds after those displayed in Figure 30. Concentrations of the waste particles between 68 and $115 \mathrm{~m}$ depth produce a large amplitude signal envelope which is distinctive from the background acoustic scattering. The flat top section of the signal (arrow l) is the result of amplifier saturation. Note the rapid variability of the signal levels within the waste cloud. 
Figure 32 The amplitude records from 3 minutes of acoustic data. The plotting method is similar to that used in the two preceding figures, except the time scale and the amplitude scale have been compressed to allow the plotting of the longer time period. This record includes the two time intervals plotted in the previous figures. Figure 19a presented this same time interval in a gray scale record. The brackets and arrows outline features discussed in Figures 30 and 31 and in the text.

Figure 33 A gray scale recording of $200 \mathrm{kHz}$ acoustic returns detected on February 2, 1978. The dense scattering from 0555 to 0618 is thought to be caused by the remains of a dump of duPont Grasselli Plant alkaline waste on January 31,1978 . Time varying gain $(I / r)$ has been used in this and the following records.

Figure 34 A gray scale record of the scattering from a Grasselli waste disposal on February 5, 1978. The ALBATROSS IV, carrying the acoustic backscattering system, crossed the center of the waste plume at about $0404 \mathrm{z}$, or 120 minutes after the barge passage. The ship's speed throughout the record was about 6 knots on a constant course.

Figure 35 Grasselli alkaline waste detected on February 5, 1978 at about 180 minutes after disposal.

Figure 36 Grasselli alkaline waste detected on February 5, 1978 at about 270 minutes after disposal.

Figure 37 Estimated widths of the Grasselli alkaline waste plume detected on February 5, 1978 as a function of time elapsed from disposal. The widths calculated after 4 hours are uncertain due to a lack of Lagrangian data.

Figure 38 The observed depth distribution of the Grasselli alkaline waste plume detected on February 5, 1978 as a function of time elapsed from the disposal.

Figure 39 A chart showing the track of two waste disposal barges which were disposing duPont Grasselli Plant and duPont acid iron waste respectively, and the NOAA ship ALBATROSS IV on February 5, 1978. Detected waste is indicated by the symbols beside the track of the research vessel.

Figure 40 A schematic of the configuration of the multiport water sampling system used during the April 1978 cruise to DWD 106. 
Figure 41 A chart showing the tracks of barges releasing a variety of industrial chemical wastes during the April 1978 cruise to DWD 106. The track of the MT. MITCHELI during the monitoring of duPont Grasselli waste on April 10, 1978 is also shown on the figure, as well as the positions of acoustic detection of the waste.

Figure 42 The depth of the multiport water sampler pump housing as a function of time from 1130 to $2000 \mathrm{z}$ on April 10, 1978 during the monitoring of dyed duPont Grasselli waste.

Figure 43 a The depth and positions at which rhodamine WT dye was detected with the multiport water sampling system during the April 10, 1978 DWD 106 experiment. Dye concentration ranges are noted with symbols labeled on the figure.

Figure $43 \mathrm{~b}$ Depth and positions at which rhodamine WT dye samples were taken with CTD sampler after multiport sampler was brought aboard for repair.

Figure 44 Depth of the Grasselli alkaline waste plume in April 1978 as a function of time elapsed since disposal.

Figure 45 The plume width of the duPont Grasselli Plant waste plotted as a function of time. The width was calculated from the acoustic data obtained during the April 10, 1978 experiment aboard the MT. MITCHELL. Because of the variable nature of the data, it was not possible to measure all the widths in a consistent way. The type of data used for the measurement is indicated by symbol as follows:

- Solid dots are derived from original fiber optics gray scale records only.

- open circles are derived from fiber optics amplitude records like those of Figures 30,31 , and 32 .

- A bar connection indicates that the width may be interpreted differently depending on the density level selected for the edge of the plume or the depth horizon of the scatterers.

- A question mark indicates uncertainty in identification of the scattering features with the plume.

- Arrows indicate that the plume was wider than measured for the reason indicated by the letter symbol. $S=$ stopped in plume; didn't transit. I = drifted into plume from north, then powered out to west. VS = very slow transit.

In addition, DP specifies that width was measured only from a depth depression of the reflecting layer. II specifies width measured only on an intense layer at 13-14 meters with no evidence of a shallower plume. 
Figure $46200 \mathrm{kHz}$ acoustic data taken about 30--60 minutes after the release of the duPont Grasselli waste plume on April 10, 1978. Note that the waste field does not penetrate deeper than the first acoustic scattering surface which varies in depth from $12-15 \mathrm{~m}$.

Figure 47 duPont Grasselli alkaline waste detected on April 10, 1978 with the $200 \mathrm{kHz}$ acoustic system. The waste remains suspended in the first $15 \mathrm{~m}$ of the water column at the $95 \mathrm{~min}$ and $116 \mathrm{~min}$ mark and is seen to lie on the interface between the first and second layers of water (arrows 1, 2, and 3).

Figure 48 A representative $200 \mathrm{kHz}$ acoustic record of the duPont Grasselli waste field taken $\sim 4.6$ hours after the chemical waste release. The acoustics were detecting a near surface plume distributed throughout the first $7.5 \mathrm{~m}$ of the water column with some weak evidence of a heavier scattering patch on the order of a meter or two in thickness at a depth of 14-15 m (see the 1550-1555 z time frame).

Figure 49 A chart of the tracks of a disposal barge, the PEIRCE, and the ALBATROSS IV on July 23 and 24, 1977 during the disposal and monitoring of a sewage sludge plume. The

areas where the waste was detected are shown by heavy lines or heavy dots flanking the ship's tracks. Dots denote lighter, lines denote heavier concentrations.

Figure 50 A plot of the width of the sewage sludge plume as a function of time elapsed since disposal. The sewage sludge plume was tracked from July 23-24, 1977. The widths have been derived from data collected aboard both the NOAA ship PEIRCE and the NOAA ship ALBATROSS IV. The circles with arrows indicate data for which the ship did not completely traverse the plume. For such data, the plume would have been wider than indicated.

Figure 51 A plot of the depth of the sewage sludge plume as a function of elapsed time since disposal. The depth has been plotted from data collected aboard both the NOAA ship PEIRCE and the NOAA ship ALBATROSS IV.

Figure 52 Sewage sludge detected on July 23, 1977 by the high frequency acoustic backscattering system installed on PEIRCE. This gray scale record shows reflections from the waste plume as PEIRCE crosses it repeatedly while following close behind the disposal barge. The $200 \mathrm{kHz}$ receiver was set on manual gain during this data acquisition period. The sewage sludge particles are seen to penetrate to a depth of $\sim 15 \mathrm{~m}$. 
Figure 53 Sewage sludge plumes detected on July 23, 1977 from the NOAA ship PEIRCE. The sewage sludge plumes were detected 27 and 48 minutes after the passage of the barge. Both plumes show the effects of shear near the pycnocline at a depth of $12-17 \mathrm{~m}$. The speed of flow in this region has been calculated to be $2.5 \mathrm{~m} / \mathrm{min}$. Note that a portion of the plume has penetrated the pycnocline to depths of $\sim 55 \mathrm{~m}$, indicating a separation of the plume by particle size. The ship's course on the first passage was $225^{\circ}$ and the course on the second passage was $60^{\circ}$.

Figure 54a A sketch of the motion of the NOAA ship PEIRCE during the two crossings of the sewage sludge plume depicted in Figure 53. The direction of the barge motion is a.lso indicated.

Figure 54b The approximate shape of the two sewage sludge plumes in the direction of $\sim 050^{\circ}$. The calculated width of the plume both with and without the use of an estimated mean current of $\sim .875 \mathrm{~m} / \mathrm{s}$ is shown in the figure. The need for accurate current and shear measurements during these experiments is pointed out by the large variability in estimated plume size.

Figure 54c A three-dimensional plot of expected plume growth characteristics in the shear field which was acoustically detected during the sewage sludge disposal. The drawing assumes that the shear was perpendicular to the barge track.

Figure 54d A three-dimensional plot of expected plume growth characteristics in the shear field which was detected. The drawing assumes the shear was at an angle other than perpendicular to the barge track.

Figure 55 Sewage sludge detected on July 23, 1977 from the ALBATROSS IV. This record shows the plume 15 minutes after disposal. A $10 \mathrm{db}$ reduction in the $200 \mathrm{kHz}$ system gain from 2105 to 2106 shows that the very dense plume which is fully black just before 2105 is concentrated on the pycnocline at a depth of about $15 \mathrm{~m}$.

Figure 56 Sewage sludge detected on July 23, 1977 with the 20 and $200 \mathrm{kHz}$ acoustic system aboard the PEIRCE. This record, made 123 minutes after release, shows a maximum concentration at 15-20 m depth. The waste is distributed through the horizontal in the above depth range except the last 2 minutes on the right of the record. 
Figure 57 Sewage sludge detected on July 24, 1977 from the ALBATROSS IV, 280 minutes after disposal. The waste field is concentrated predominantly on the base of the mixed layer in thin scattering layers throughout the record.

Figure 58 Sewage sludge detected on July 24, 1977 from the ALBATROSS IV, 510 minutes after disposal. Records at 39 and $200 \mathrm{kHz}$ are shown. Again, the persistent layer scatterers are noted, as is the absence of a plume in the first $7.5 \mathrm{~m}$ of the water column.

Figure 59 Sewage sludge detected on July 24, 1977 from the ALBATROSS IV, 560 minutes after disposal. Again, records at 39 and $200 \mathrm{kHz}$ are shown. The concentration on the pycnocline at about $12 \mathrm{~m}$ depth and at about $25 \mathrm{~m}$ appears in the higher frequency record.

Figure 60 Sewage sludge detected on July 24, 1977 from the ALBATROSS IV, 722 minutes after disposal. Concentrations at 16, 37, and $50 \mathrm{~m}$ depth are shown. A heavy scattering surface in the 15-30 m depth range is continued in Figure 61.

Figure 61 Sewage sludge detected on July 24, 1977 from the ALBATROSS IV, 760 minutes after disposal. The concentration from 15 to $30 \mathrm{~m}$ depth is extremely heavy throughout this record. The sinking particles from 1000 to $1010 \mathrm{z}$ suggest that, as the particle concentration on the pycnocline becomes large, there is either a breakdown in the pycnocline or, initially, a weaker gradient in this area or a coagulation

of particles such that they flow through the high gradient areas of the pycnocline and slowly sink to greater depths. The presence of shear in the water column is suggested as the deeper particles found in the 45-60 m depth range near $1010 \mathrm{Z}$ may have originated in the area around 1000 to $1003 \mathrm{z}$.

Figure 62 A $200 \mathrm{kHz}$ gray scale acoustic record showing a crossing of a pharmaceutical waste disposal track on April 6, 1978. The dark concentration from about 30 to $60 \mathrm{~m}$ and the lighter gray area above it are caused by natural biological scatterers. The very light near surface bracketed area from 2050 to 2055 and extending to about $15 \mathrm{~m}$ depth shows that biological scatterers have moved or sunk away from the pharmaceutical waste, which may have been mixing in the water. The time between the acoustical observations and the release of the waste is unknown as the barge track was unknown. 
Figure 63 Record of a crossing of a pharmaceutical waste plume about 8 minutes after disposal. The natural biological scatterers account for all dark areas of the record except for the dark scattering, which stands out clearly. The dark scattering area is the turbulent wake of the barge and tow tug. The record indicates that insufficient time has passed such that the biological scatterers could be affected by the chemicals in the waste.

Figure 64 Mixing event at the mixed layer boundary. Scattering layer (arrow 1) exhibiting large amplitude non-linear displacement. Scattering layer (arrow 2) breaking. Scattering area (arrow 3) which resembles cats eye structure observed in clear air turbulence. Note the remanent line scatterers (arrow 4) in the area of diffuse scattering (0544 Z to $0624 \mathrm{Z}$, September 7 , 1976). The solid dark line at the bottom of each section of the figure indicates the increase or decrease in rhodamine WT dye concentration monitored by a flow-through fluorometer. The fluorometer's water was drawn from a depth of $10 \mathrm{~m}$ (see the alternating $\mathrm{black} /$ white line). The increase in rhodamine dye concentration indicates a downward mixing of the waste field.

Figure 65 A pictorial view of the mixing event described in Figure 64. A section of the water column with dye present (concentration of $3.8 \mathrm{ppb}$ ) is mixed down from a depth of $6 \mathrm{~m}$ to a depth of $15 \mathrm{~m}$. Assuming that the first $15 \mathrm{~m}$ of the water column is uniformly mixed, the dye concentration becomes $2.7 \mathrm{ppb}$. Using these dye concentrations and an estimated mixing time ( 5 minutes or 15 minutes), the diffusion coefficient for the event was estimated to be between 190 and 60 $\mathrm{cm}^{2} / \mathrm{s}$. 


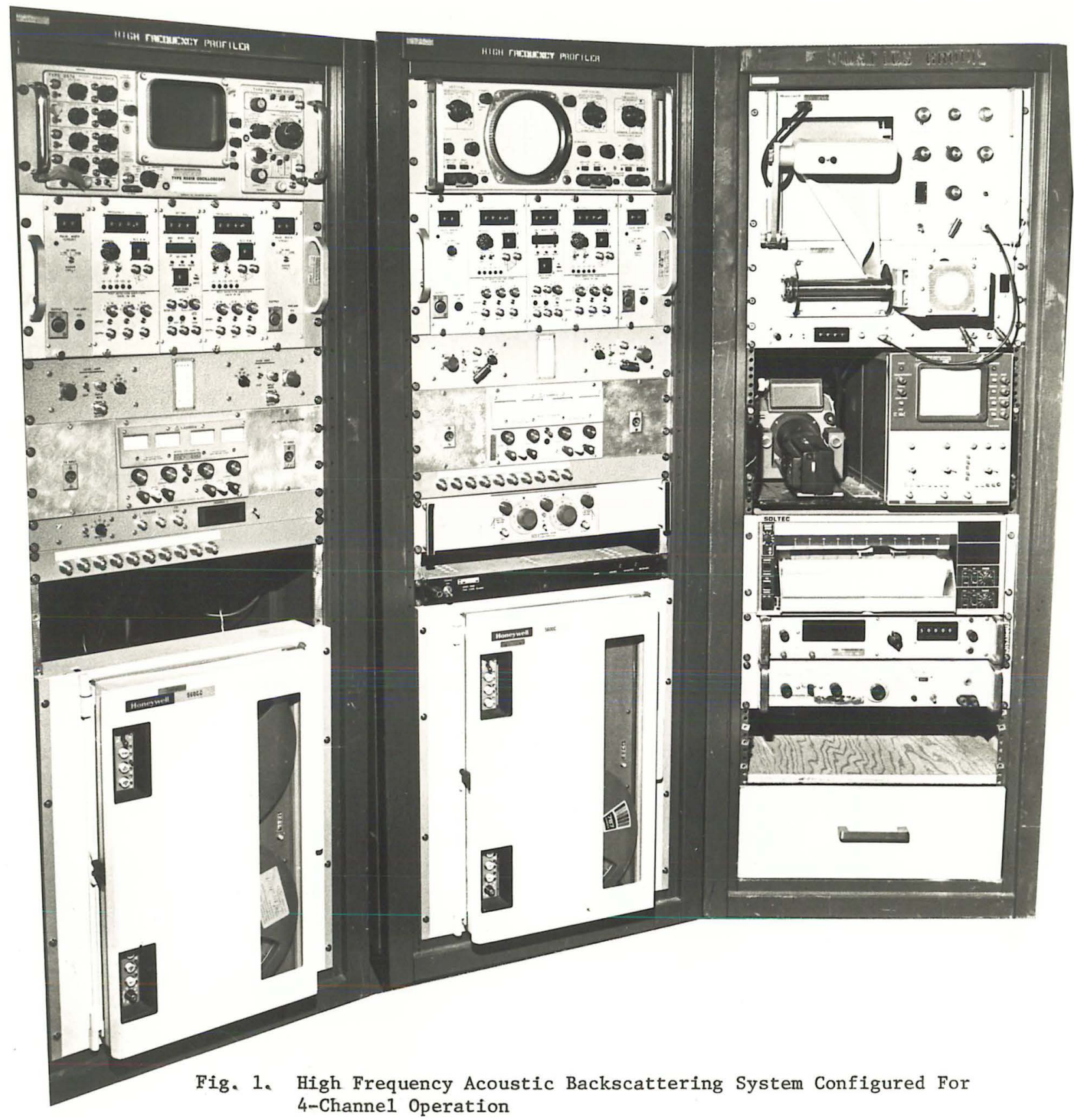




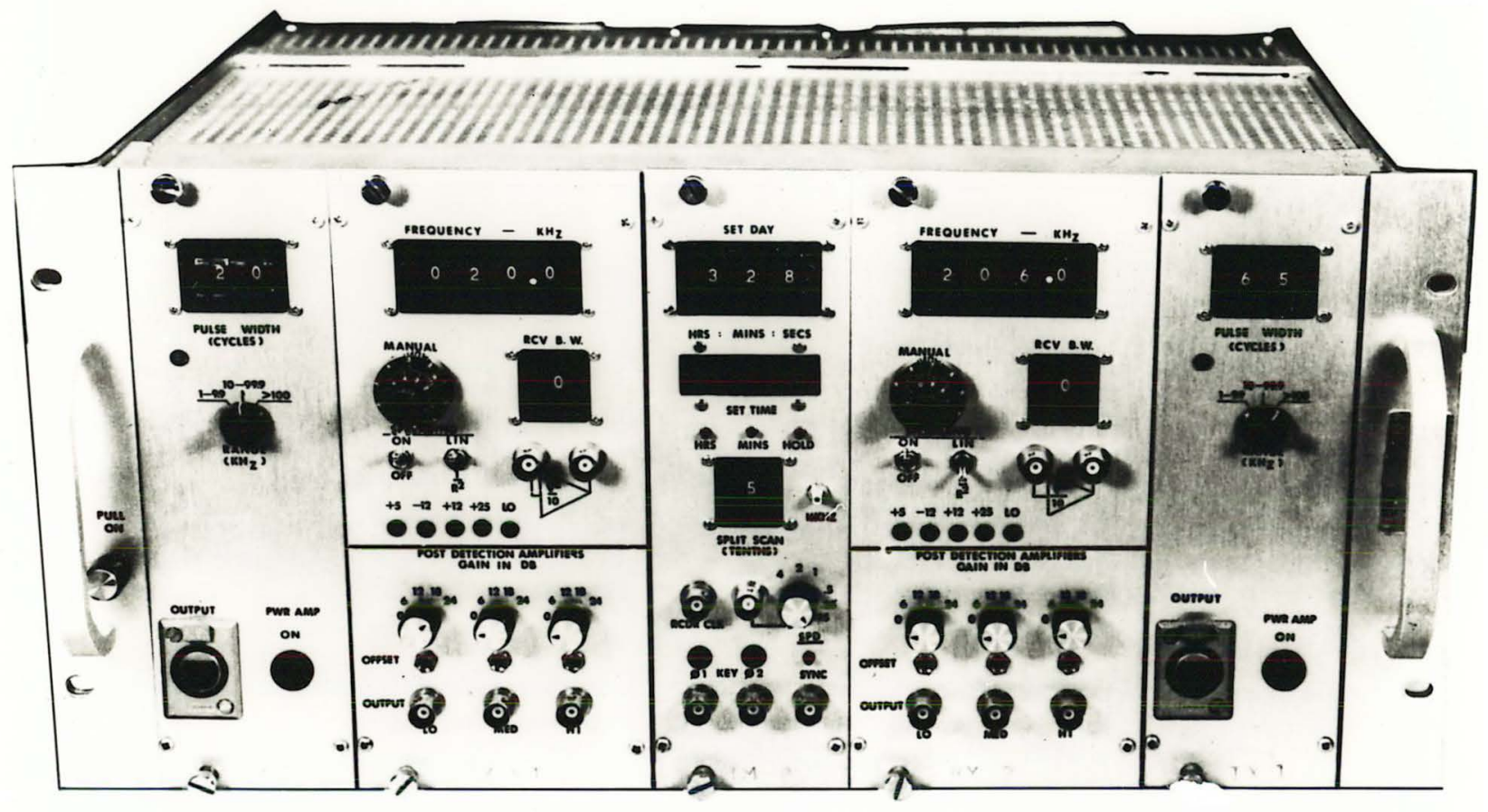

Figure 2. Main Frame - Dual channel high frequency acoustic backscattering system mounted in Nuclear Instrumentation Module rack. 


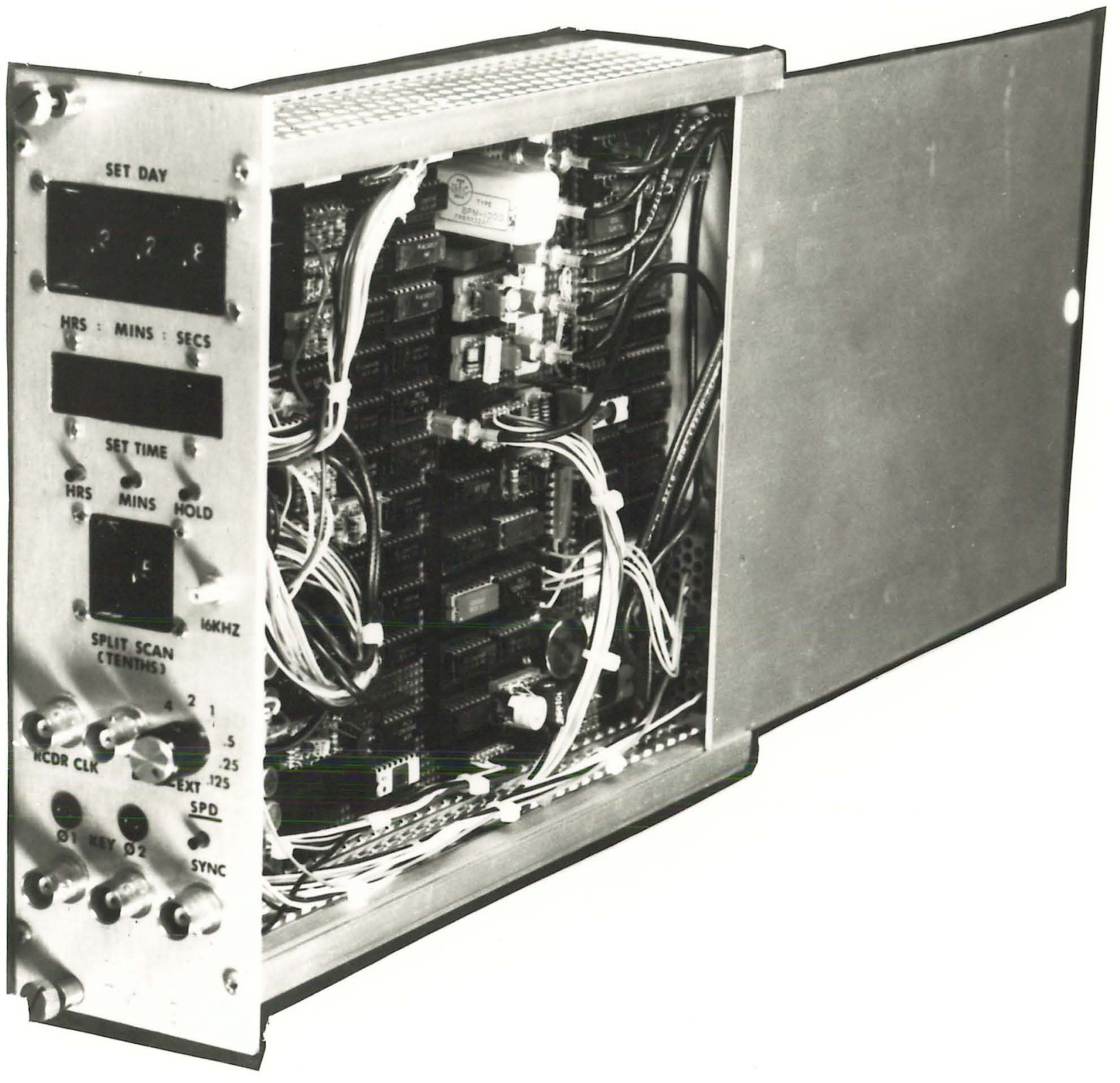

Fig. 3. Clock and Timing Control Chassis 


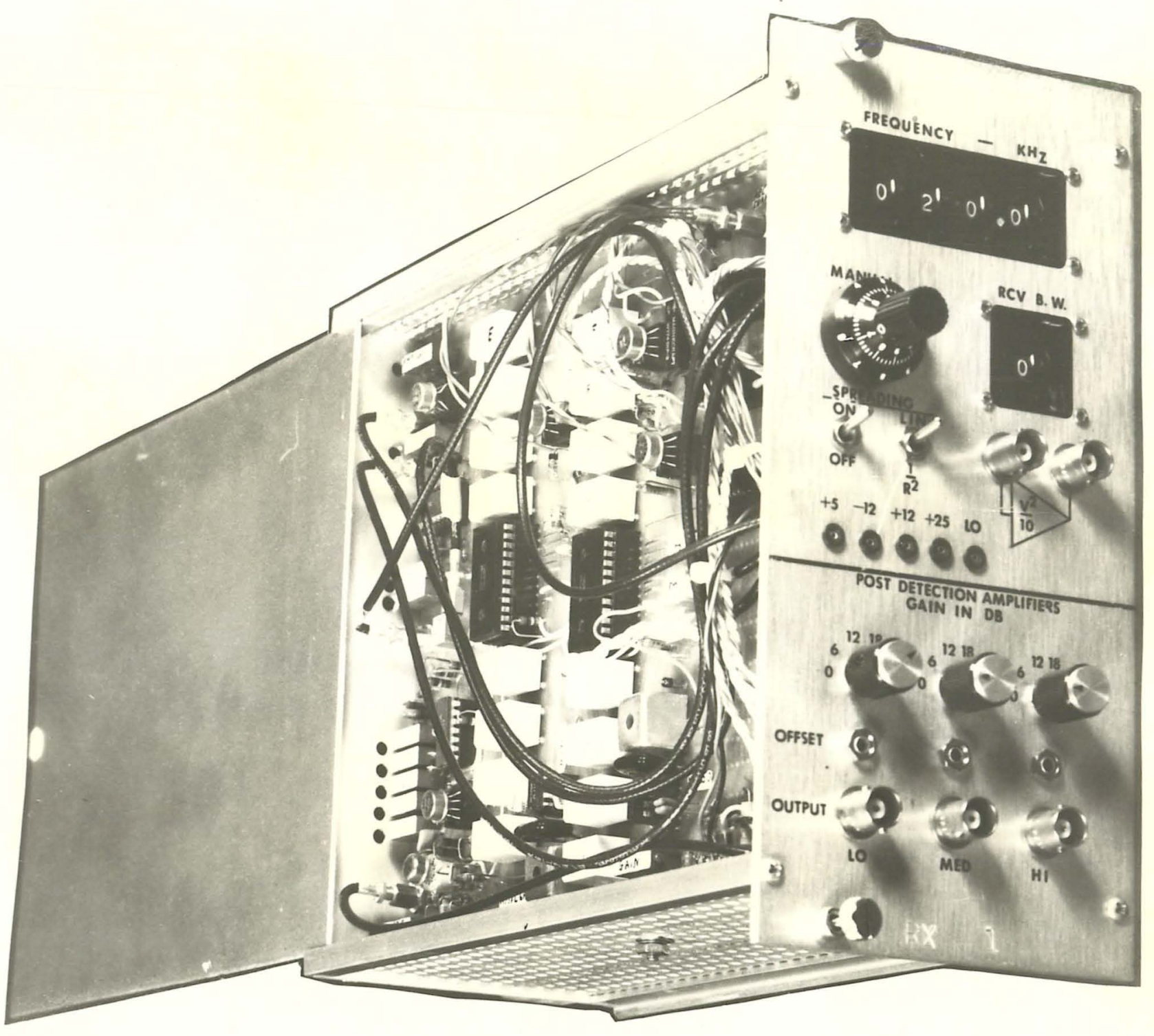

Fig. 4. Receiver Module 


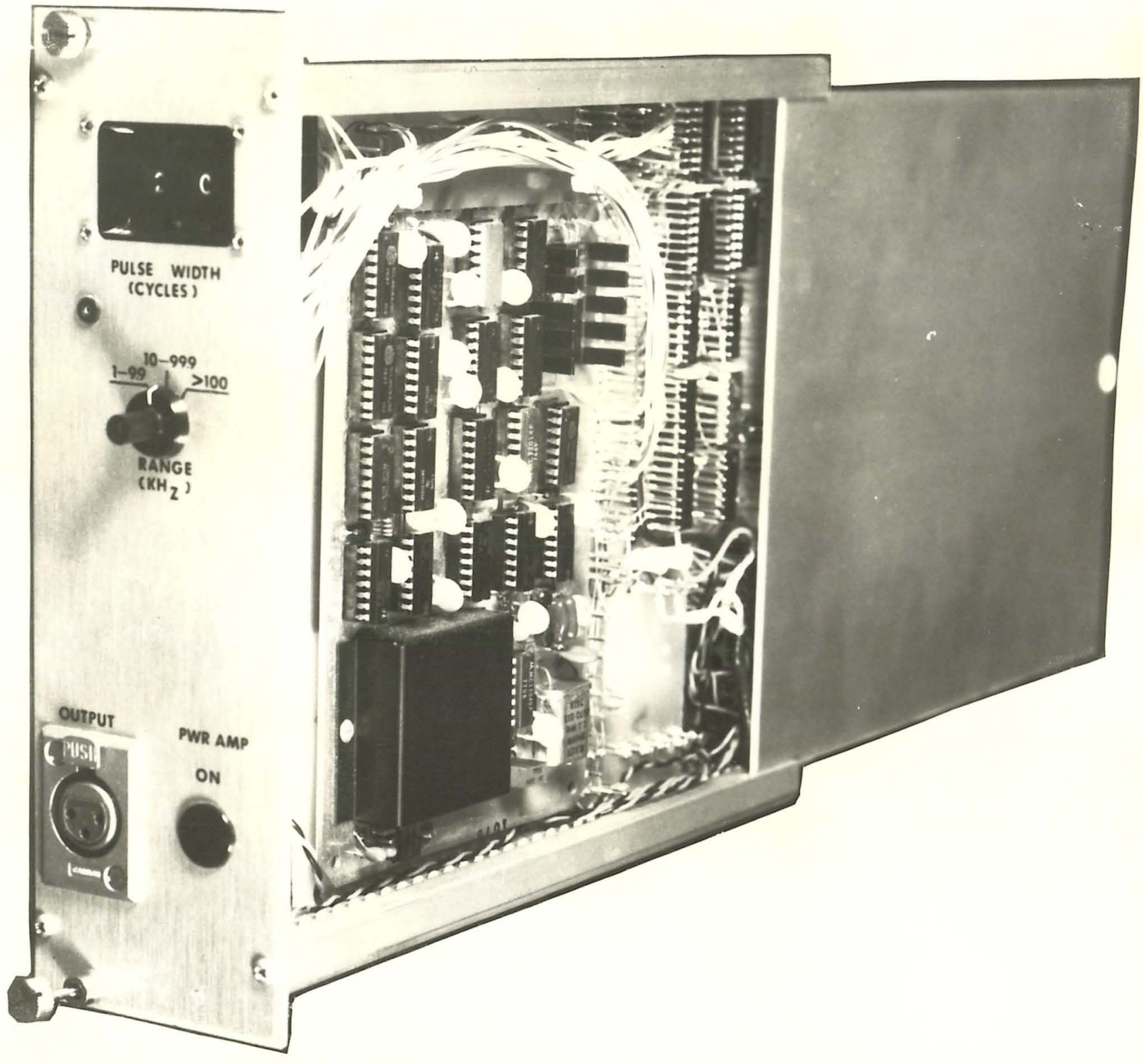

Fig. 5. Transmitter 


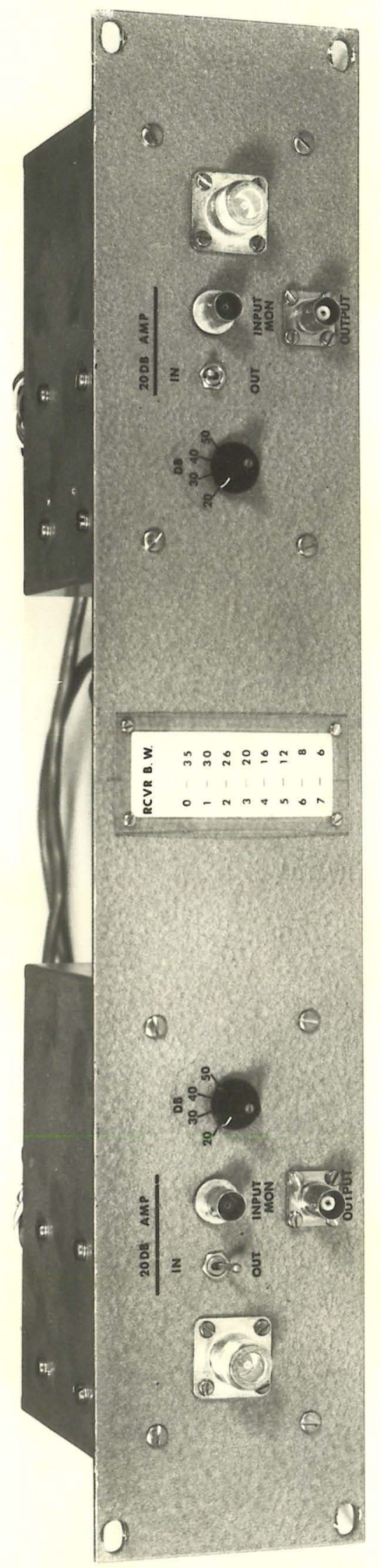

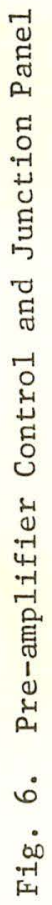




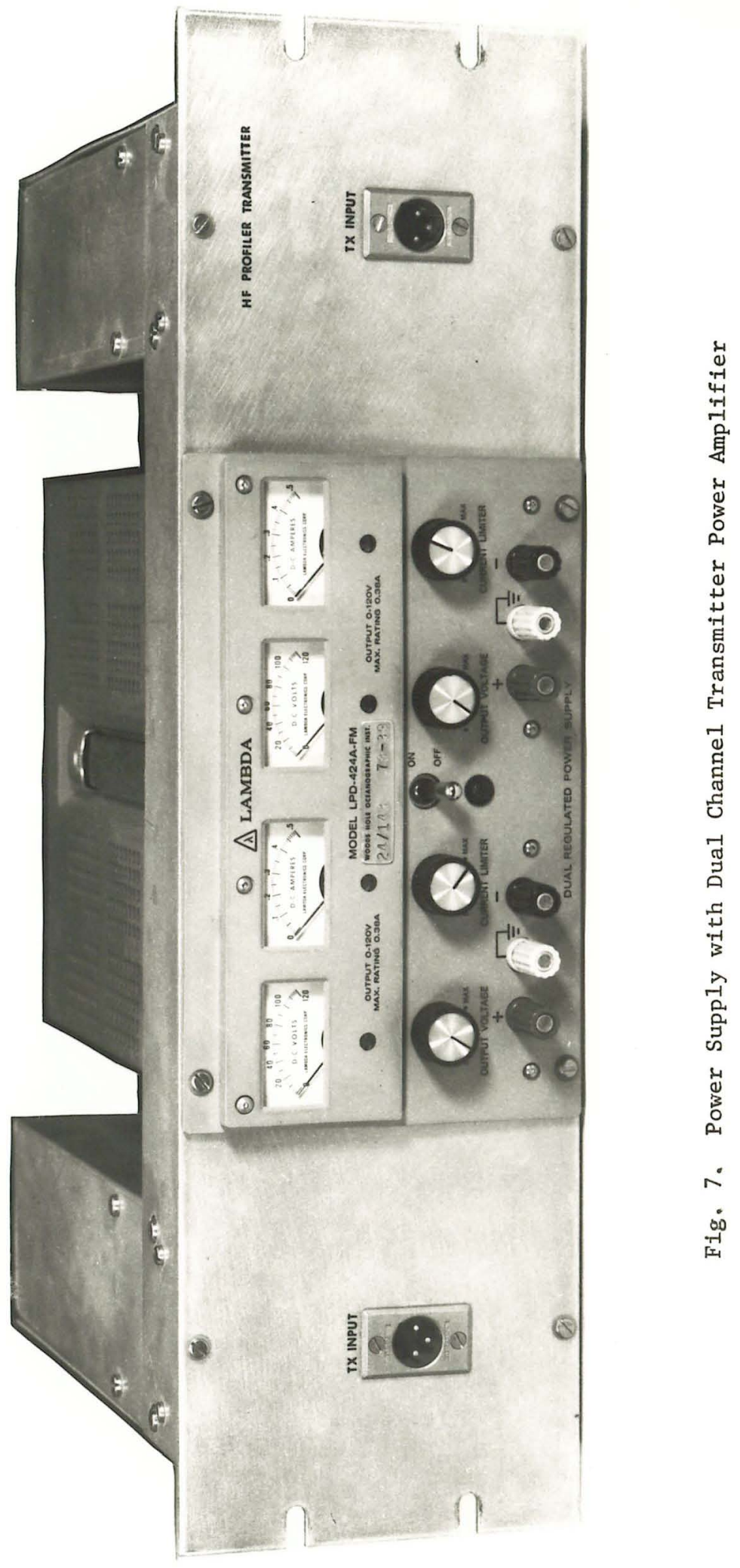




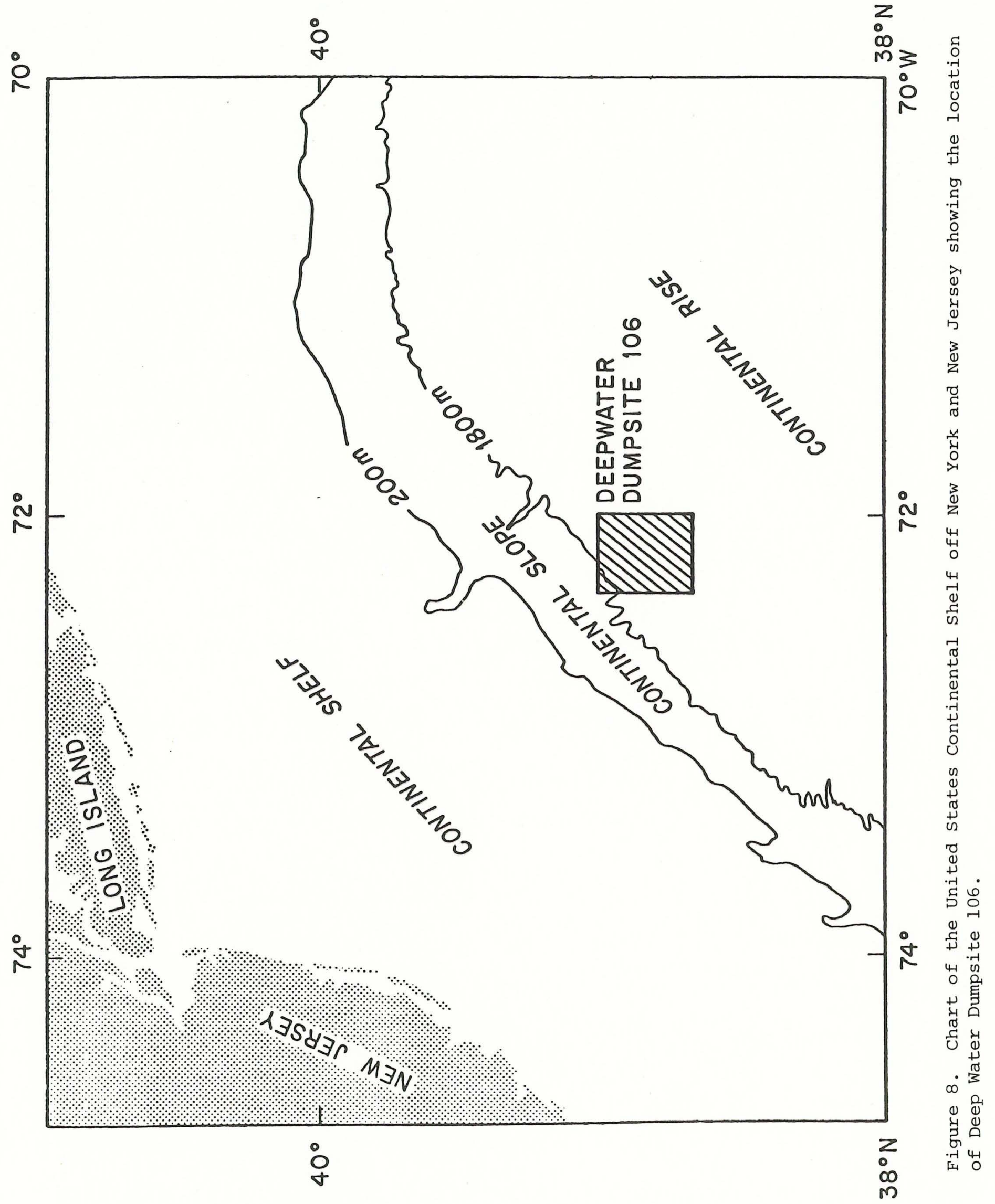




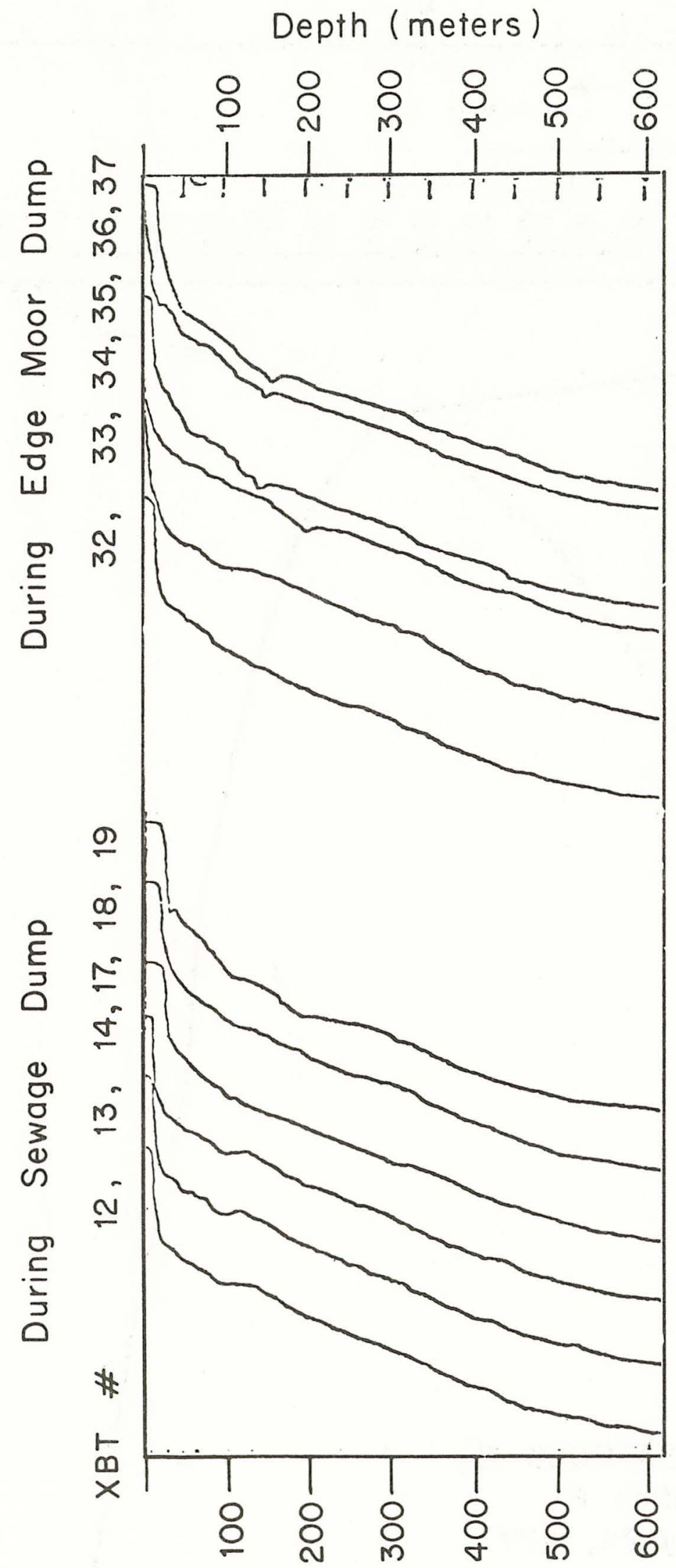

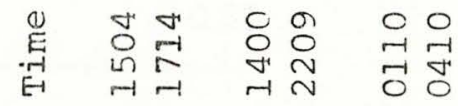

rar rar

$\sum \sum \sum \sum 5$

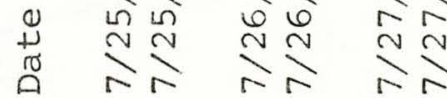

Hi 000000000

㞻

$\stackrel{\sim}{\infty}$

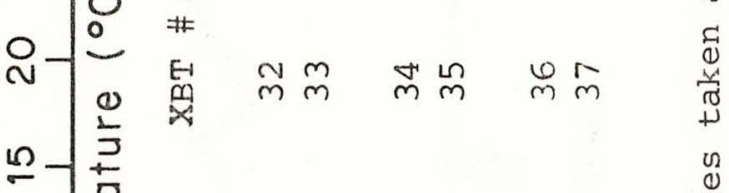

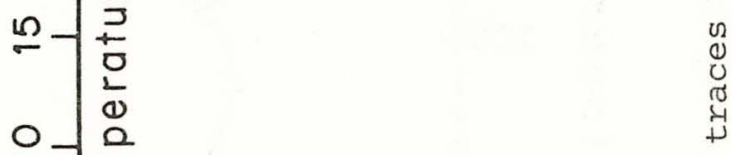

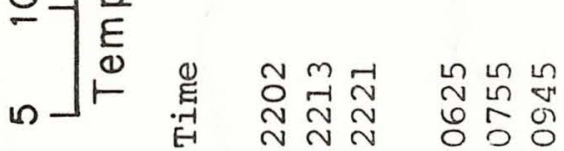

NAN NEN

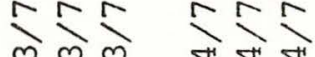

$\stackrel{m}{\sim} \stackrel{\sim}{\sim} \stackrel{\sim}{\sim} \stackrel{\sim}{\sim}$

ब

$\mathrm{H}^{\circ}$

- 0000000

岁

\#

กิ

2
-1
3
5
5
-1
0
0
-1 

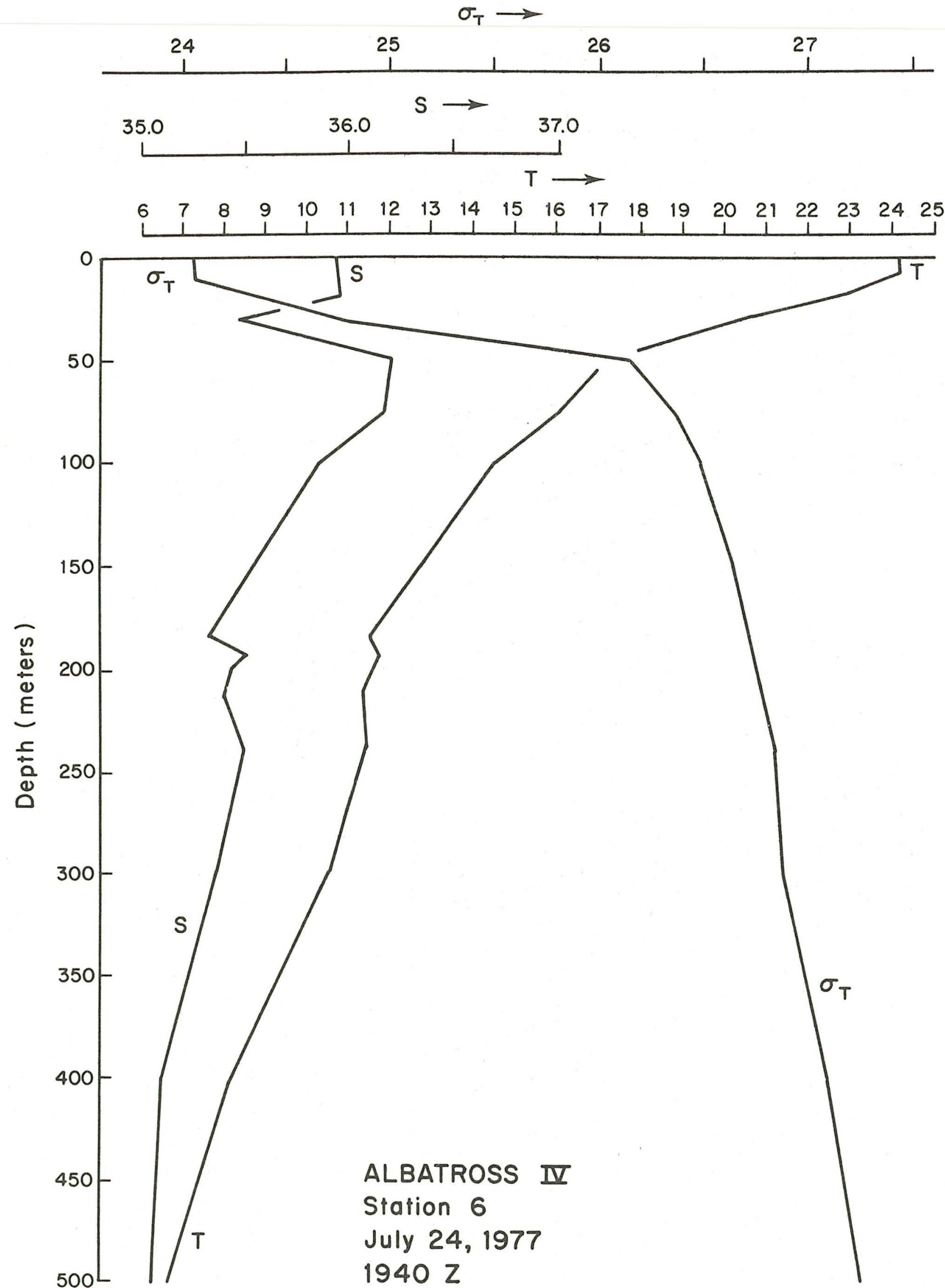

Figure 9b. Temperature, salinity, and potential density at DWD 106 in July 1977 from ALBATROSS IV. Station 6, July 24, 1977, $1940 \mathrm{z}$. 


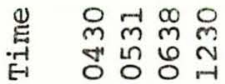

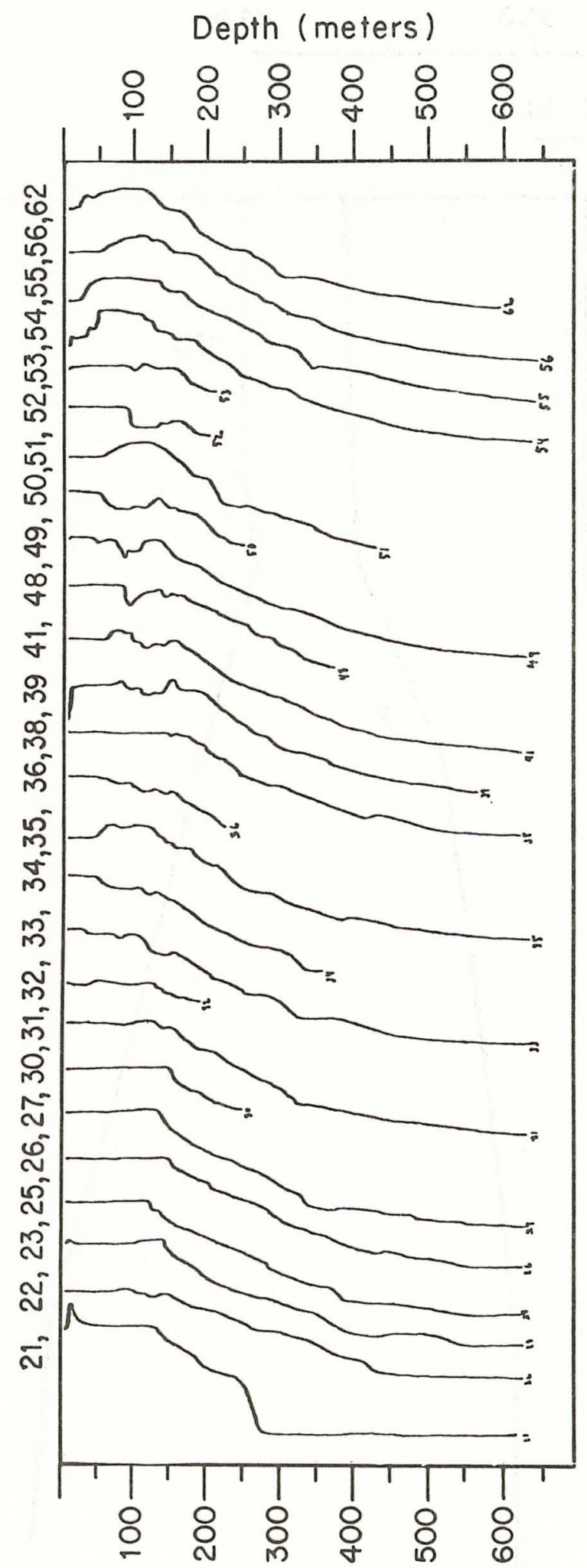

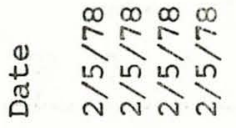

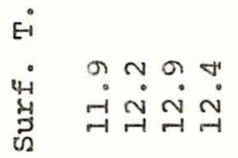

\#

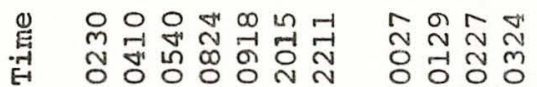

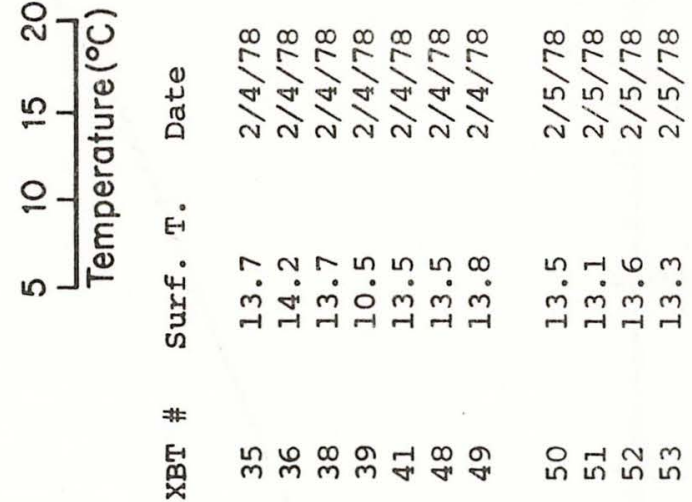

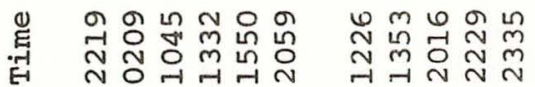

गี

सi

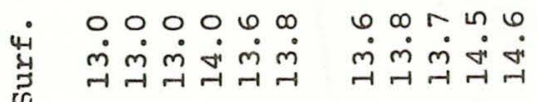

\# 


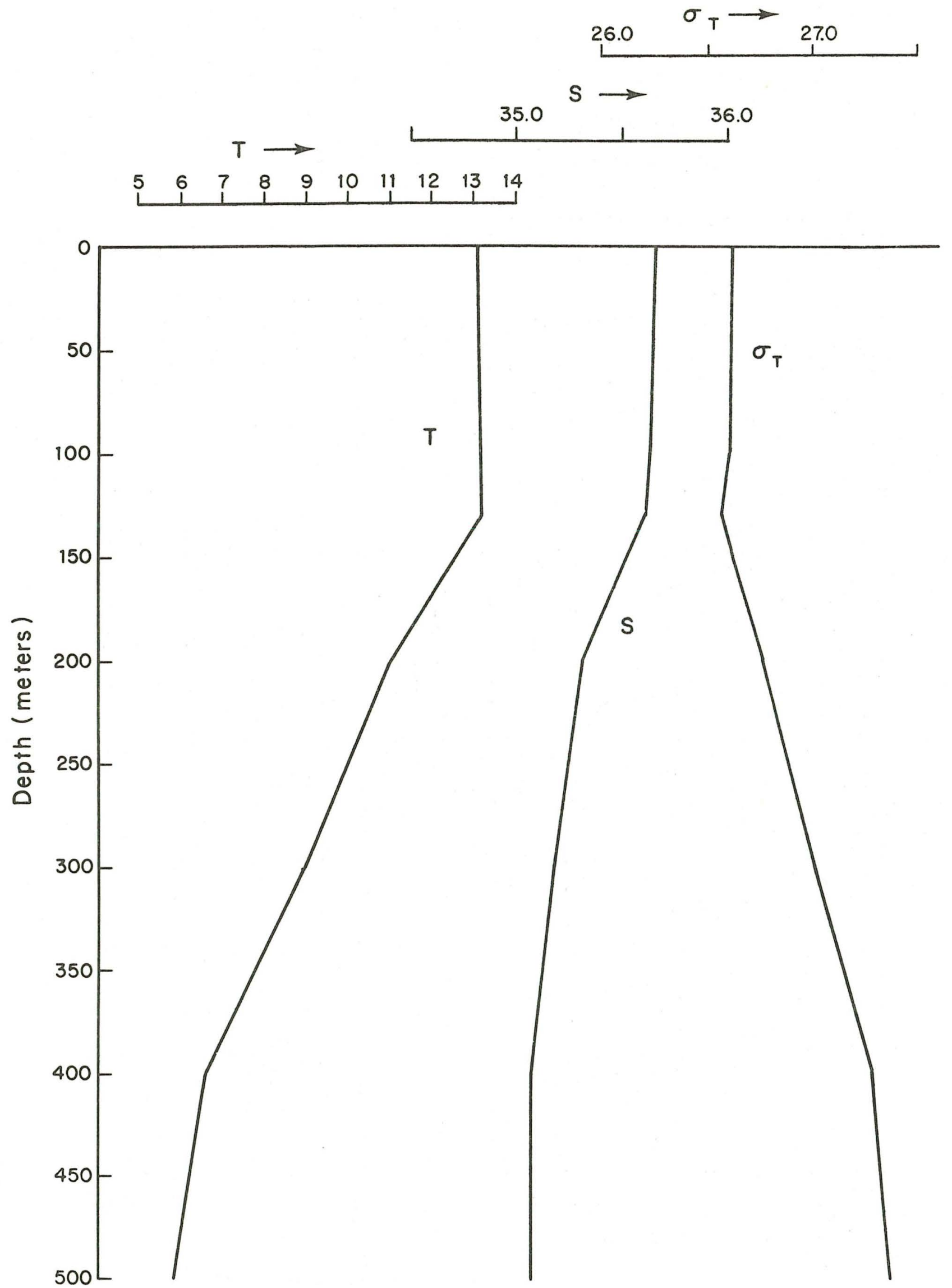

\section{ALBATROSS II Sta \# 2 Feb 2, 1978}

Figure 10b. Temperature, salinity, and potential density at DWD 106 in February 1978 from ALBATROSS IV. Station 2, February 1, 1978, 2236. 
$\begin{array}{llllll}\text { \# } & 54 & 55 & 56 & 58 & 59\end{array}$

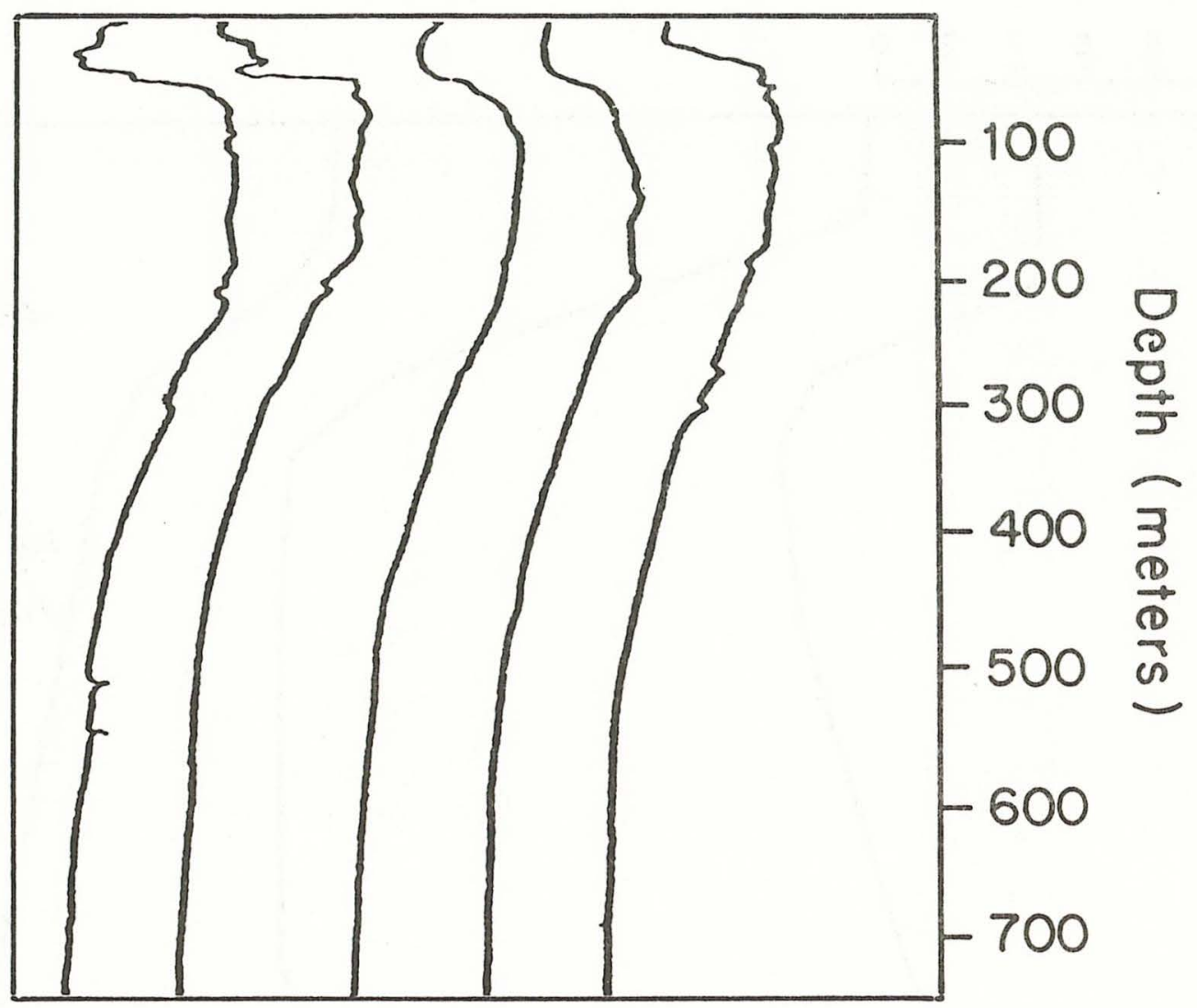

\begin{tabular}{cccc}
5 & 10 & 15 & 20 \\
\hline & 1 & 1 & 1
\end{tabular}

Temperature $\left({ }^{\circ} \mathrm{C}\right)$

At 600 meter depth all traces read approximately $5^{\circ} \mathrm{C}$

$\# 54=$ April 10

$2330 z$

\#55 = April 11

$\# 56$ = April 11
$0350 z$

$0612 z$
\#58 = April 11

\#59 = April 11
$0828 z$

17352

Figure 1la. Expendable bathythermograph traces at DWD 106 in April 1978. 


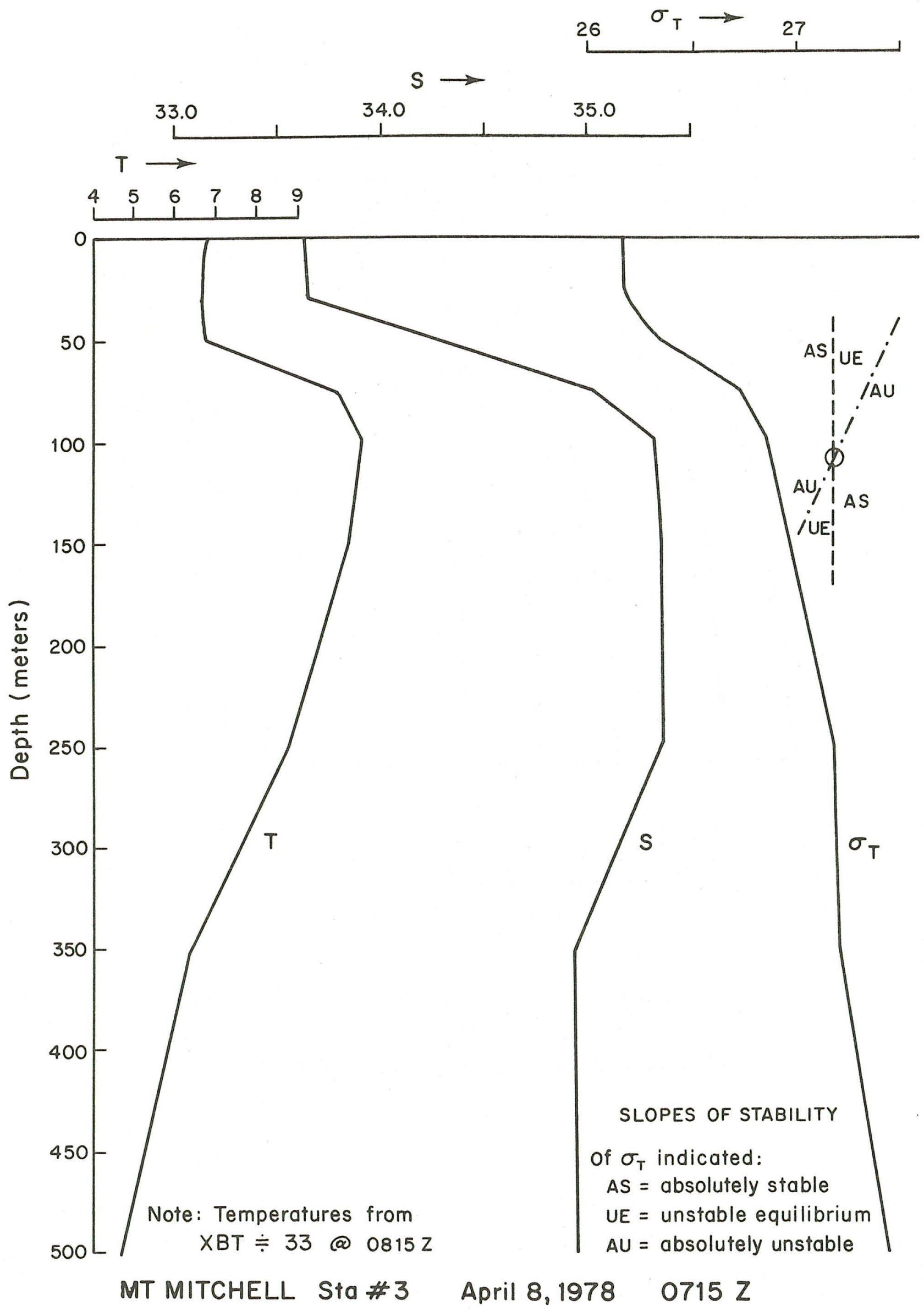

Figure 1lb. Temperature, salinity, and potential density at DWD 106 in April 1978 from MT. MITCHELL. Station 3 on April 8, 1978 at $0715 \mathrm{z}$. 
$80 a$

Blank 


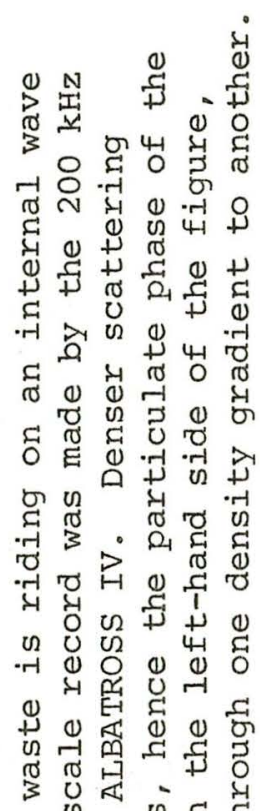

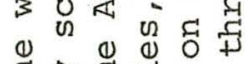

हो है द्य है

$\therefore$ व

N.t 001

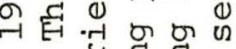

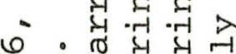
N 0000 $\lambda$ 다마 $30+000$ द न (1) 요욤 + on $\begin{array}{ll}0 \\ 0\end{array}$ उ० ॥ $4 \pi$ 도 ॠ

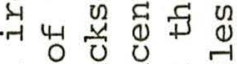
० - 000. त 0 ॠ

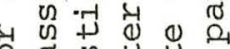
○

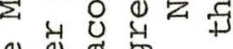
का

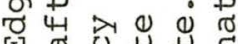
更 (1) 30 ᄀ ב (1) पै $ह$ थ

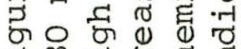

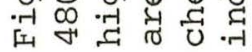


(sıәเәس) $H \perp d \exists O$
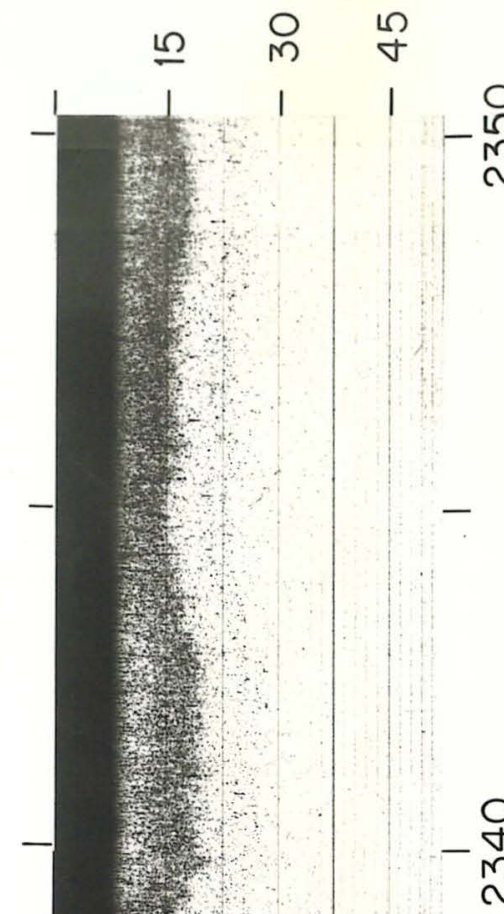

$\omega$

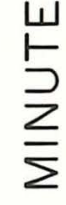

$\infty$

0
$\stackrel{\Upsilon}{0}$

$\stackrel{O}{m}$
$-\stackrel{N}{m}$

ᄂ

$\sum$
$N$

กั

๖
$\supset$

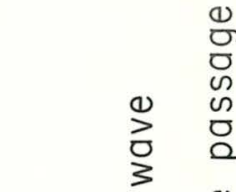

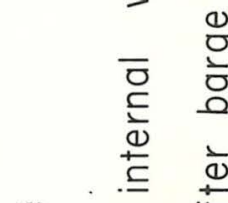

造

$\gg$ o

힝

옴

$\stackrel{\cup}{N}$

日

$\theta$

0
0
$\frac{1}{1}$
$\frac{1}{4}$
$\frac{1}{4}$ 


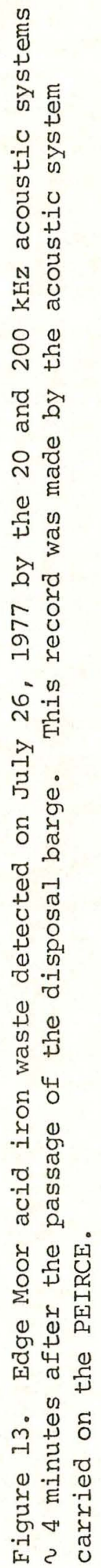



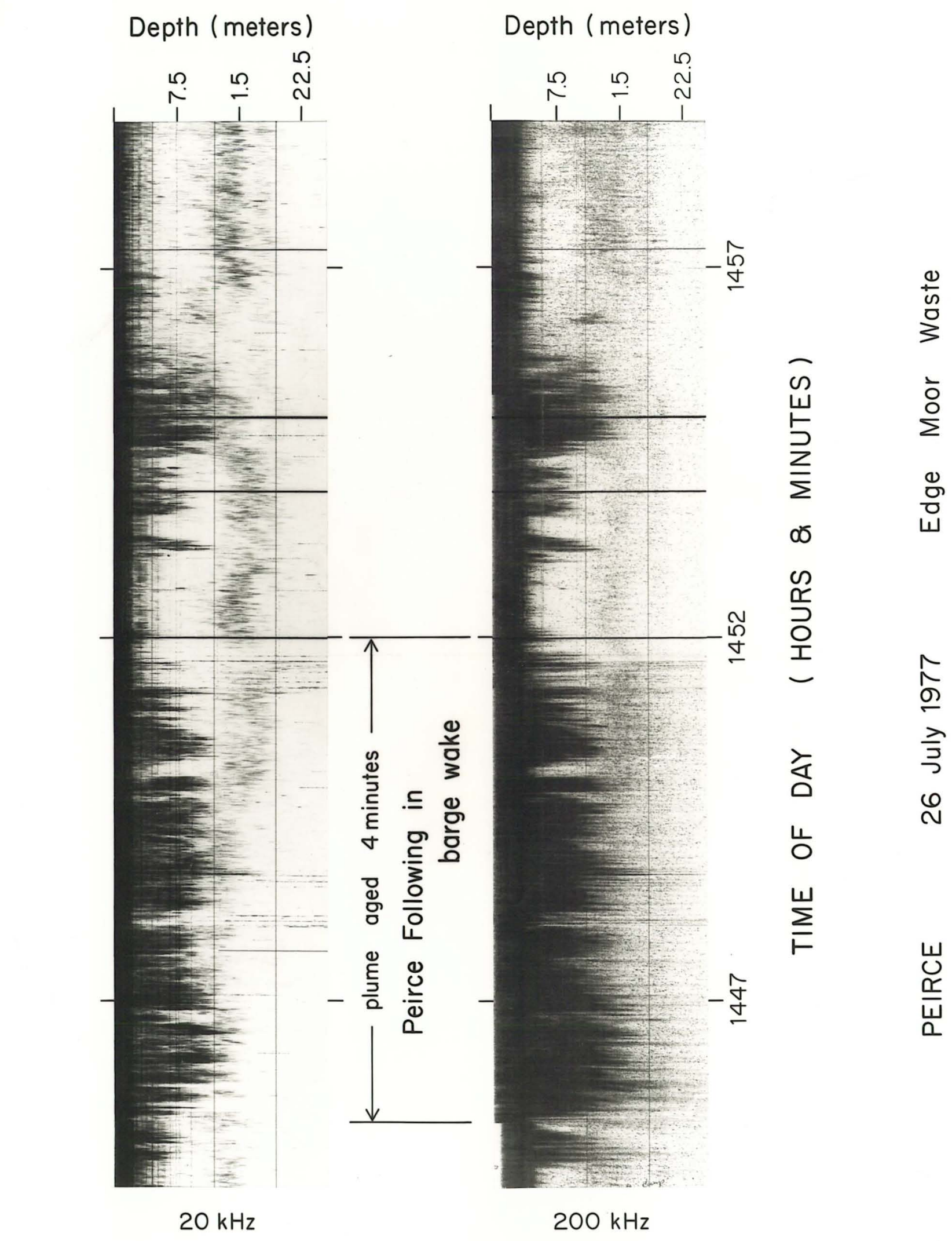


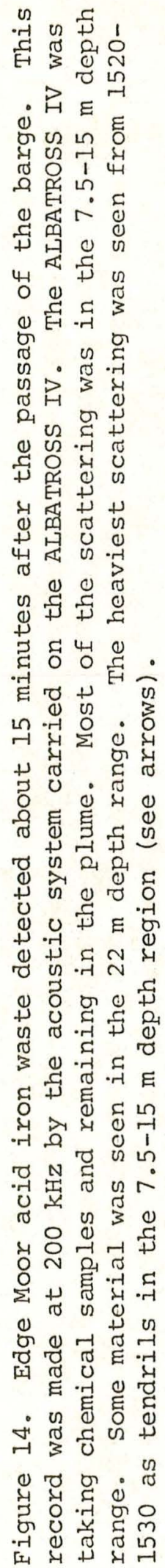




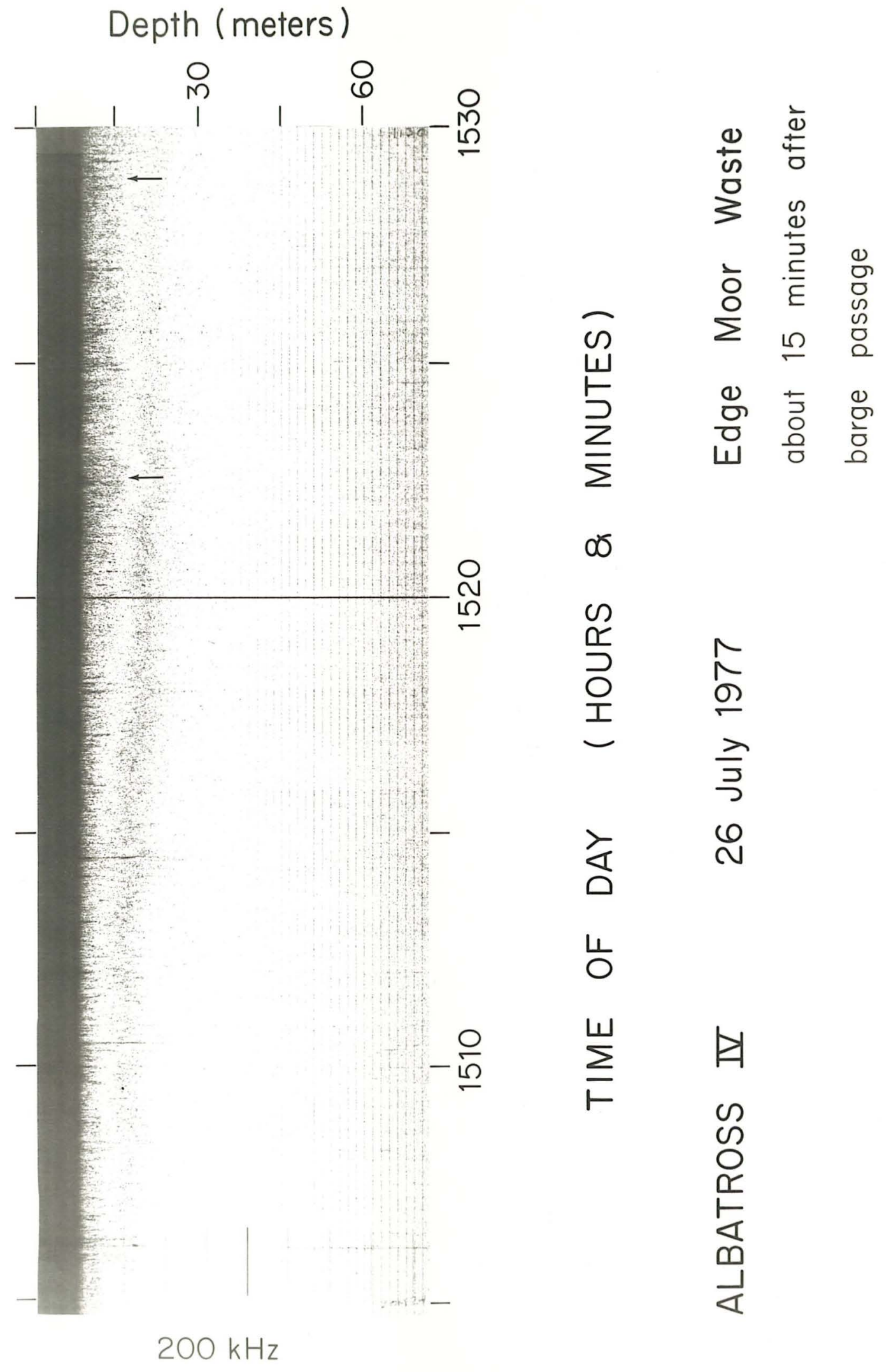




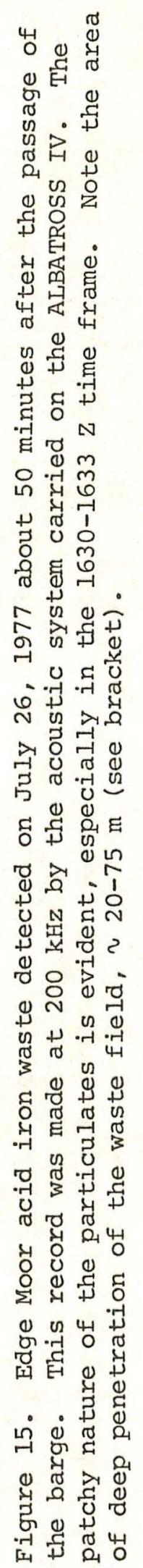




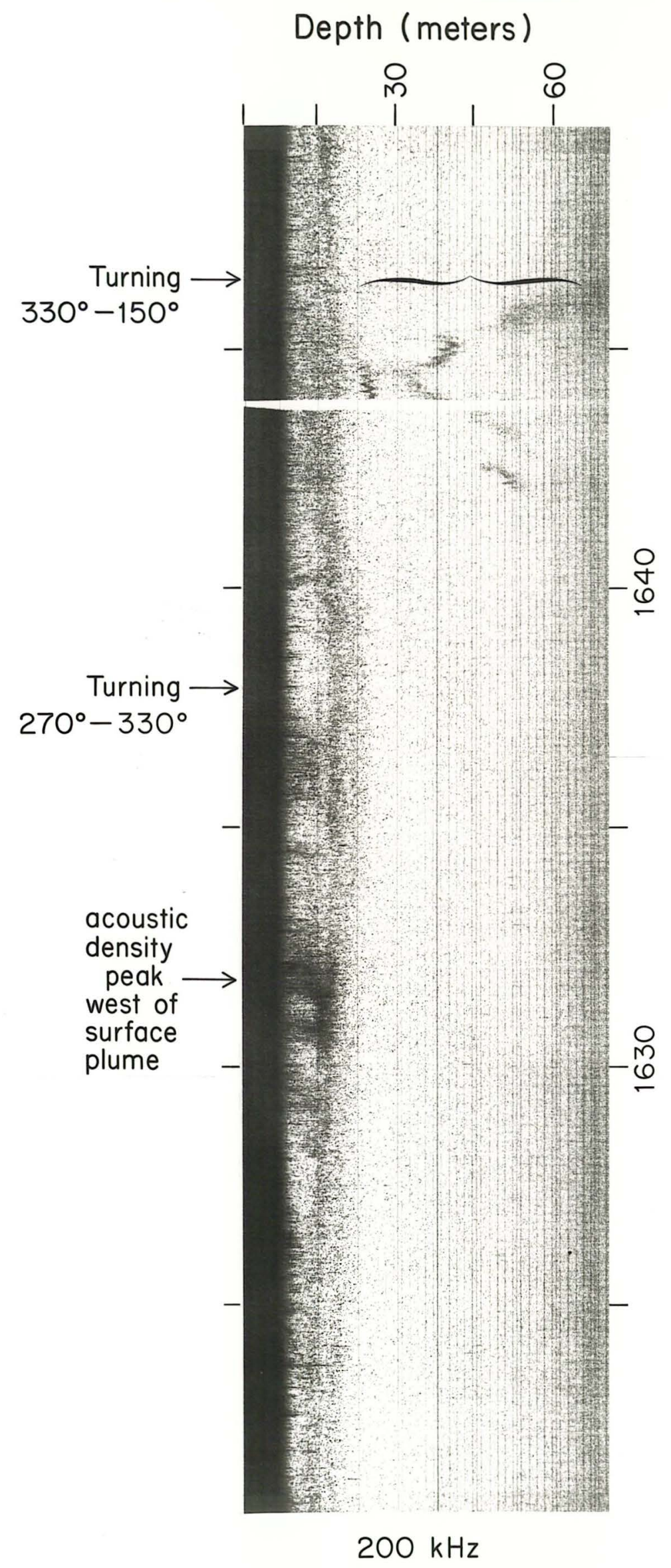




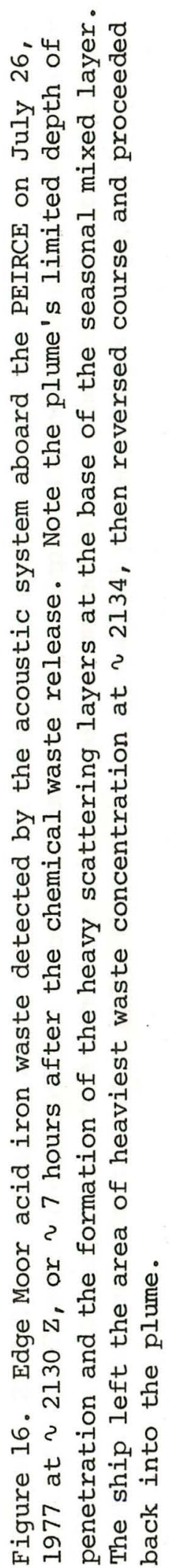



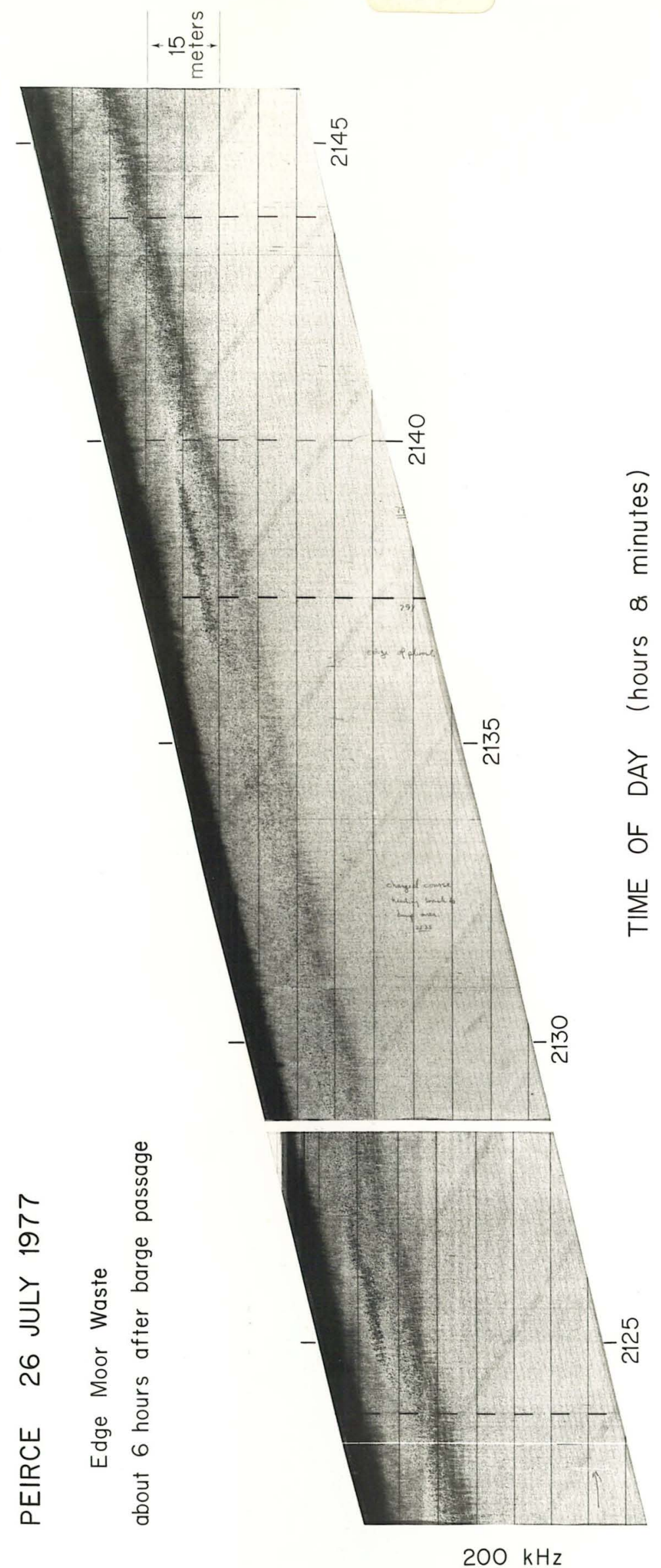


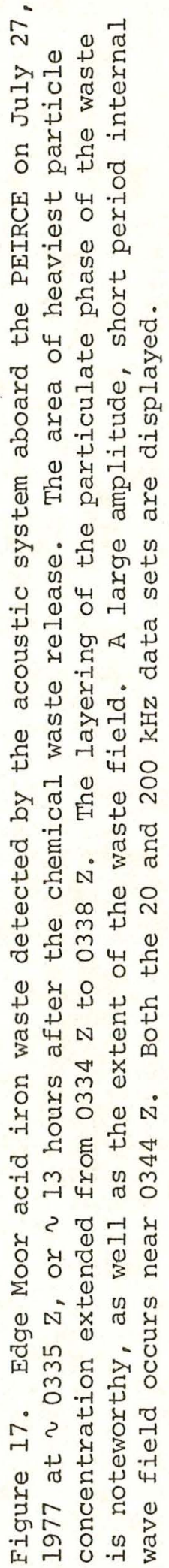




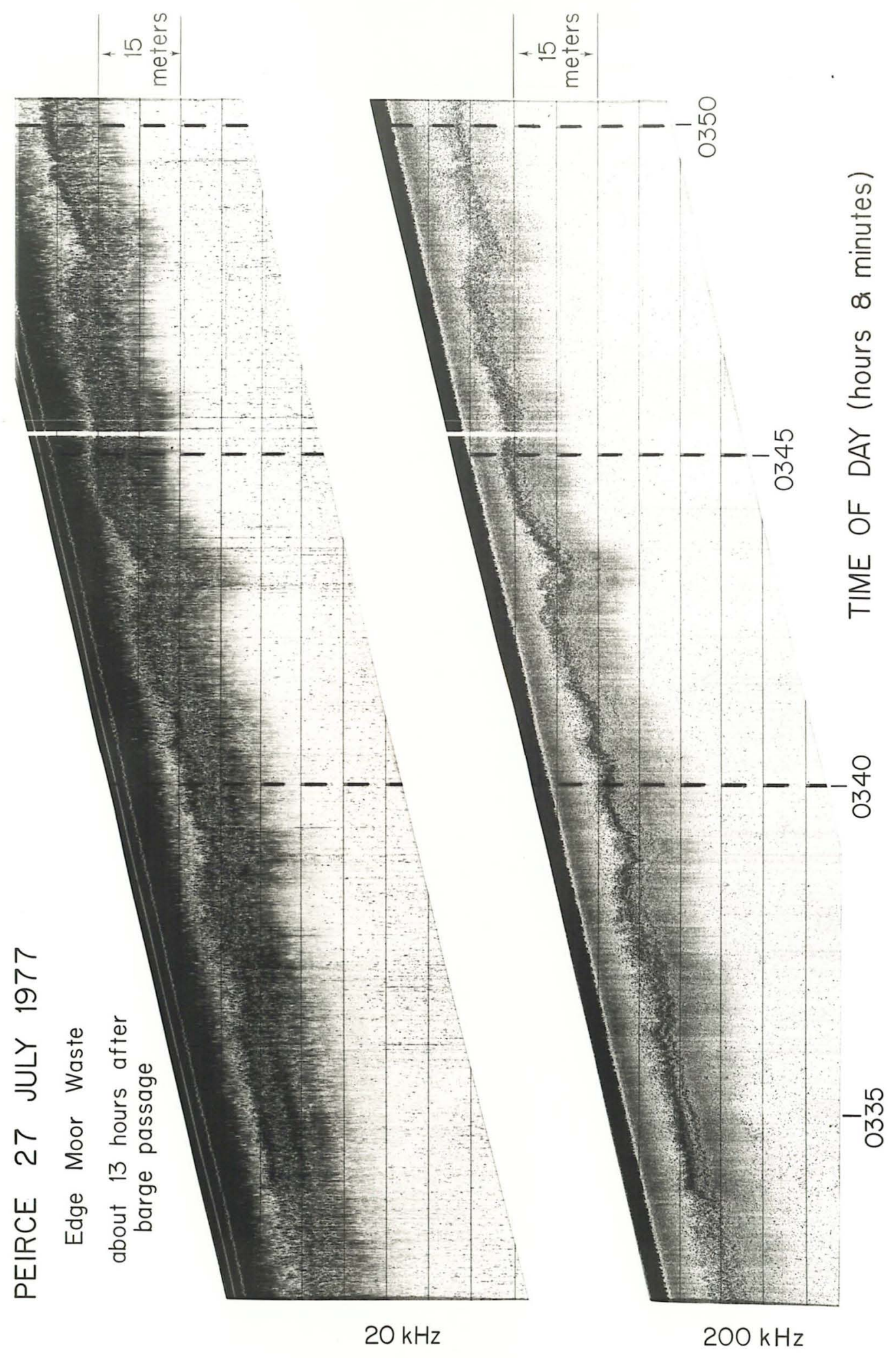




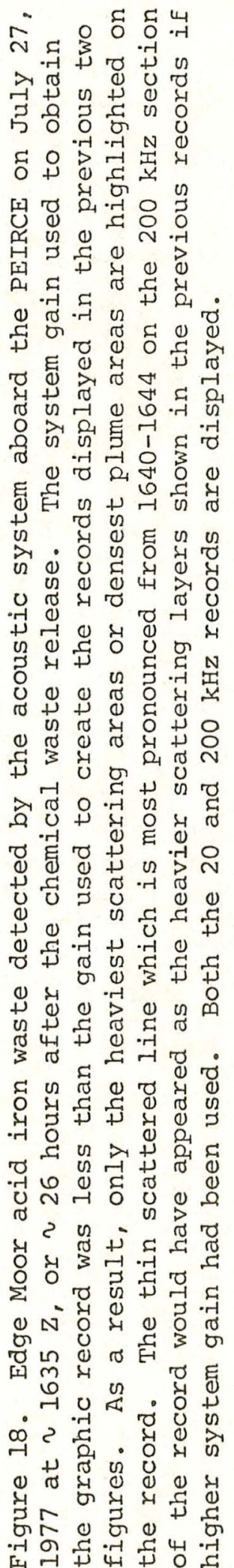



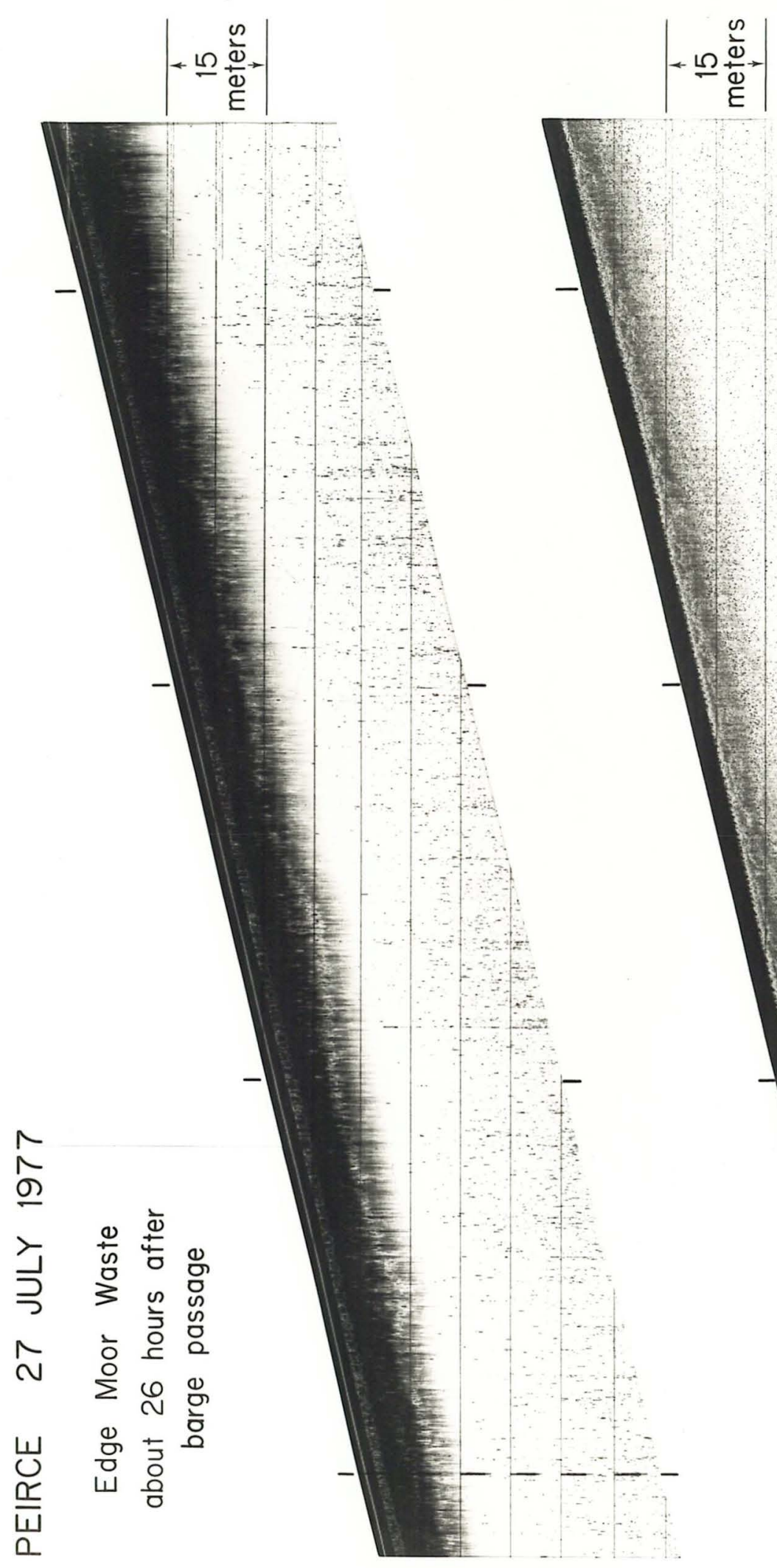


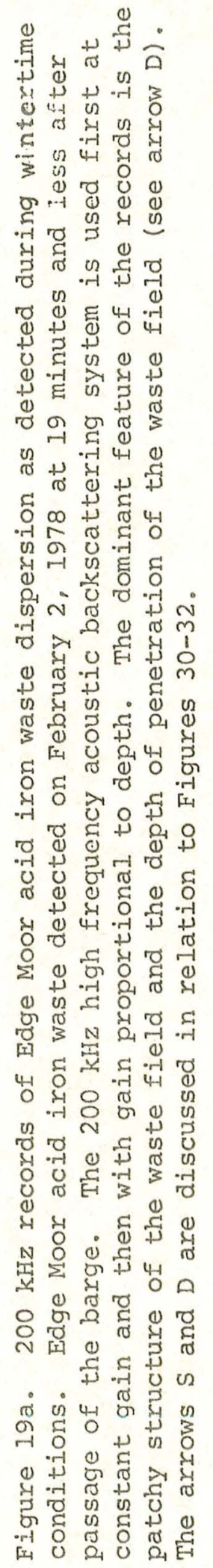




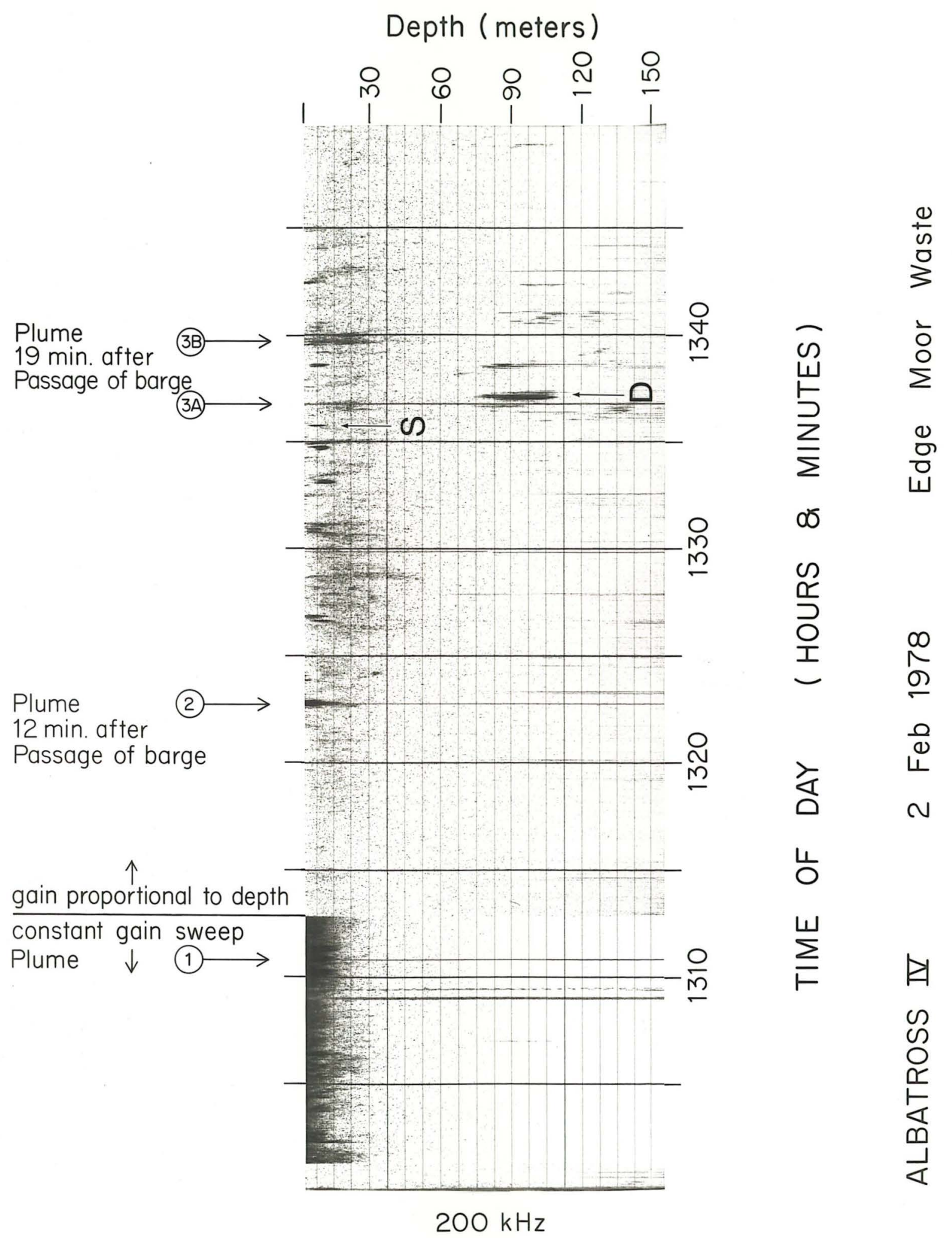




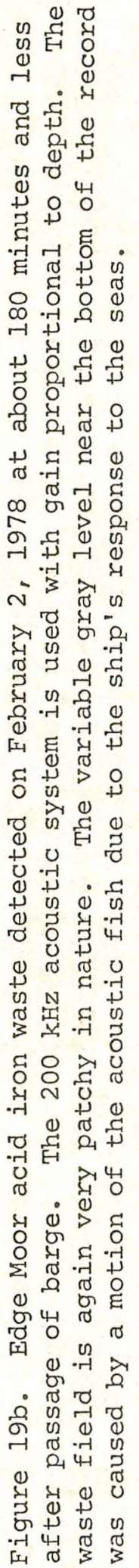




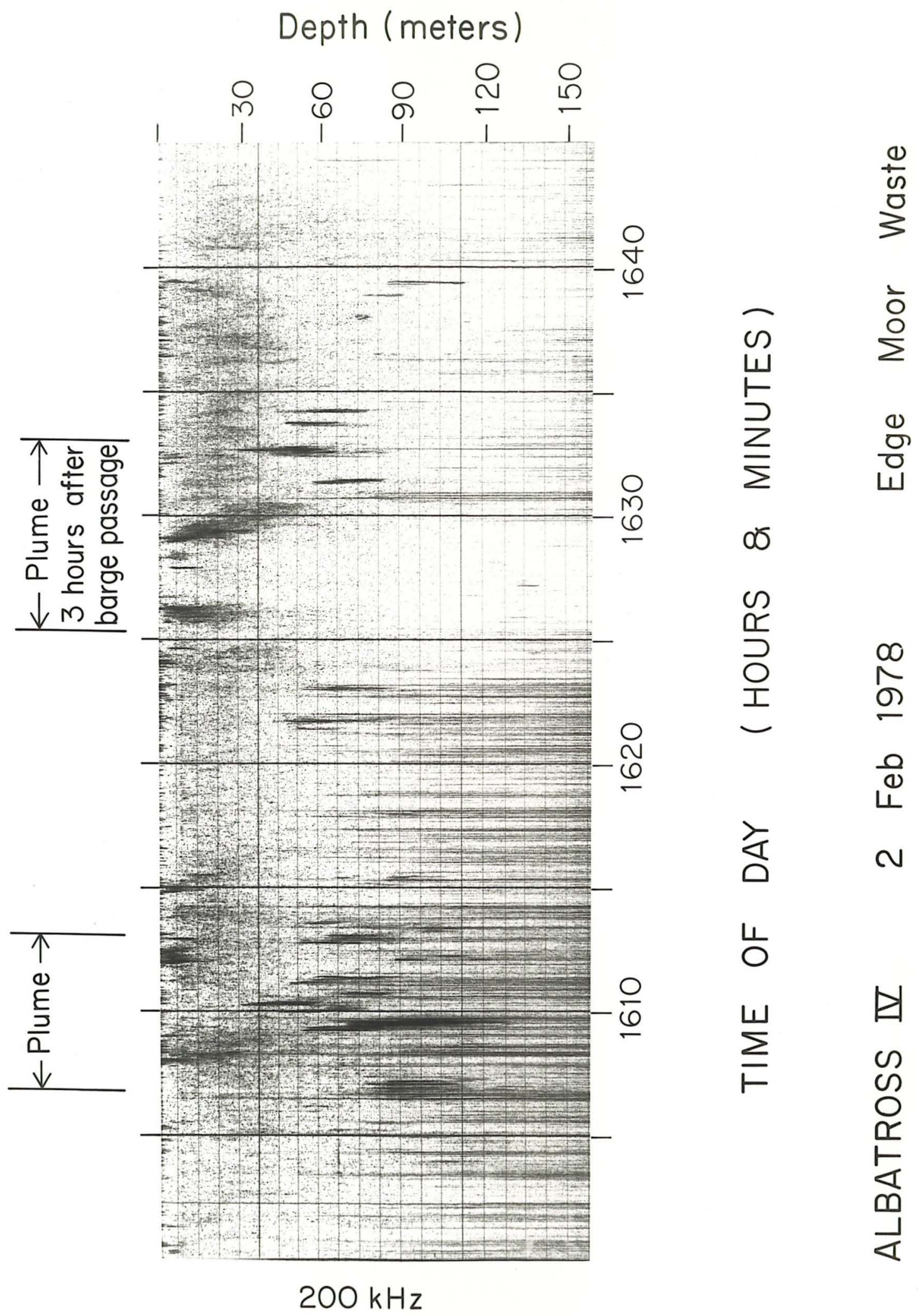




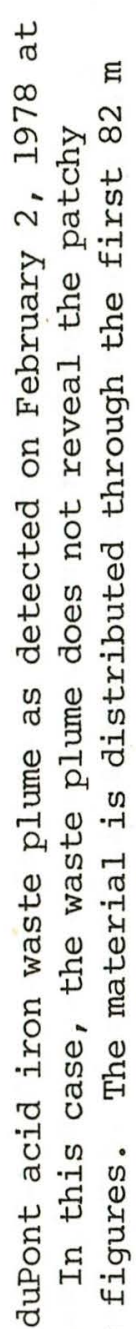

(1)

की

出

प्र

O

D东出

资

空 0 .

일

$\varangle 000$

ن 0 \%

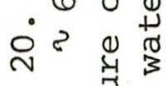

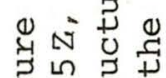

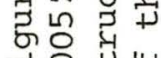

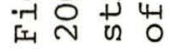




\section{DEPTH (meters)}

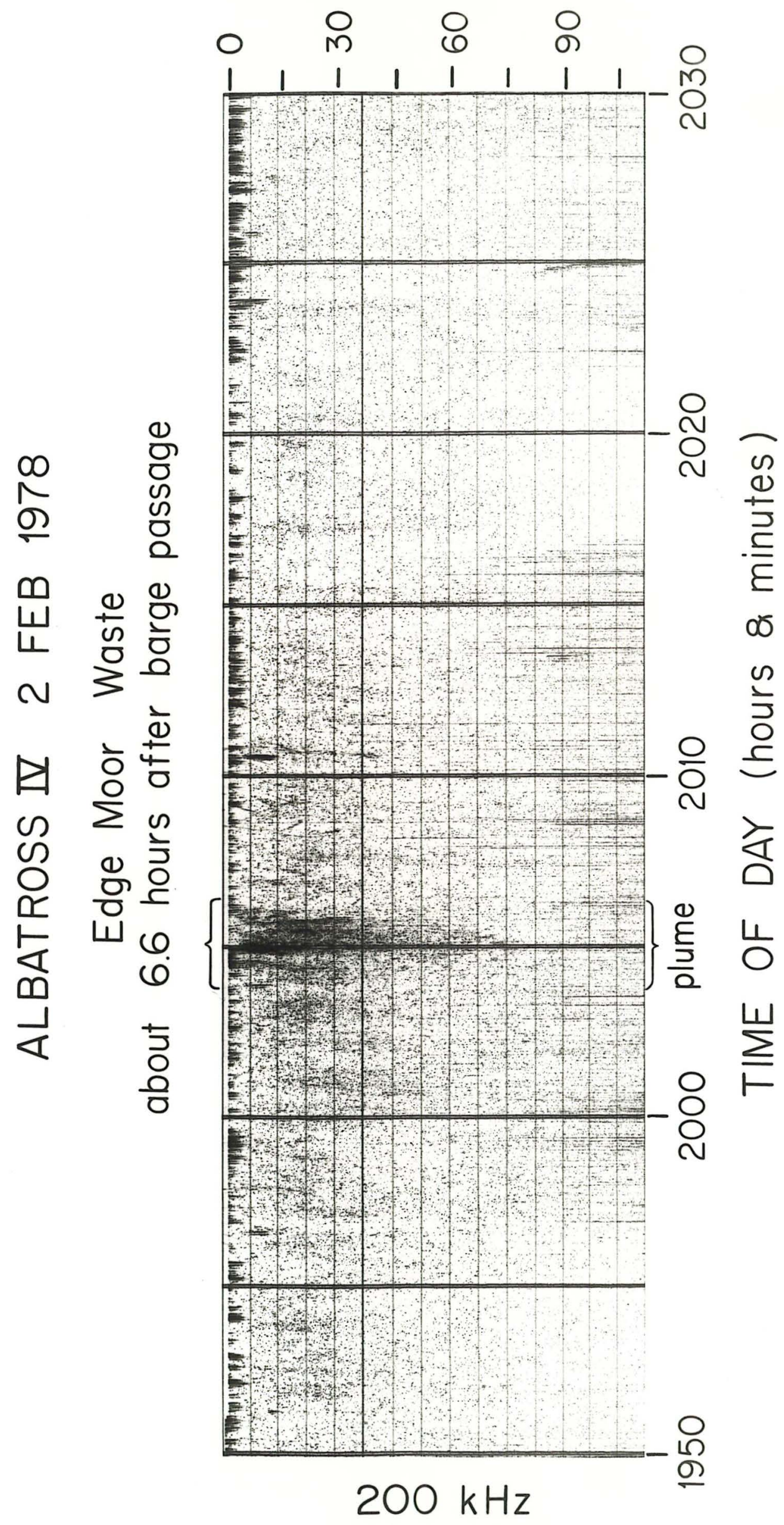




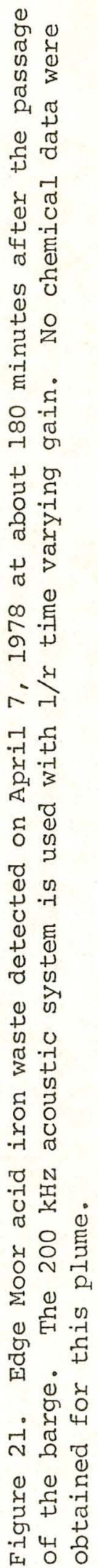




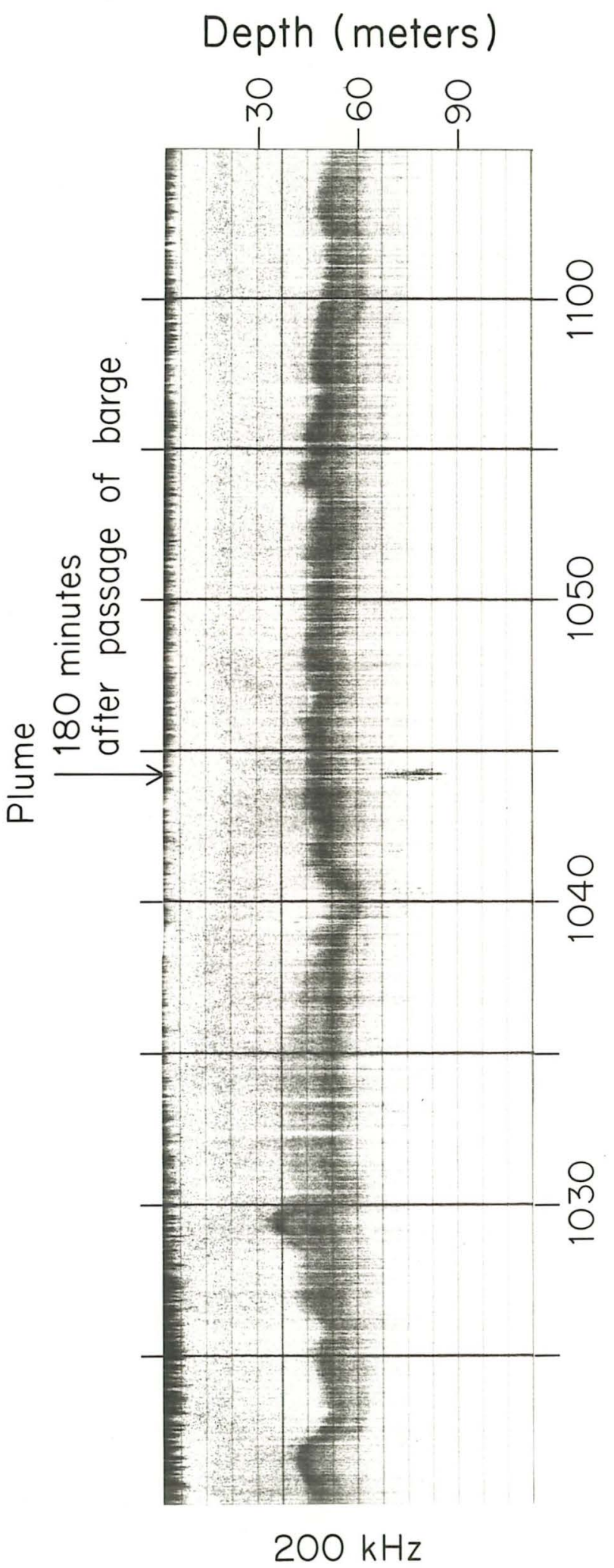

$\frac{\frac{1}{4}}{0}$

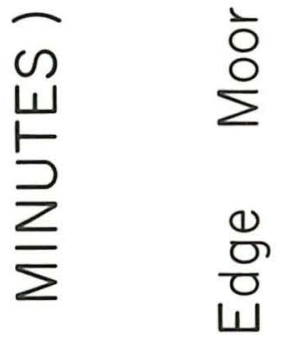

$\infty$

$\circlearrowleft$

당 I $\quad \infty$

-

훈

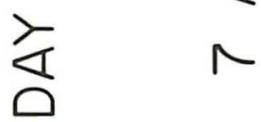

๒

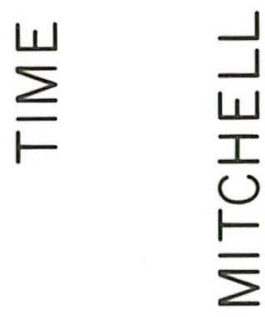

占 


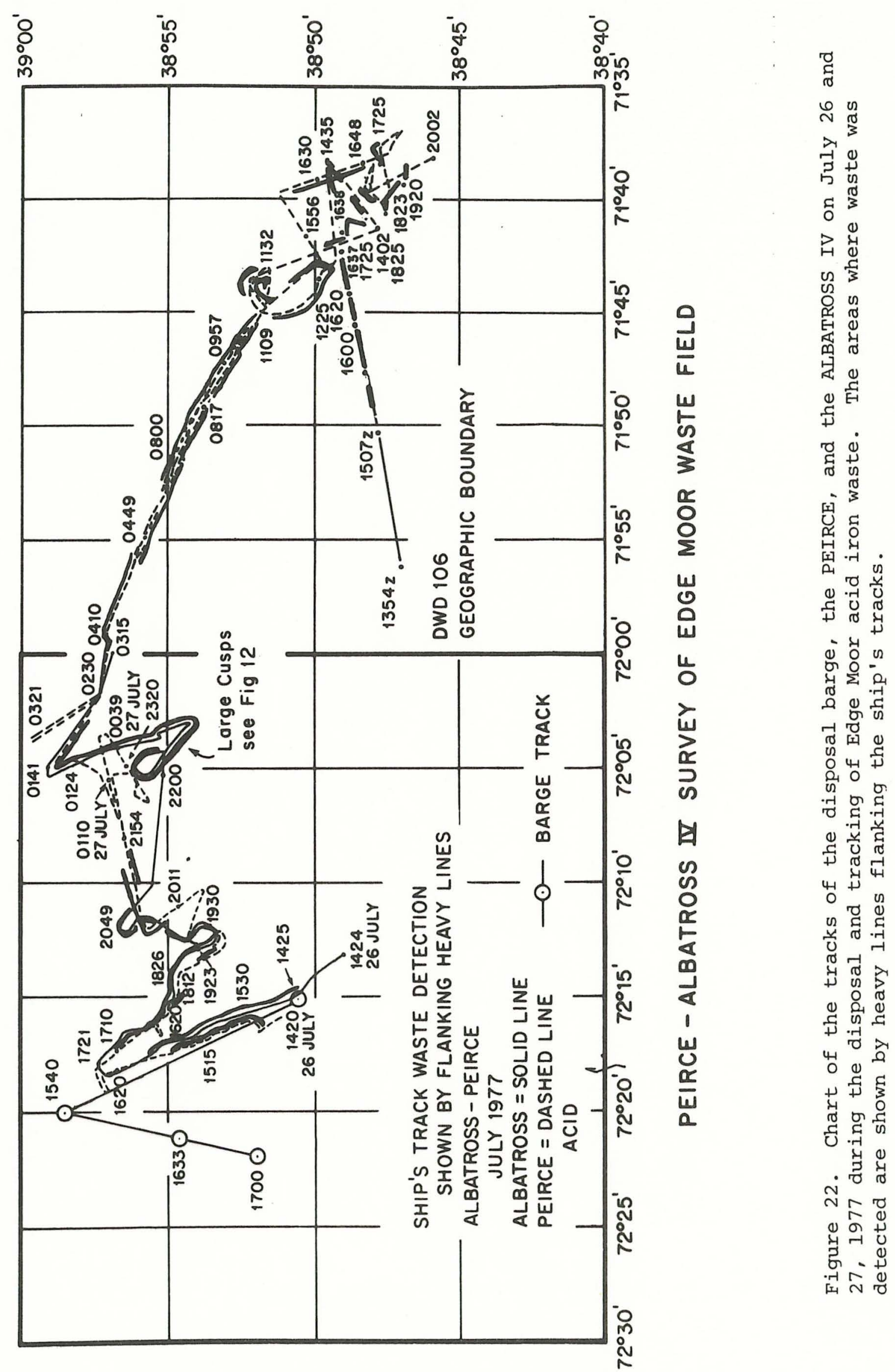




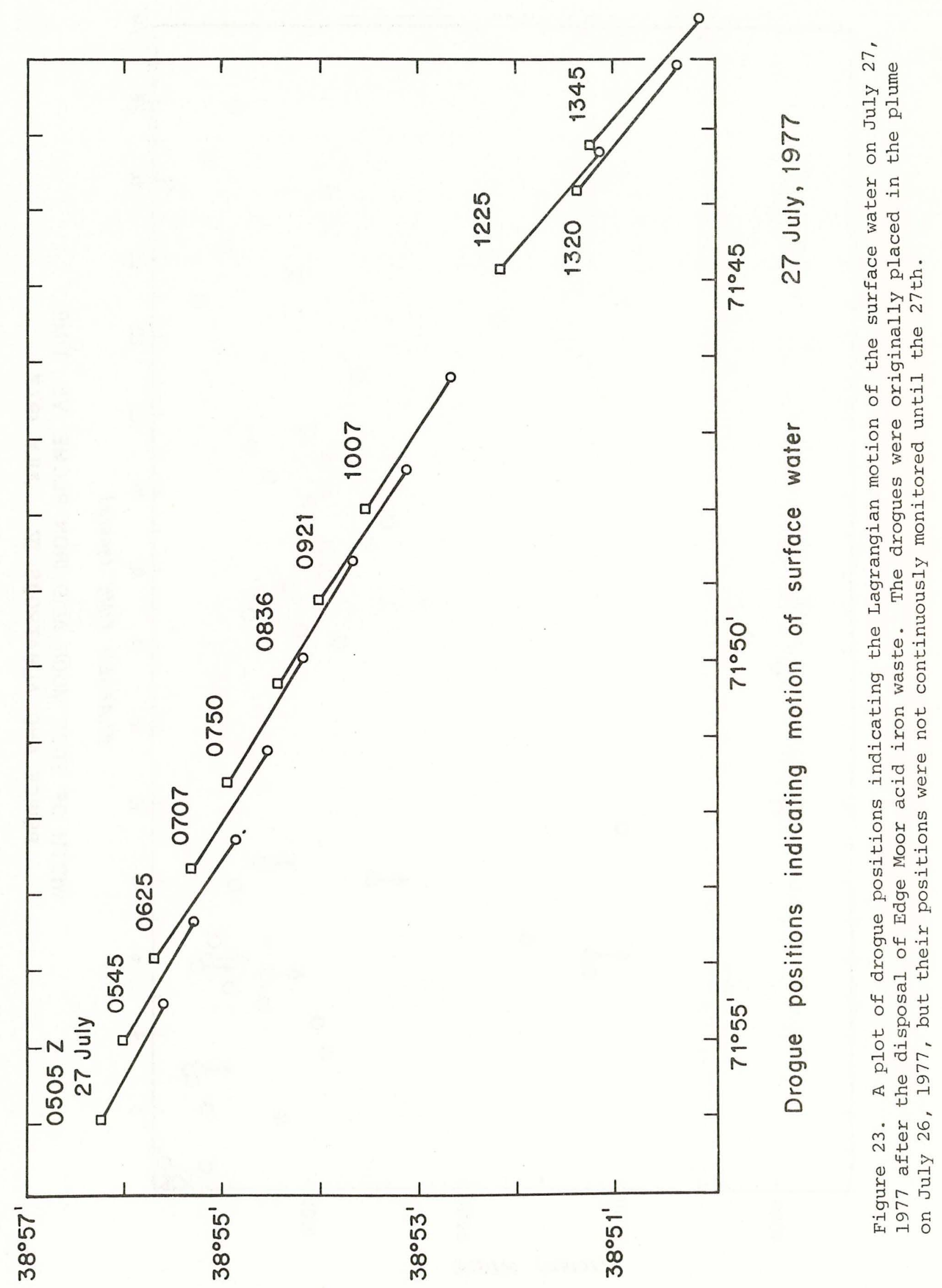




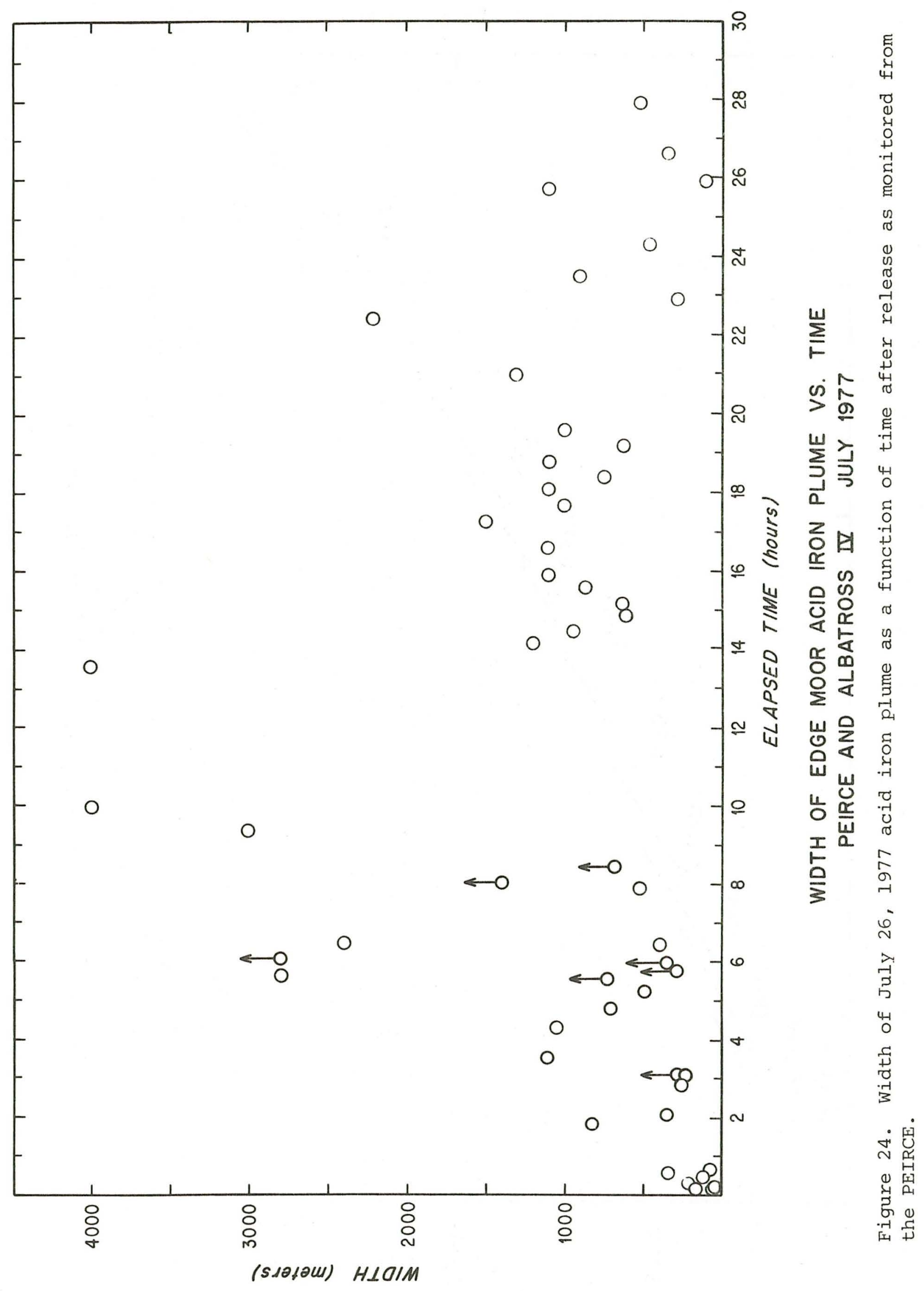



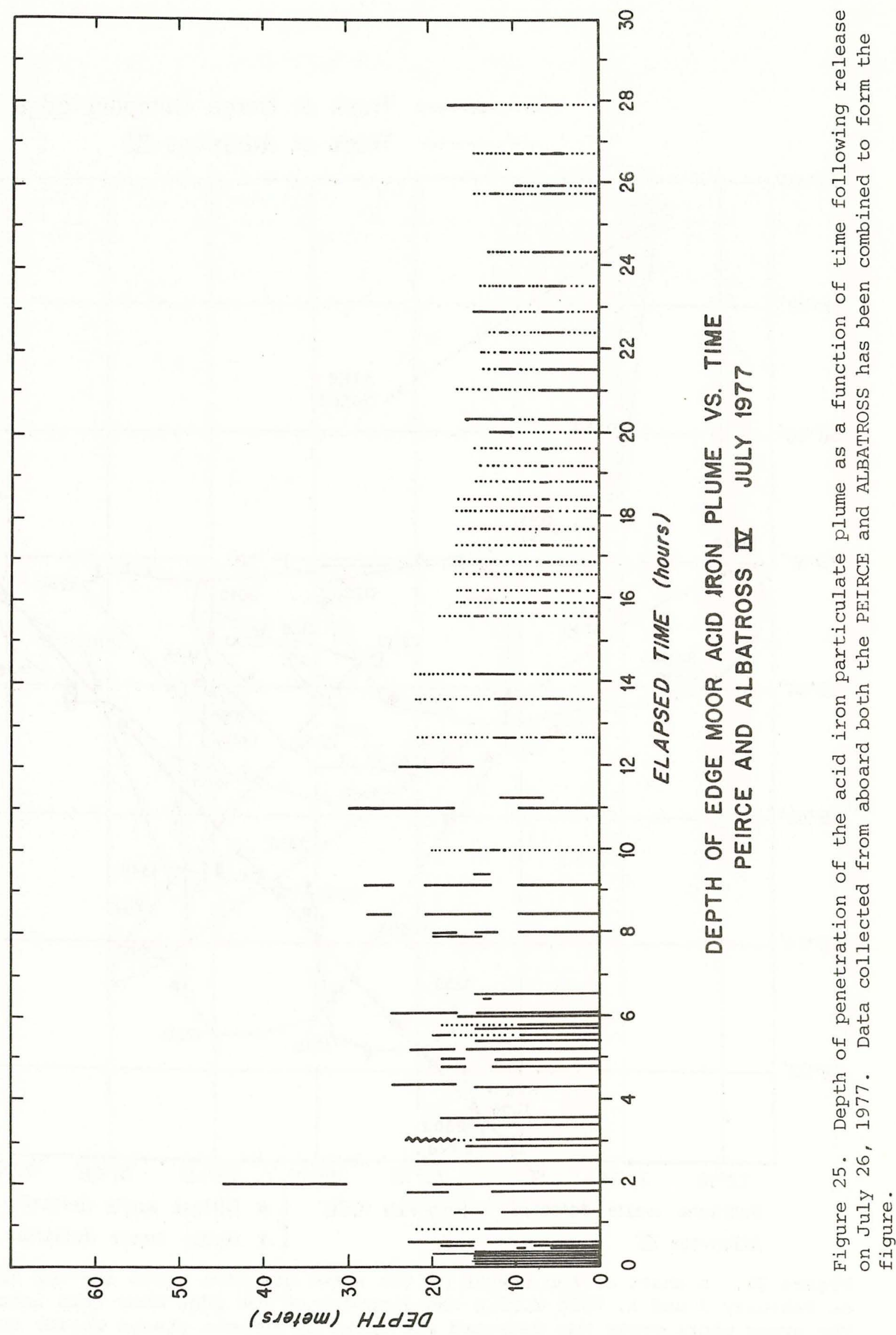
$\longrightarrow$ Track of Barge Dumping Edge Moor Track of Albaiross IV

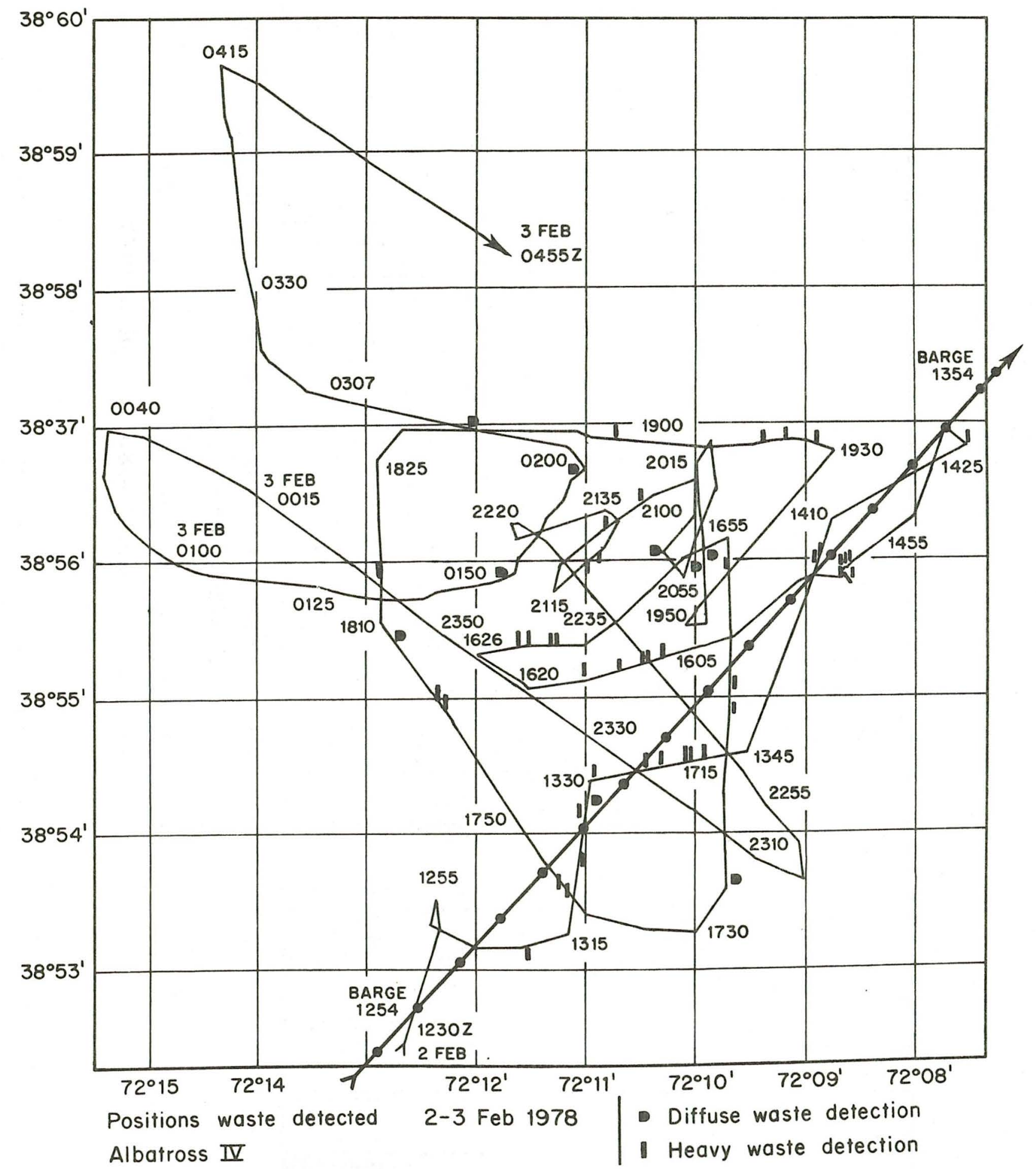

Figure 26. A chart of the tracks of the waste disposal barge and the ALBATROSS IV on February 2 and 3, 1978 during the disposal of the Edge Moor acid iron waste. The areas where waste was detected are shown by symbols placed beside the ALBATROSS IV tracks. 


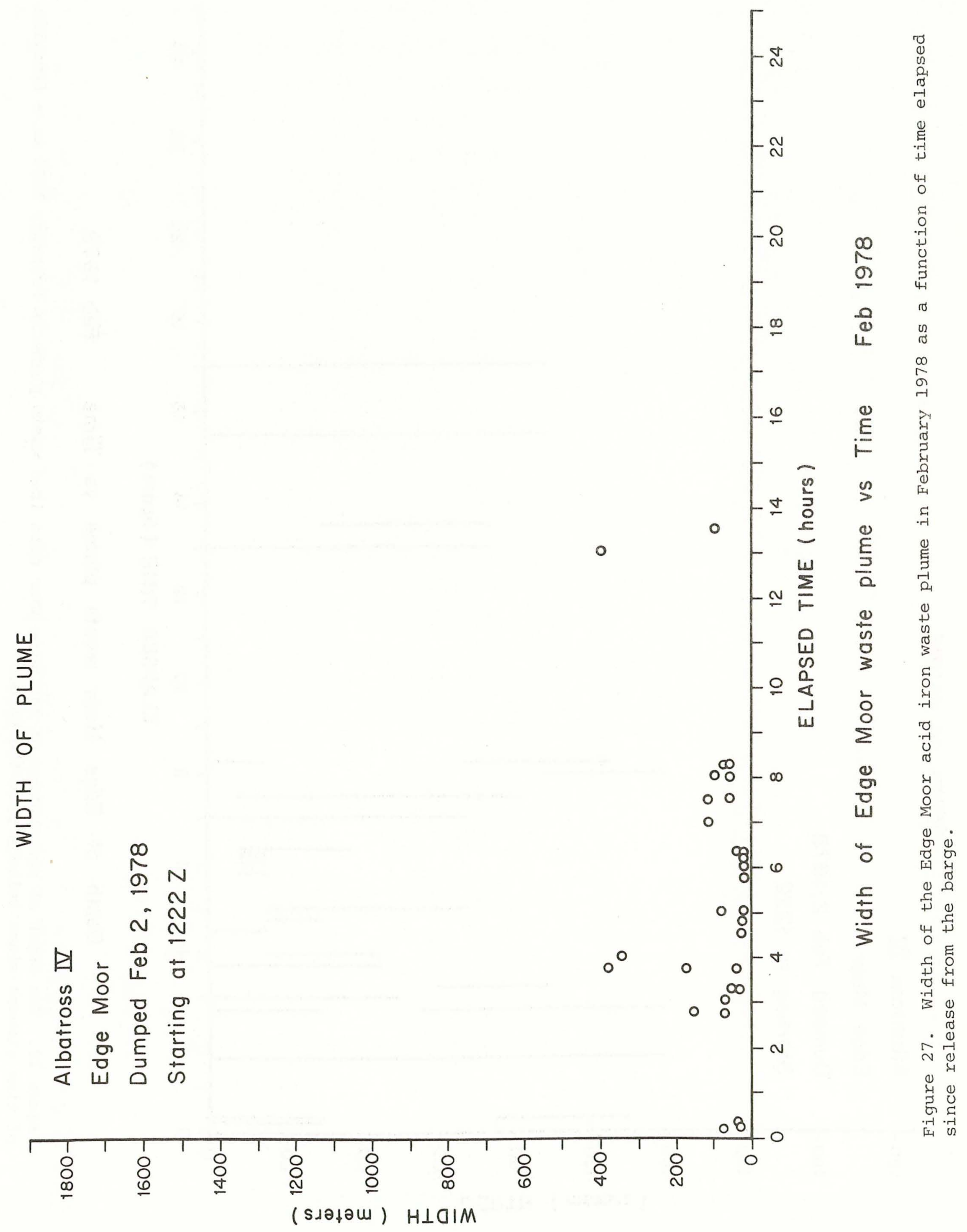




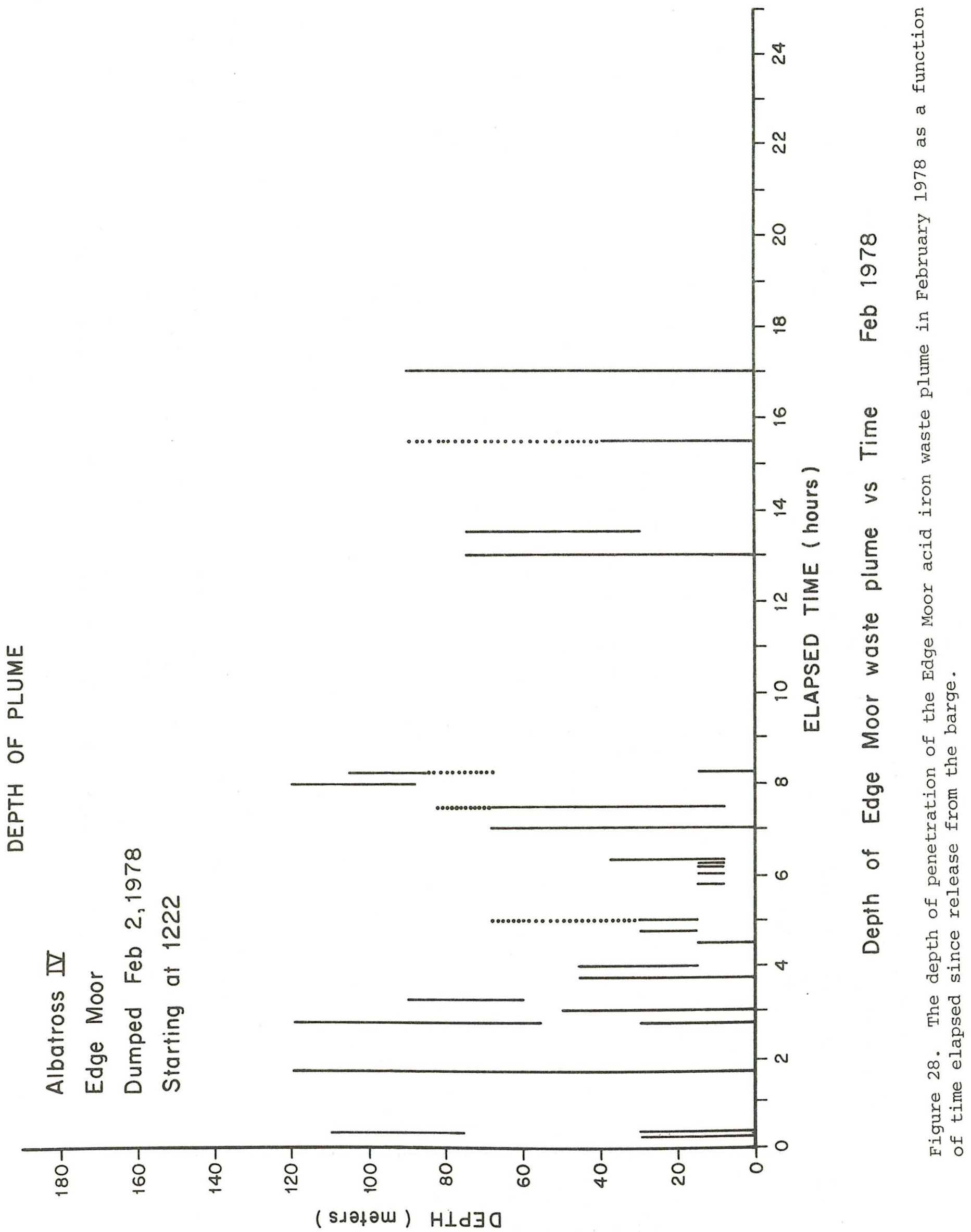




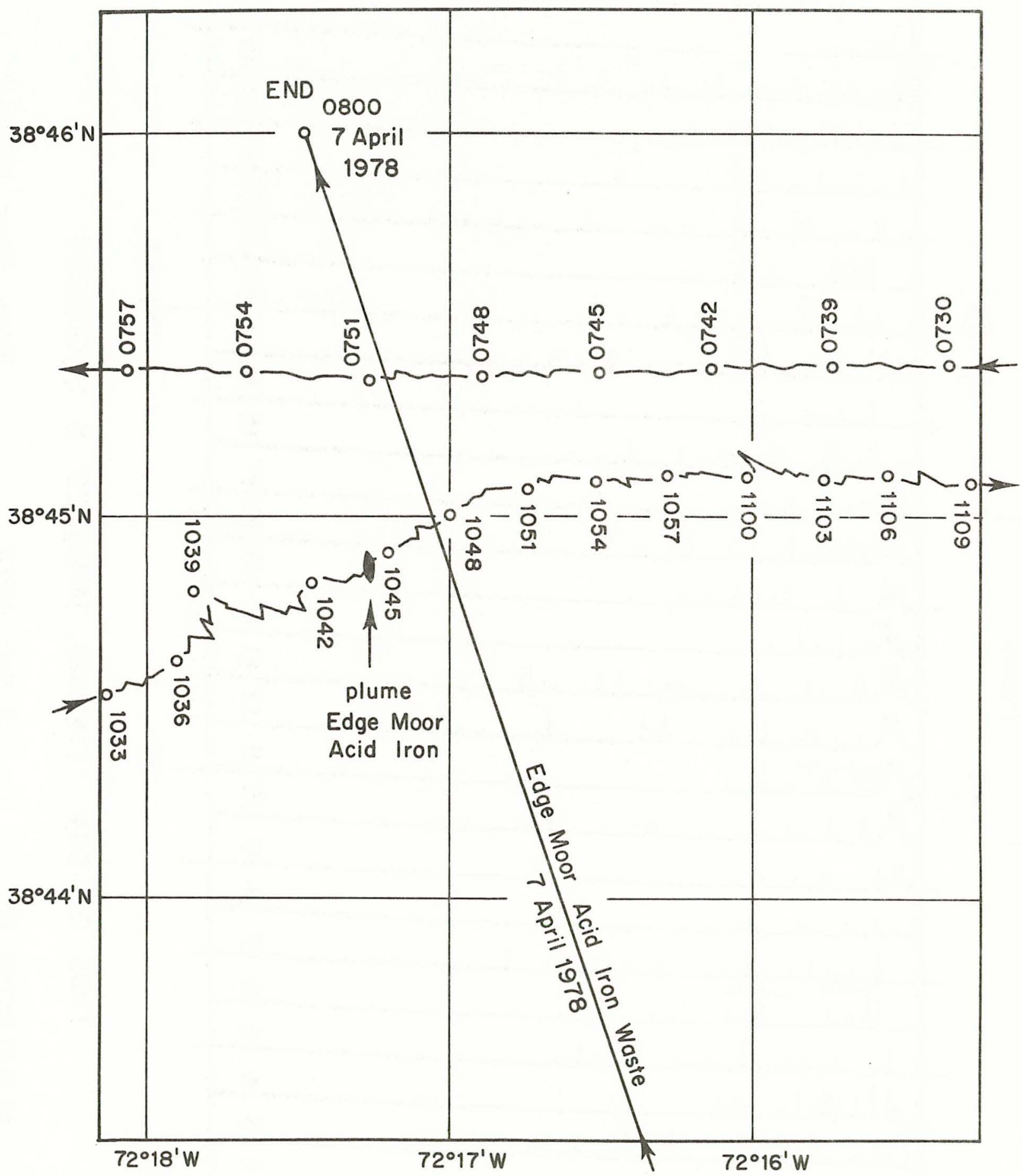

Figure 29. A chart of tracks of the barge and the MT. MITCHELL on April 7 , 1978 during disposal of Edge Moor acid iron waste. The position of the only acoustic backscattering event which was considered to be a plume is indicated. 
Depth (meters)

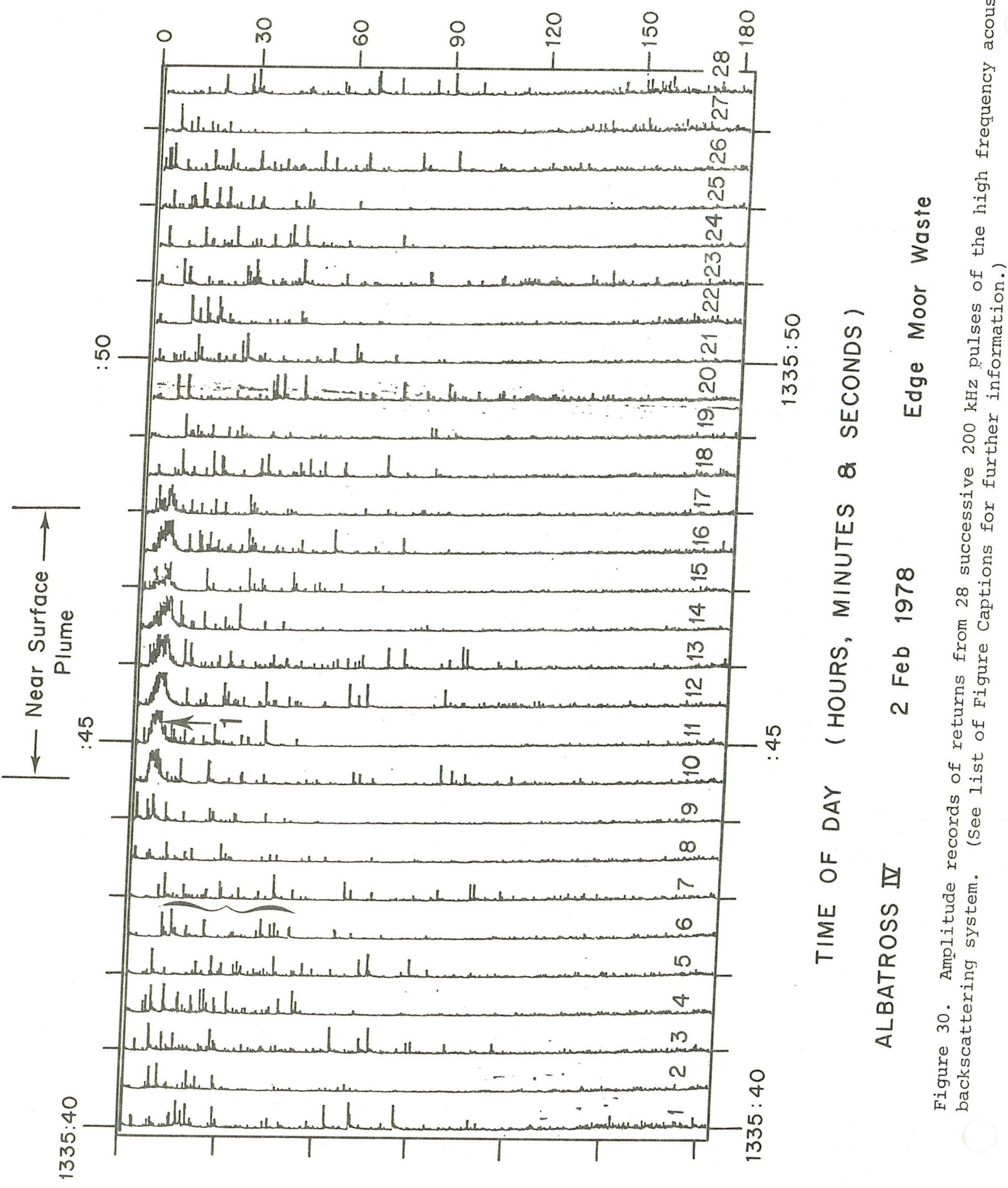




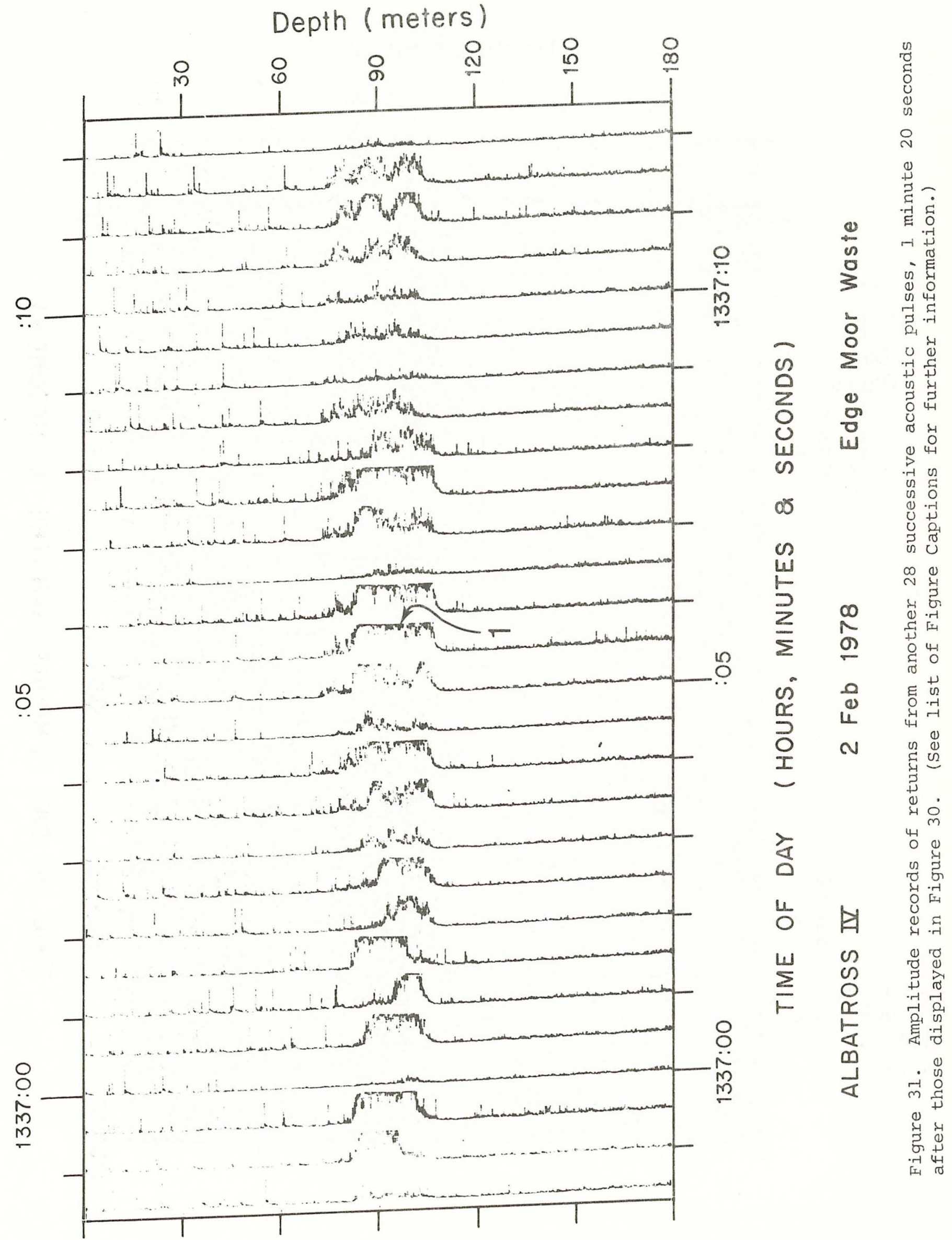




\section{Depth (meters)}

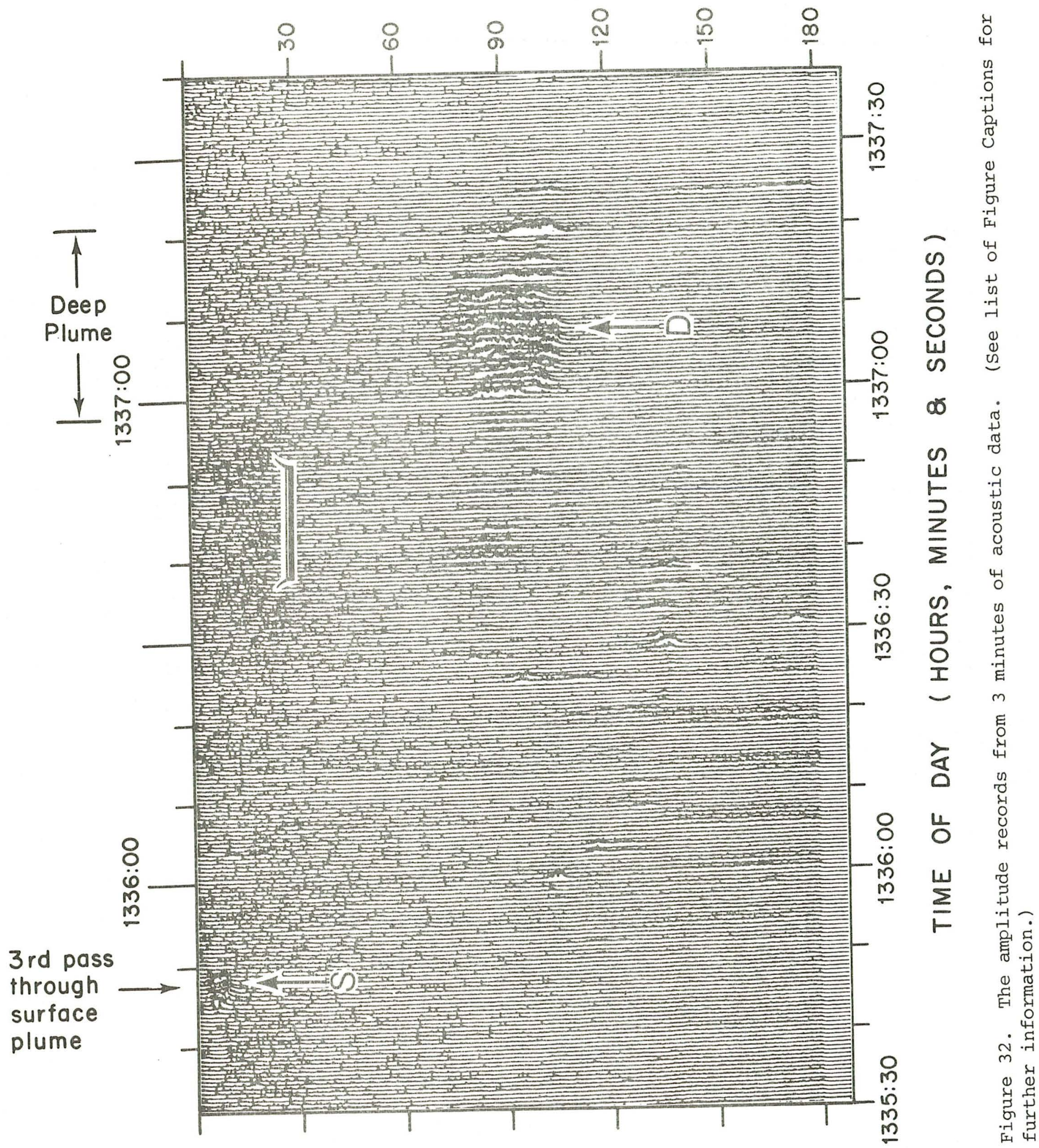


Blank 


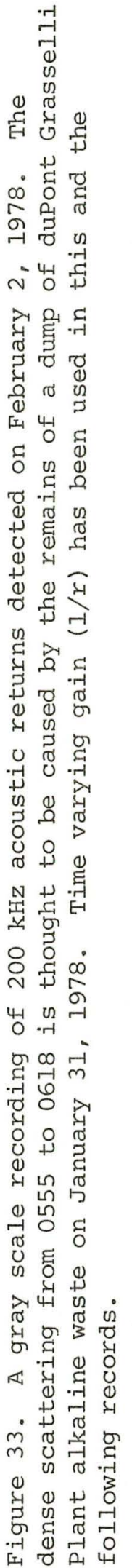


Depth (meters)

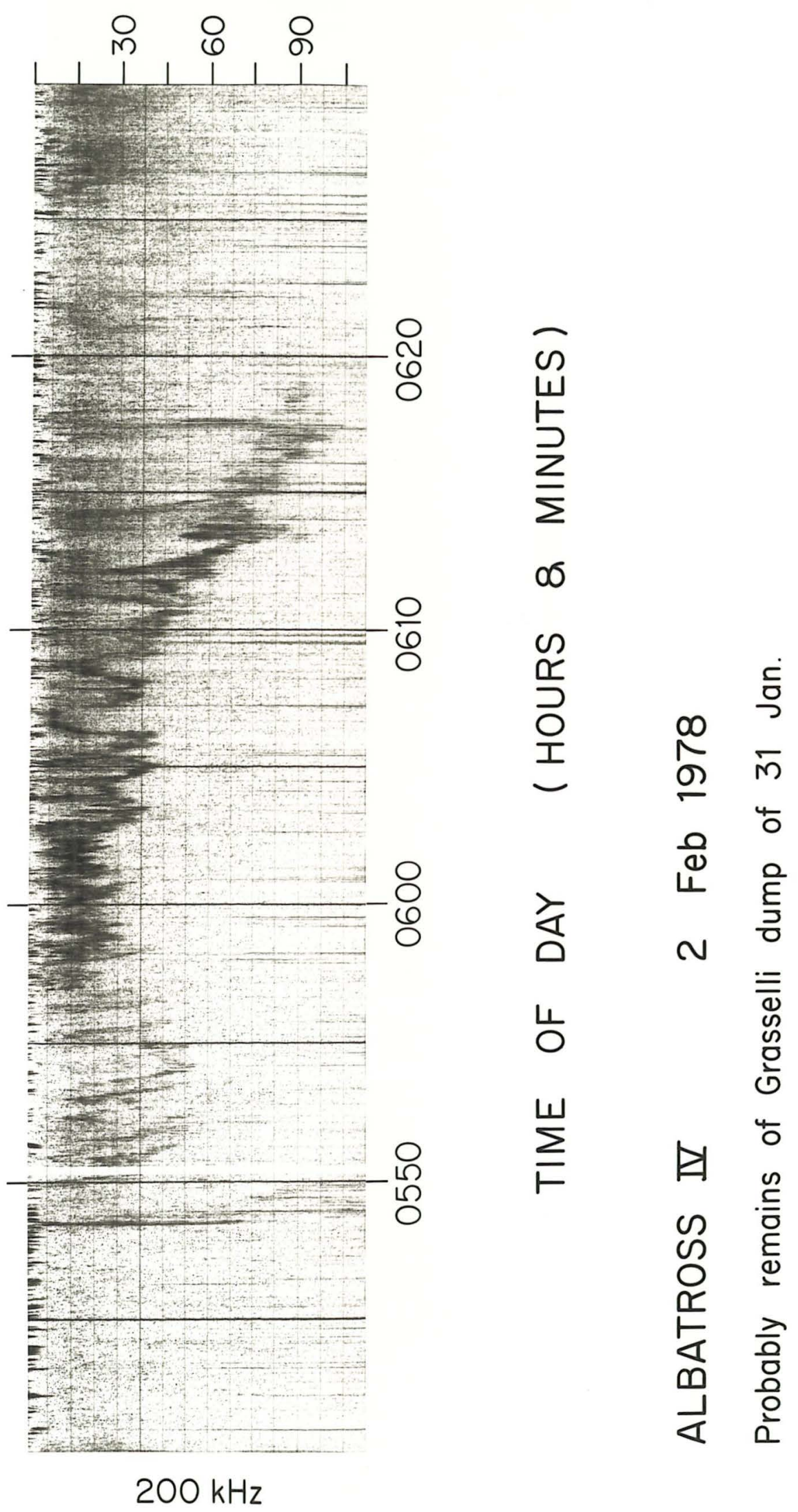




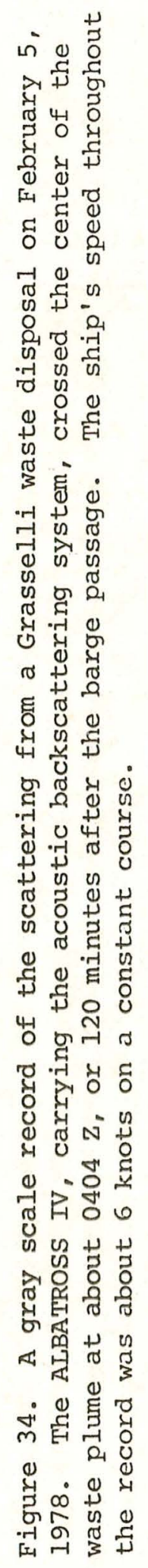




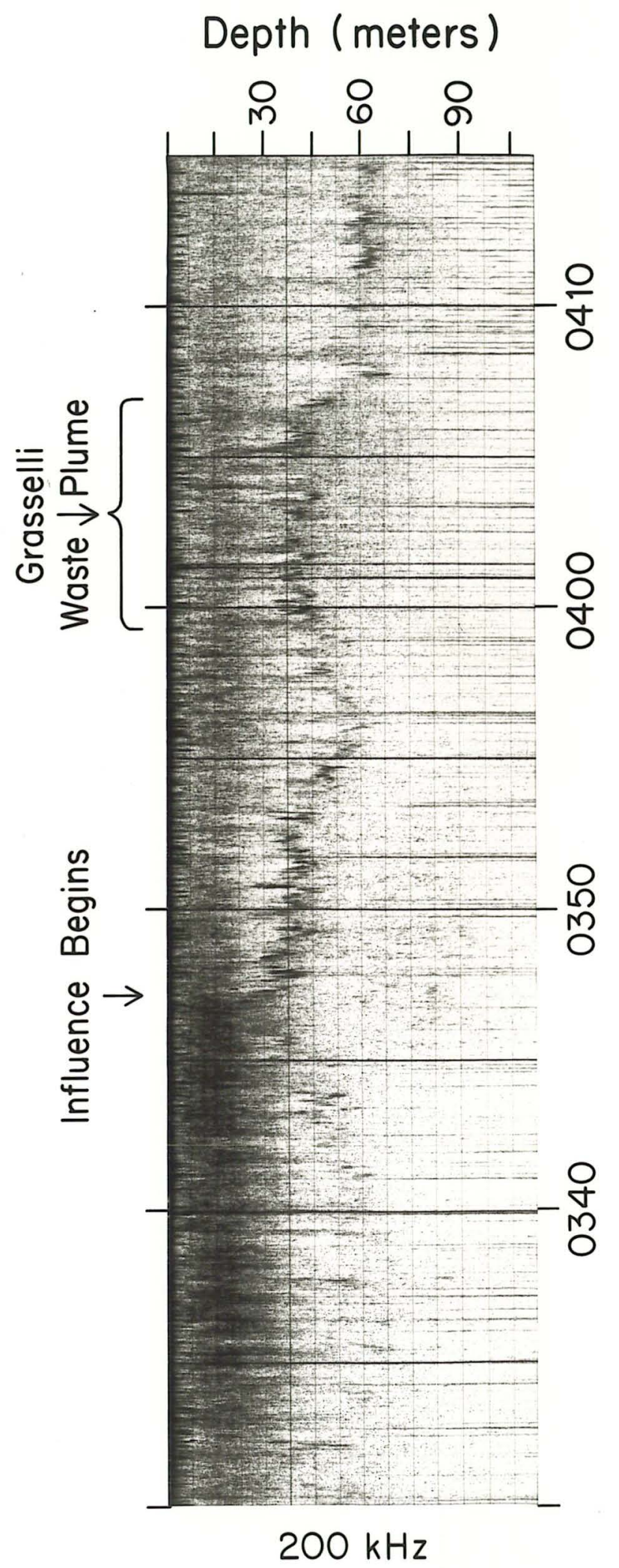

$\tilde{E}$
$\dot{E}$
$\bar{z}$
$\bar{\Sigma}$

$\infty$
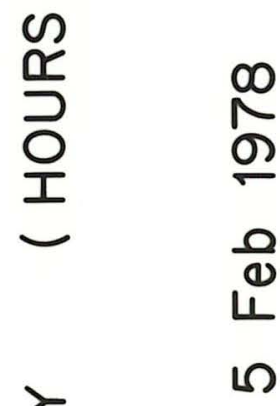

1)

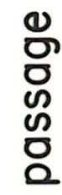

$\stackrel{ }{\circ}$

ฮ์

$\sum$

曰

$\theta$ 屯

0

ก

$\stackrel{\frac{1}{F}}{\frac{2}{\varepsilon}}$

$\frac{m}{\mathbb{1}} \stackrel{0}{\sim}$ 


$$
\begin{aligned}
& \begin{array}{l}
-1 \\
0 \\
0 \\
0 \\
0 \\
0 \\
01 \\
-1 \\
0 \\
-1 \\
0 \\
4 \\
4 \\
0
\end{array} \\
& \text { 崩 } \\
& \begin{array}{l}
0 \\
\infty \\
-1
\end{array}
\end{aligned}
$$$$
\text { U) }
$$$$
\text { E }
$$$$
\begin{aligned}
& 1 \\
& 5 \\
& 0 \\
& 0
\end{aligned}
$$$$
+
$$$$
\text { م }
$$$$
\text { 10 }
$$$$
\text { मे }
$$$$
\text { 苟 }
$$ 


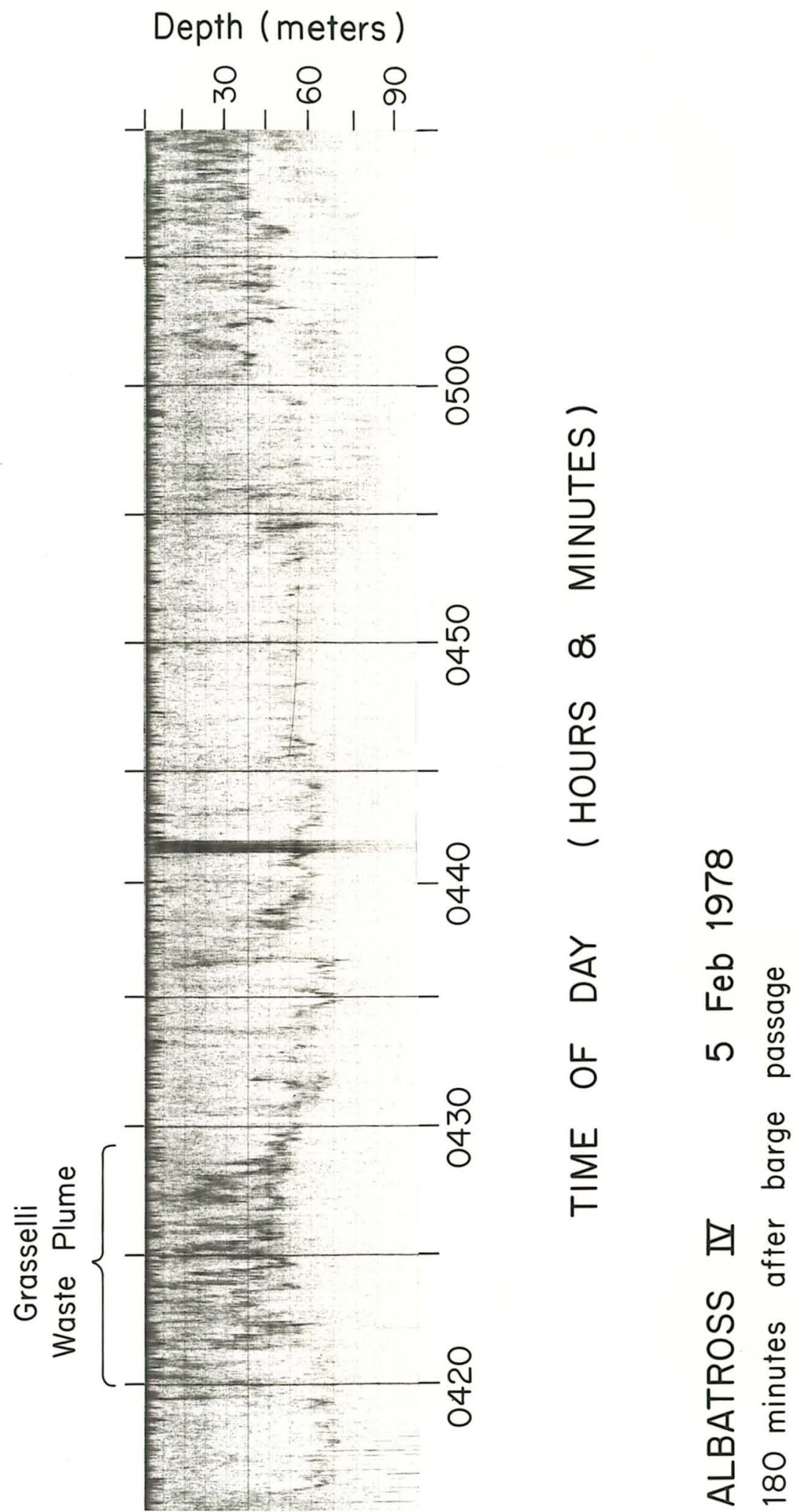

$200 \mathrm{kHz}$ 


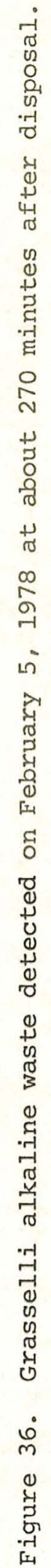




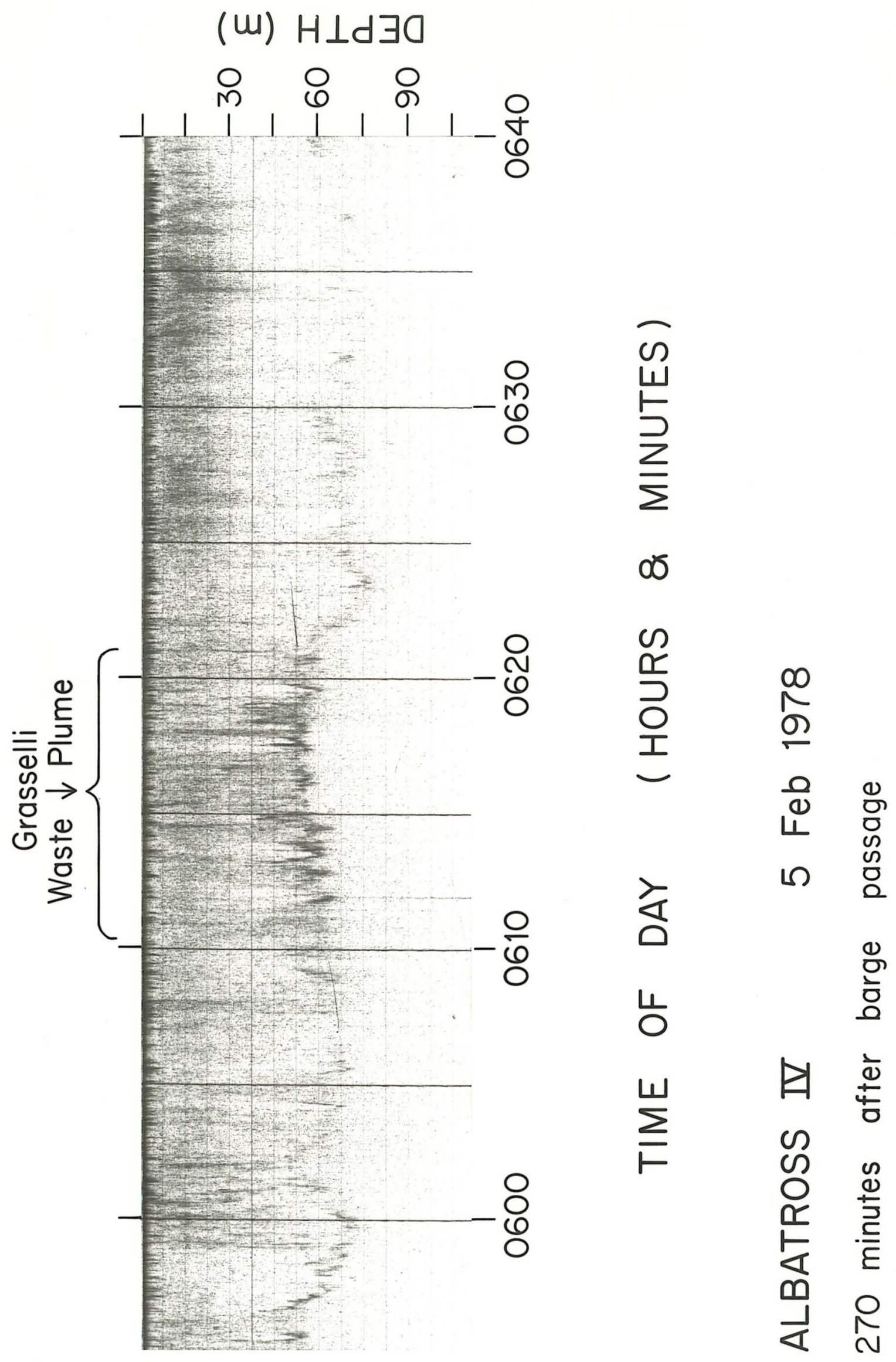


$\frac{1}{3}$
$\vdots$
0
0
0
$\frac{1}{5}$
$\frac{1}{3}$

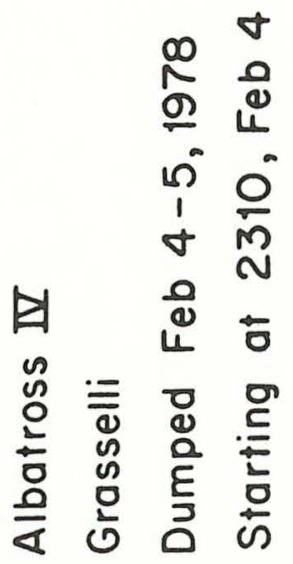

도

装

羟

उ्ञ

(1)

प)

$\stackrel{0}{0}$

क्ष

i

$\rightarrow 1$

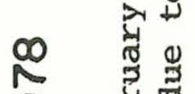

O

요 约

4.

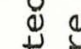

कृ

है

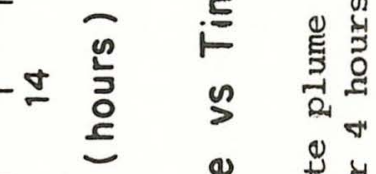

-

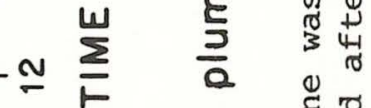

○ ब छ

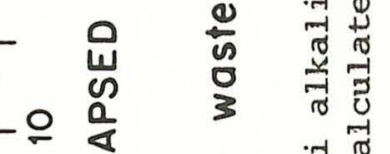

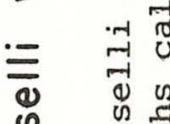

क क

인 过

๘

$\frac{5}{5}$
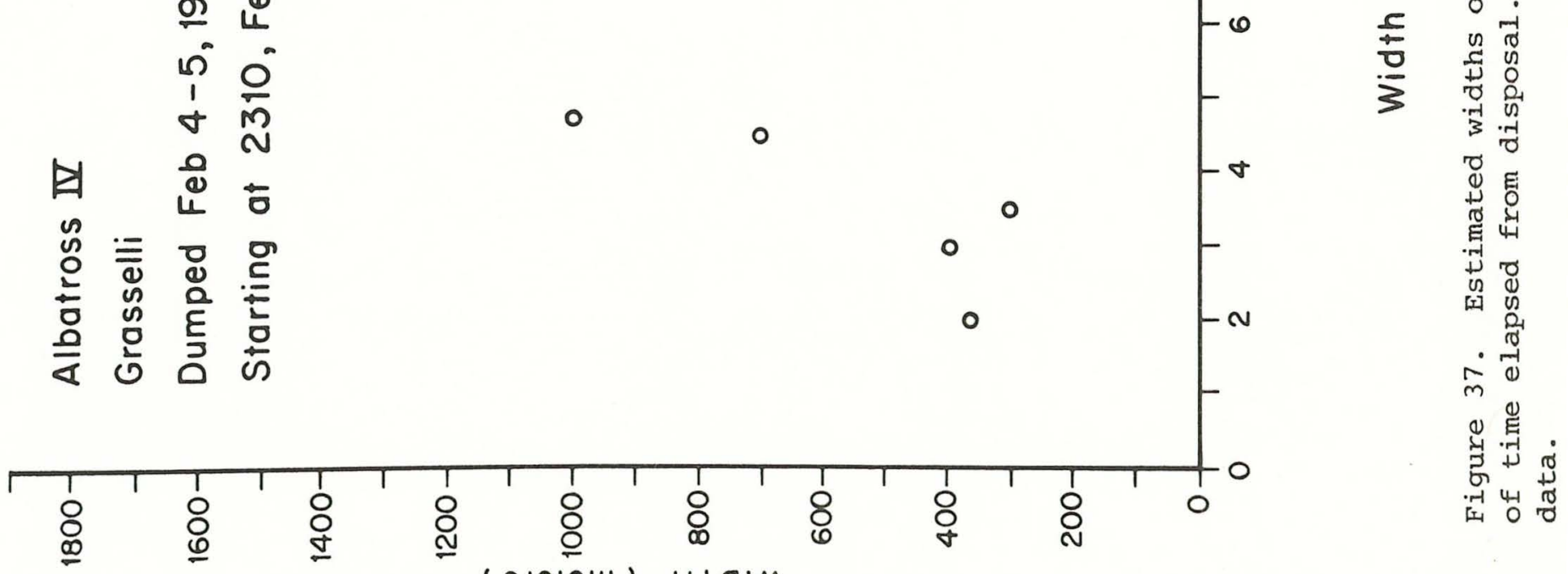


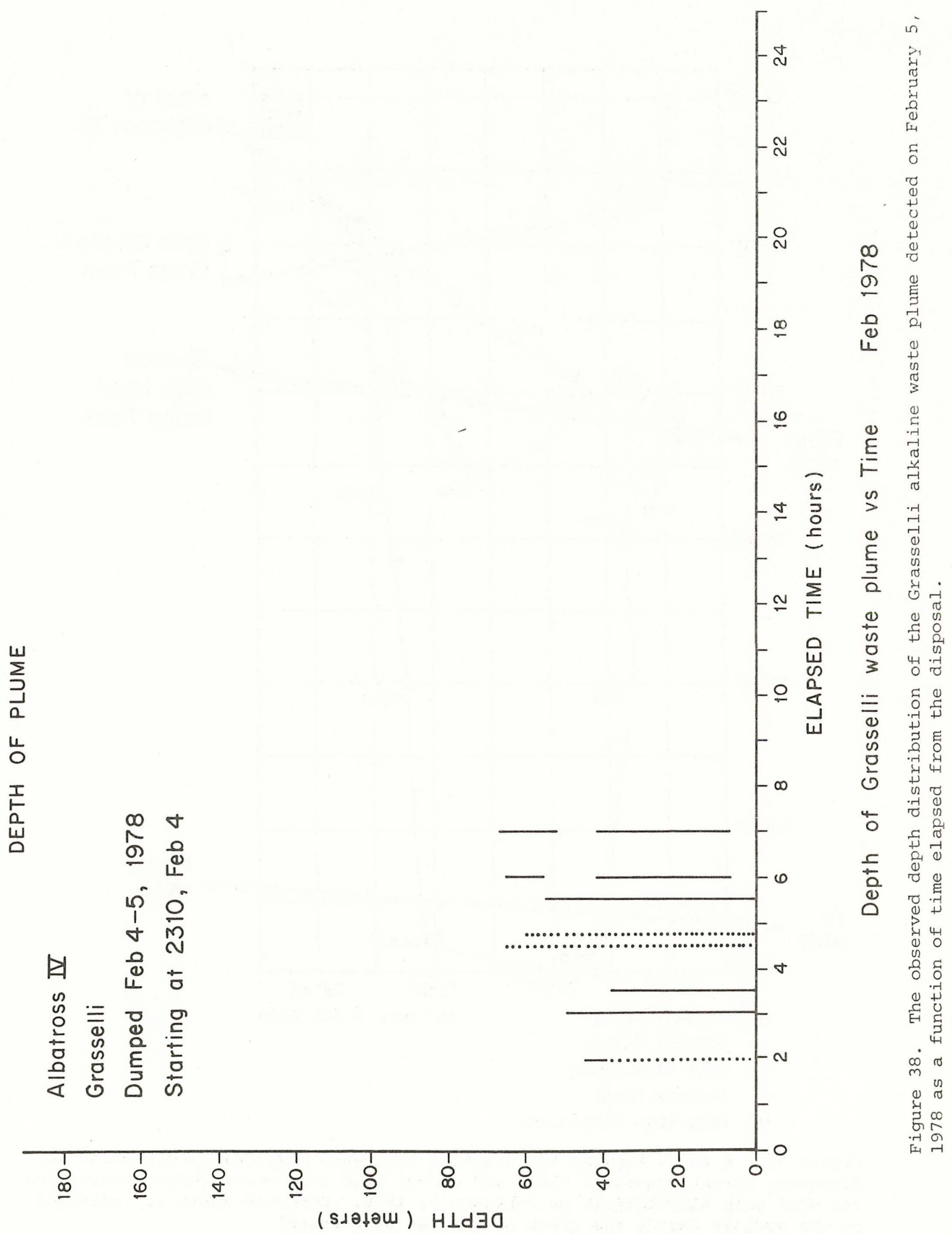




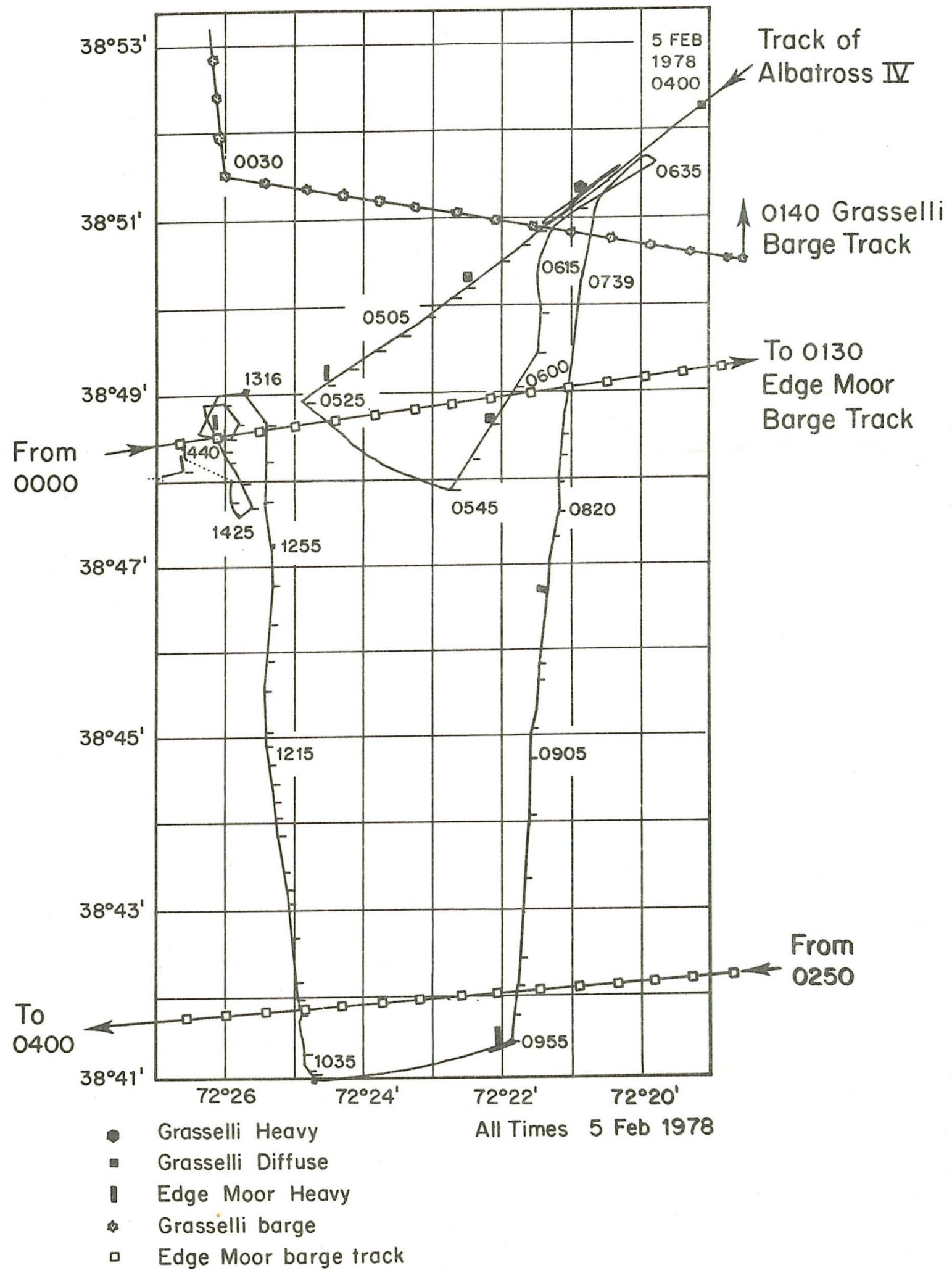

Figure 39. A chart showing the track of two waste disposal barges which were disposing duPont Grasselli Plant and duPont acid iron waste respectively, and the NOAA ship ALBATROSS IV on February 5, 1978. Detected waste is indicated by the symbols beside the track of the research vessel. 


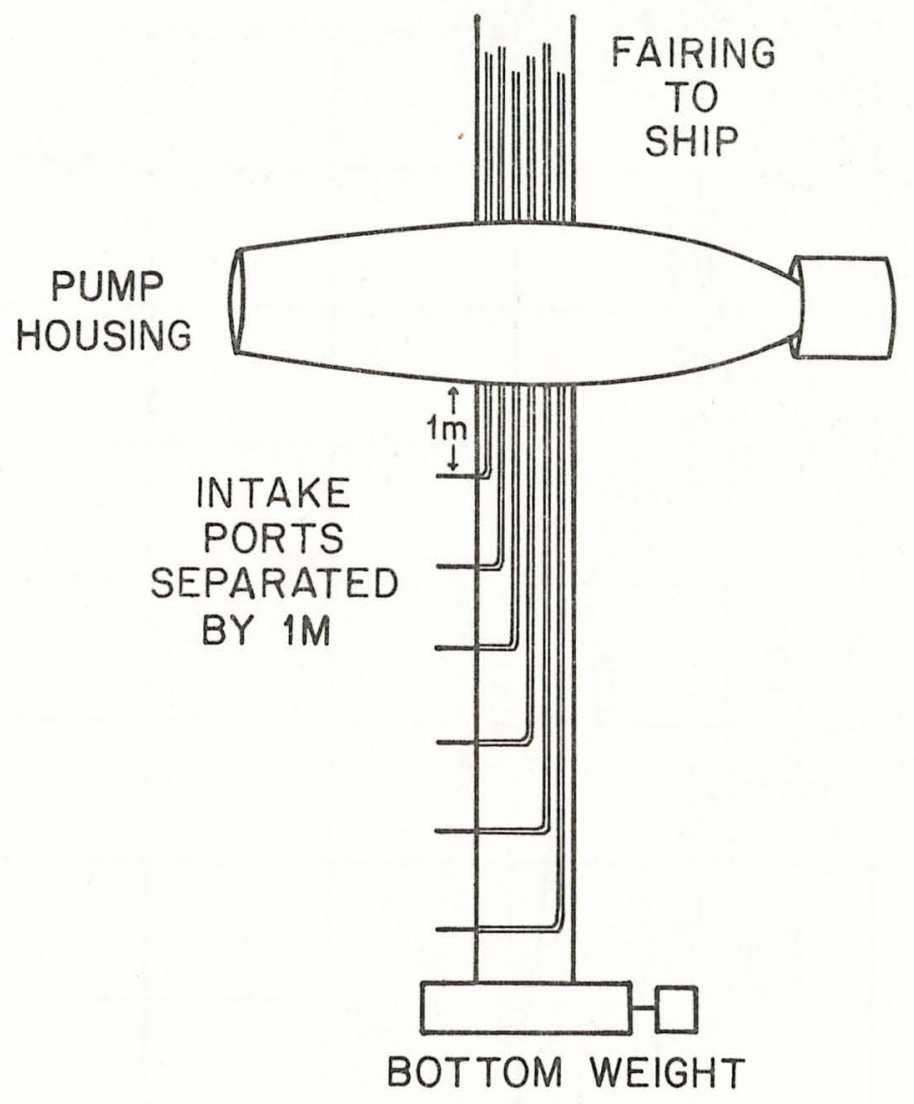

\section{CONFIGURATION OF THE MULTIPORT WATER SAMPLER}

Figure 40. A schematic of the configuration of the multiport water sampling system used during the April 1978 cruise to DWD 106. 
TRACK OF MT MITCHELL ON 10-11 APRIL 1978

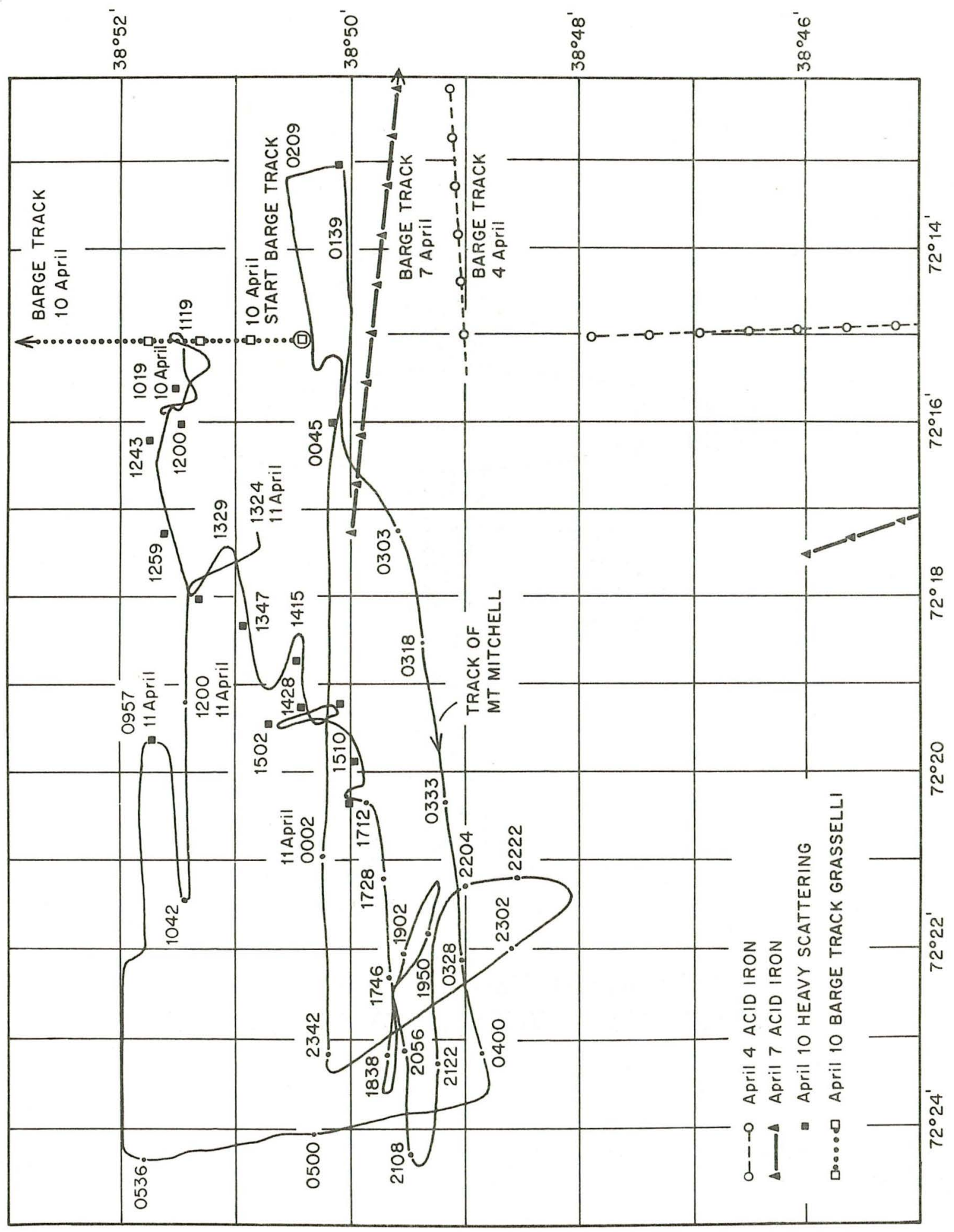

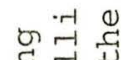

द -1

至 on

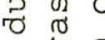

w 냉 द्व

䨔

U

3 号

त्

U $4-10$

है 0 .

(1) ज

0 .

न

-

+ O

गे है

兵岳

4

0 द 0

必㐘寻

些管

$>$ 告

๘

व

U

\%

1)

()

ज 람

(1) $4-1$

莒皆

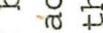

प्स प्र

U 11

瓷焉兘

每. 兵

(1)

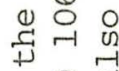

。菅

落 U

管

ข 10

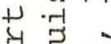

던 다음

0

《

की

-i -1 更

ه

(4) 品0

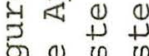




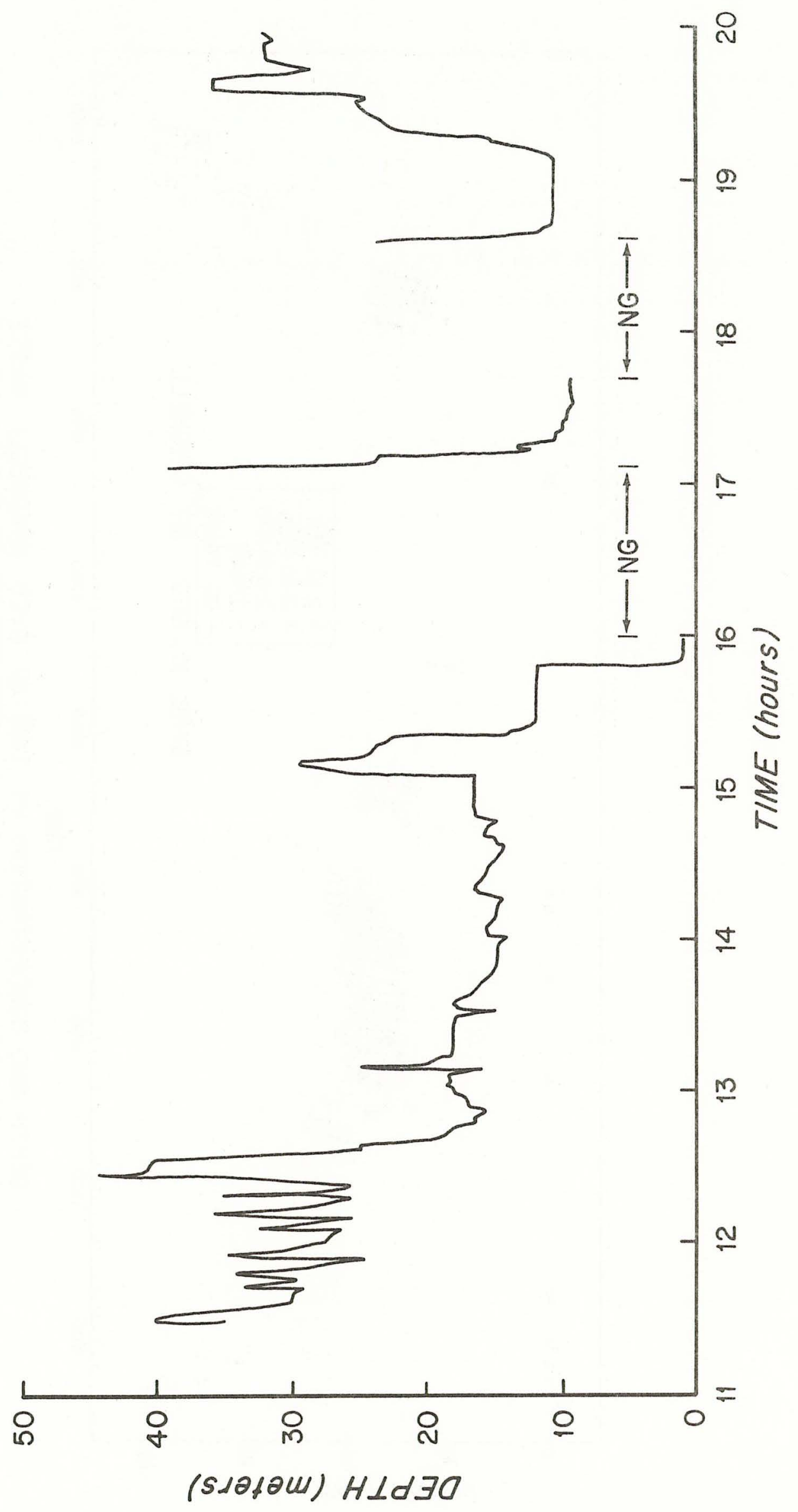




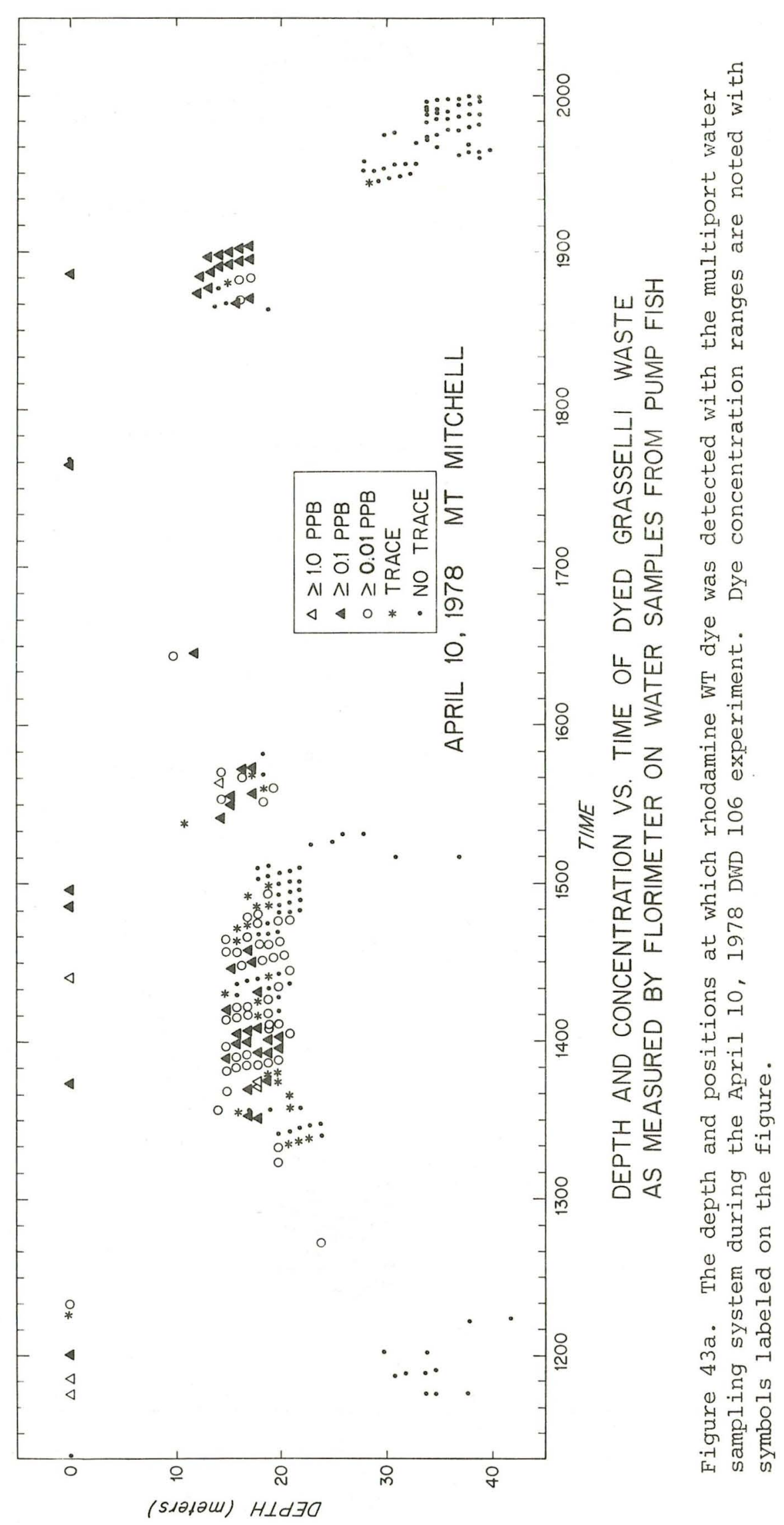



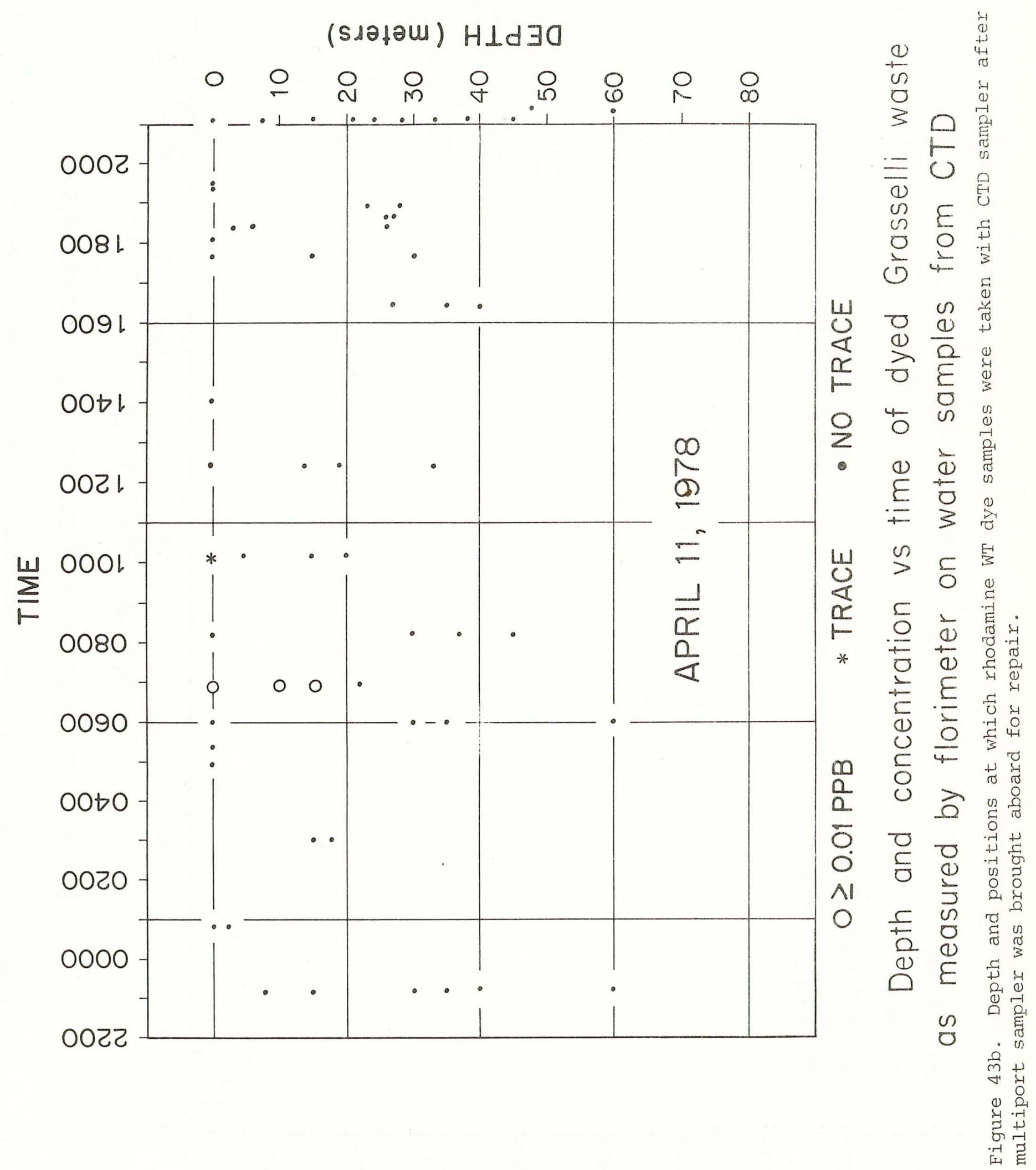

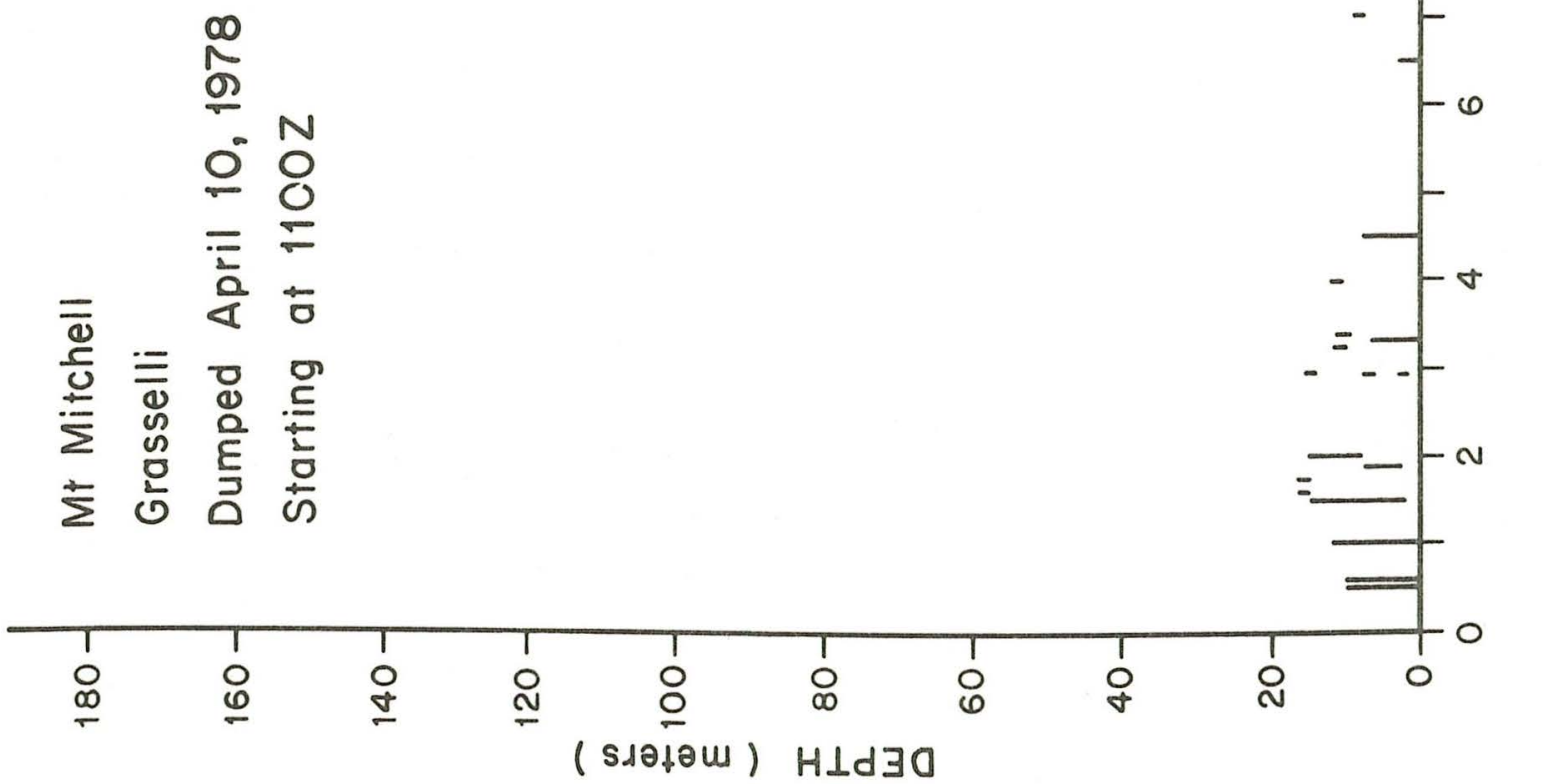

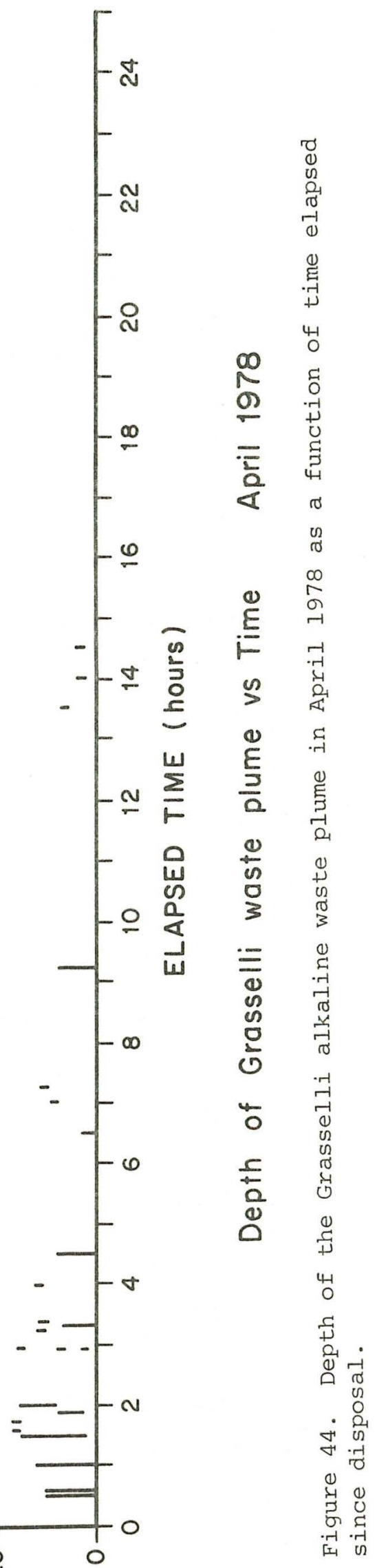


$\perp 0$

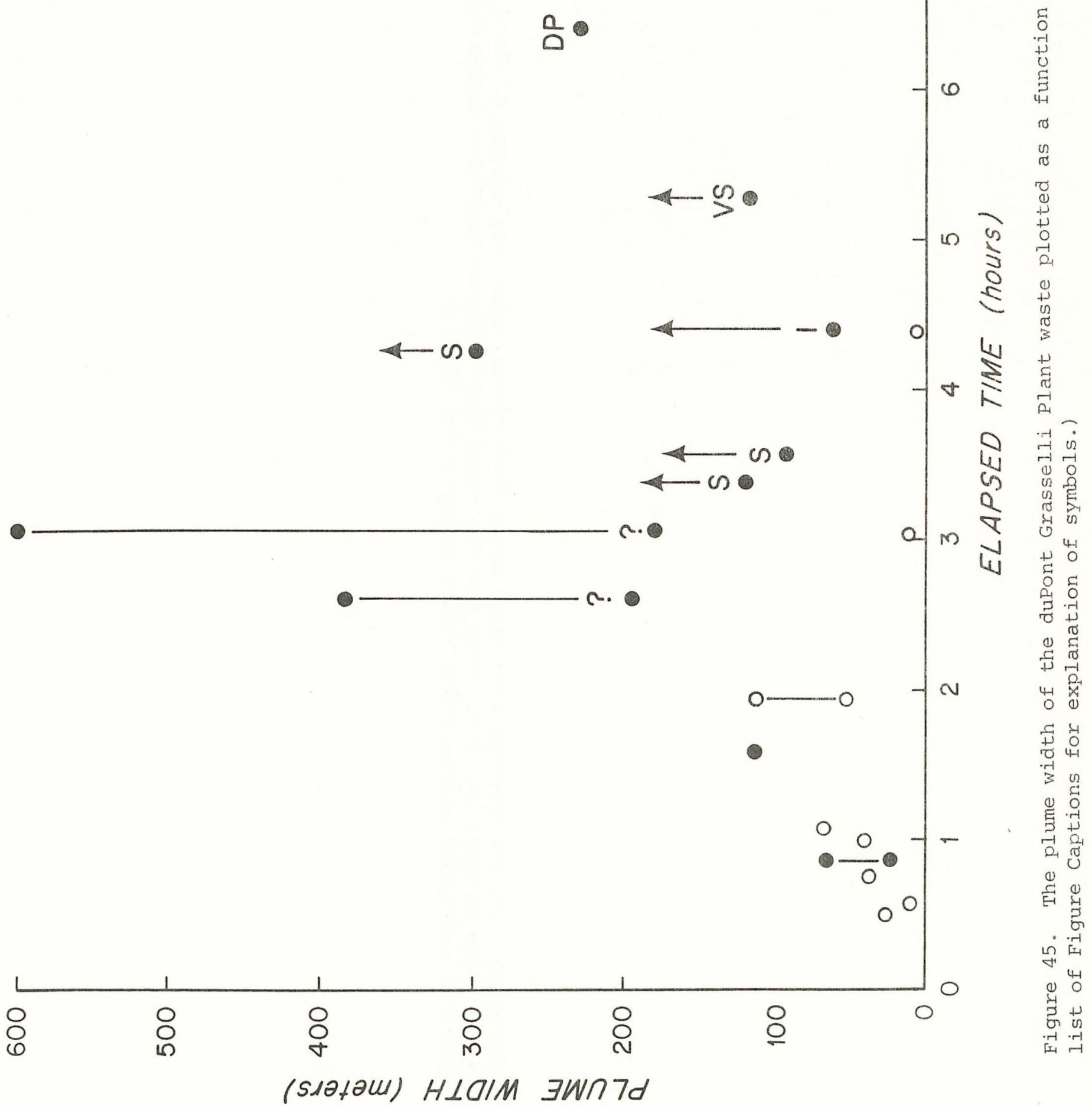




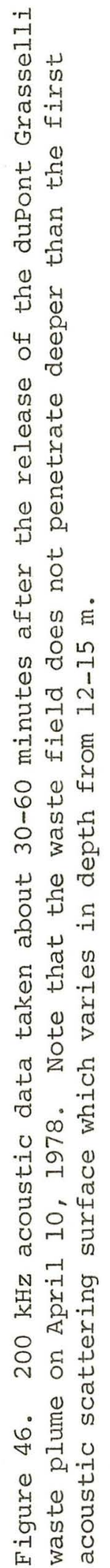


Crossings

of

Plume

Time

Elapsed

From

Barge

Passage

as

noted

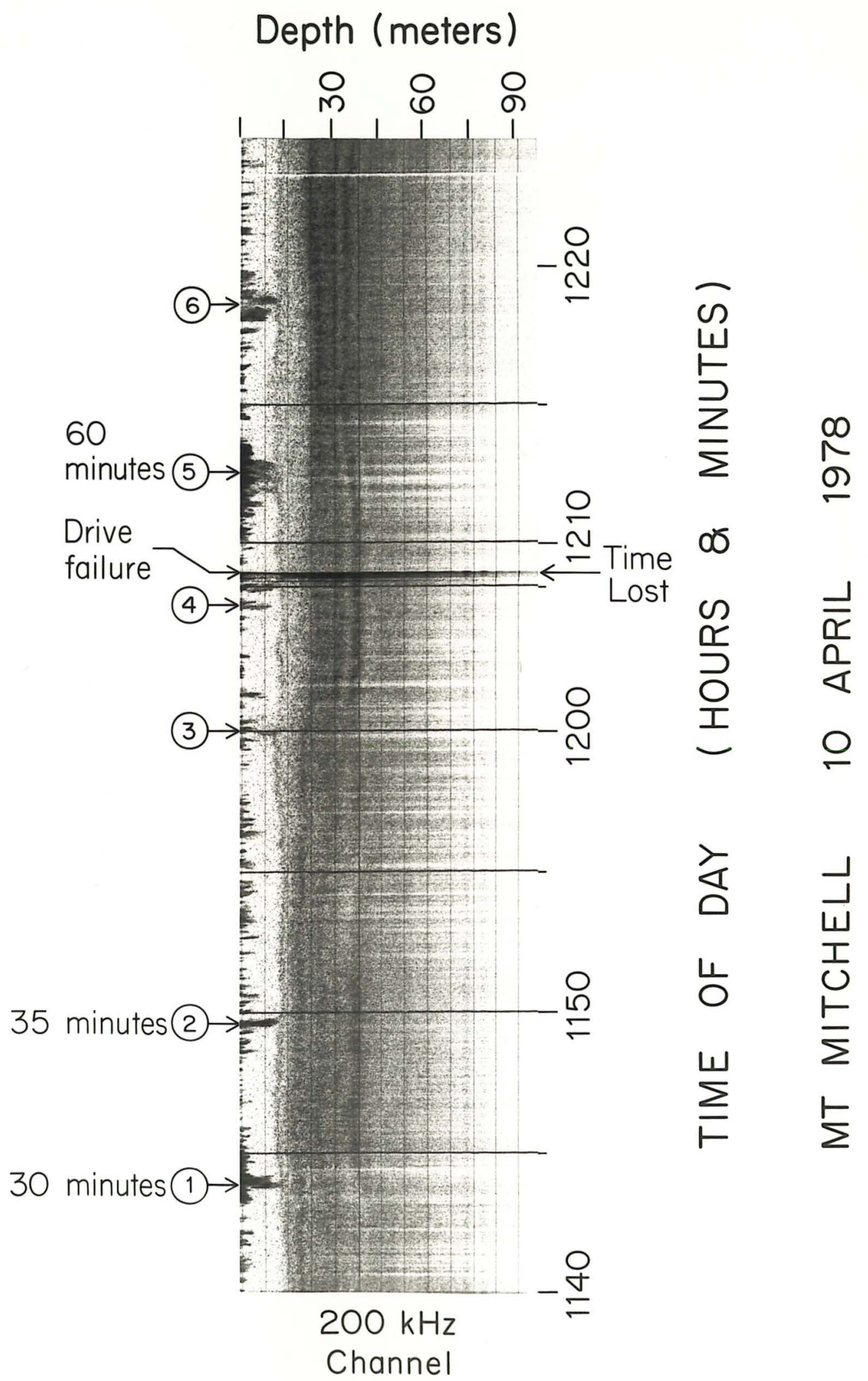




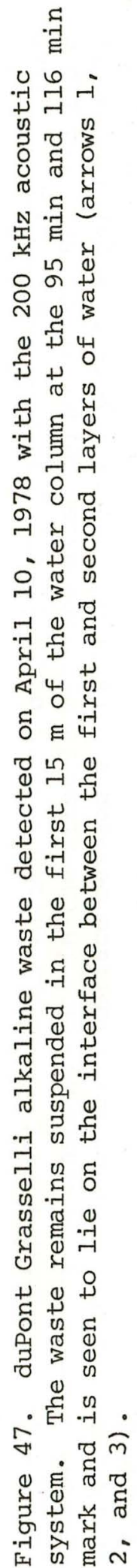




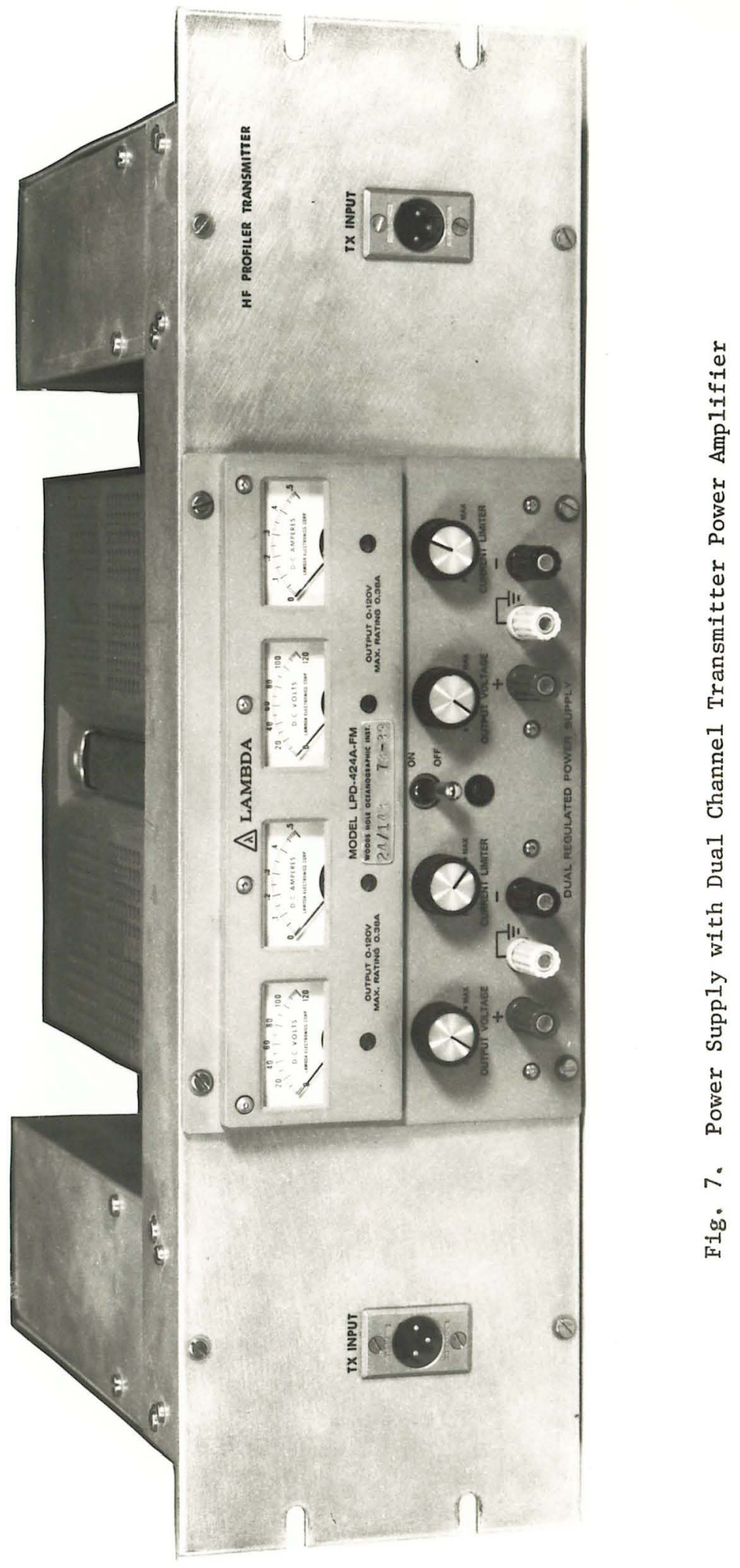




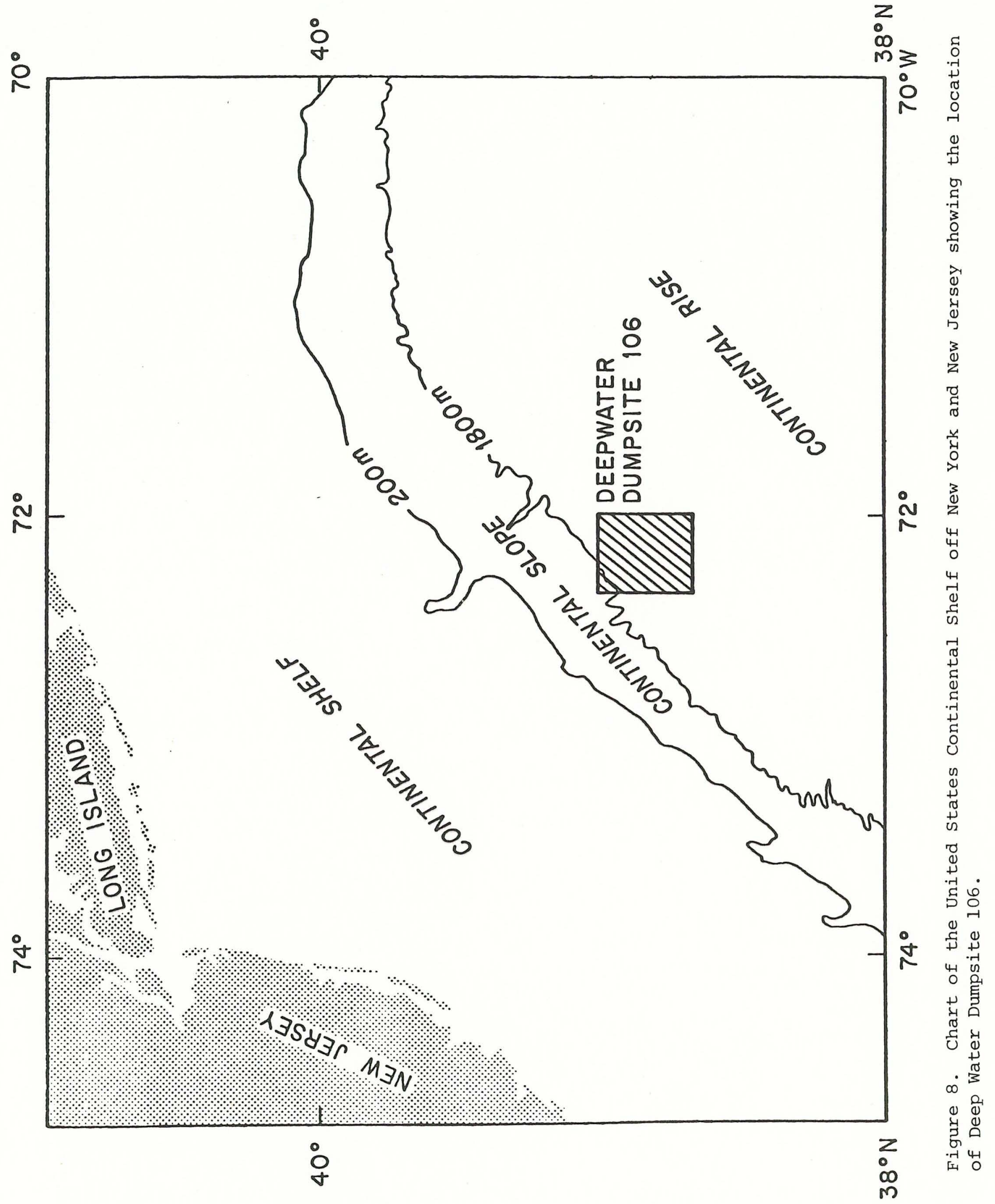




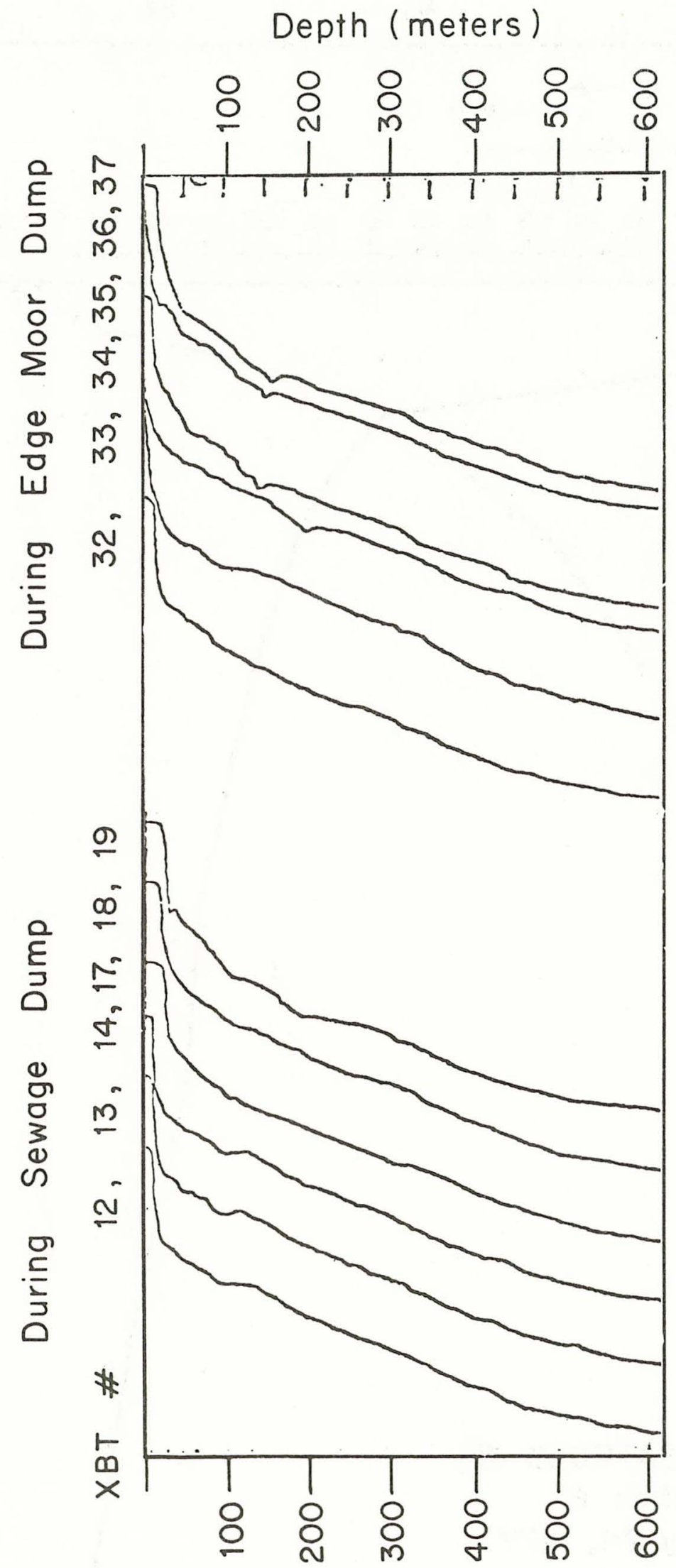

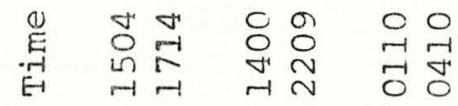

rar rar

$\sum \sum \sum \sum 5$

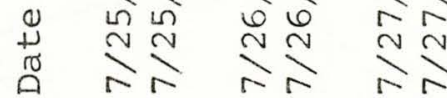

Hi 000000000

㞻

$\stackrel{\sim}{\infty}$

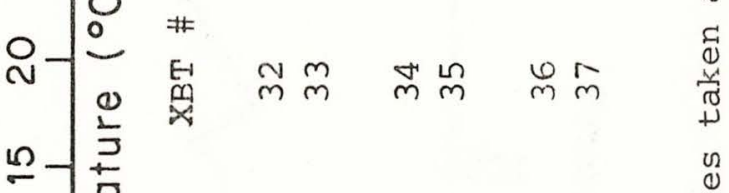

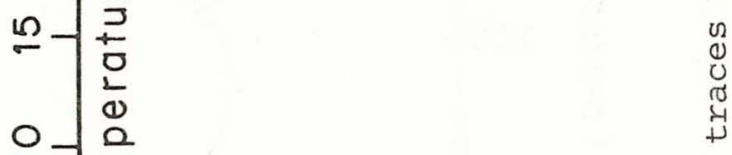

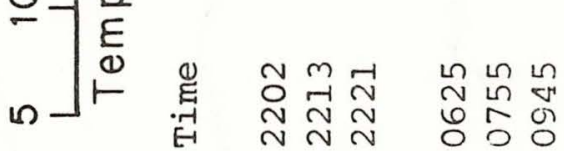

NAN NEN

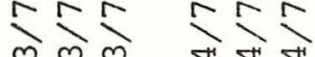

$\stackrel{m}{\sim} \stackrel{\sim}{\sim} \stackrel{\sim}{\sim} \stackrel{\sim}{\sim}$

ब

$\mathrm{H}^{\circ}$

- 0000000

岁

\#

กิ

2
-1
3
5
5
-1
0
0
-1 


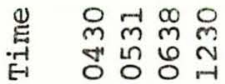

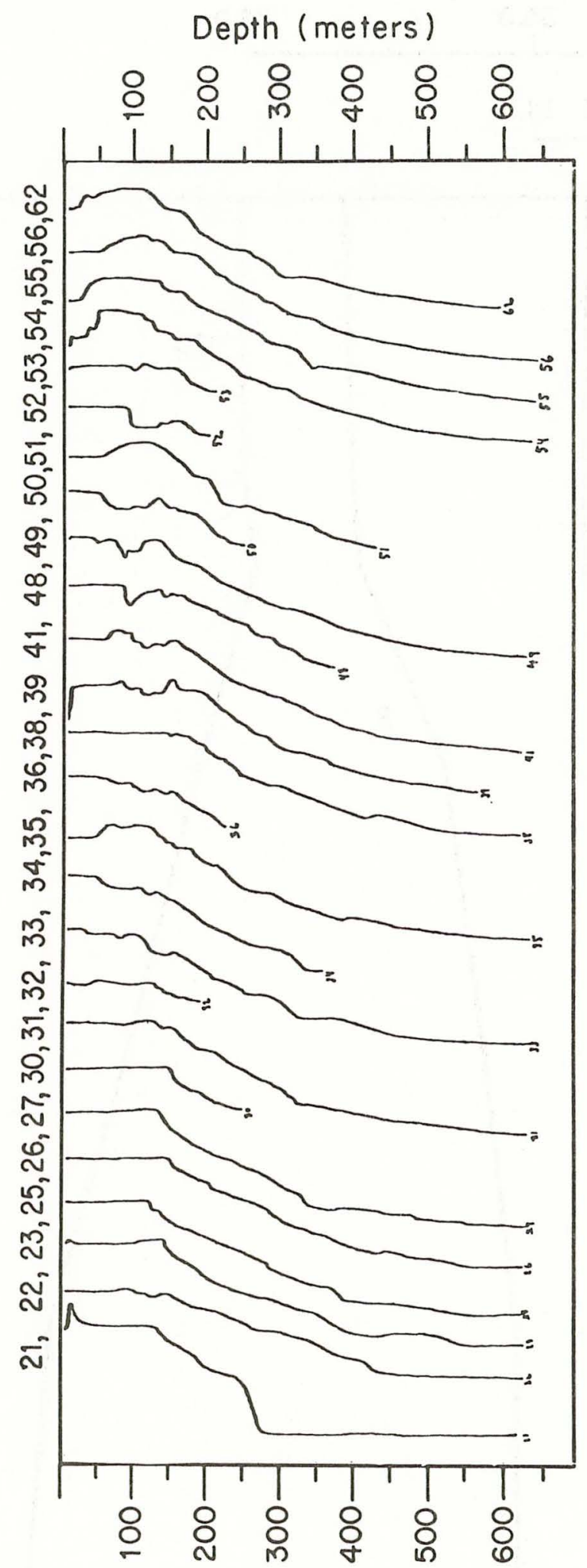

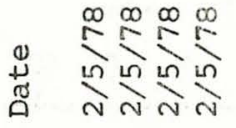

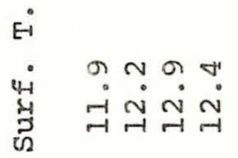

\#

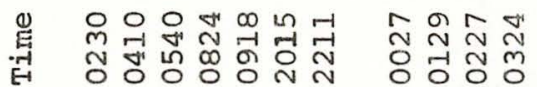

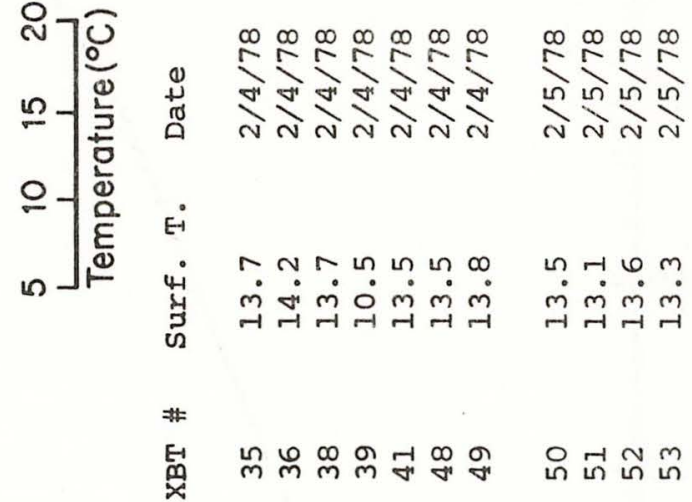

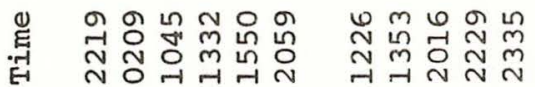

गี

सi

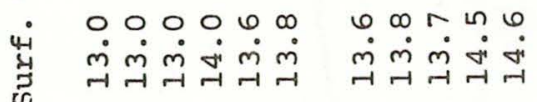

\# 


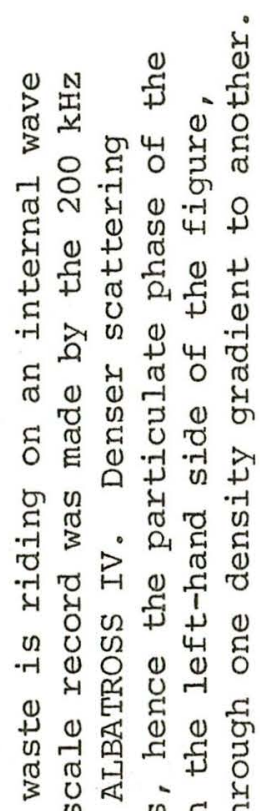

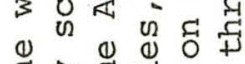

हो है द्य है

$\therefore$ व

N.t 001

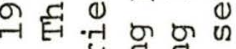

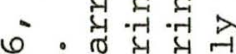
N 0000 $\lambda$ 다마 $30+000$ द न (1) 요욤 + on $\begin{array}{ll}0 \\ 0\end{array}$ उ० ॥ $4 \pi$ 도 ॠ

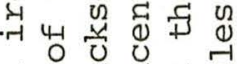
० - 000. त 0 ॠ

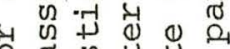
○

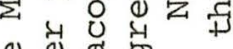
का

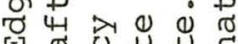
更 (1) 30 ᄀ ב (1) पै $ह$ थ

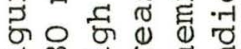

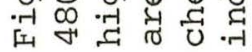


(sıәเәس) $H \perp d \exists O$
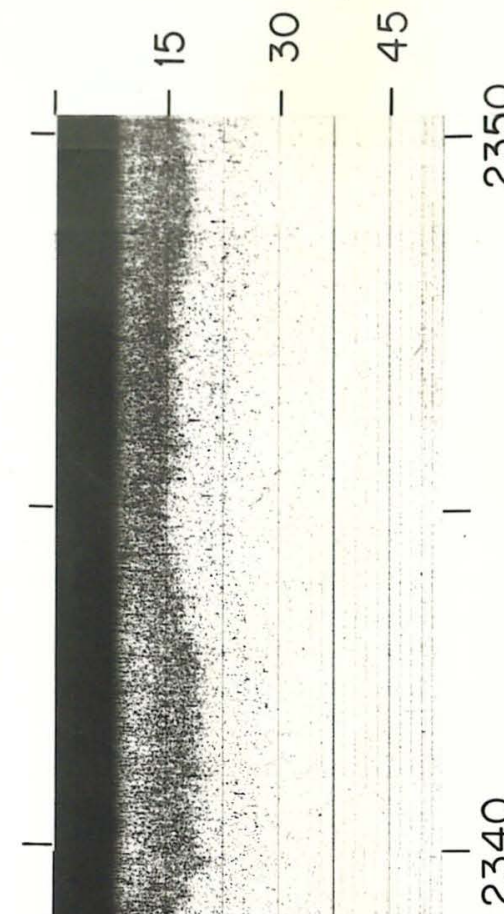

$\omega$

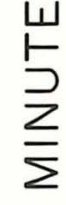

$\infty$

0
$\stackrel{\Upsilon}{0}$

$\stackrel{O}{m}$
$-\stackrel{N}{m}$

ᄂ

$\sum$
$N$

กั

๖
$\supset$

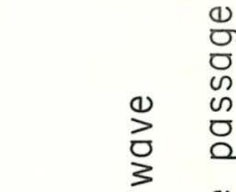

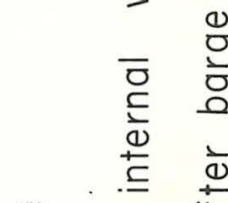

造

$\gg$ o

힝

옴

$\stackrel{\cup}{N}$

日

$\theta$

0
0
$\frac{1}{1}$
$\frac{1}{4}$
$\frac{1}{4}$ 


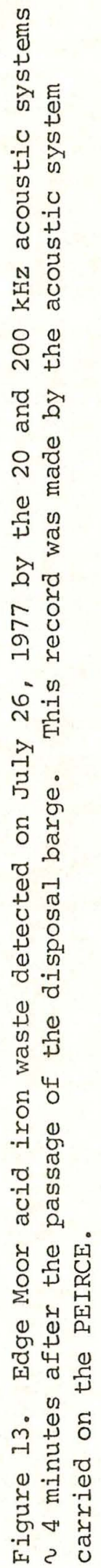



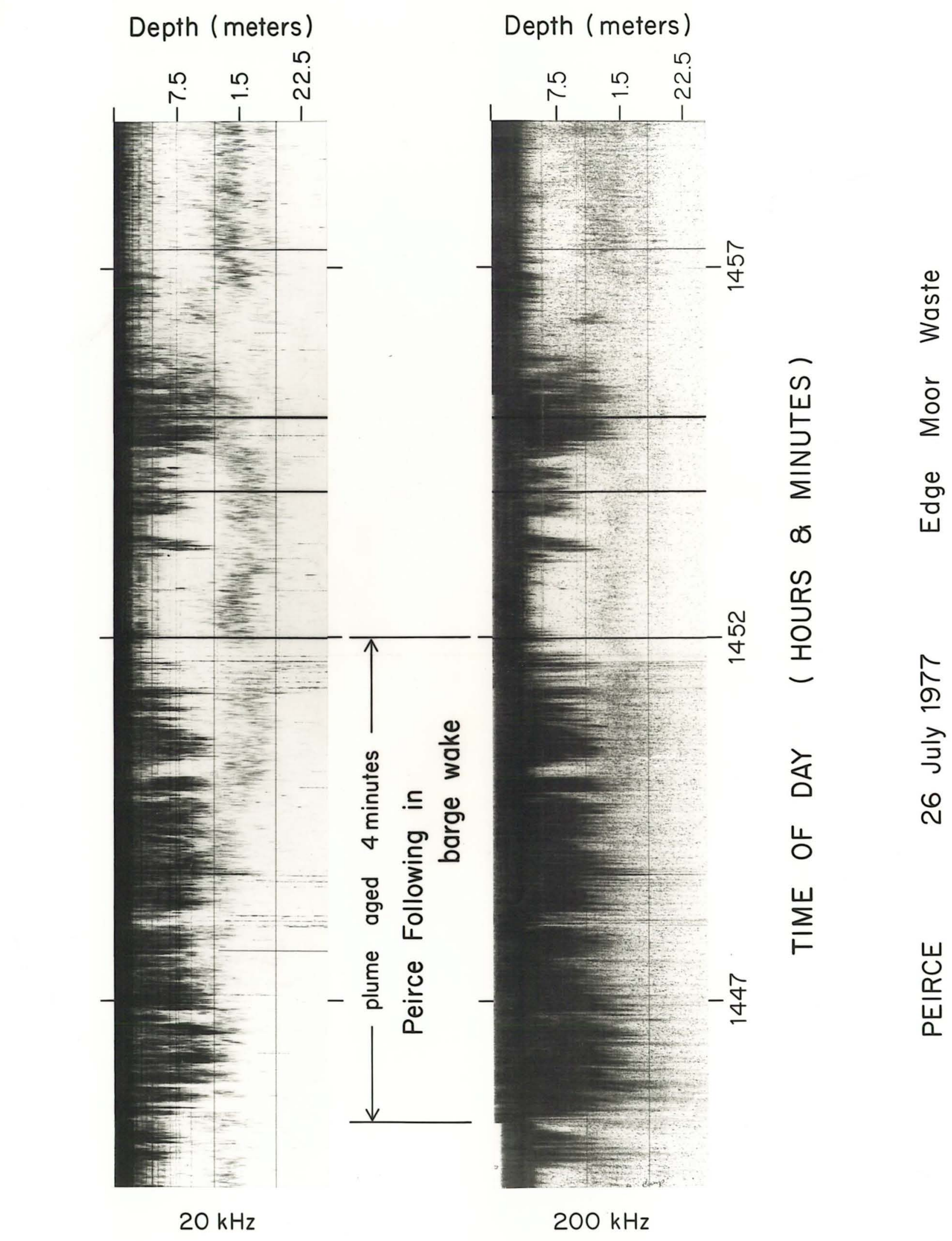


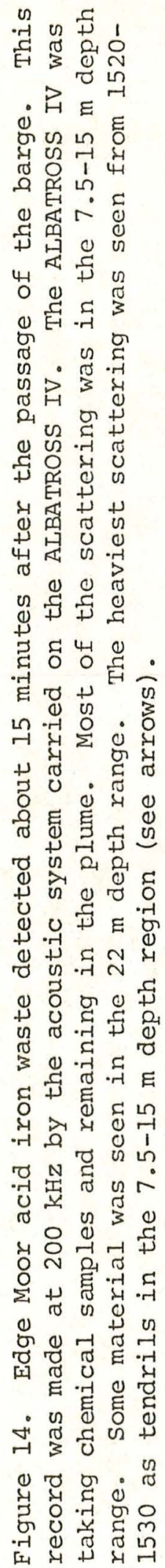




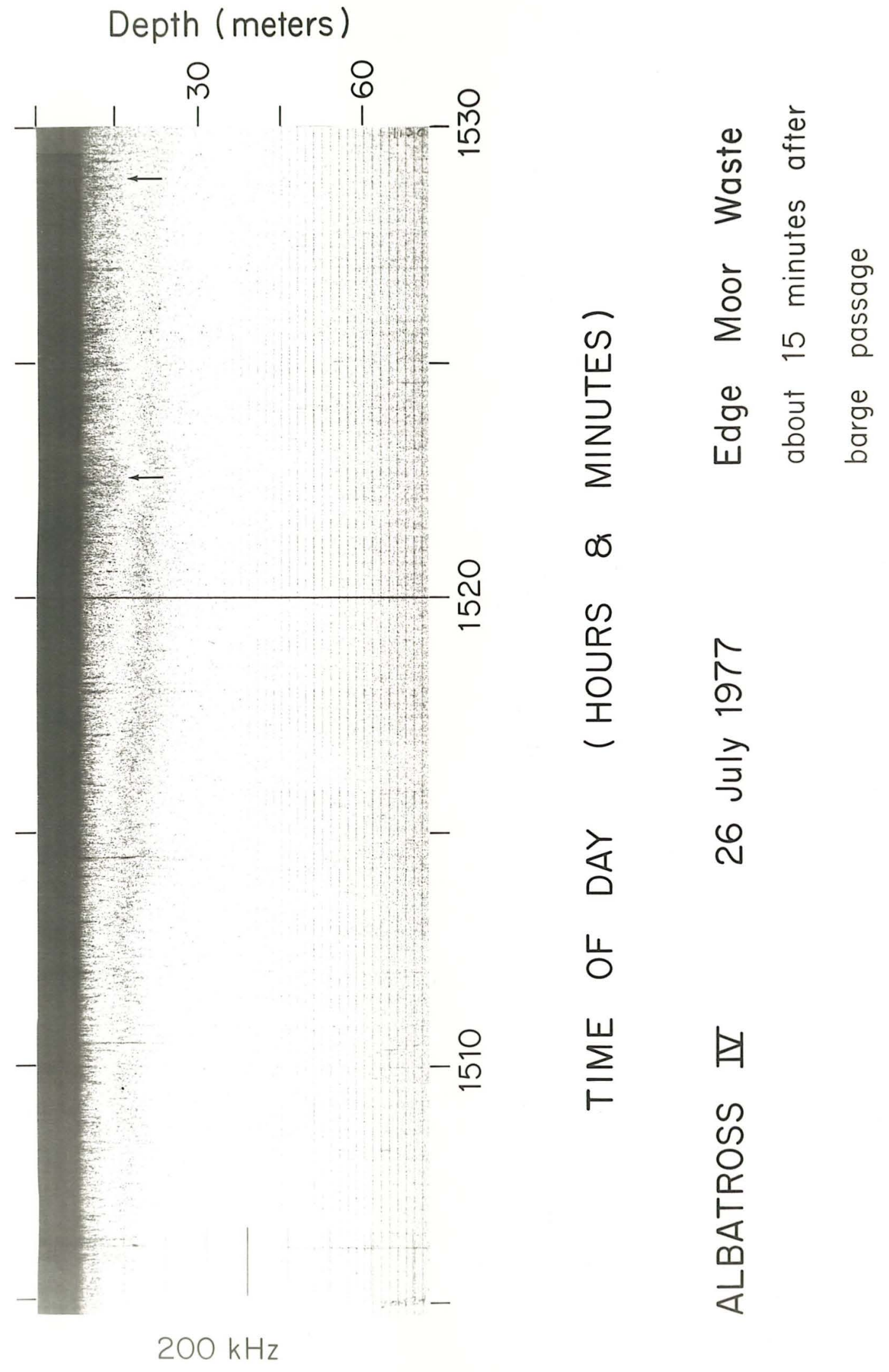




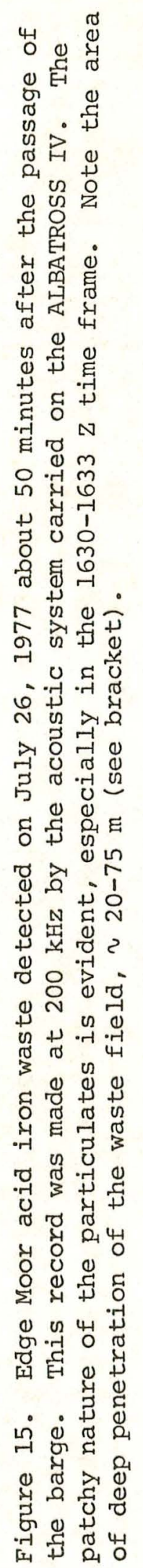




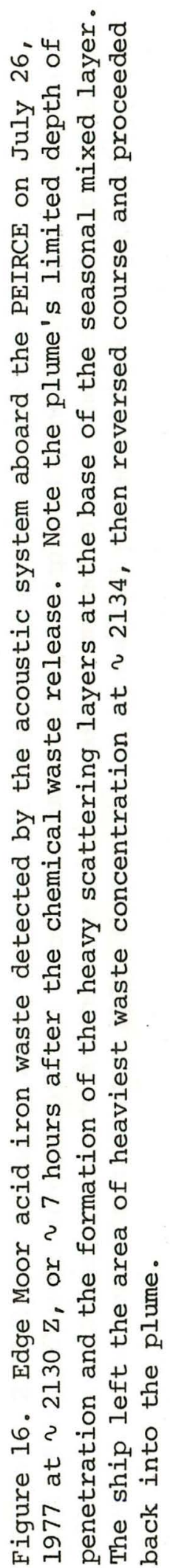



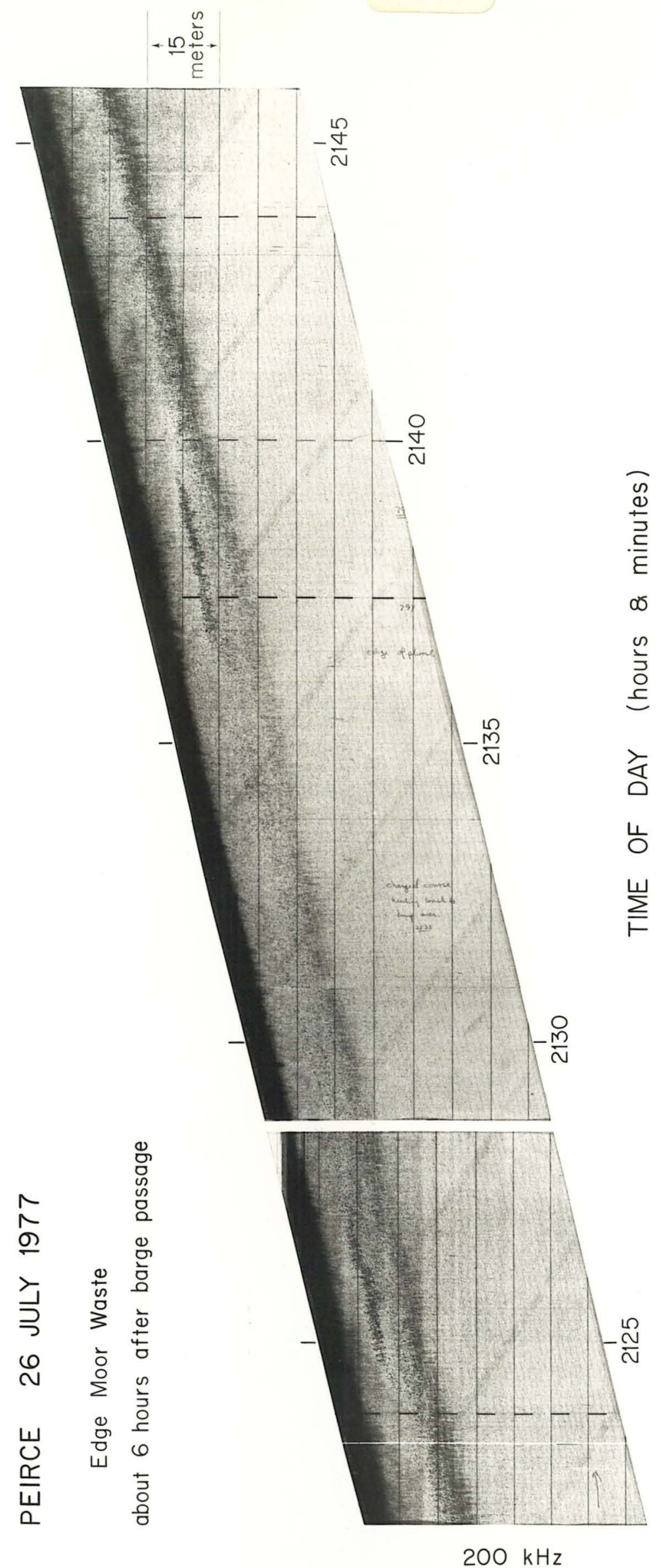


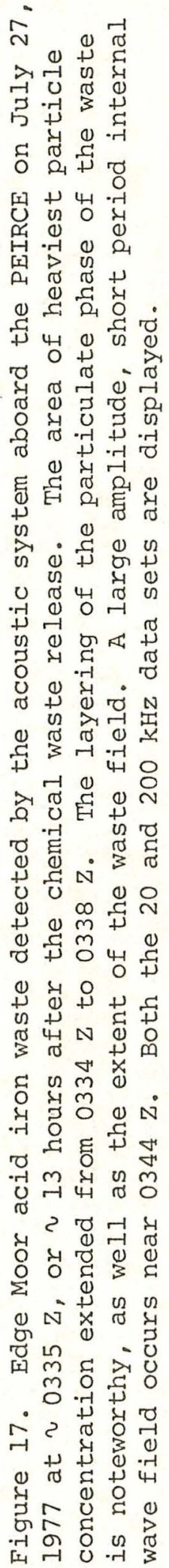




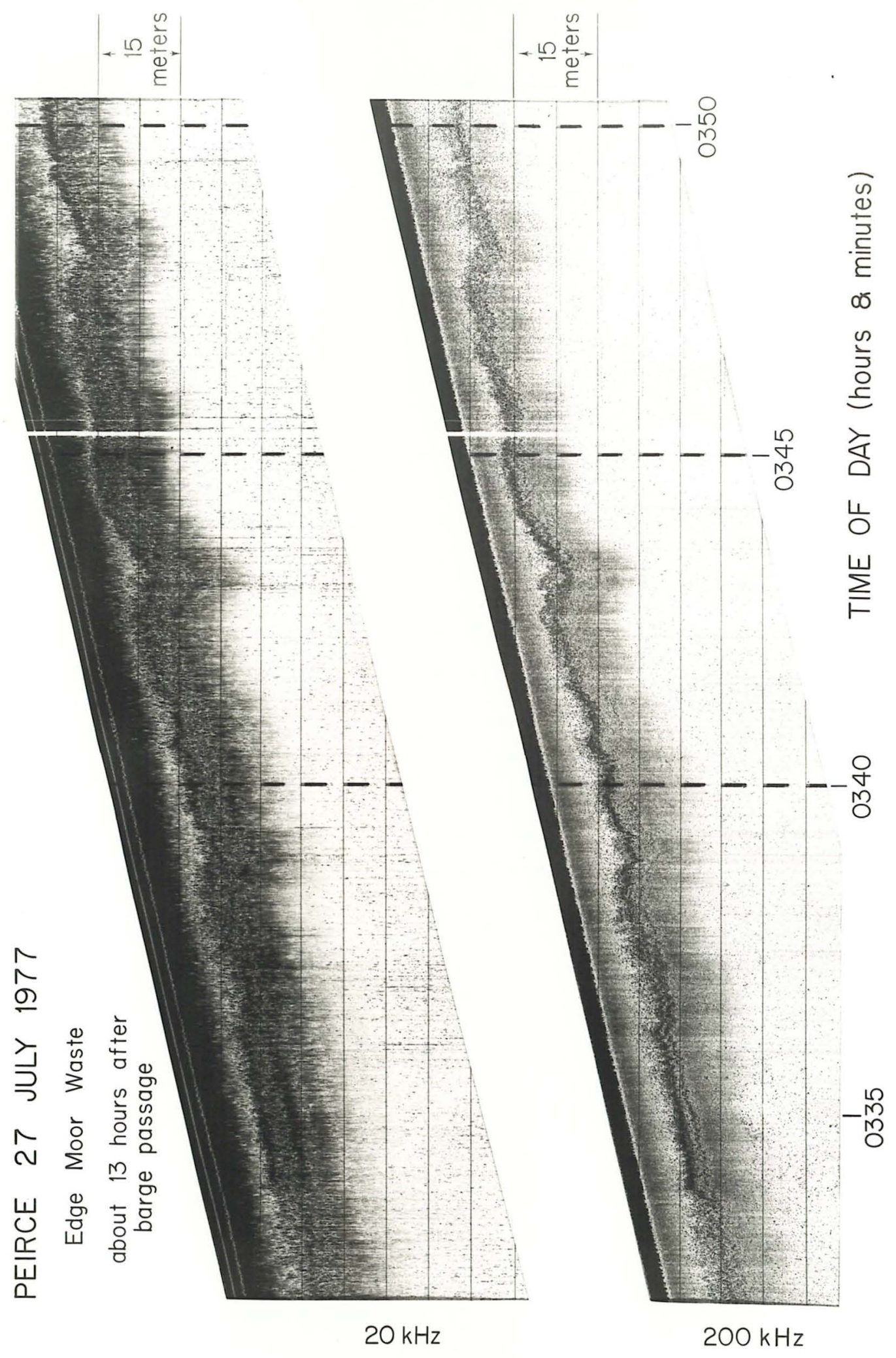




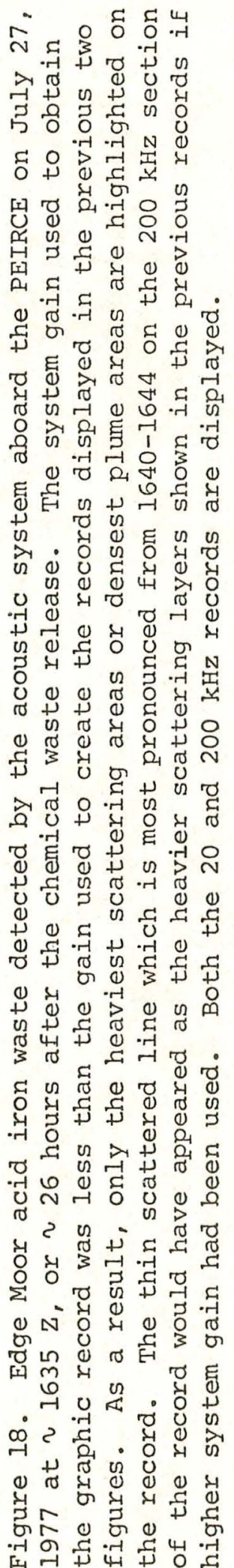



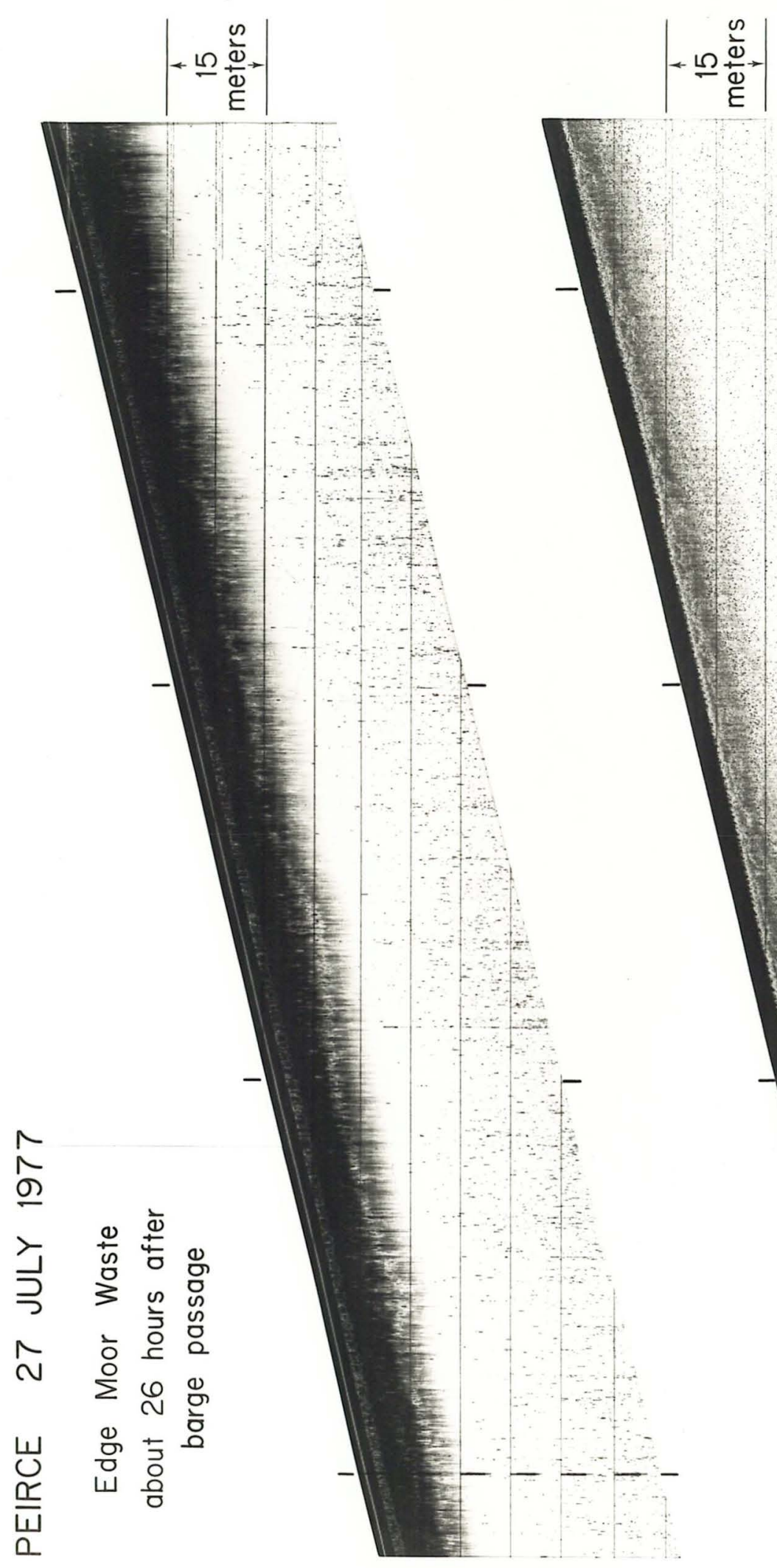


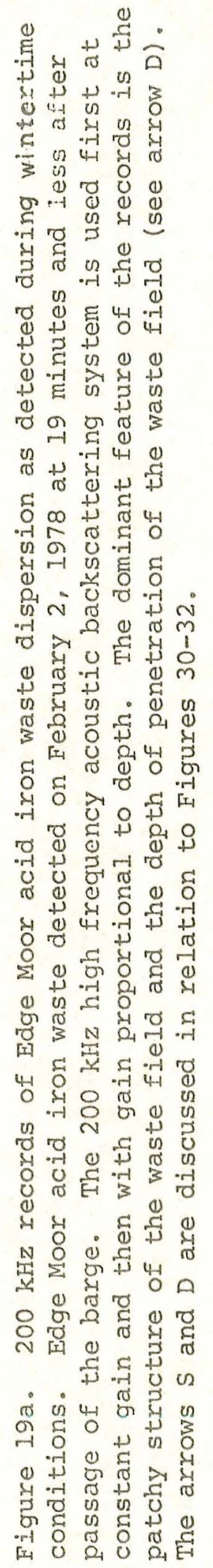




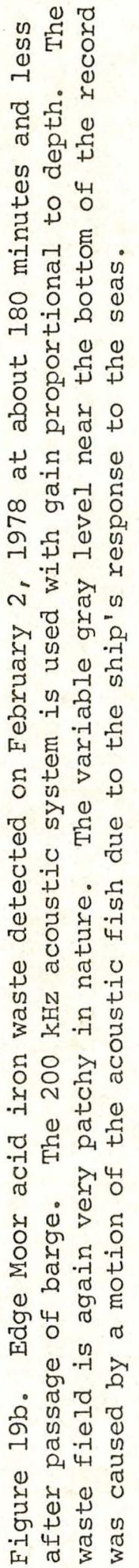




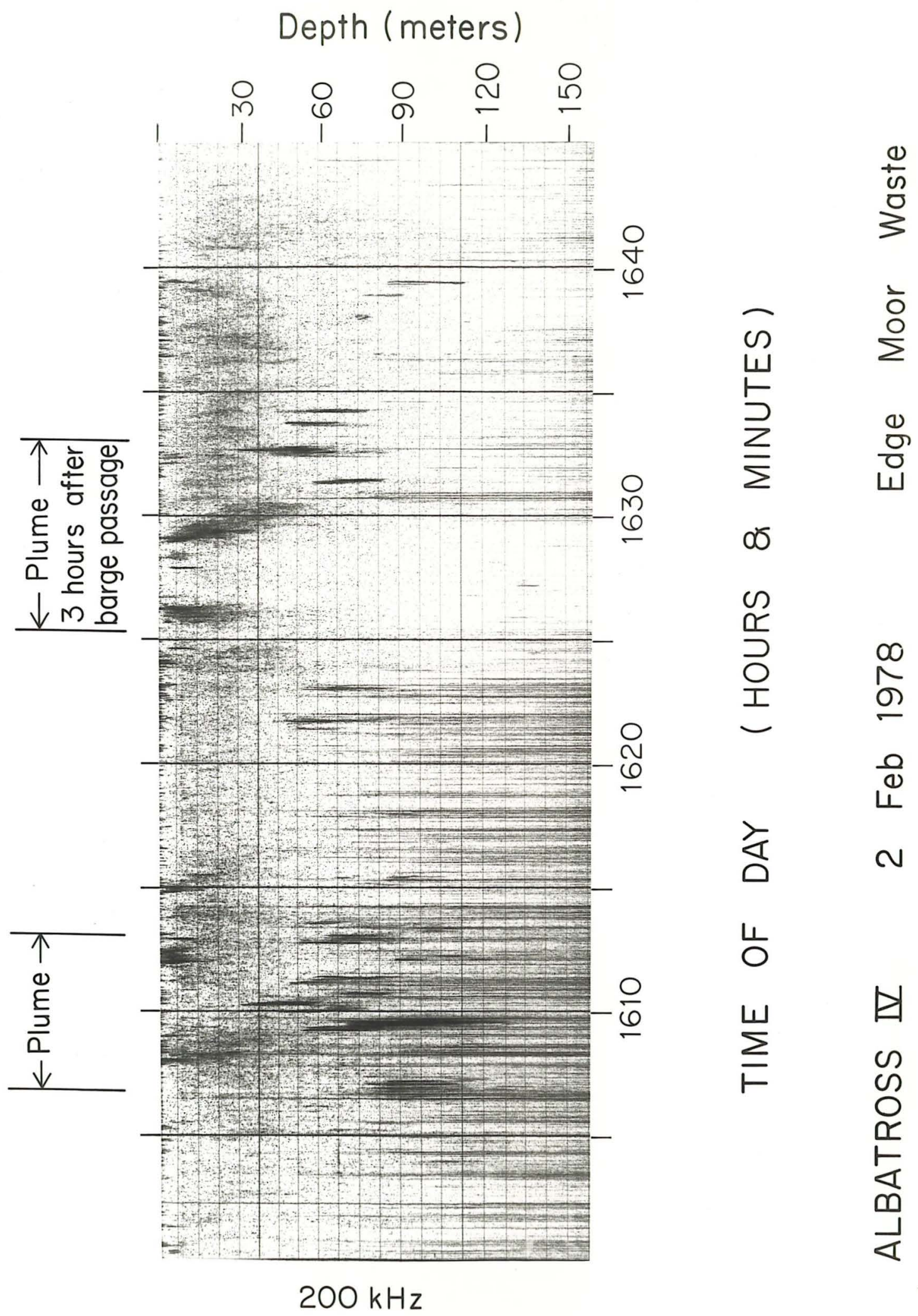




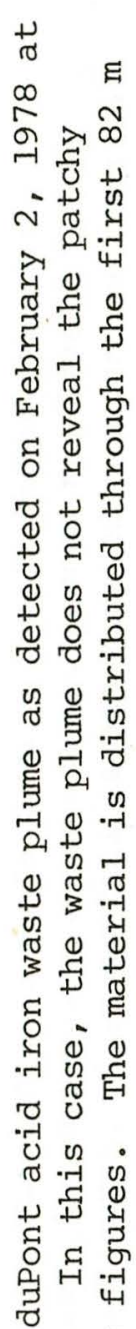

(1)

की

出

प्र

O

D东出

资

空 0 .

일

$\varangle 000$

ن 0 \%

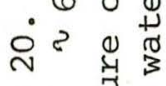

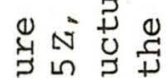

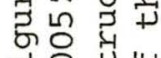

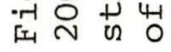




\section{DEPTH (meters)}

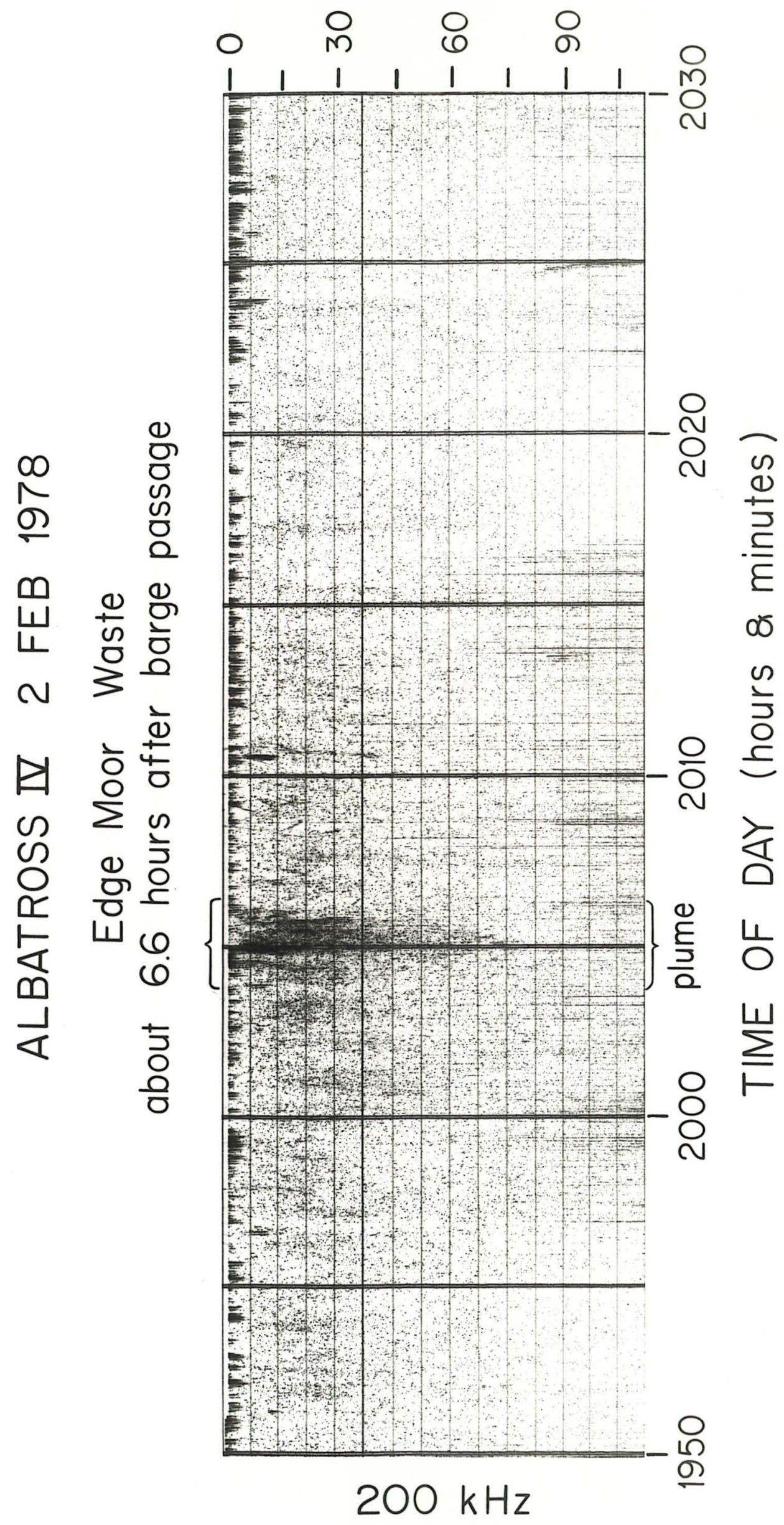




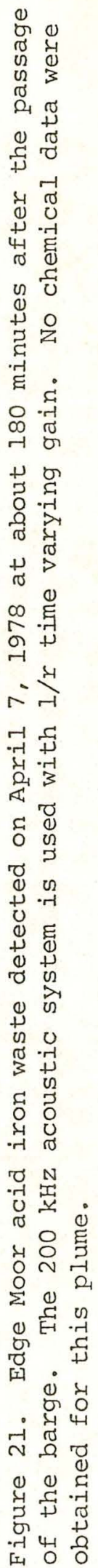




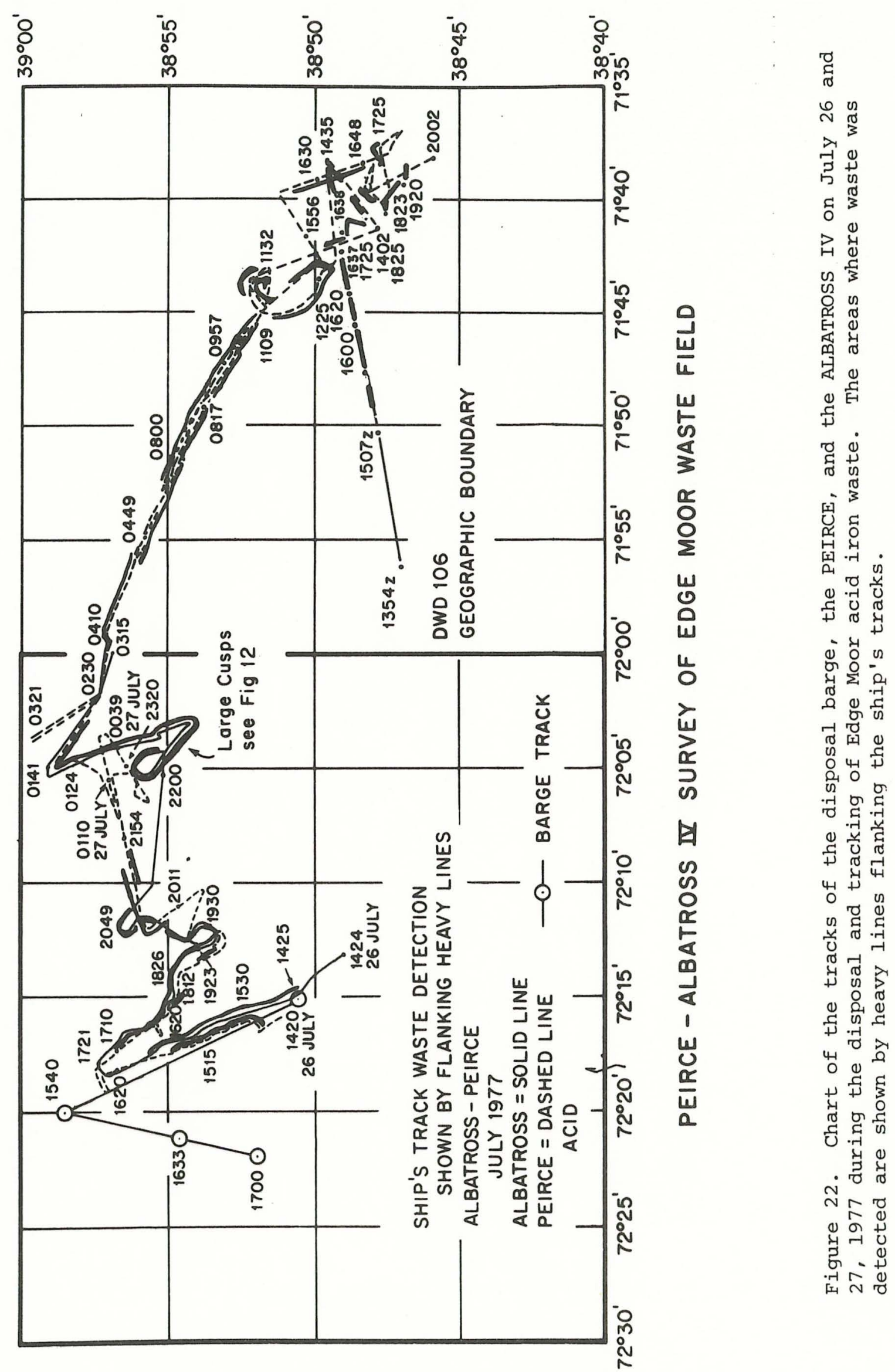




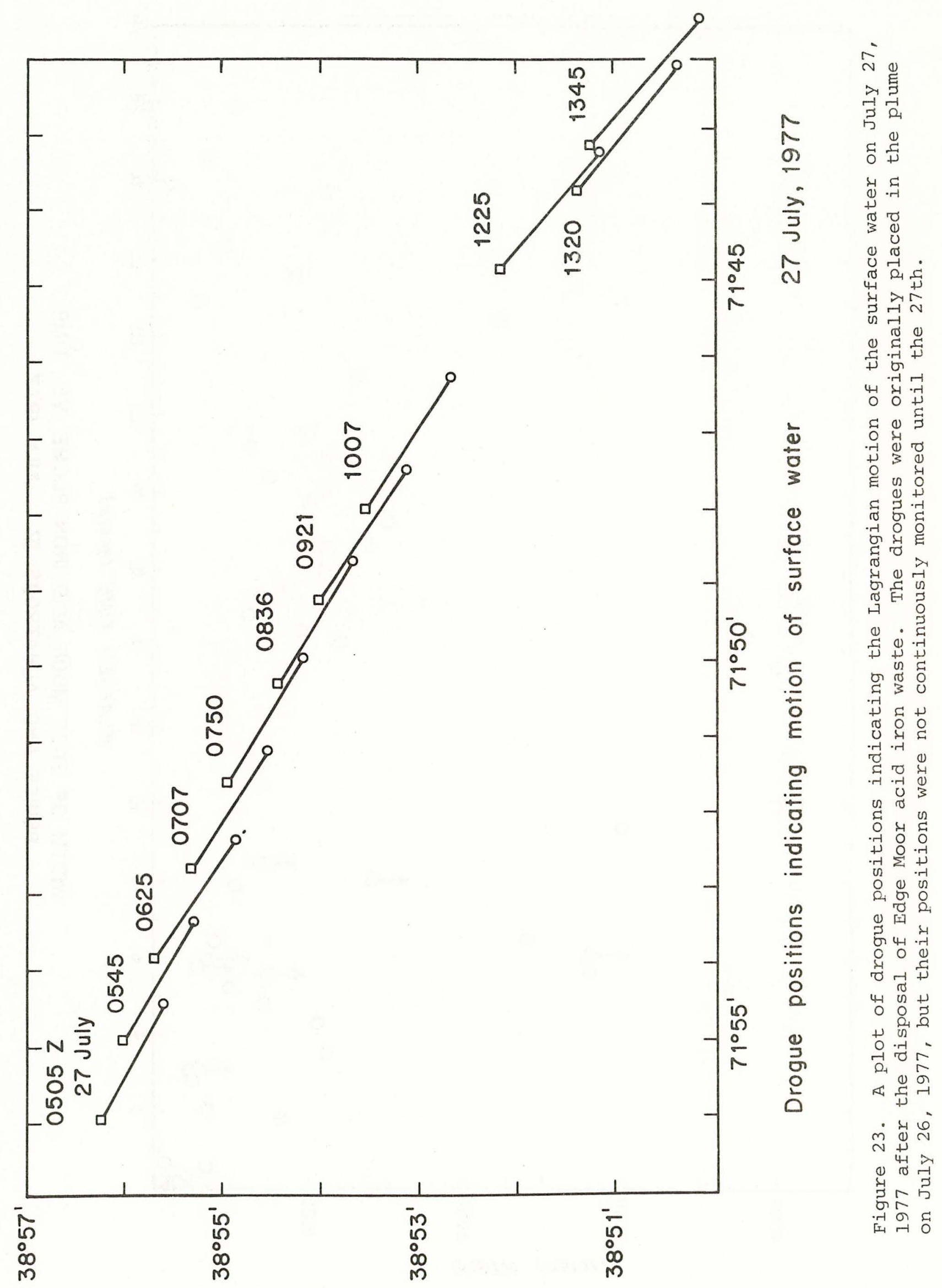




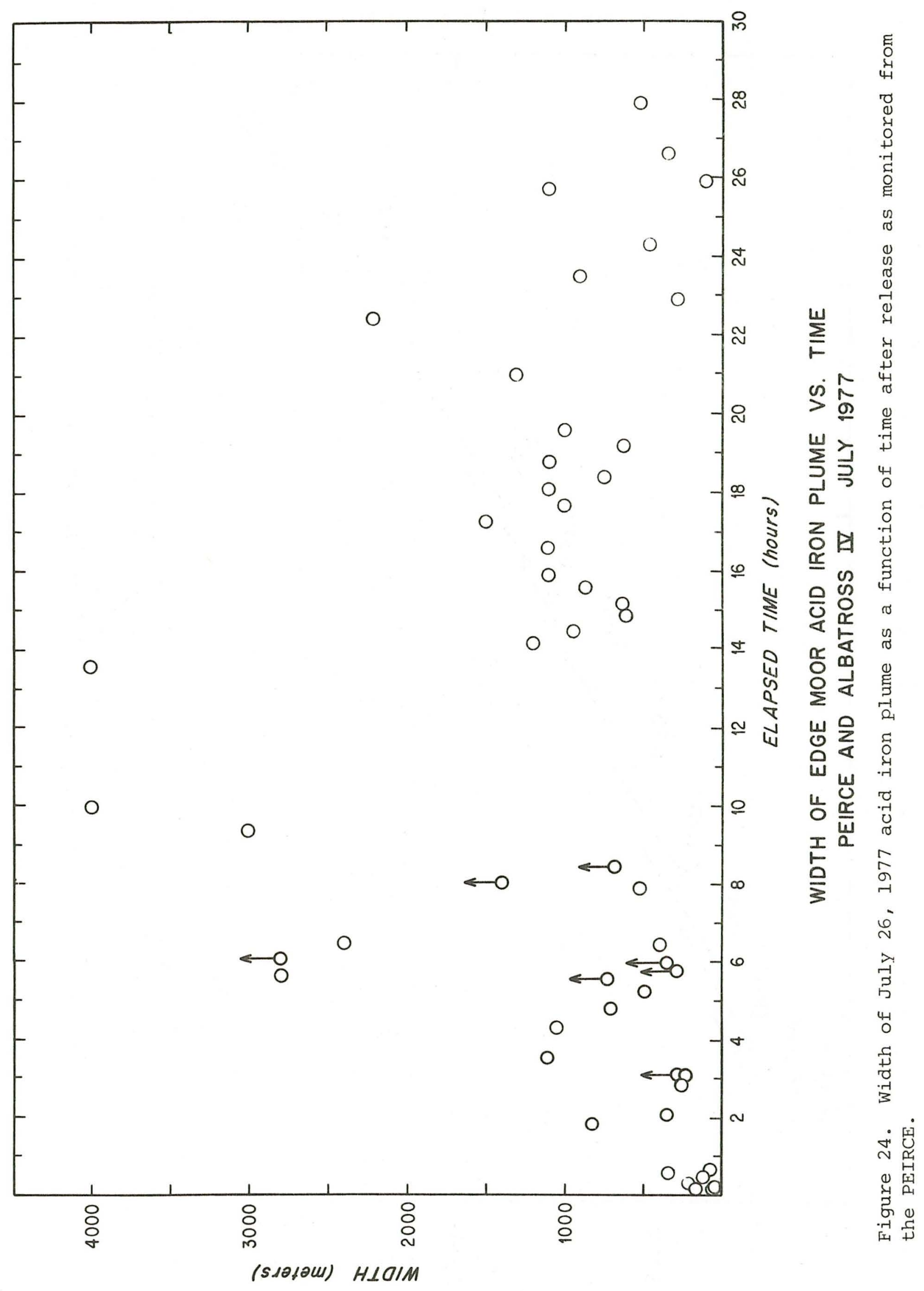



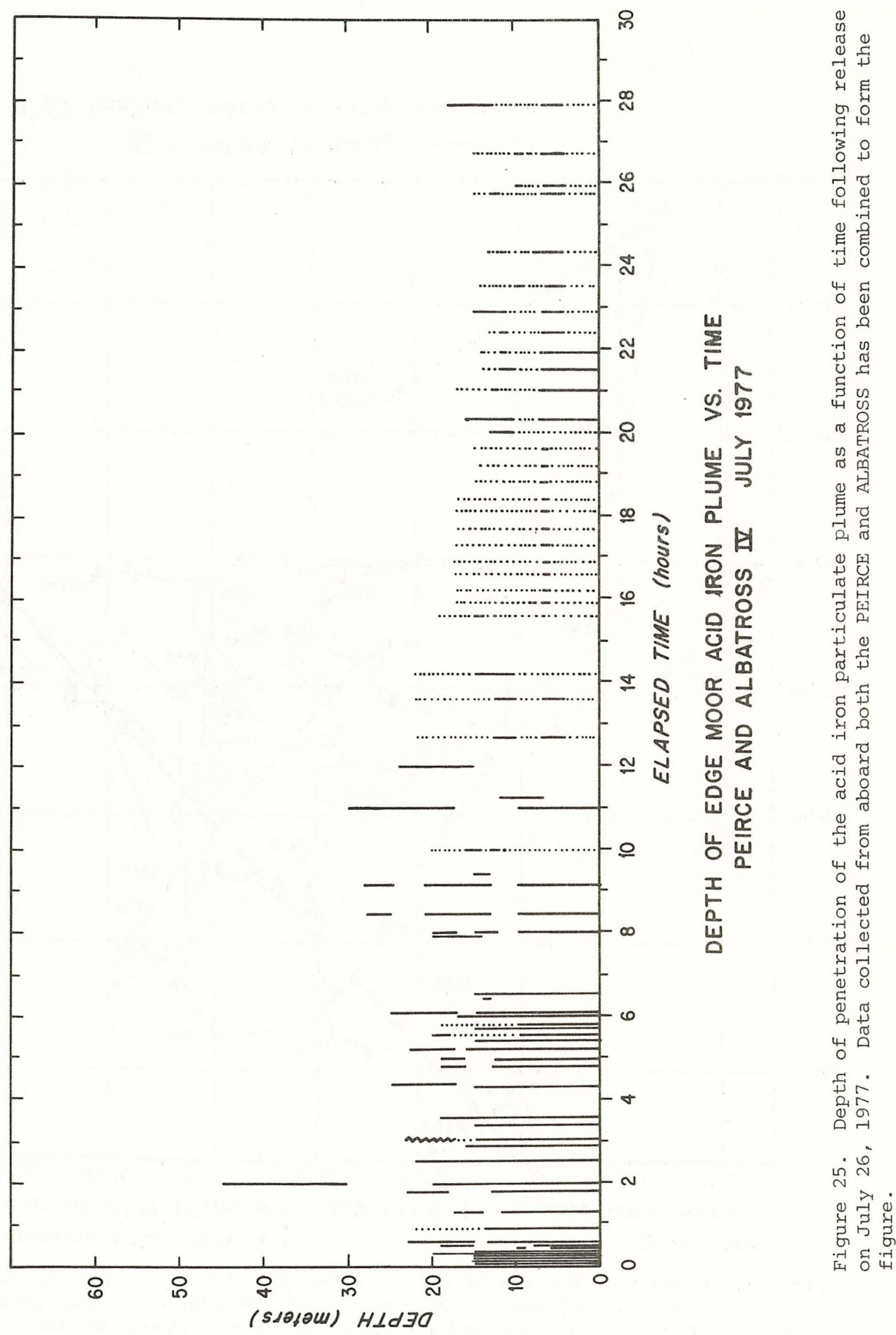


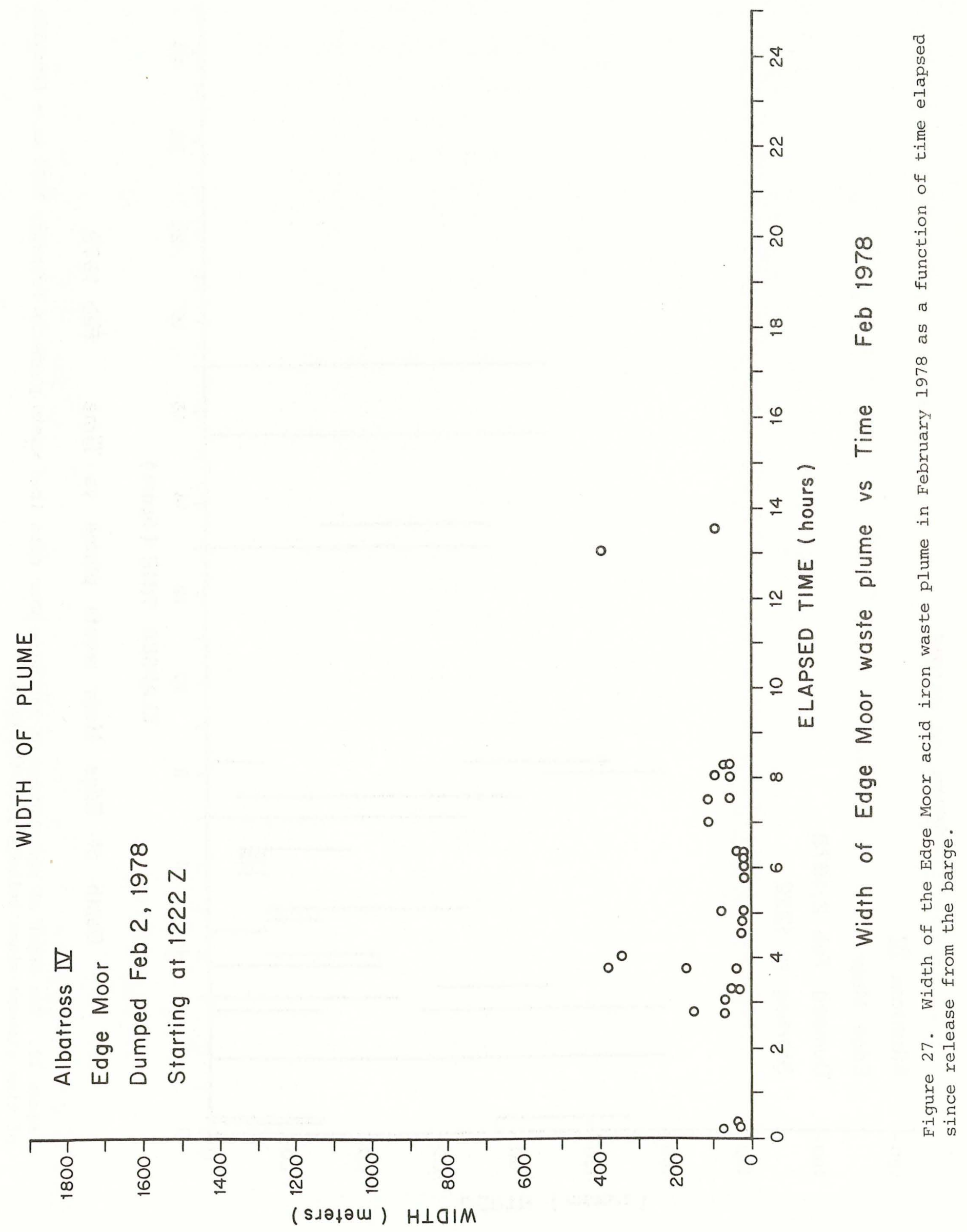




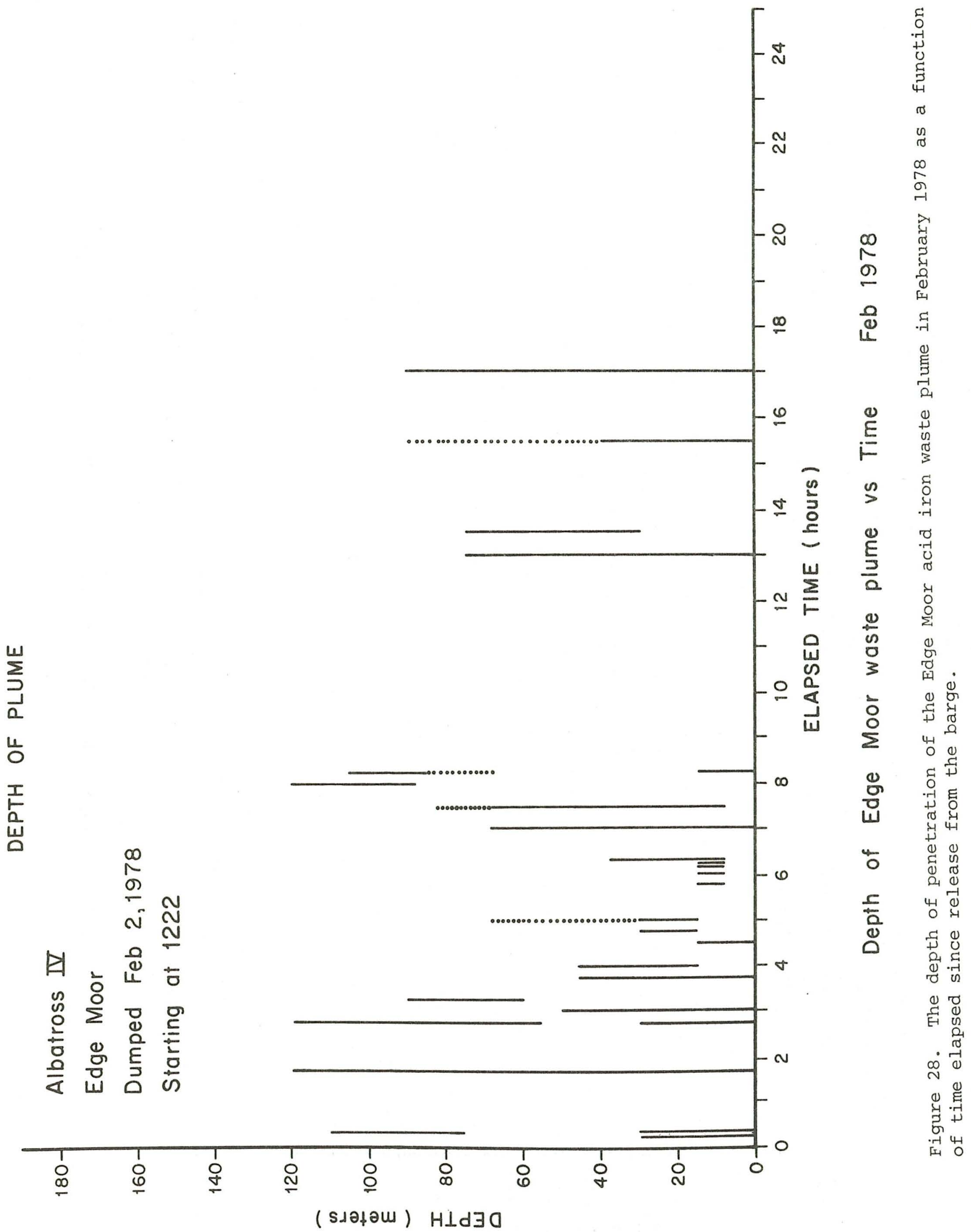


Depth (meters)

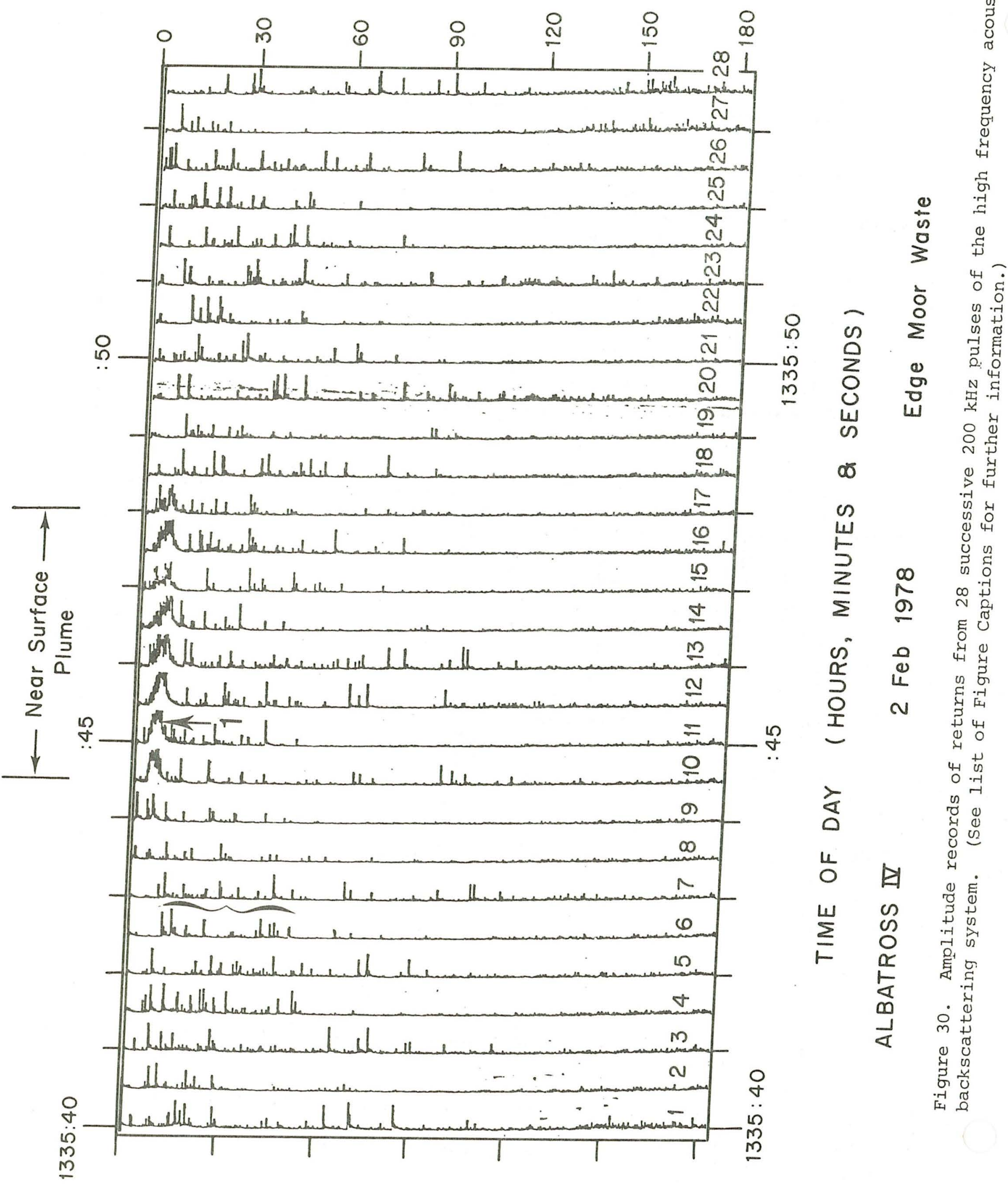




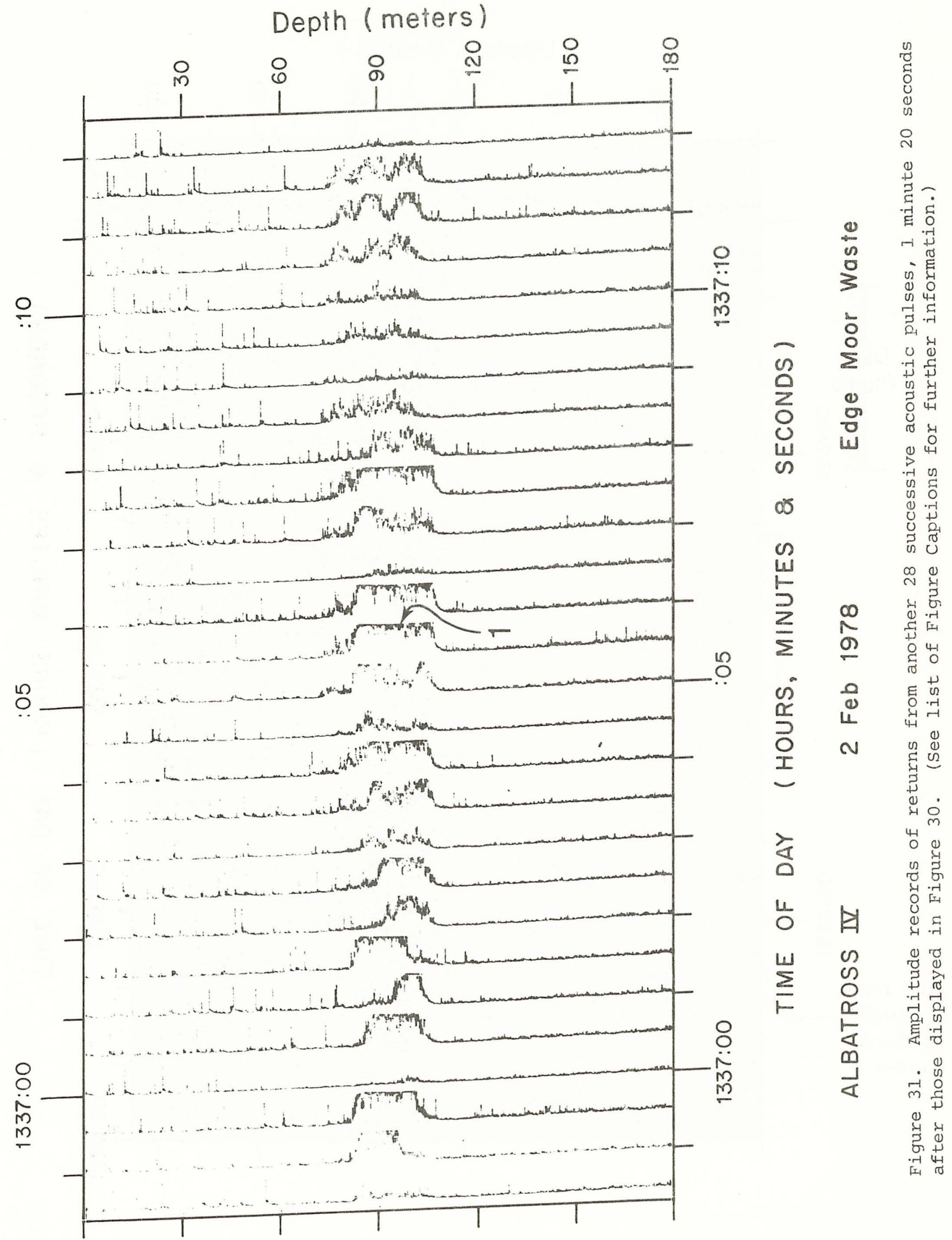




\section{Depth (meters)}

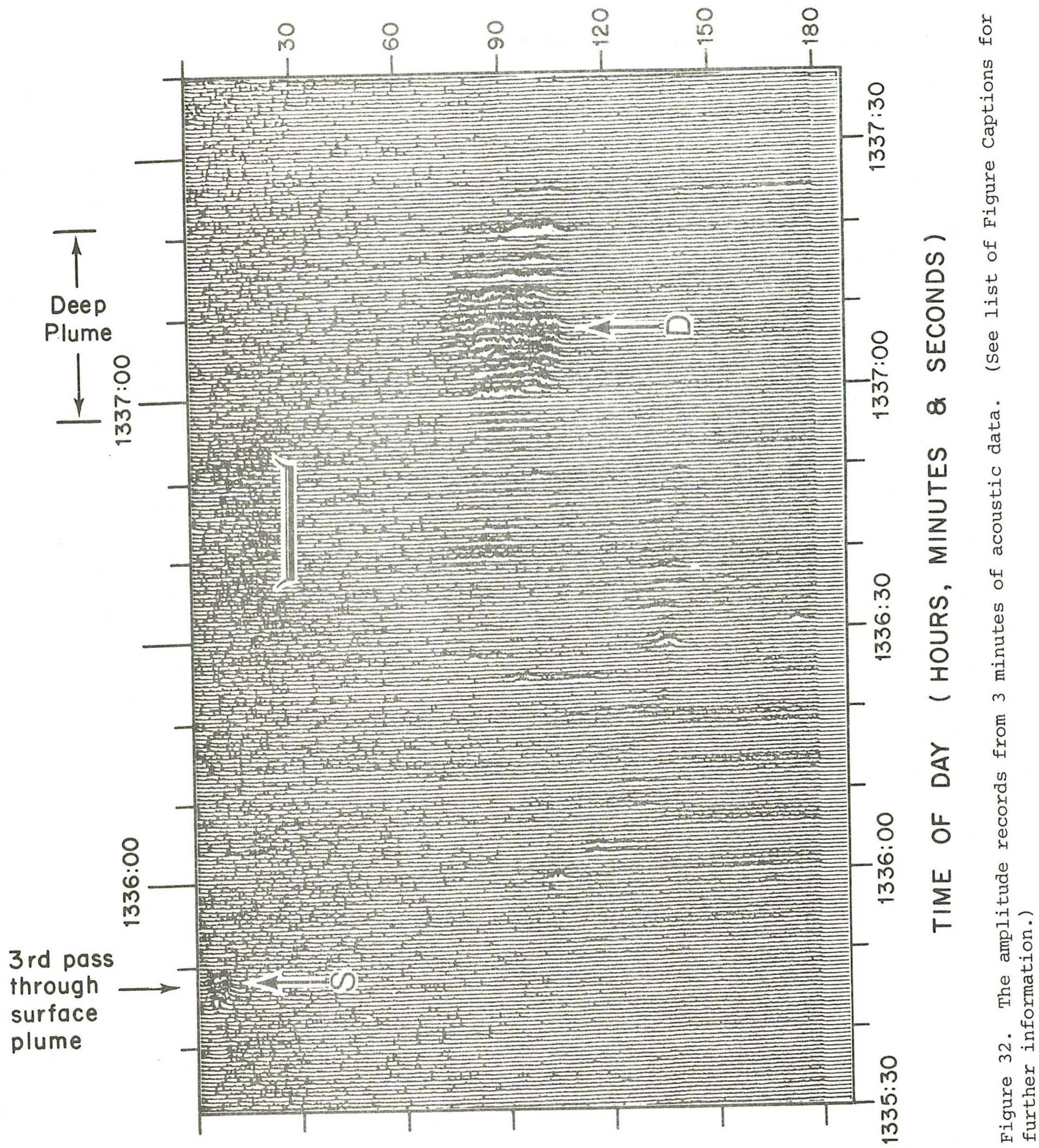




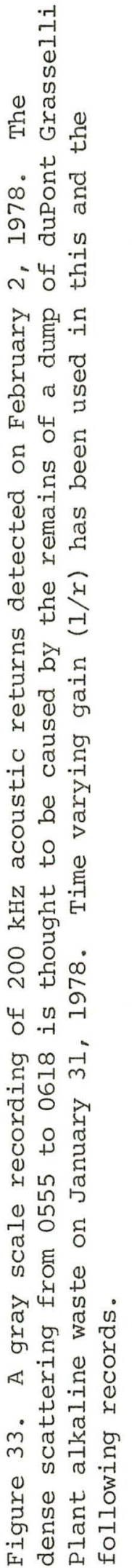




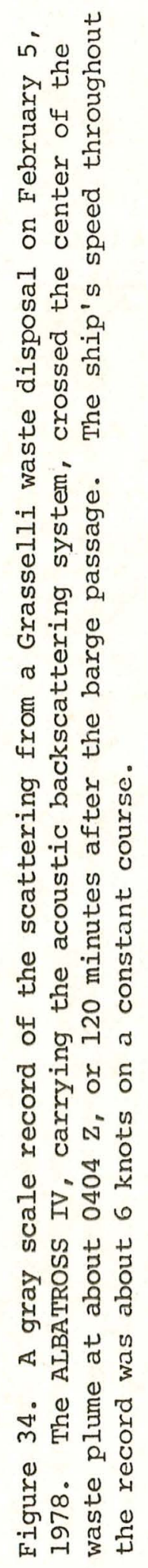




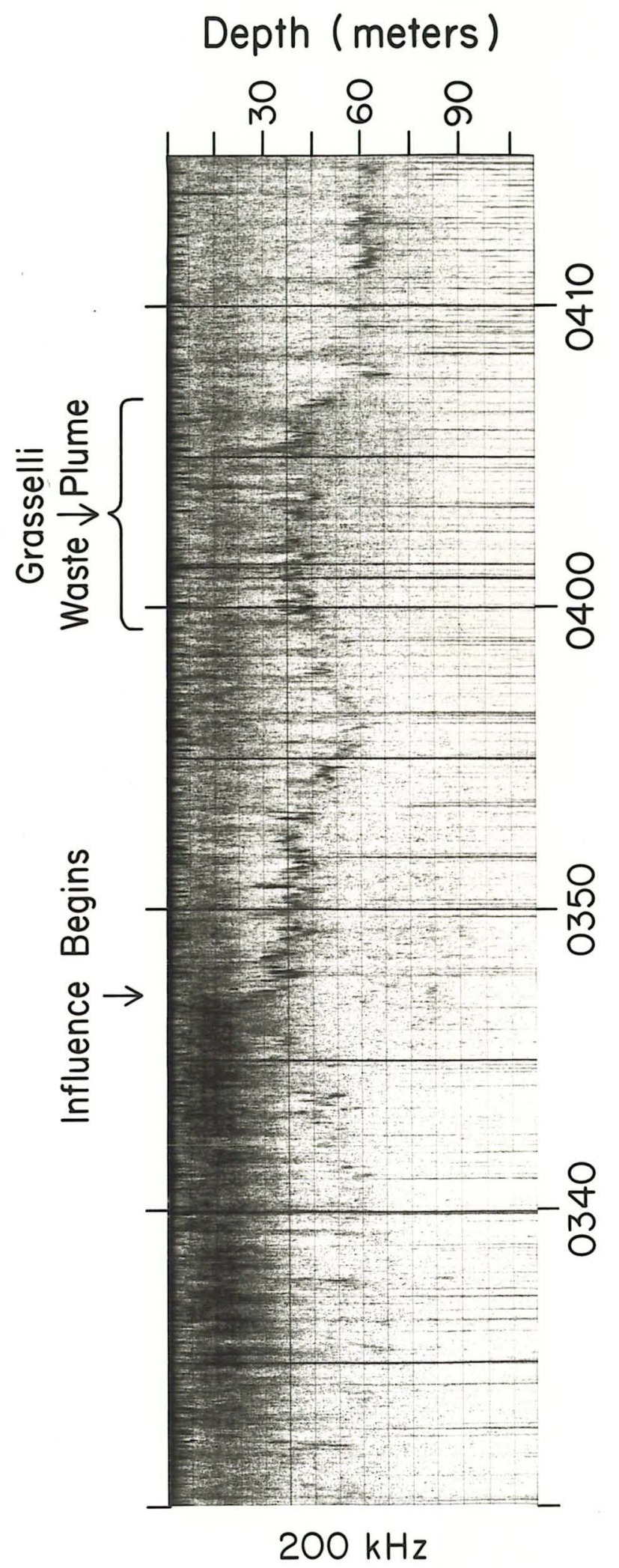

$\tilde{E}$
$\dot{E}$
$\bar{z}$
$\bar{\Sigma}$

$\infty$
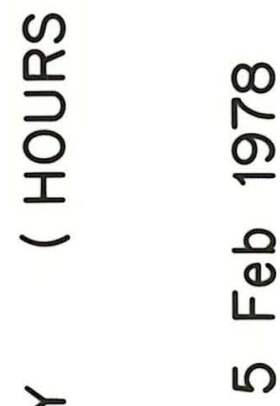

1)

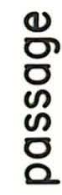

$\stackrel{ }{\circ}$

ฮ์

$\sum$

曰

$\theta$ 屯

0

ก

$\stackrel{\frac{1}{F}}{\frac{2}{\varepsilon}}$

$\frac{m}{\mathbb{1}} \stackrel{0}{\sim}$ 


$$
\begin{aligned}
& \begin{array}{l}
-1 \\
0 \\
0 \\
0 \\
0 \\
0 \\
01 \\
-1 \\
0 \\
-1 \\
0 \\
4 \\
4 \\
0
\end{array} \\
& \text { 崩 } \\
& \begin{array}{l}
0 \\
\infty \\
-1
\end{array}
\end{aligned}
$$$$
\text { U) }
$$$$
\text { E }
$$$$
\begin{aligned}
& 1 \\
& 5 \\
& 0 \\
& 0
\end{aligned}
$$$$
+
$$$$
\text { م }
$$$$
\text { 10 }
$$$$
\text { मे }
$$$$
\text { 苟 }
$$ 


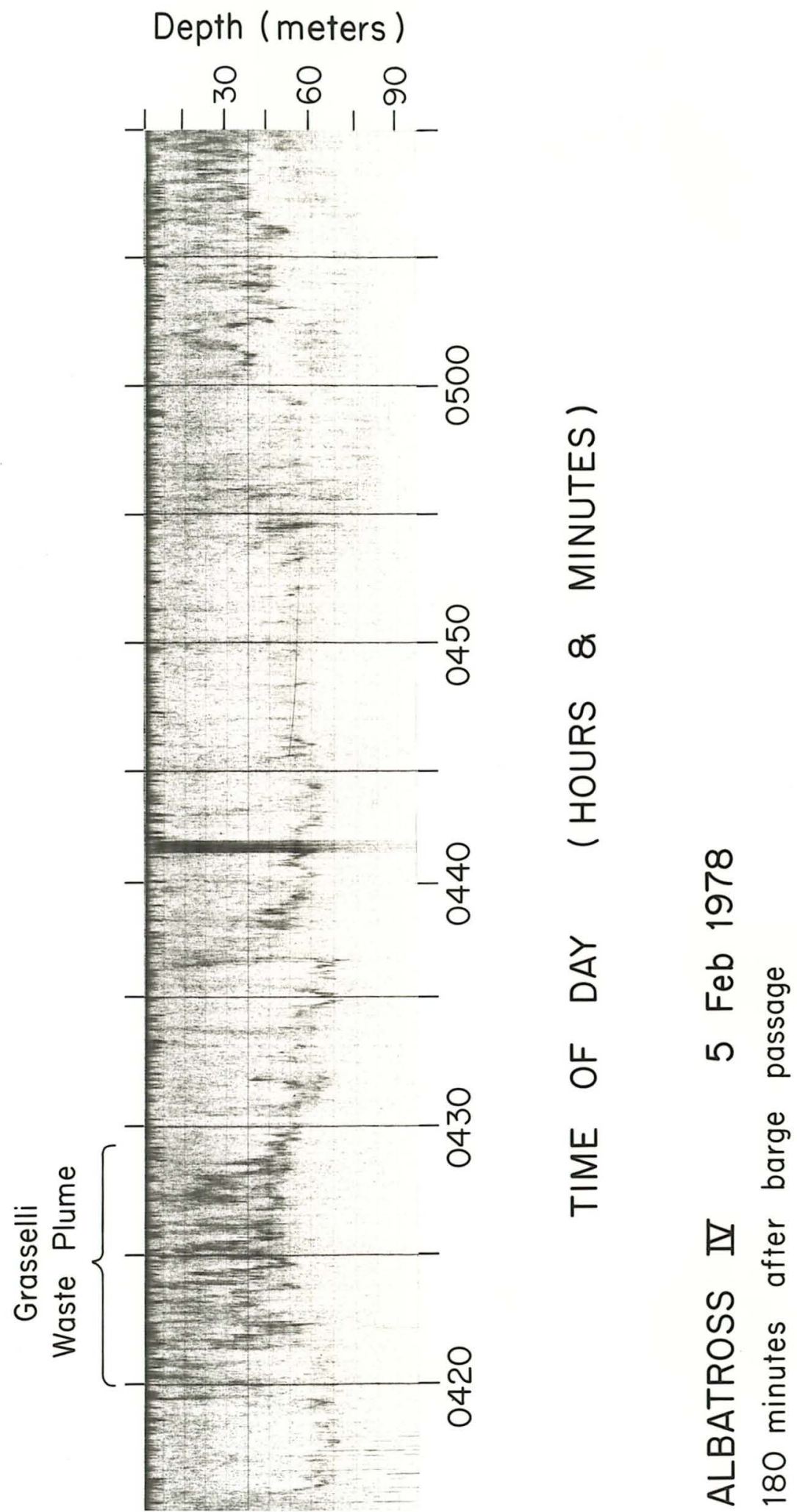

$200 \mathrm{kHz}$ 


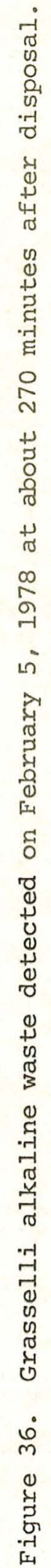




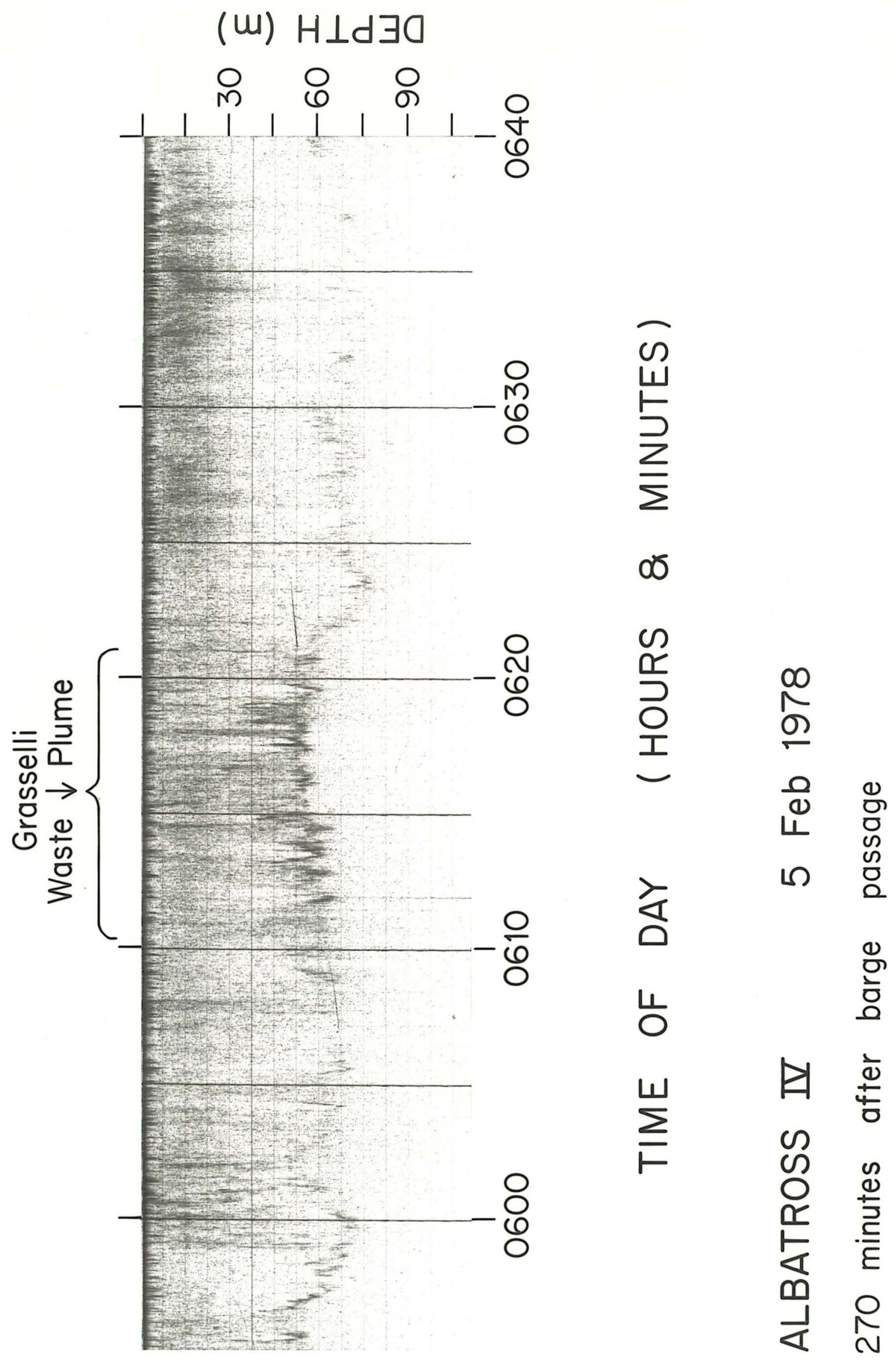


$\frac{1}{3}$
$\vdots$
0
0
0
$\frac{1}{5}$
$\frac{1}{3}$

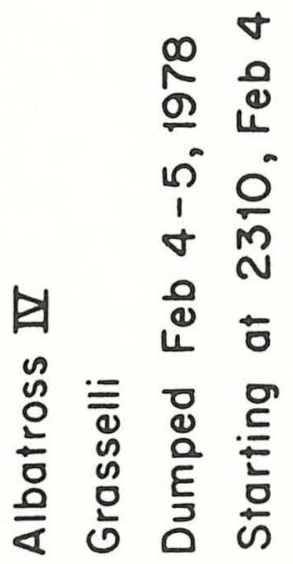

도

装

羟

उ्ञ

(1)

प)

$\stackrel{0}{0}$

क्ष

i

$\rightarrow 1$

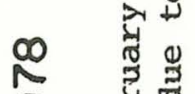

O

요 约

4.

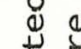

कृ

है

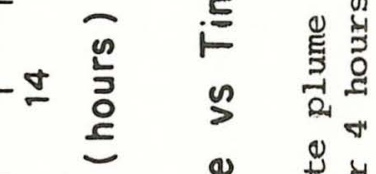

-

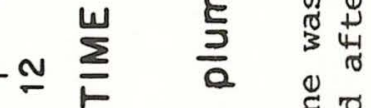

○ ब छ

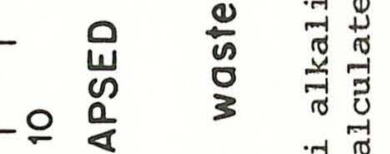

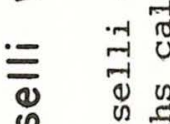

क क

인 过

๘

$\frac{5}{5}$
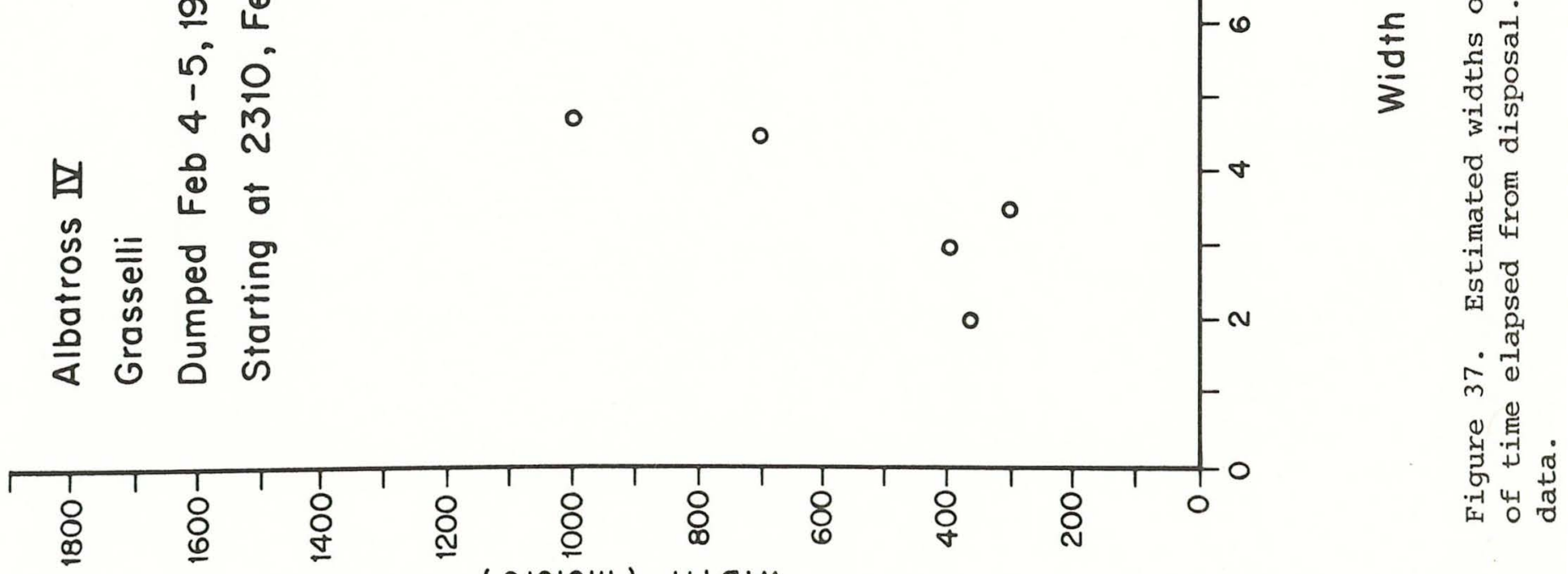


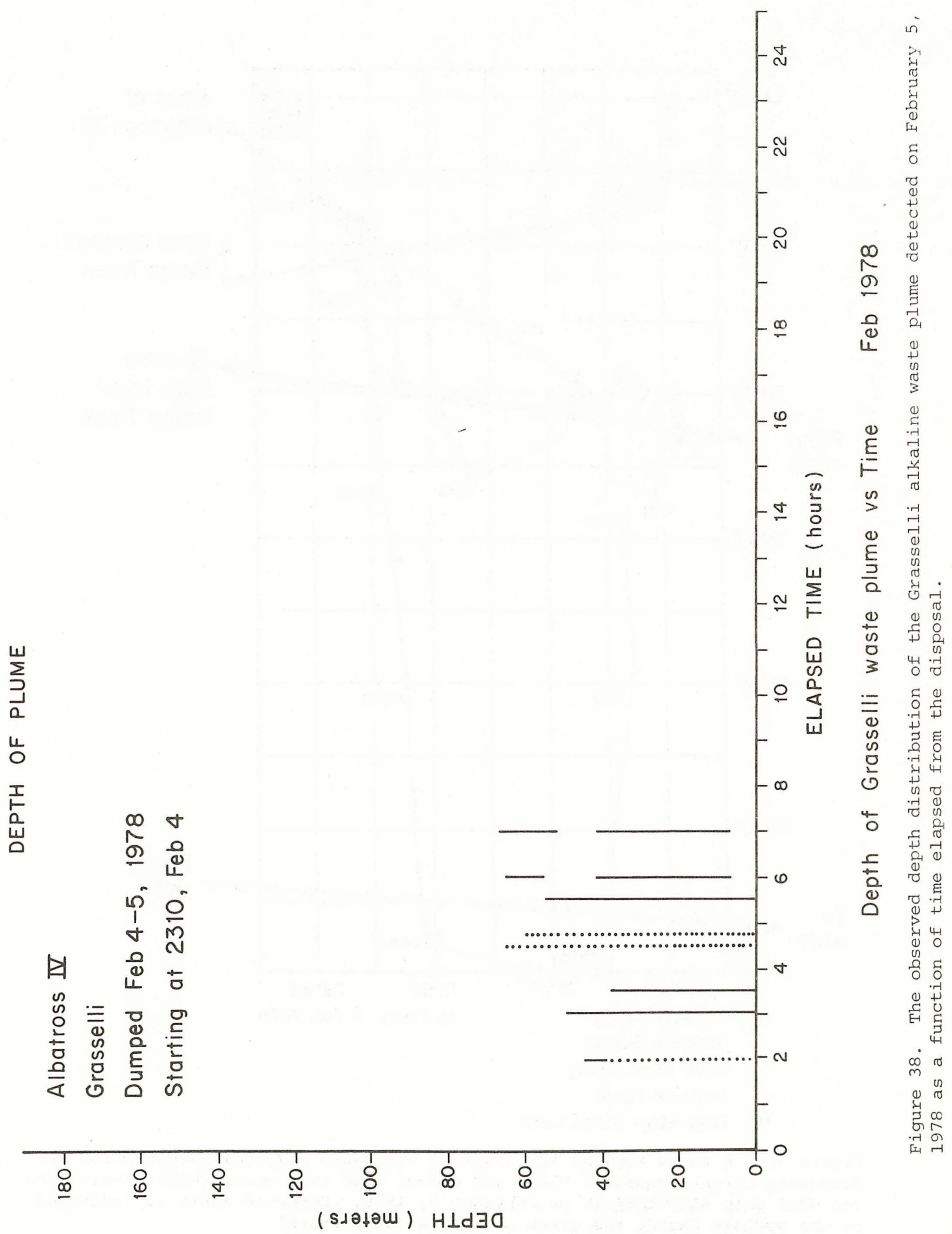


TRACK OF MT MITCHELL ON 10-11 APRIL 1978

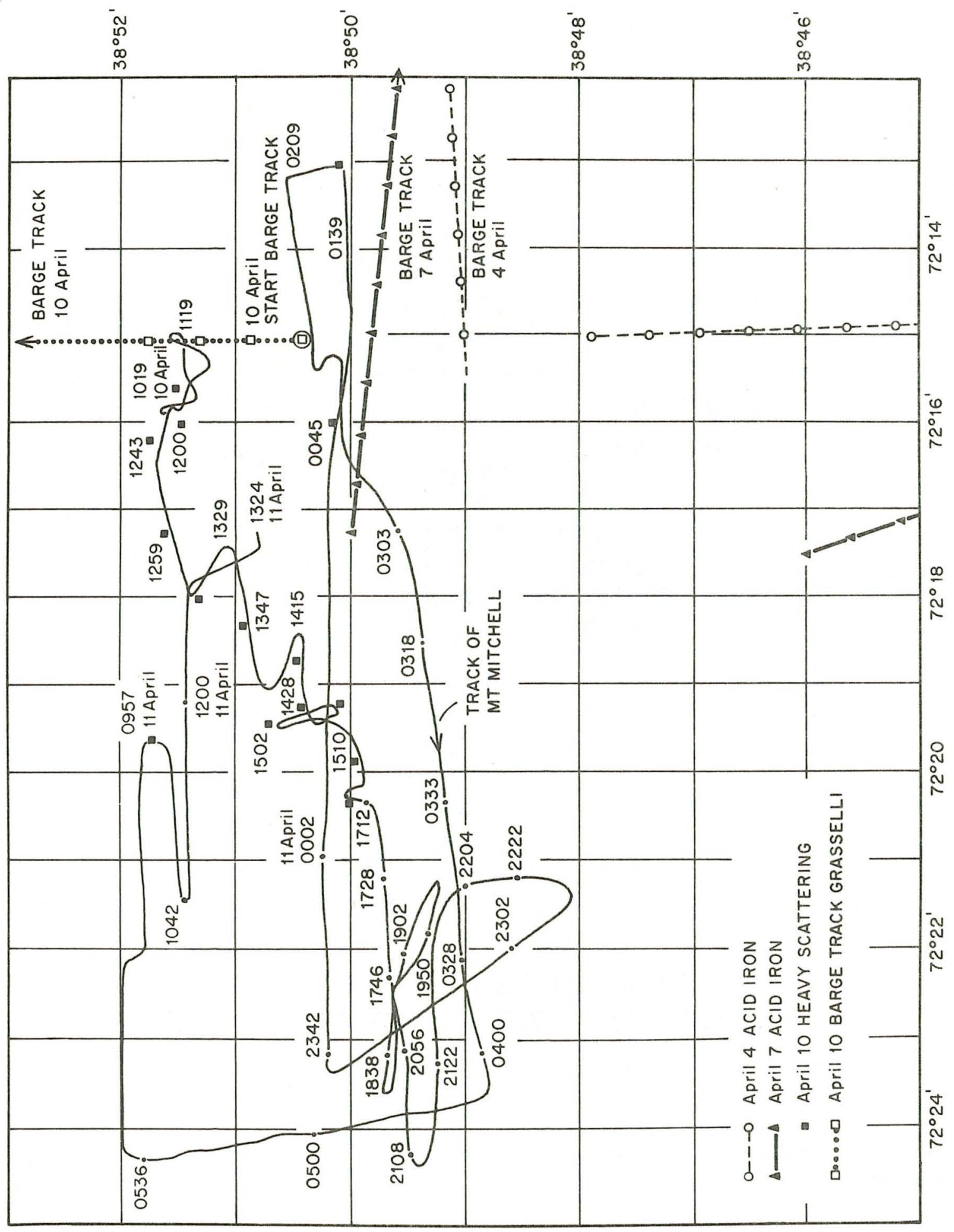

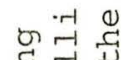

द -1

至 on

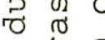

w 냉 द्व

䨔

U

3 号

त्

U $4-10$

है 0 .

(1) ज

0 .

न

-

+ O

गे है

兵岳

4

0 द 0

必㐘寻

些管

$>$ 告

๘

व

U

\%

1)

()

ज 람

(1) $4-1$

莒皆

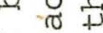

प्स प्र

U 11

瓷焉兘

每. 兵

(1)

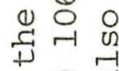

。菅

落 U

管

ข 10

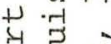

던 다음

0

《

की

-i -1 更

ه

(4) 品0

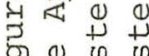




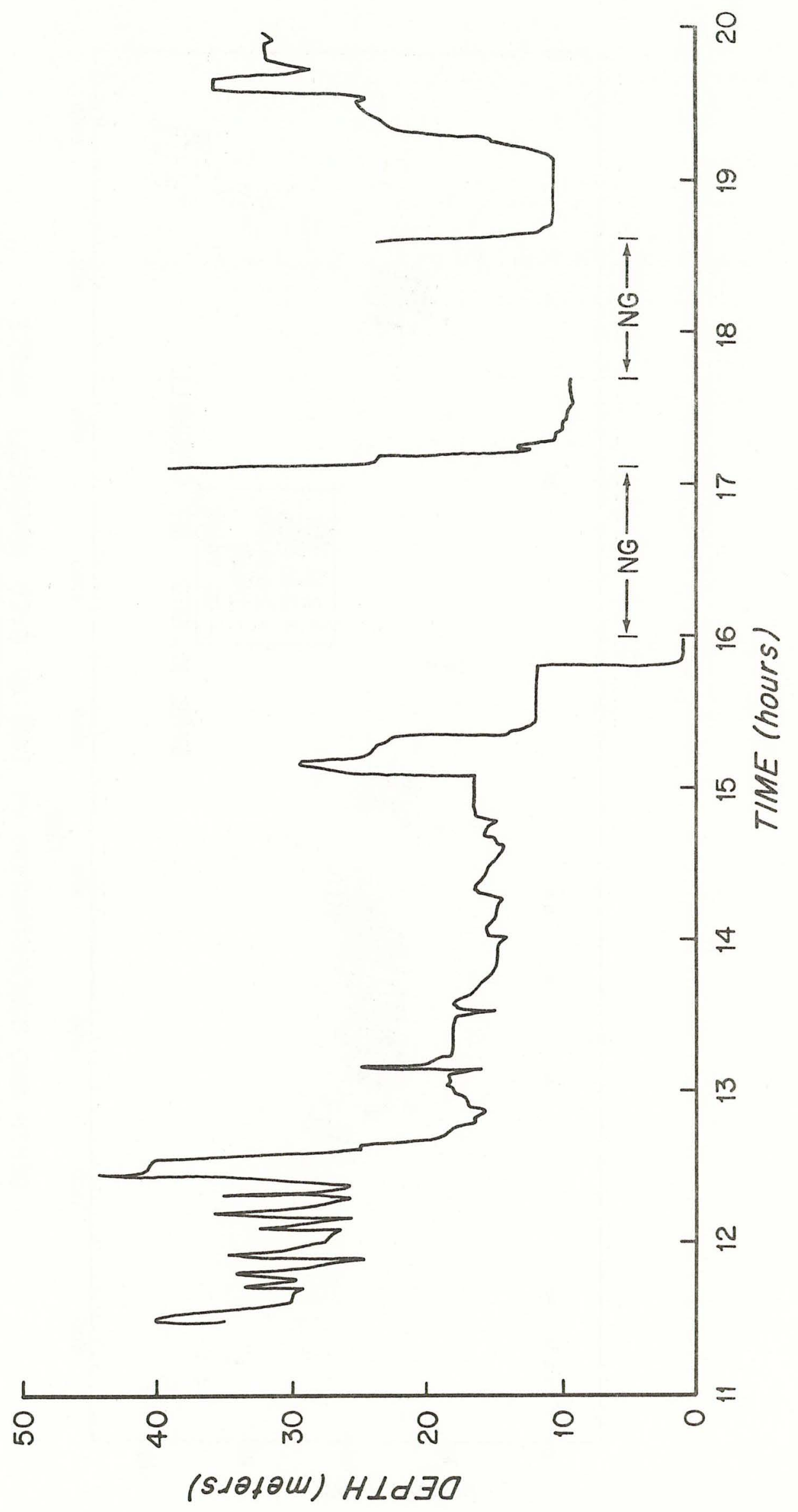




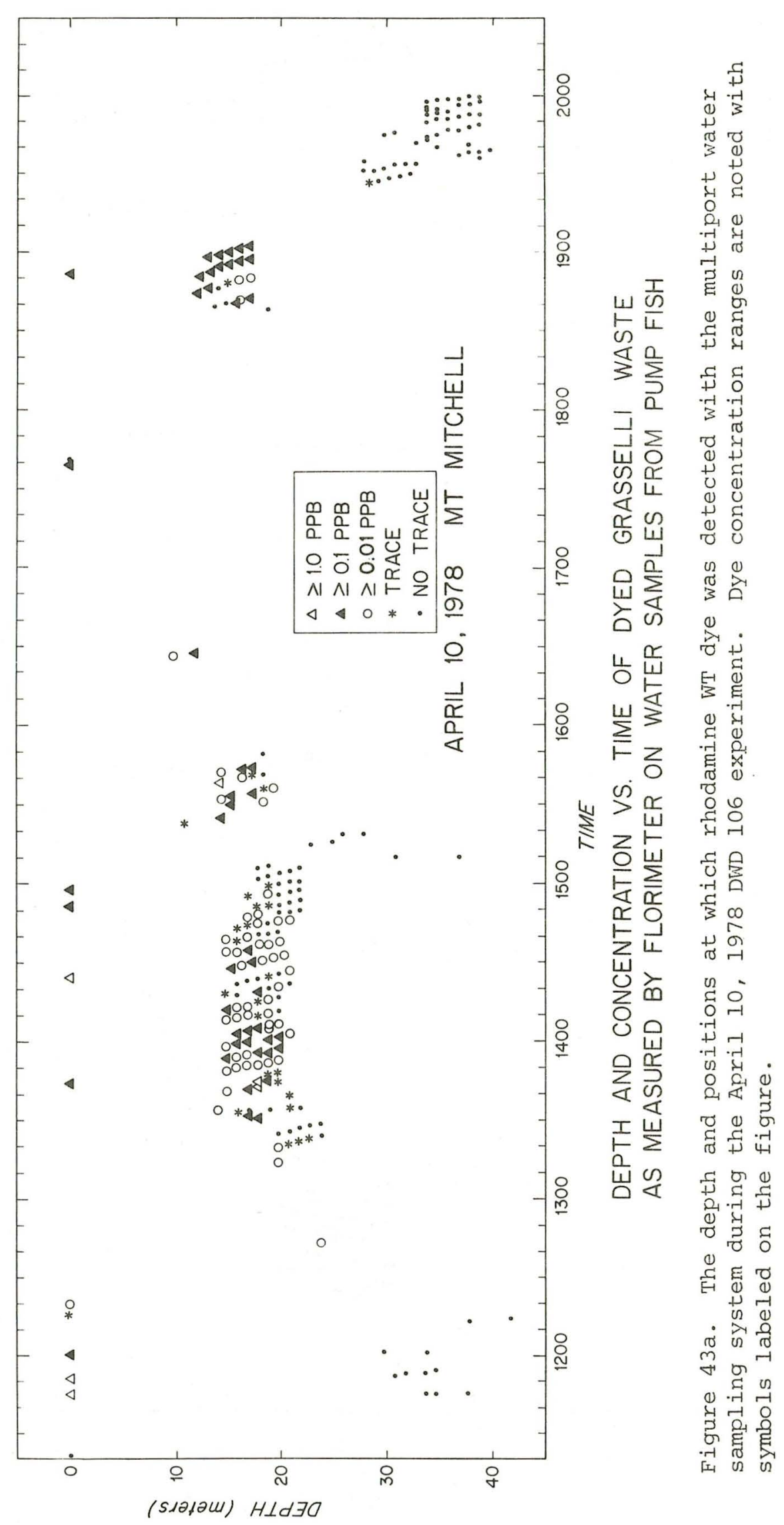



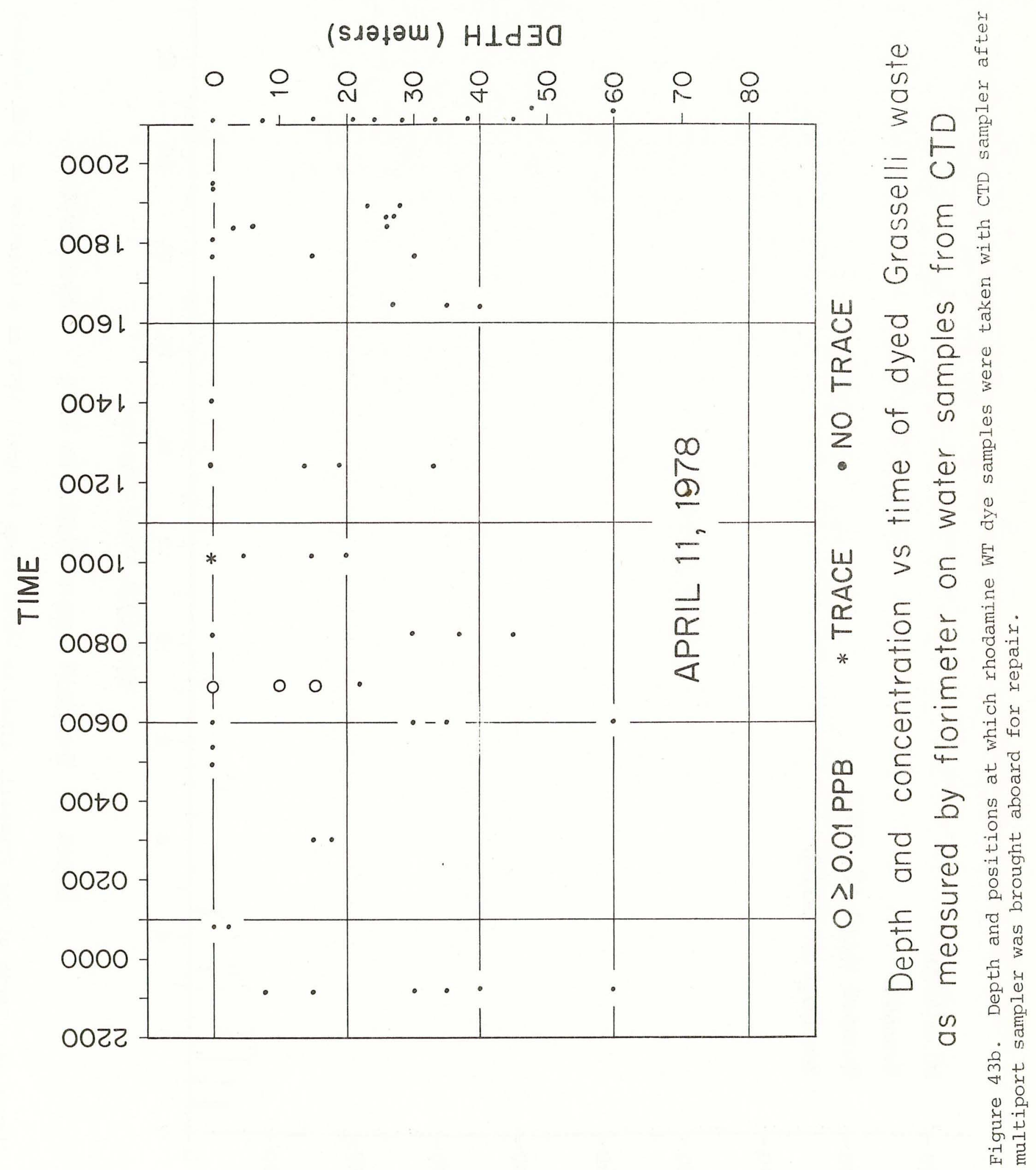

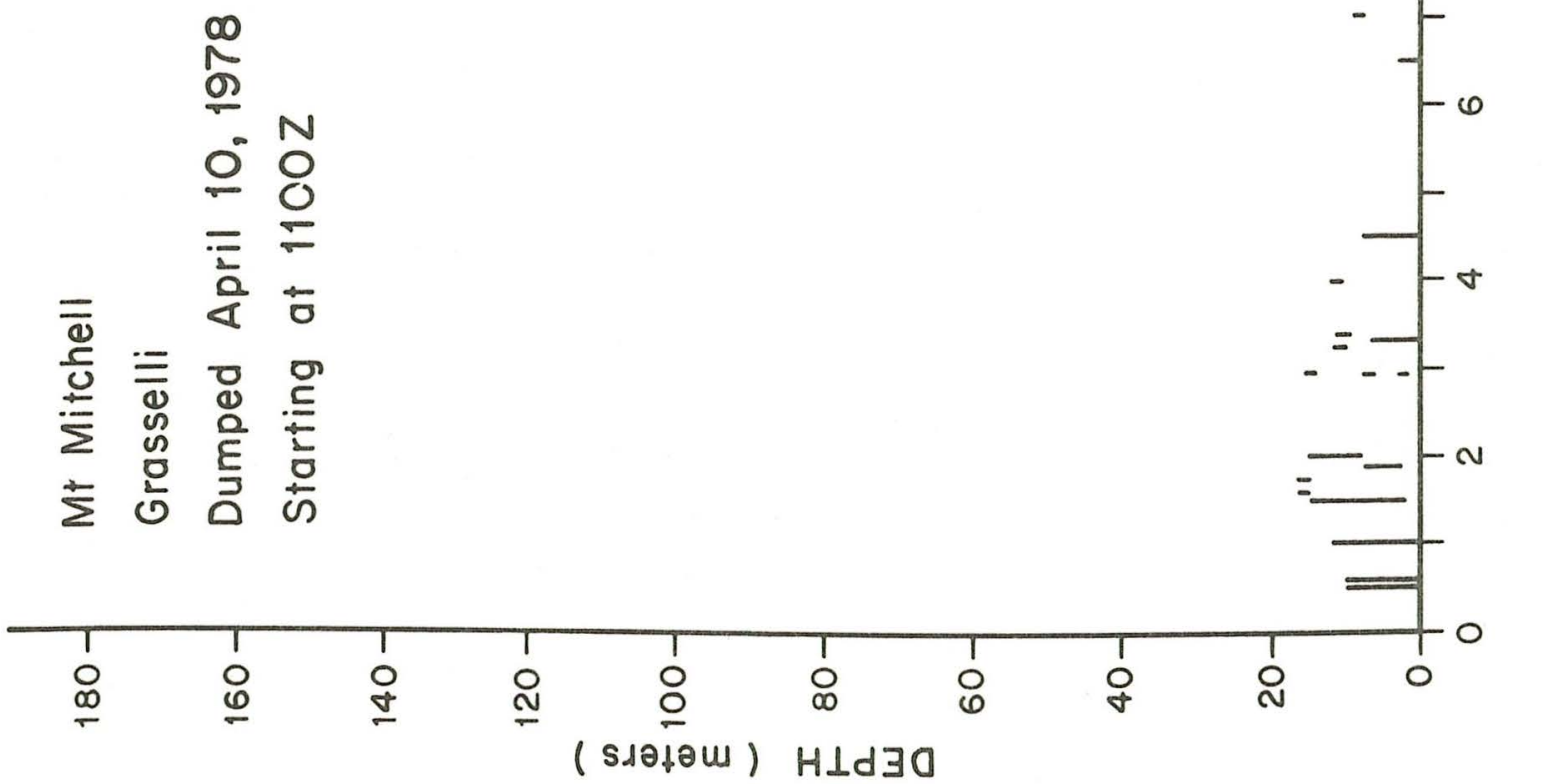

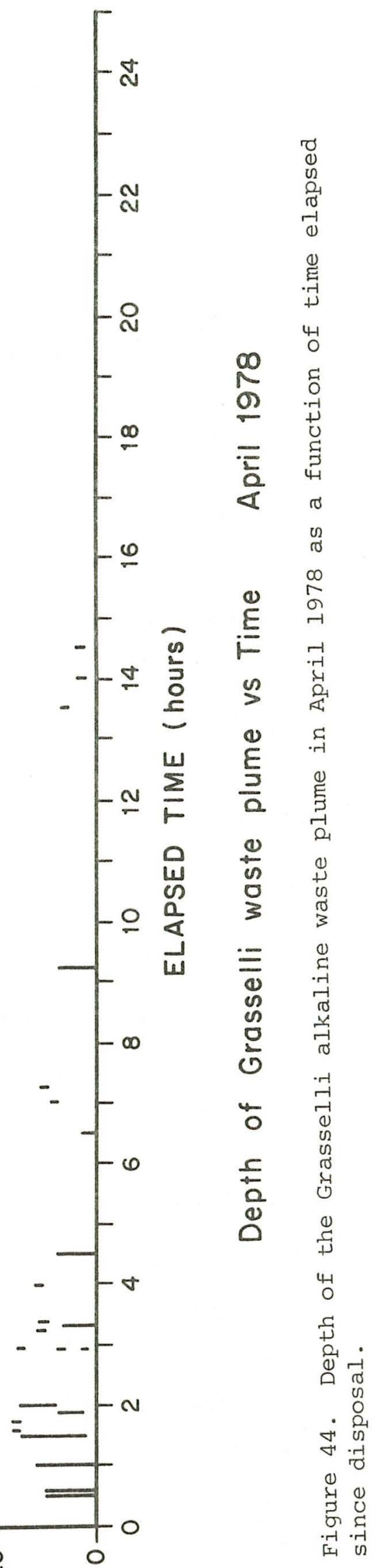


$\perp 0$

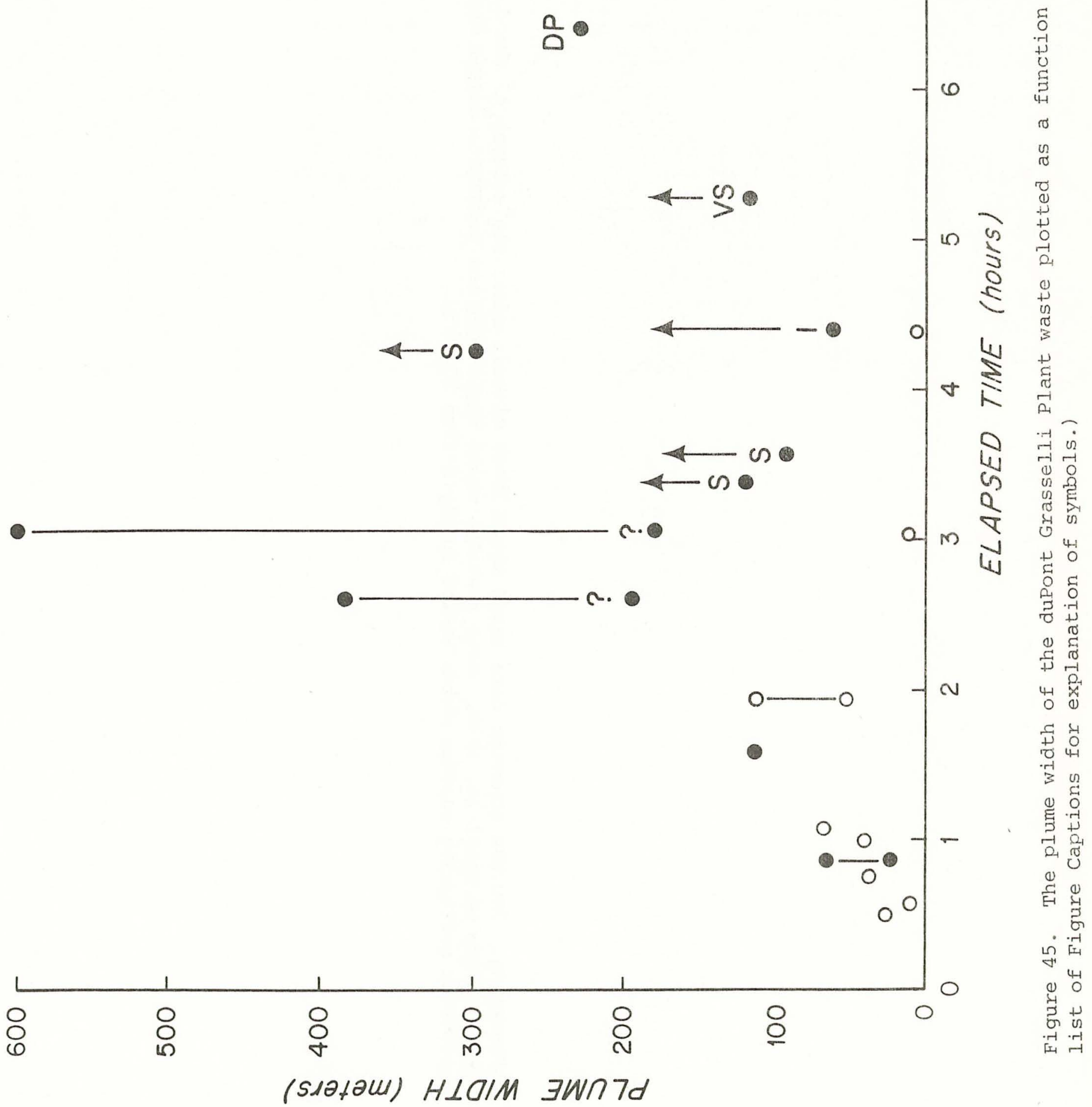




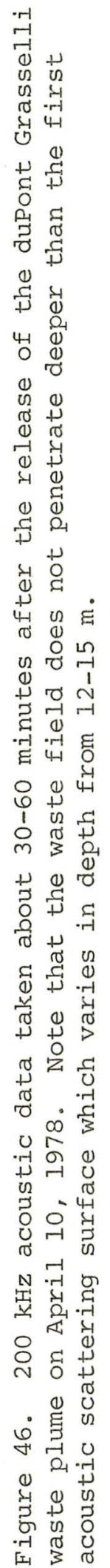


Crossings

of

Grasselli

Plume

Time

Elapsed

From

Barge

Passage as

noted
Depth (meters)

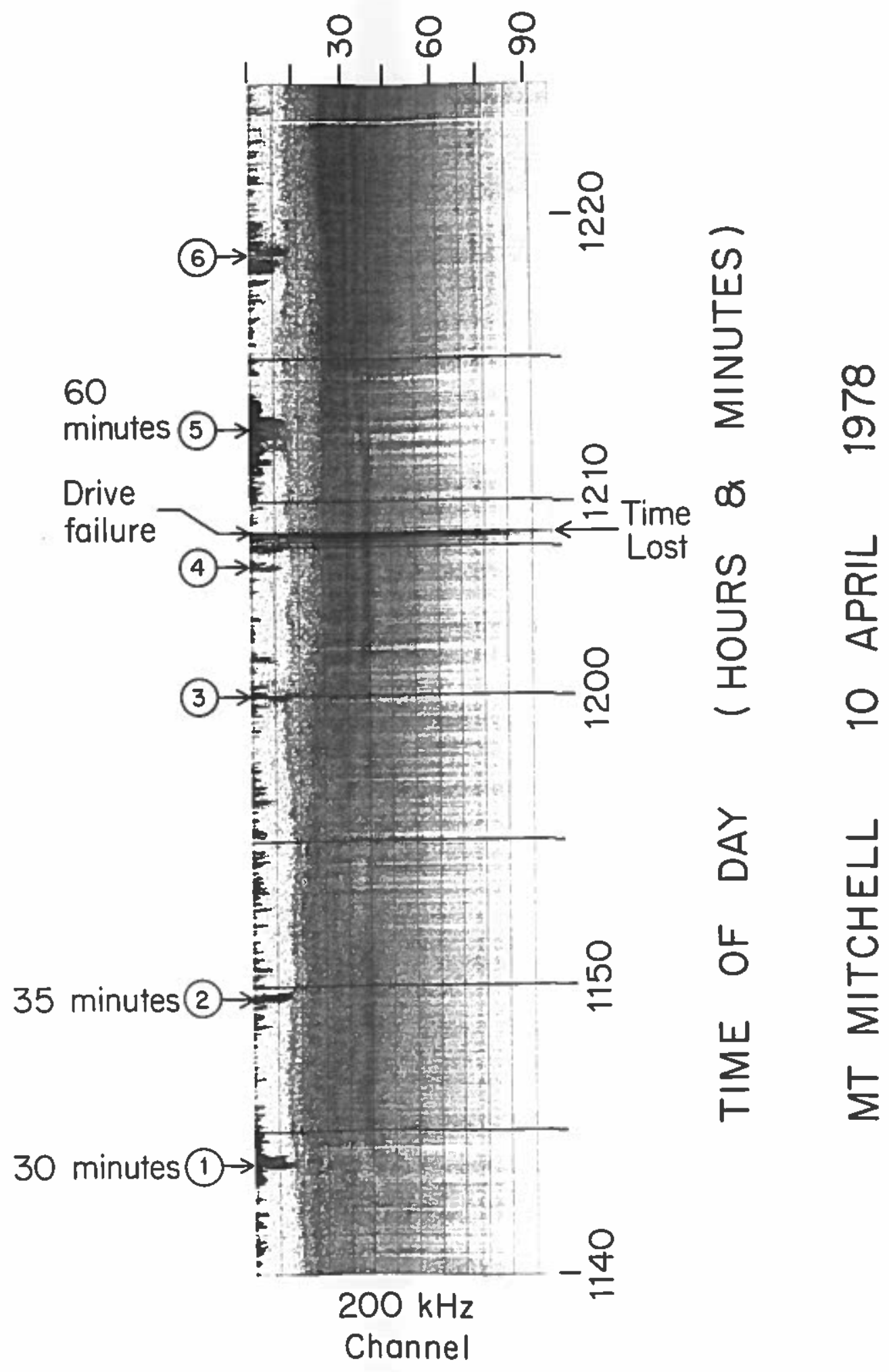




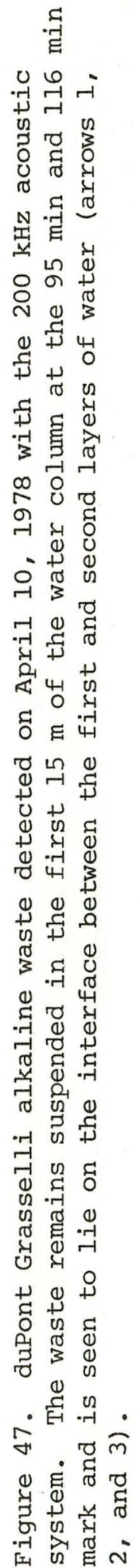


Crossings

of

Plume

Time

Elapsed

From

Barge

Passage

as

noted

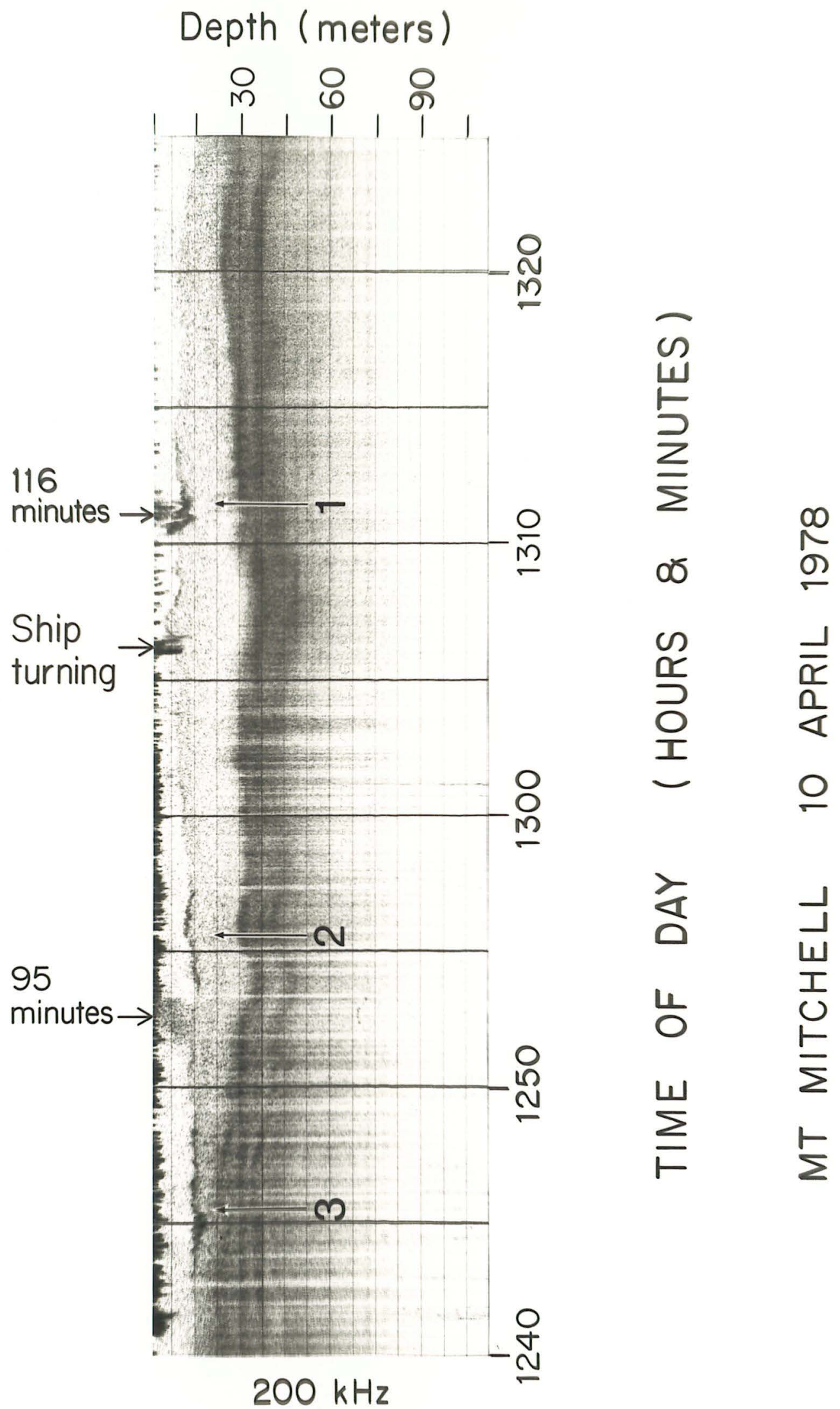




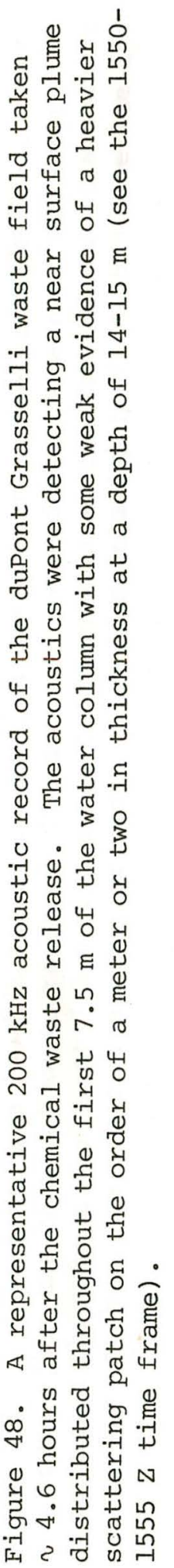




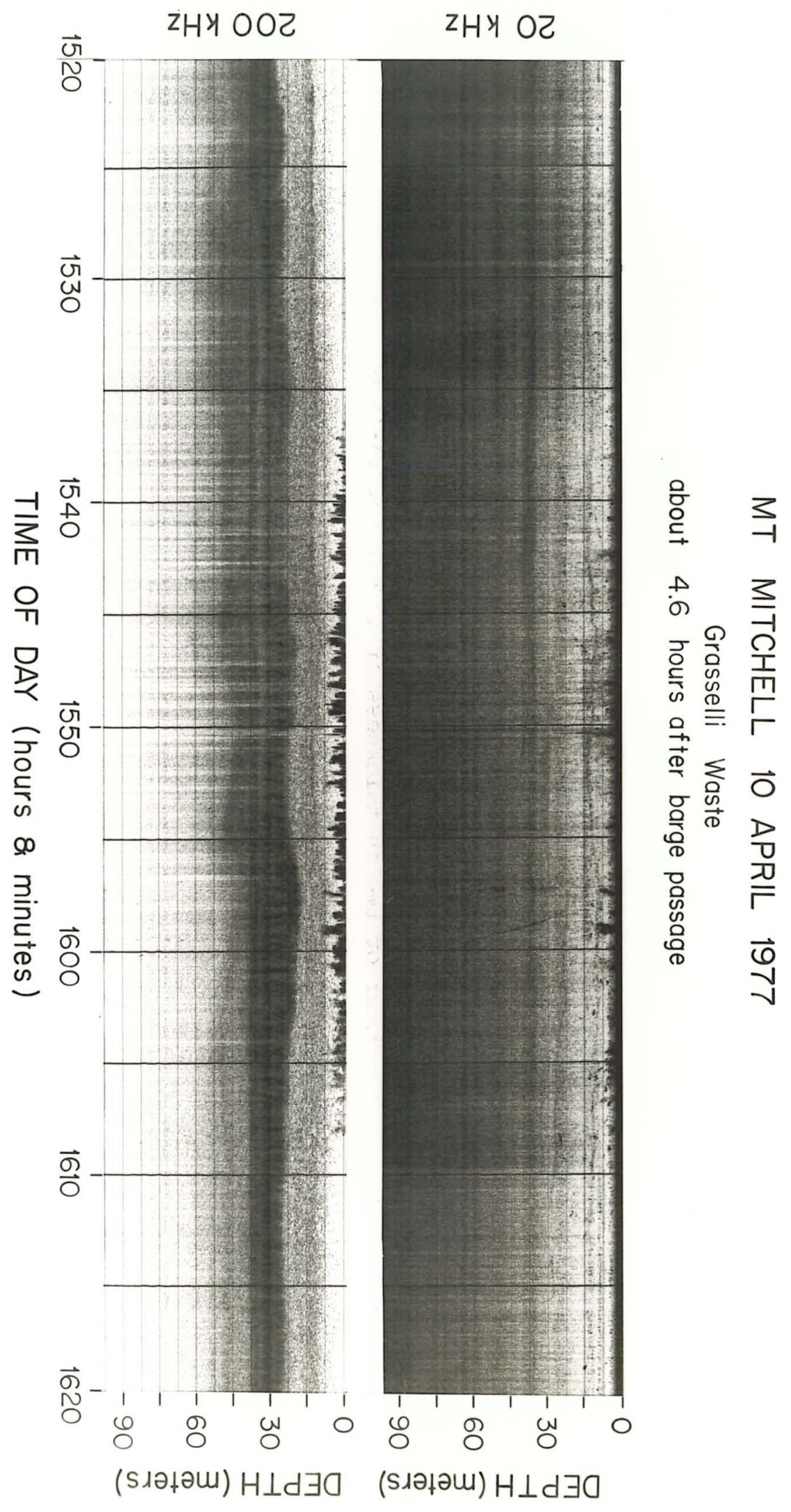




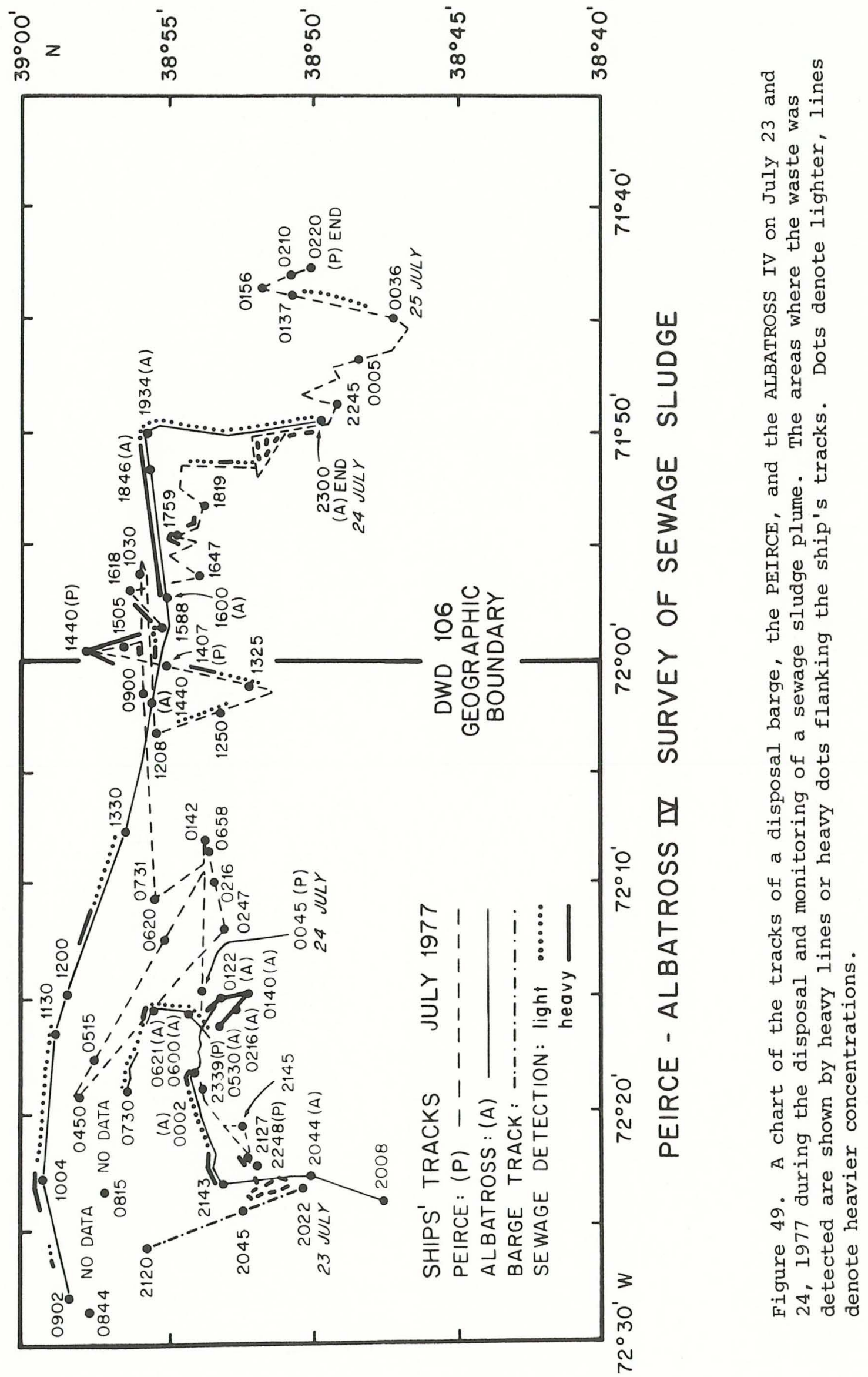




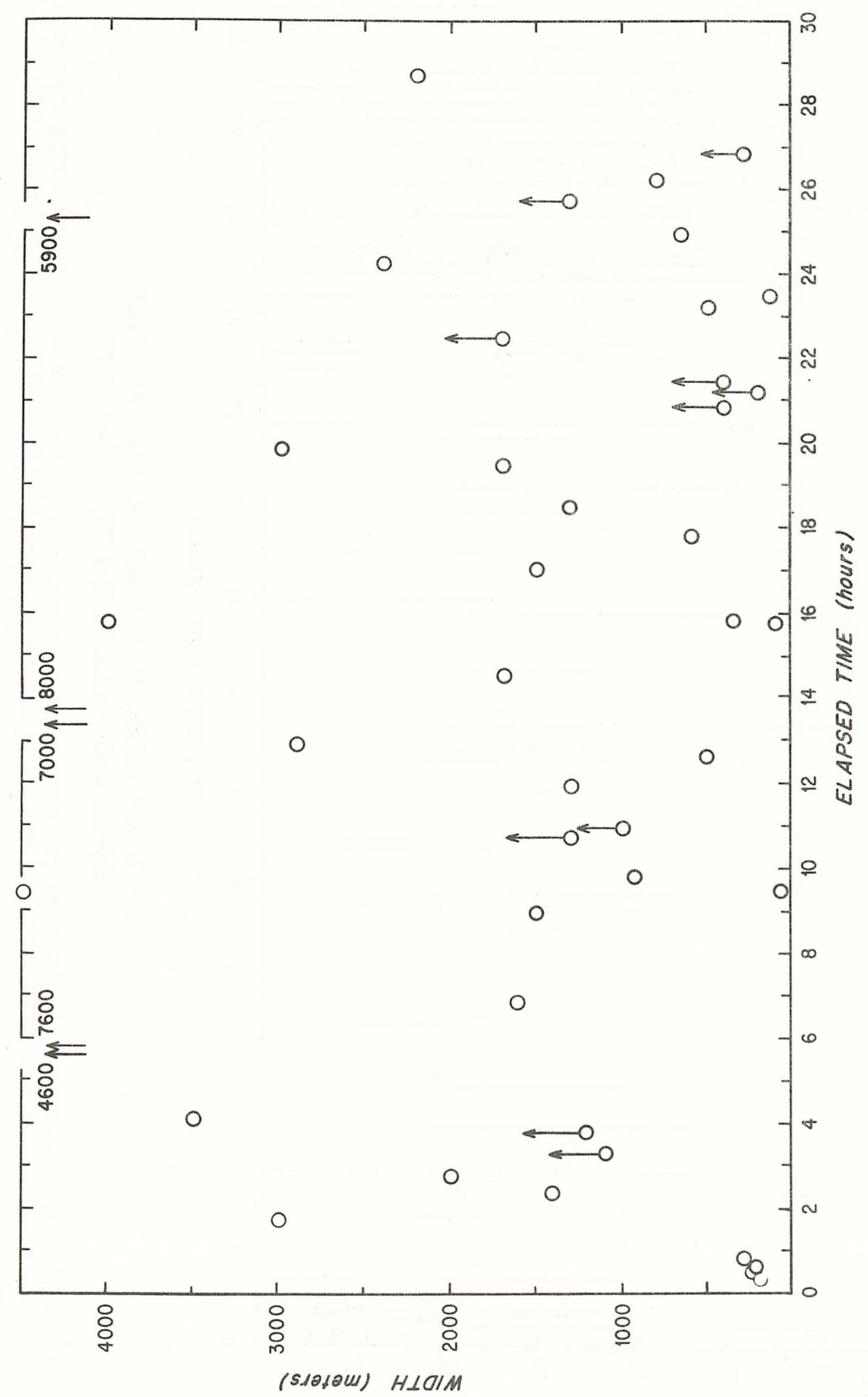

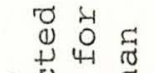

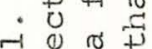

का

की

$880 \%$

क व

-

(1) त्व $r-1$ क क

0 व

.

(1) $\begin{array}{r}4 \\ 4-1\end{array}$

ช 30

(1) 0

사 $\Rightarrow$

(1) मे

$7+$

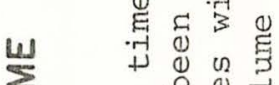

$\geqq \wedge \quad 4.000$

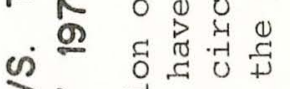

$>>$ 年记

w

द्य

व $>0$

a.

of ${ }_{1}+10$

एक त

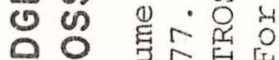

还

क年为

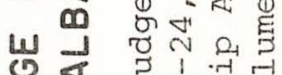

< ${ }_{01} m{ }^{-1}$

虫

पर 2 थ

实舟市

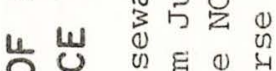

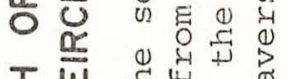

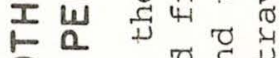

प वृ

○皆岳焉

प्र 4

-

3 in 0

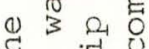

स

है

出点匹

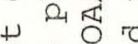

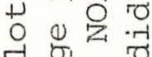

वा ने व

《诂近

- ब द्र

$\circ$ O 0 o ro

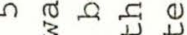

(1) 0

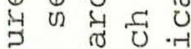

का 0 \%

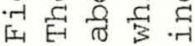




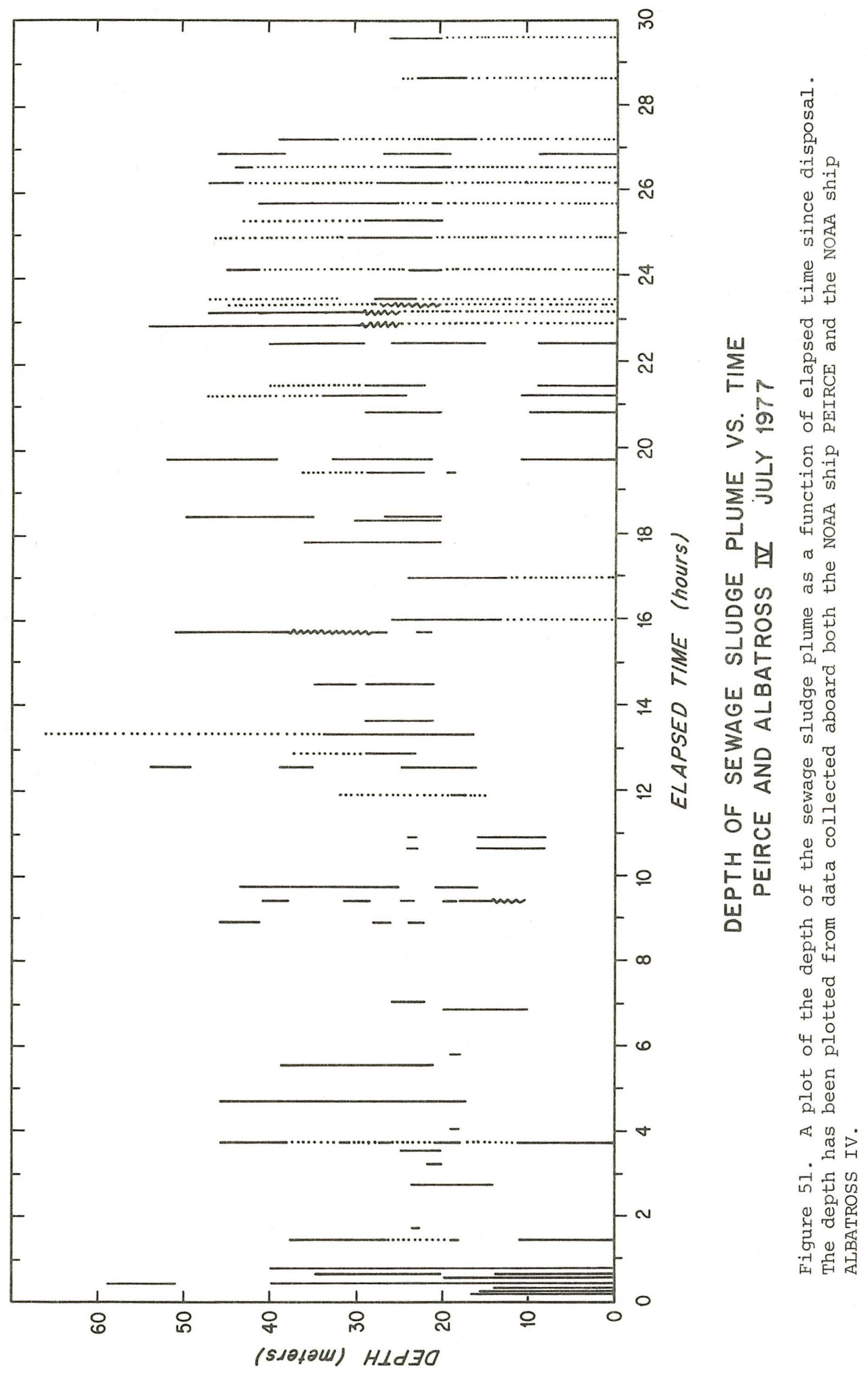


$122 a$

Blank 


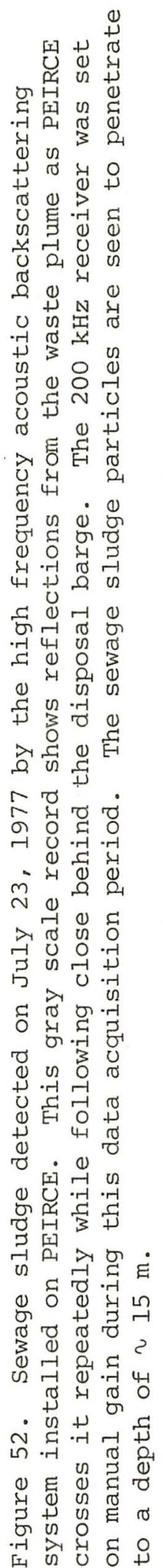




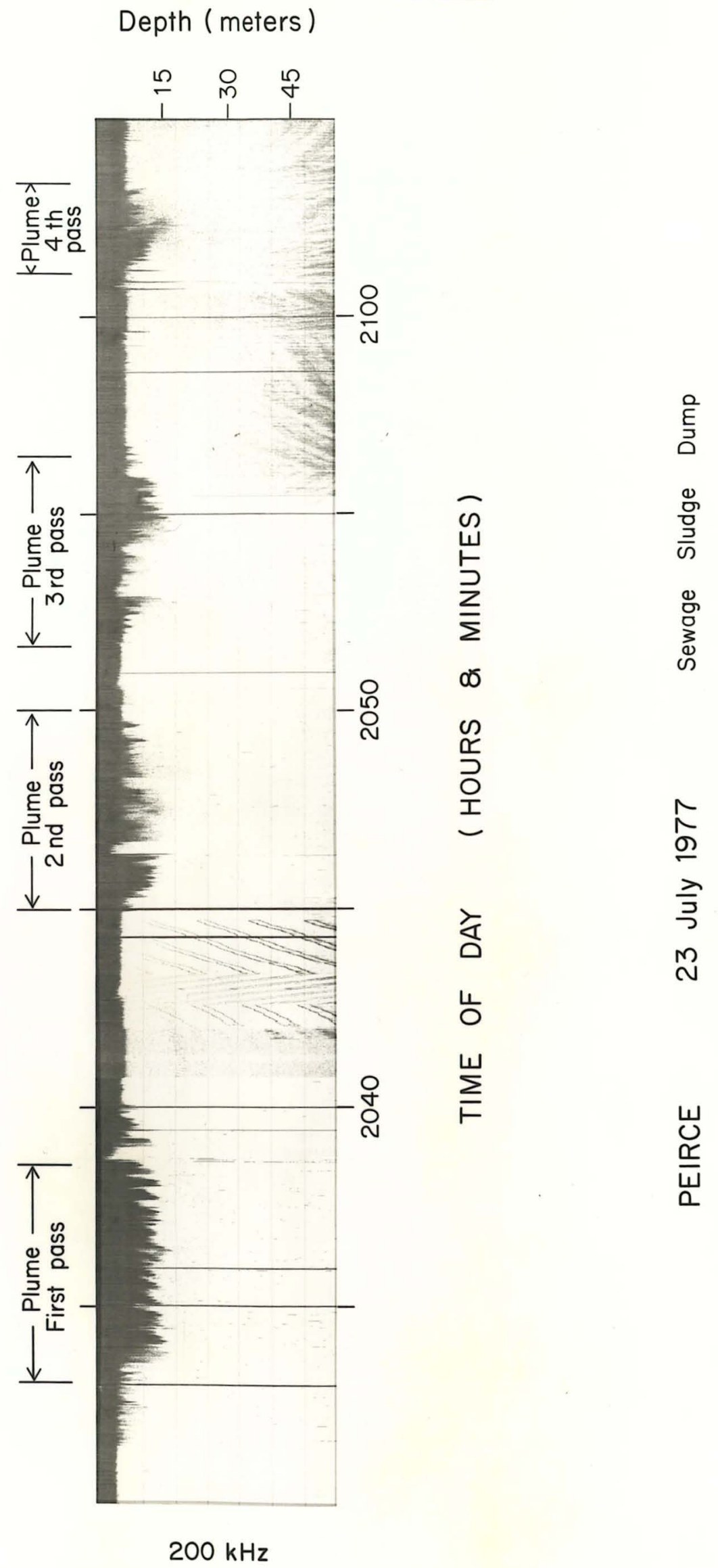




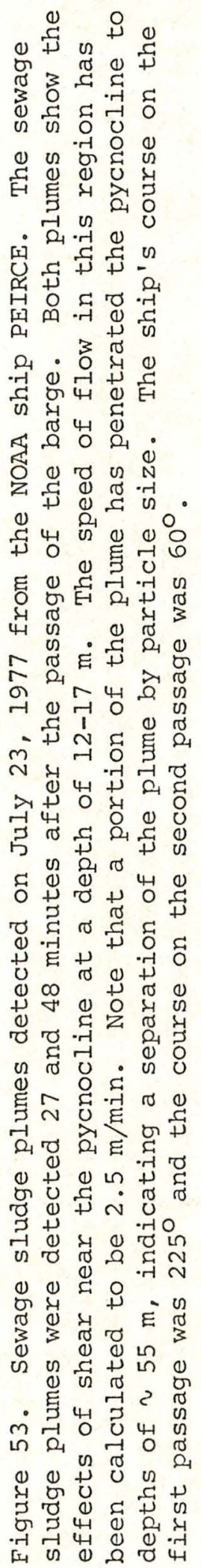




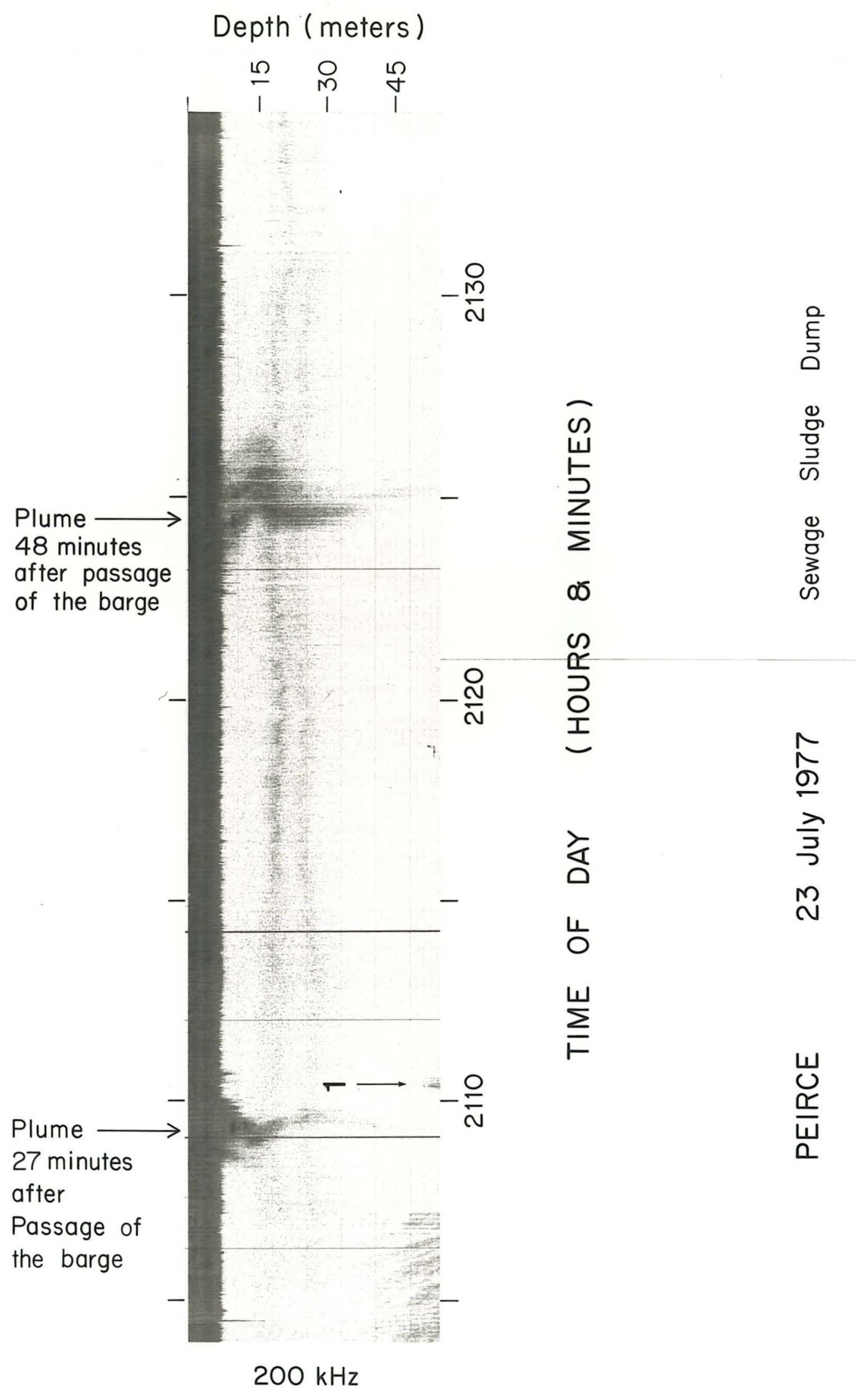


A.

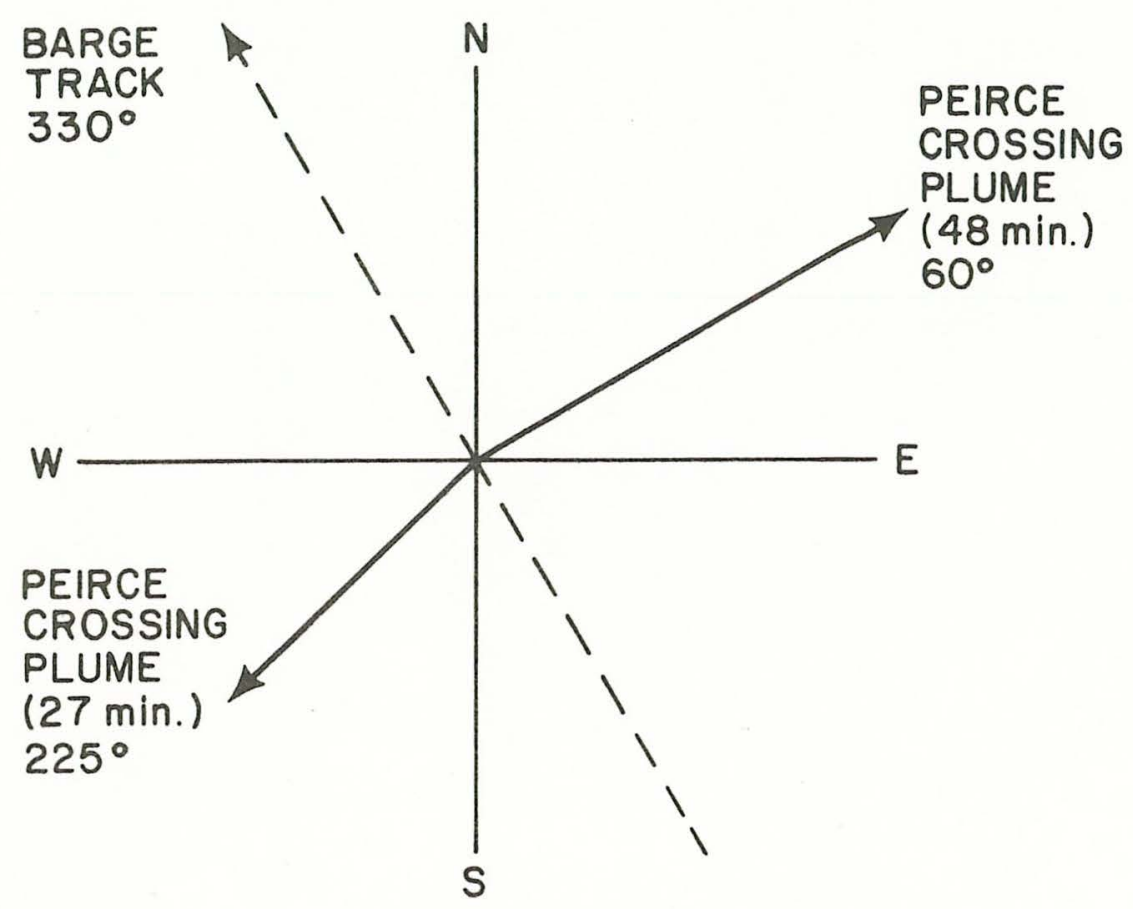

B.

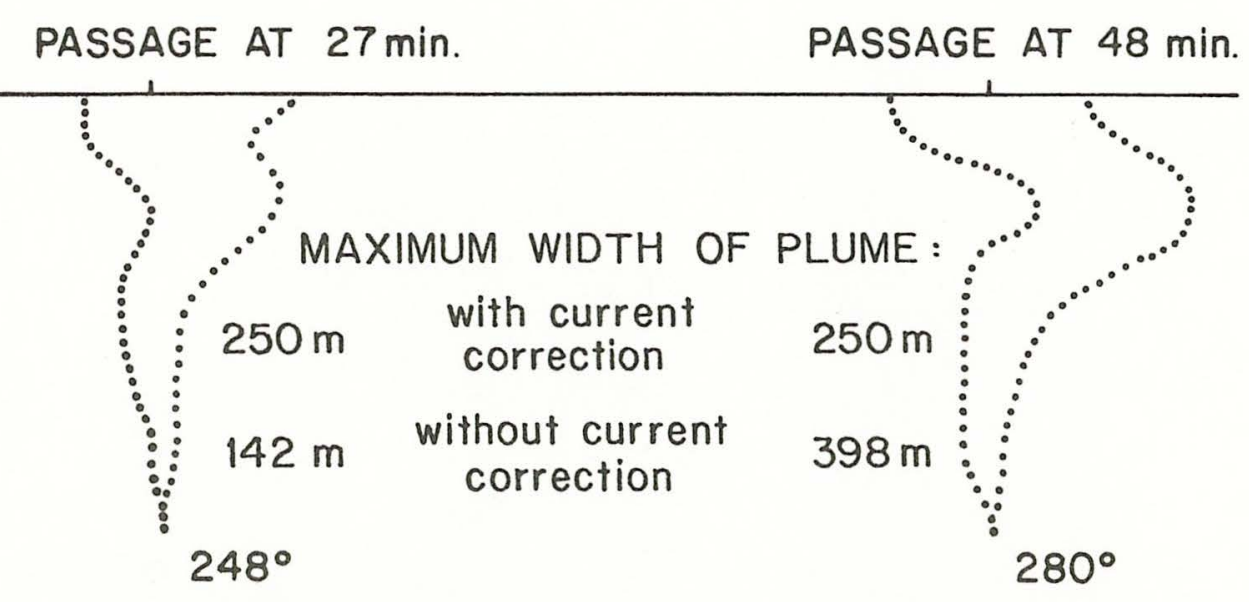

\section{THE APPROXIMATE SHAPE OF THE PLUME IN THE DIRECTION OF $\approx 050^{\circ}$}

Figure 54a. A sketch of the motion of the NOAA ship PEIRCE during the two crossings of the sewage sludge plume depicted in Figure 53. The direction of the barge motion is also indicated.

Figure 54b. The approximate shape of the two sewage sludge plumes in the direction of $\sim 050^{\circ}$. The calculated width of the plume both with and without the use of an estimated mean current of $\sim .875 \mathrm{~m} / \mathrm{s}$ is shown in the figure. The need for accurate current and shear measurements during these experiments is pointed out by the large variability in estimated plume size. 


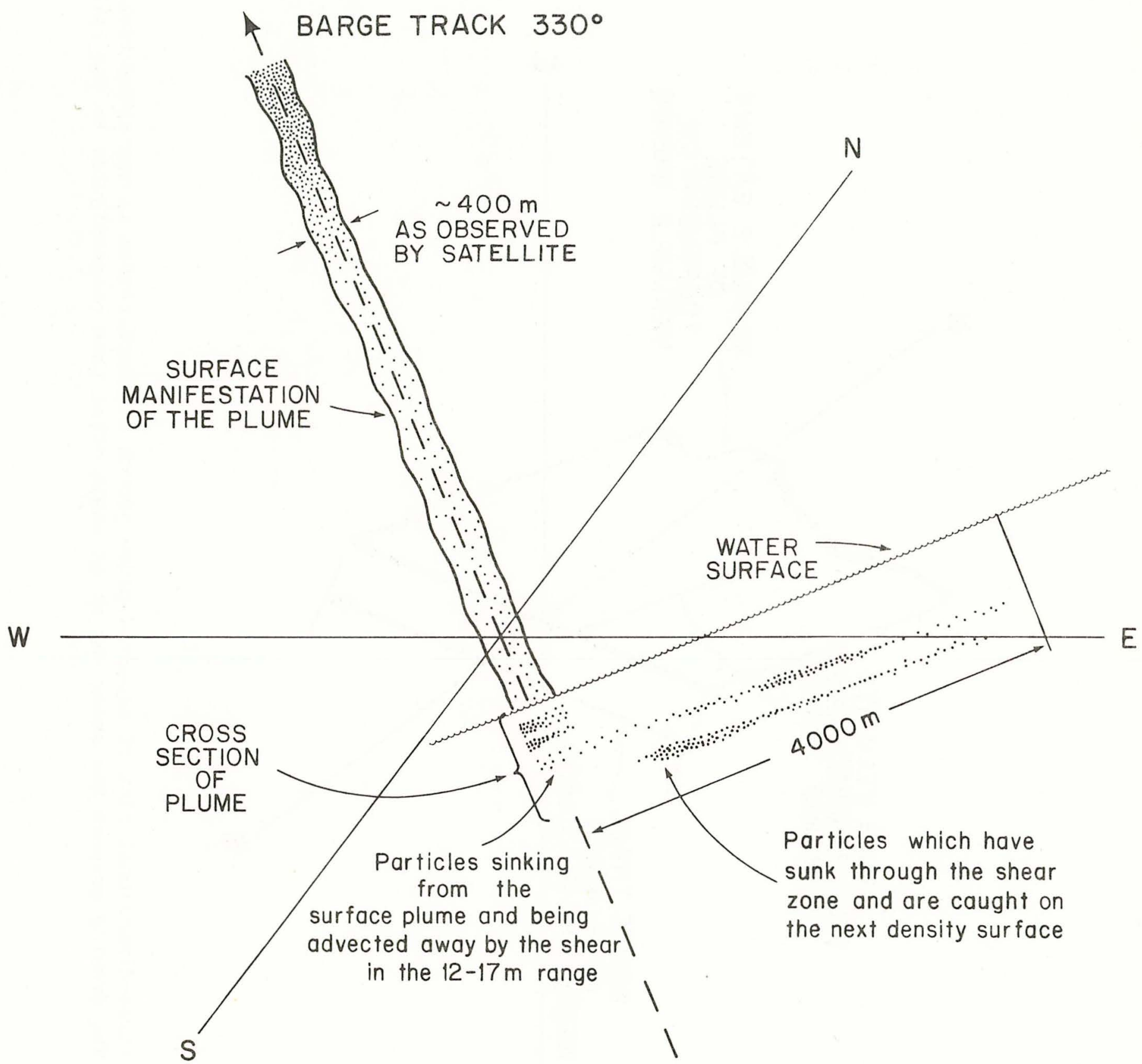

Figure 54c. A three-dimensional plot of expected plume growth characteristics in the shear field which was acoustically detected during the sewage sludge disposal. The drawing assumes that the shear was perpendicular to the barge track 


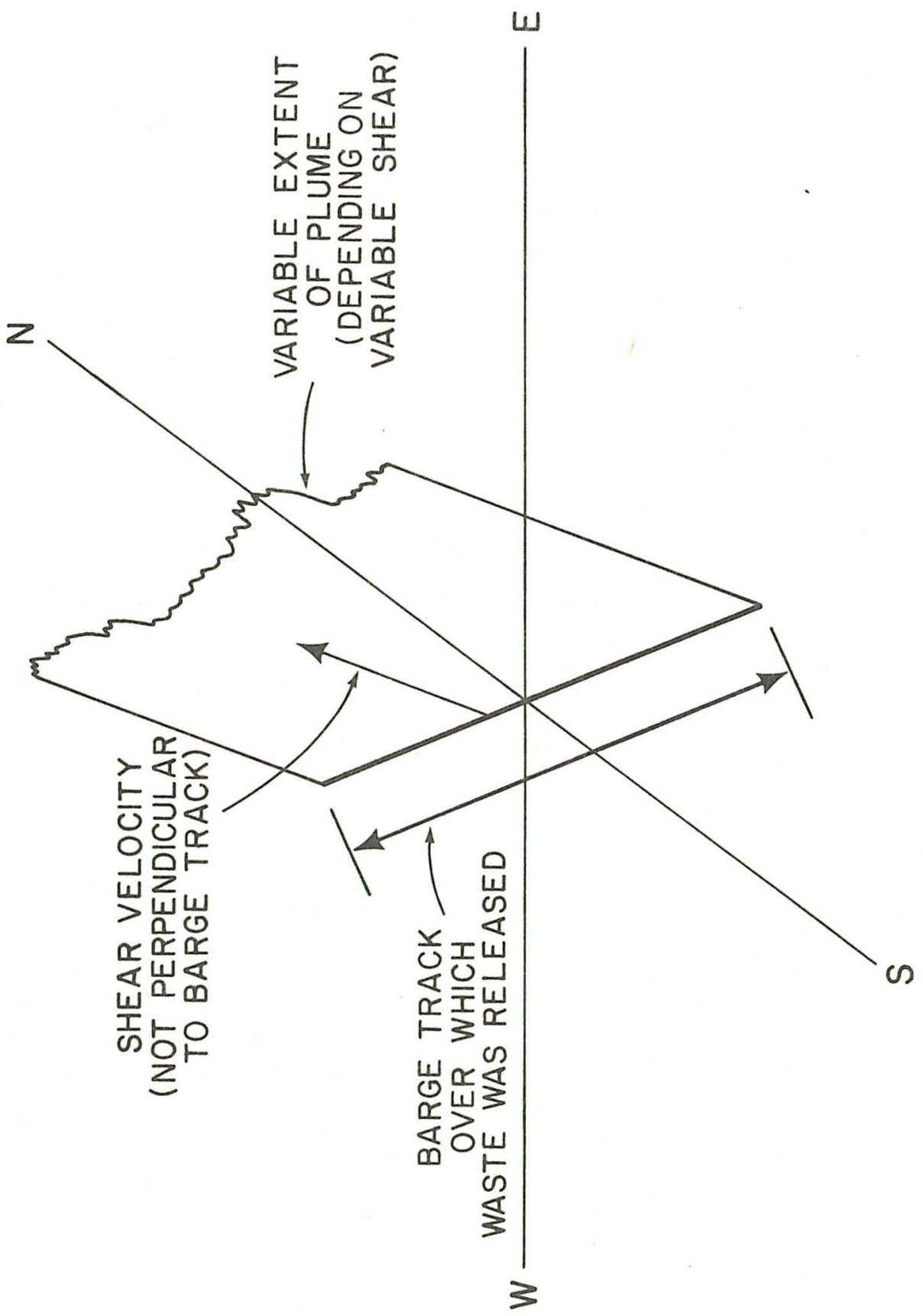

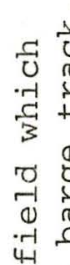


Blank 


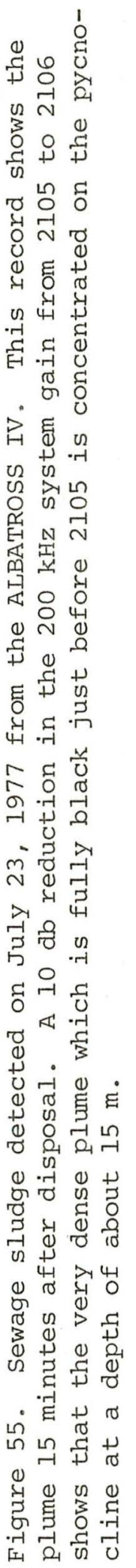




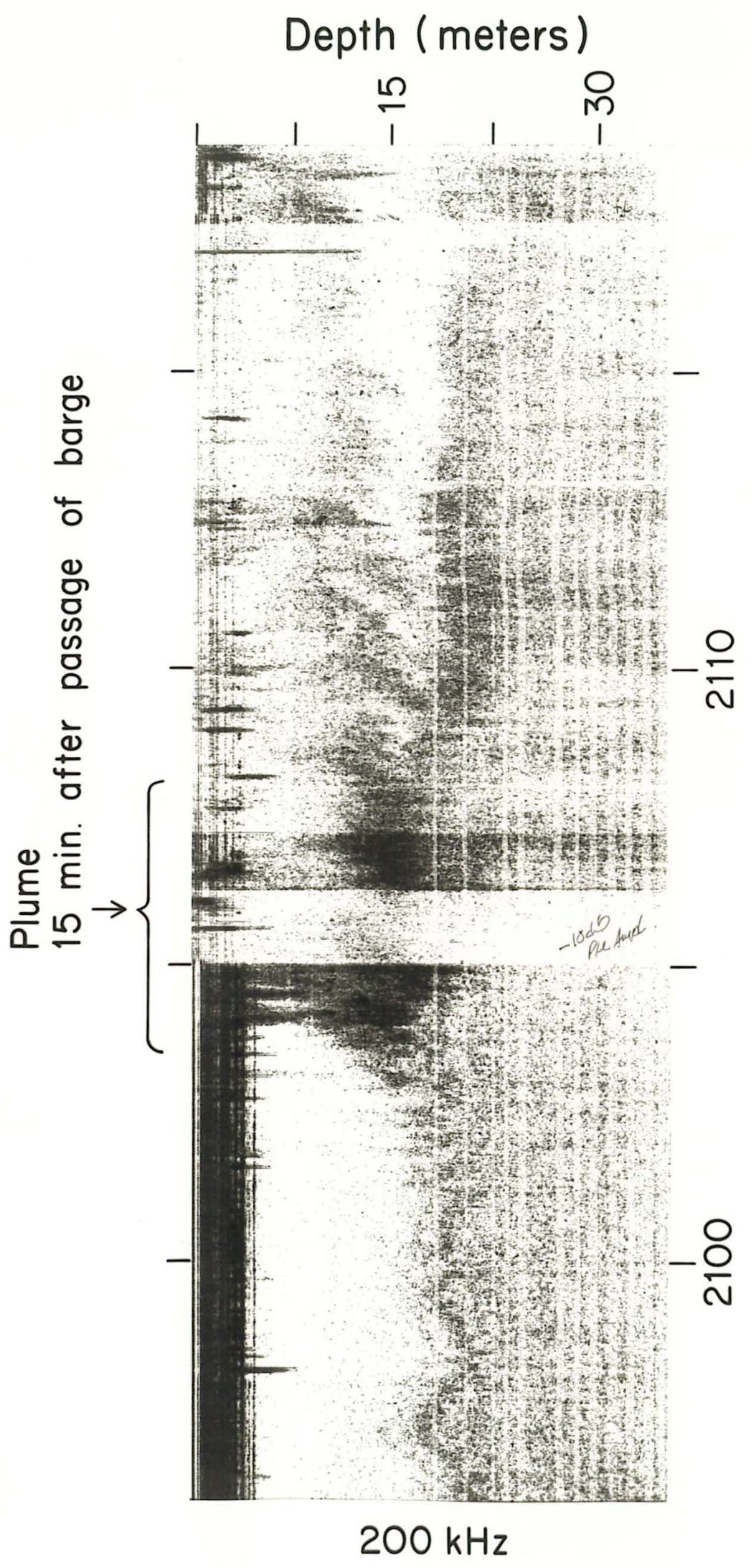

을

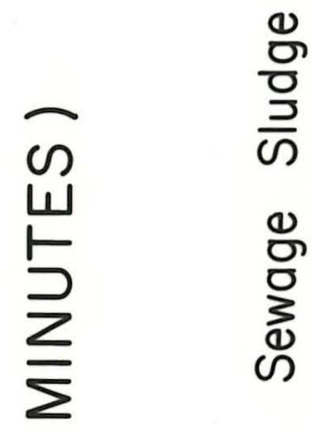

$\infty$

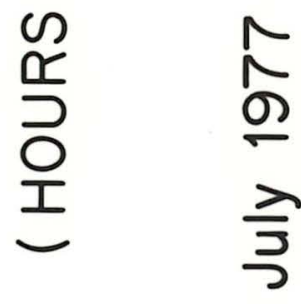

홍

n

$\frac{1}{0}$

$\sum$

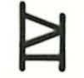

$\infty$
0
0
0
$\frac{1}{1}$
$\frac{1}{4}$ 


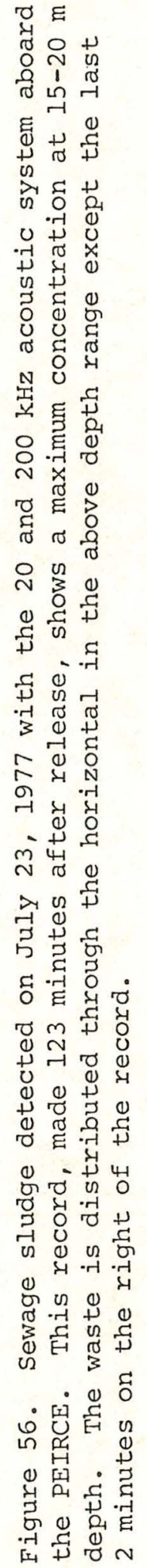




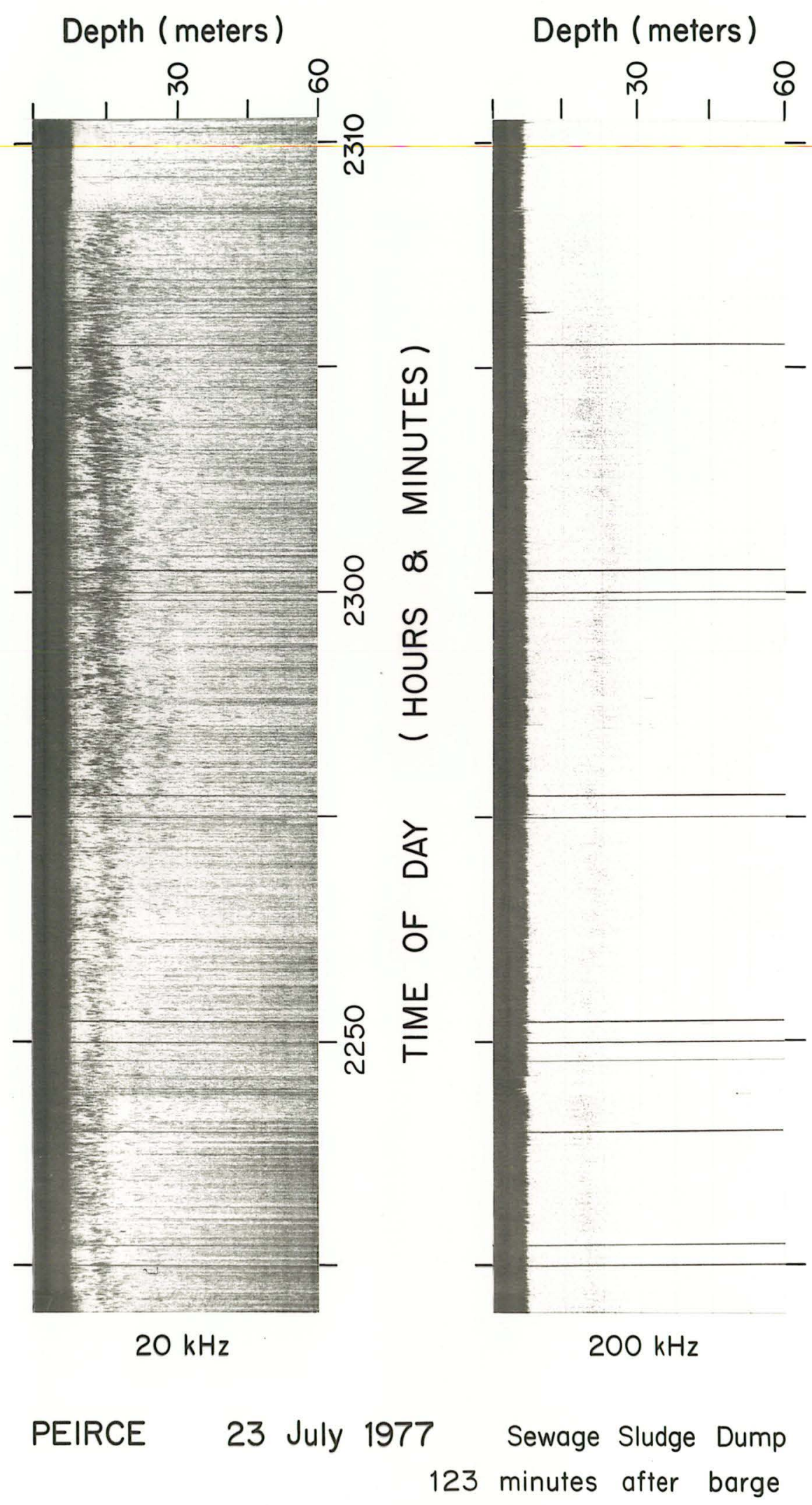




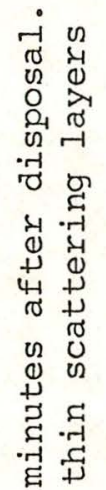

옹

N

届召

U

पू

毘

窟

是是

†잉

ธ్ ญ

น

命曾

- ริ

त्ञ

각

म.

ธิ ซี

r 0

व मू

07

00

$+1$

ठ

(1)

क्ष

'્t

जी O प्र

ब. n 0

तु

ज्ञ

桴

$\therefore 0$

in + o

(1)

누요

की द्न 

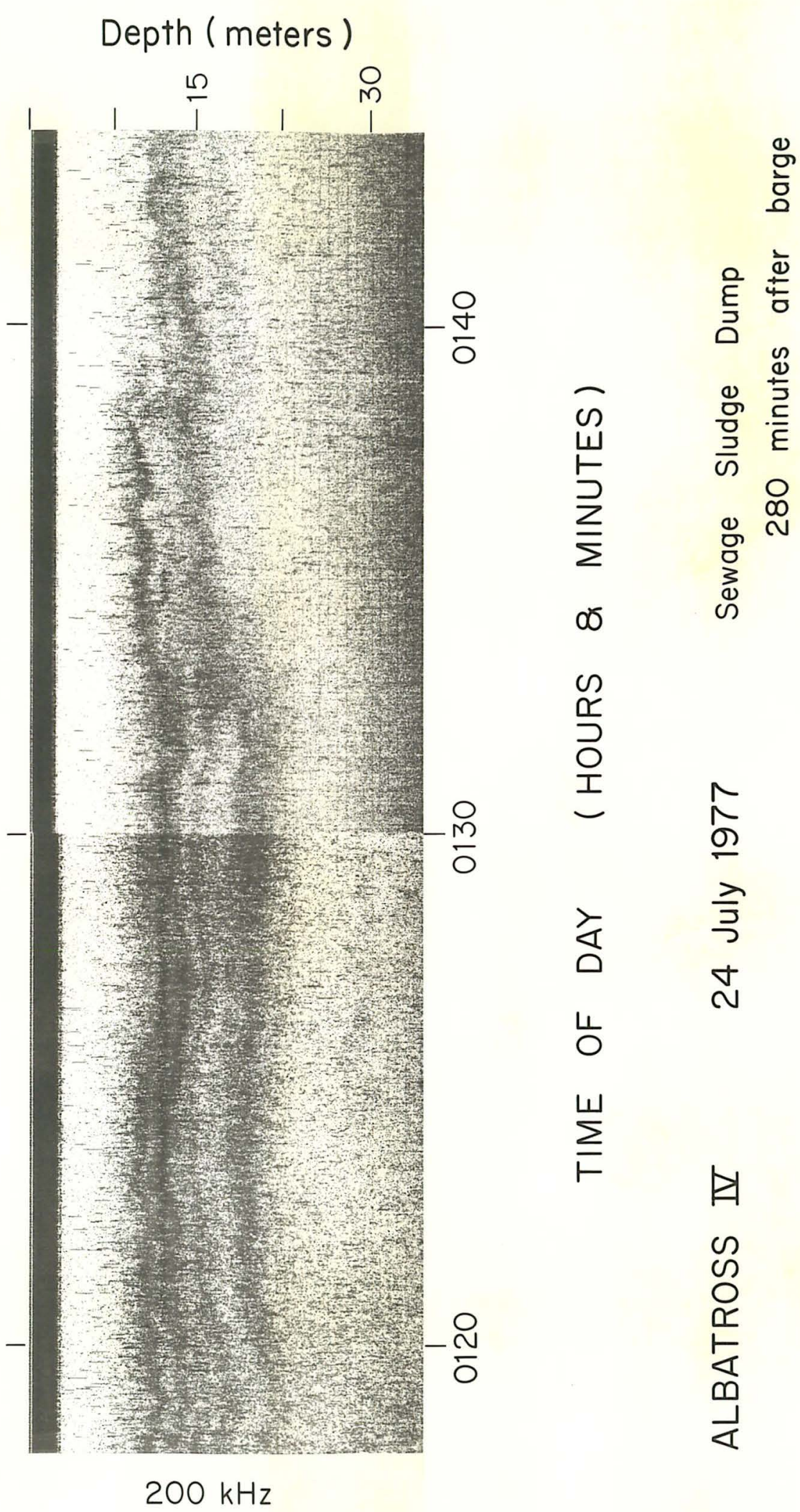

แั

言

产 


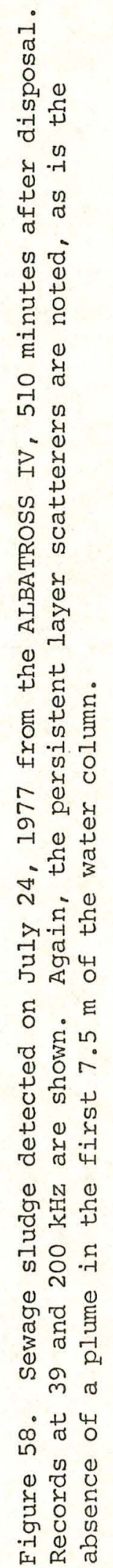




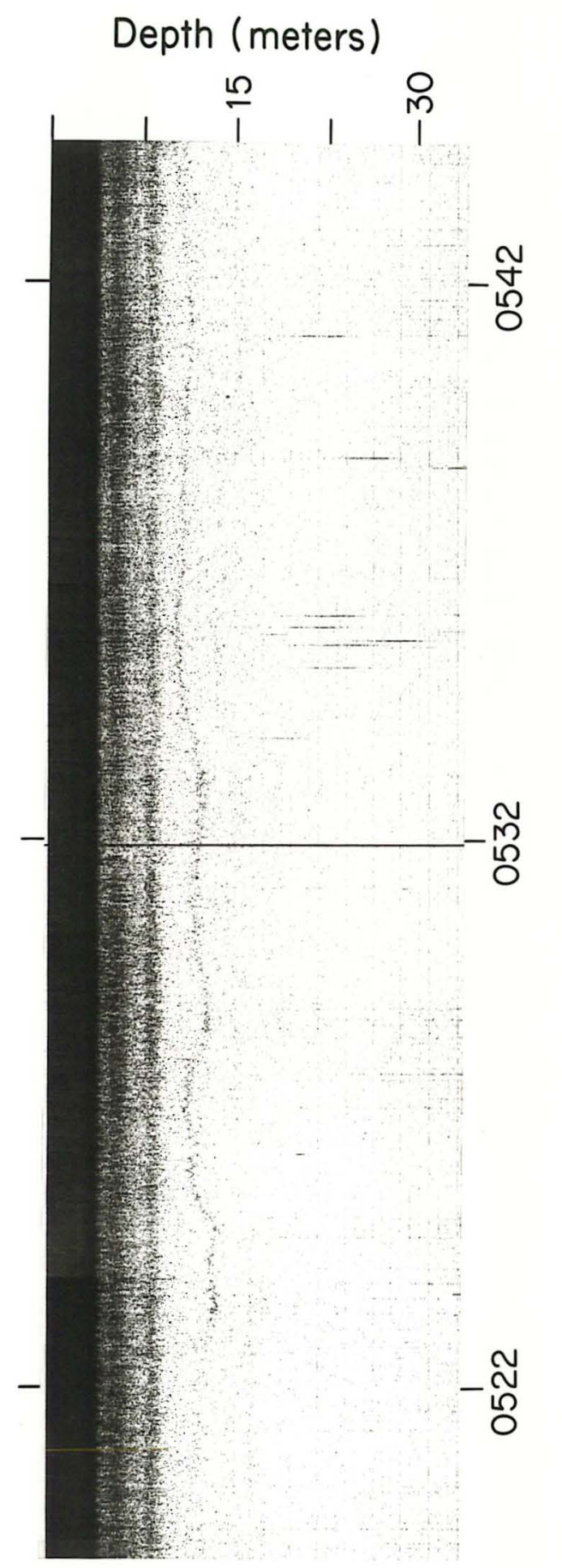

$39 \mathrm{kHz}$

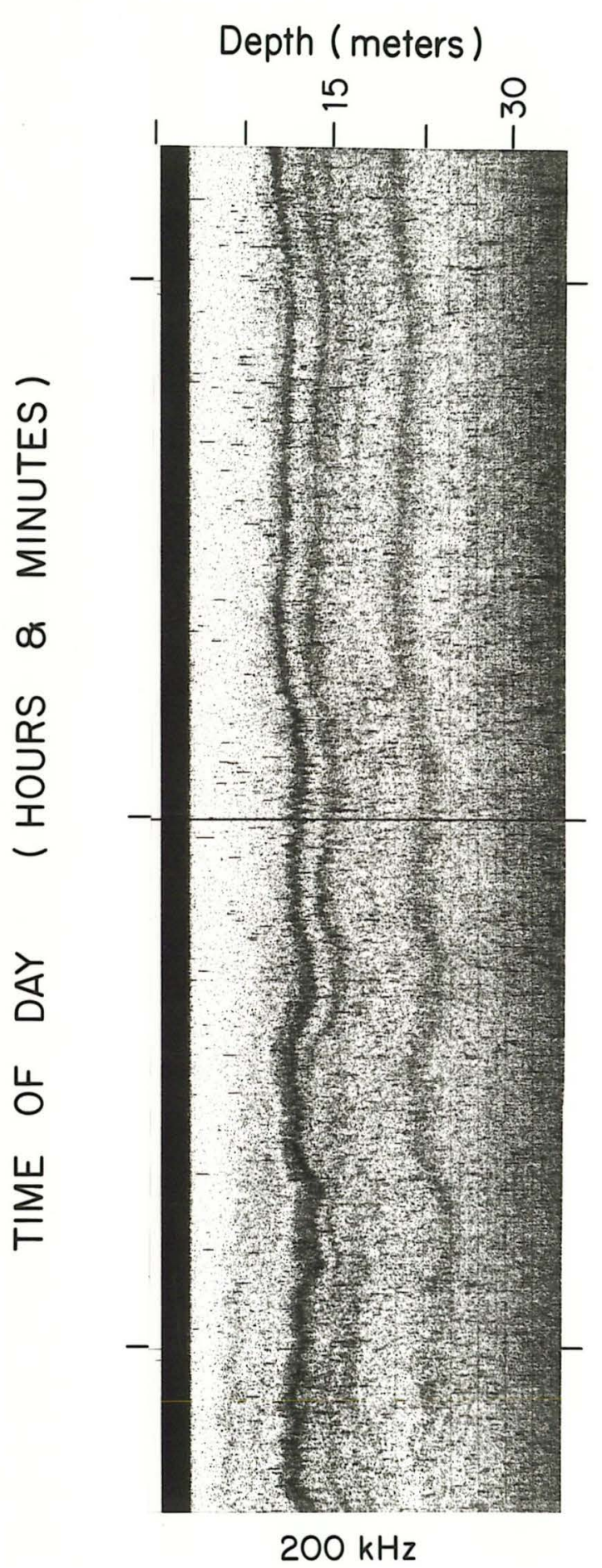

ALBATROSS IV 24 July $1977 \quad$ Sewage Sludge Dump 510 minutes after barge 


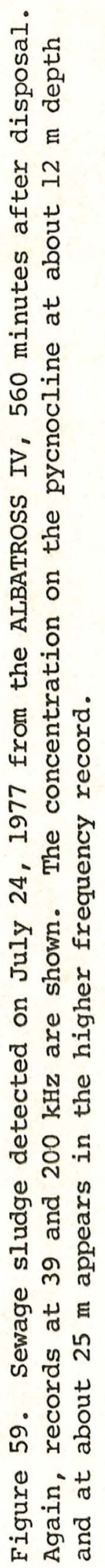




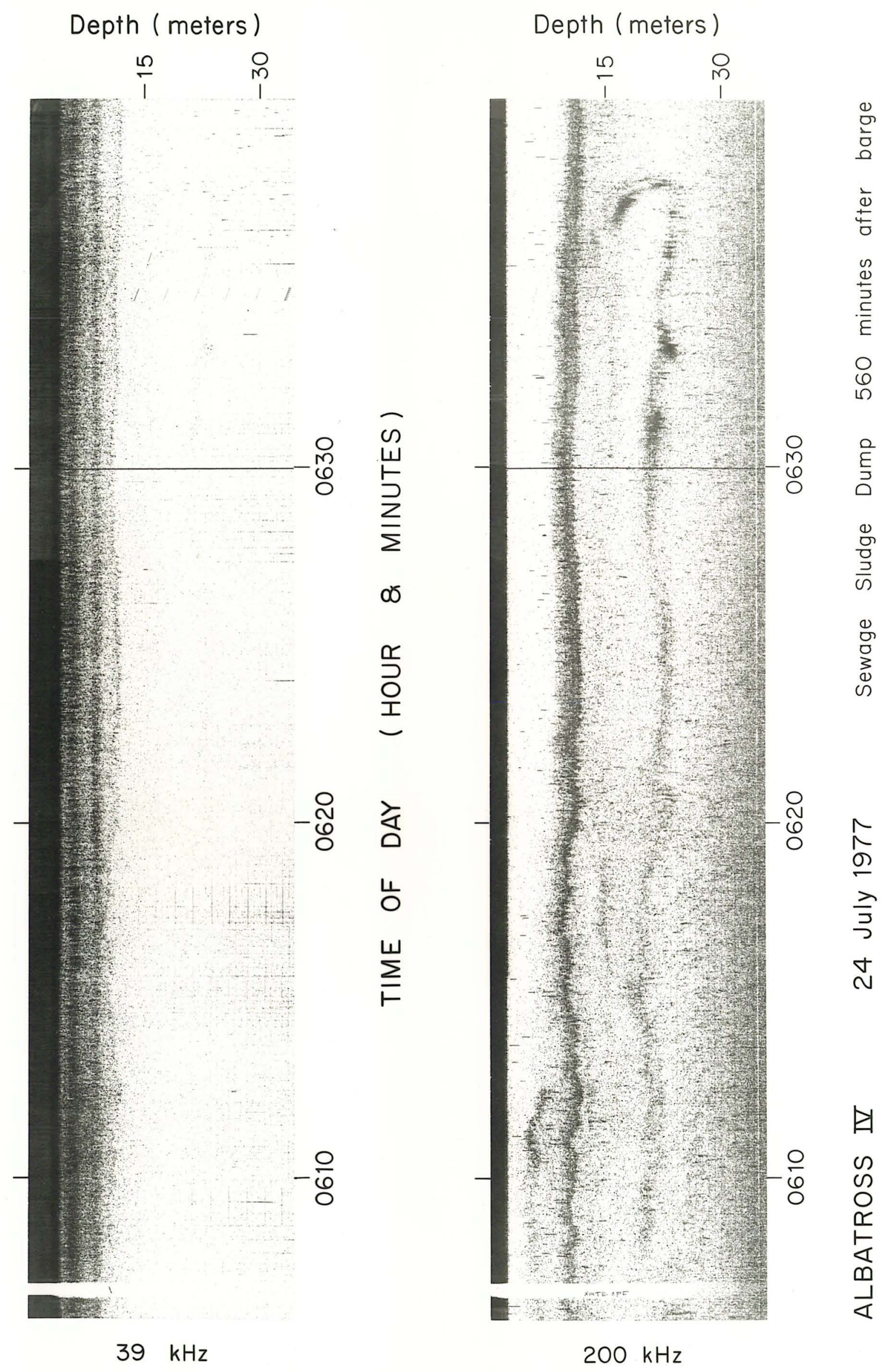




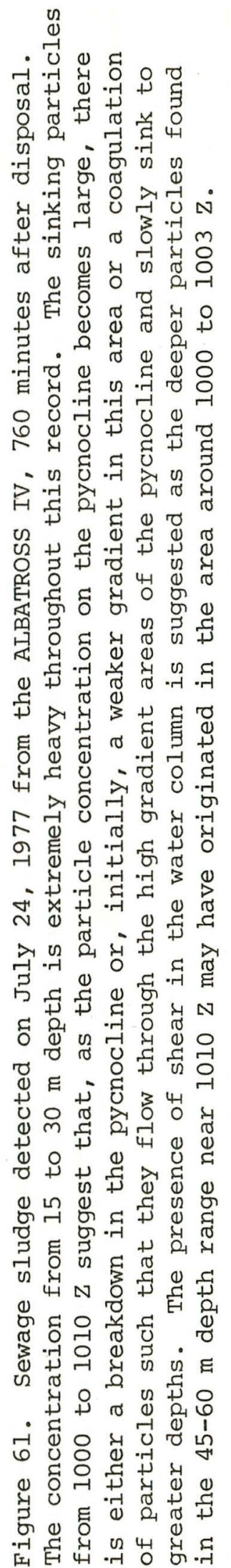




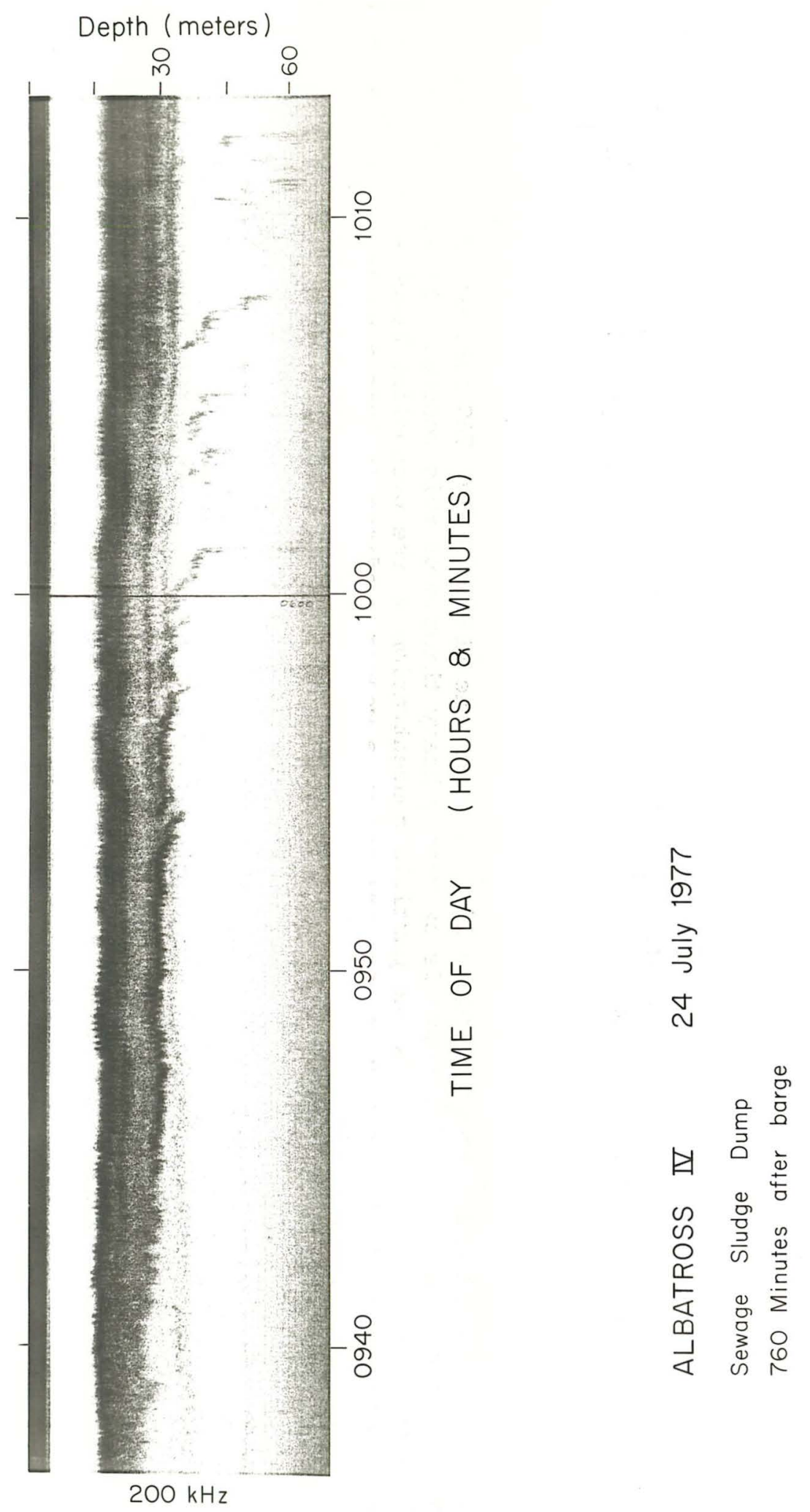




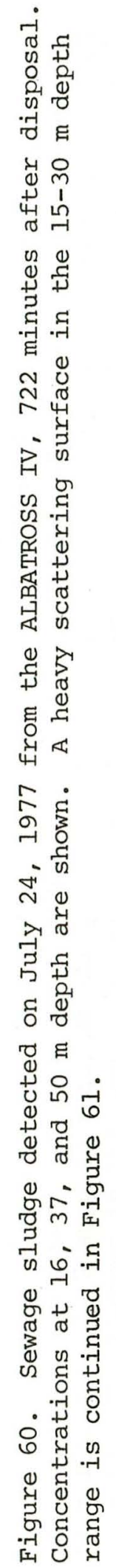




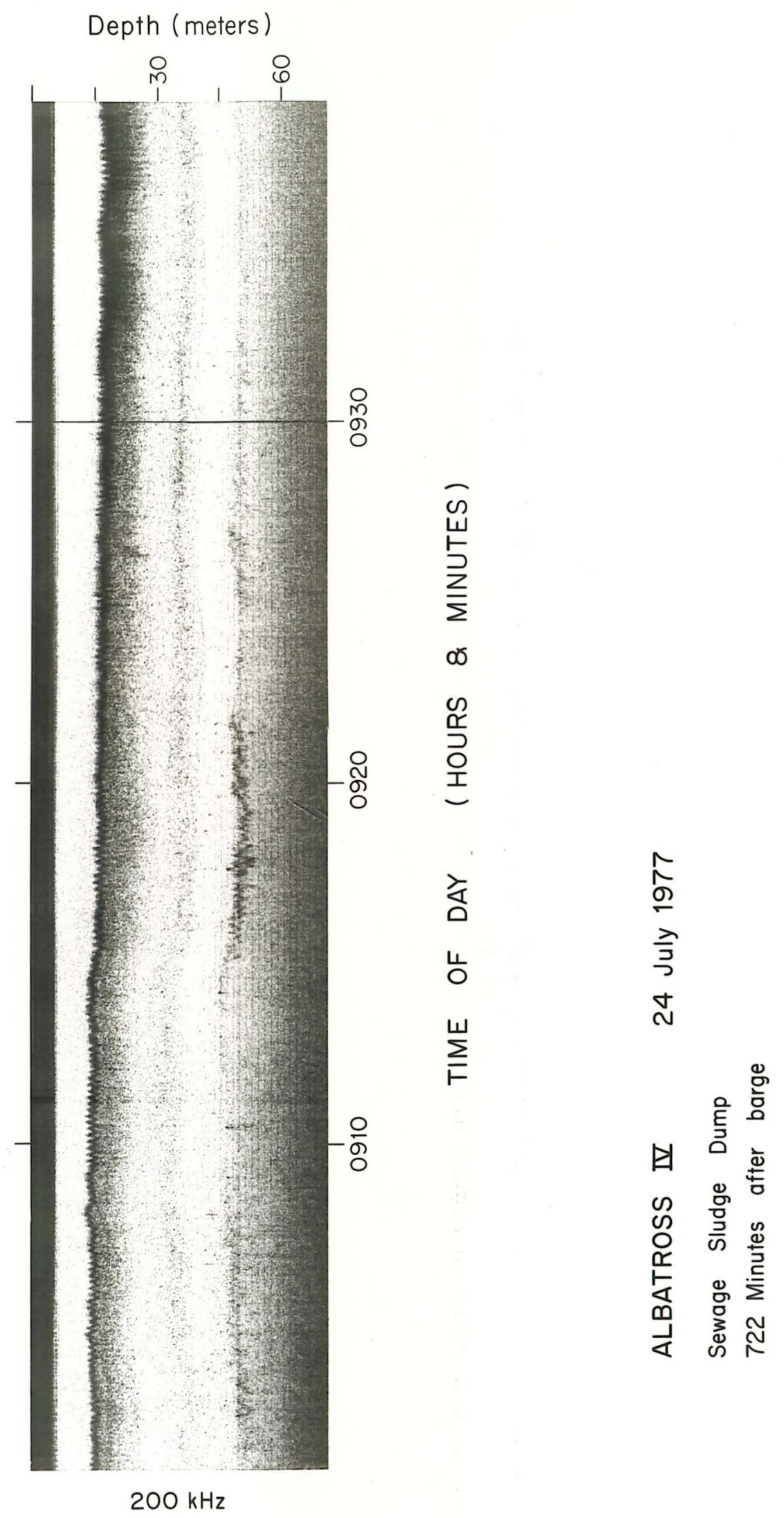




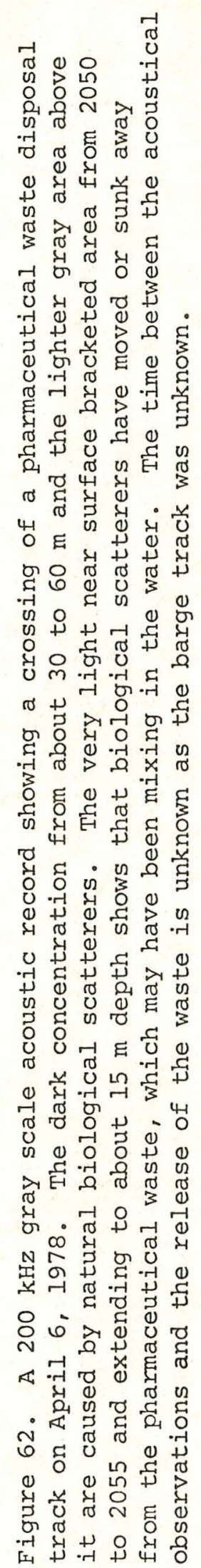




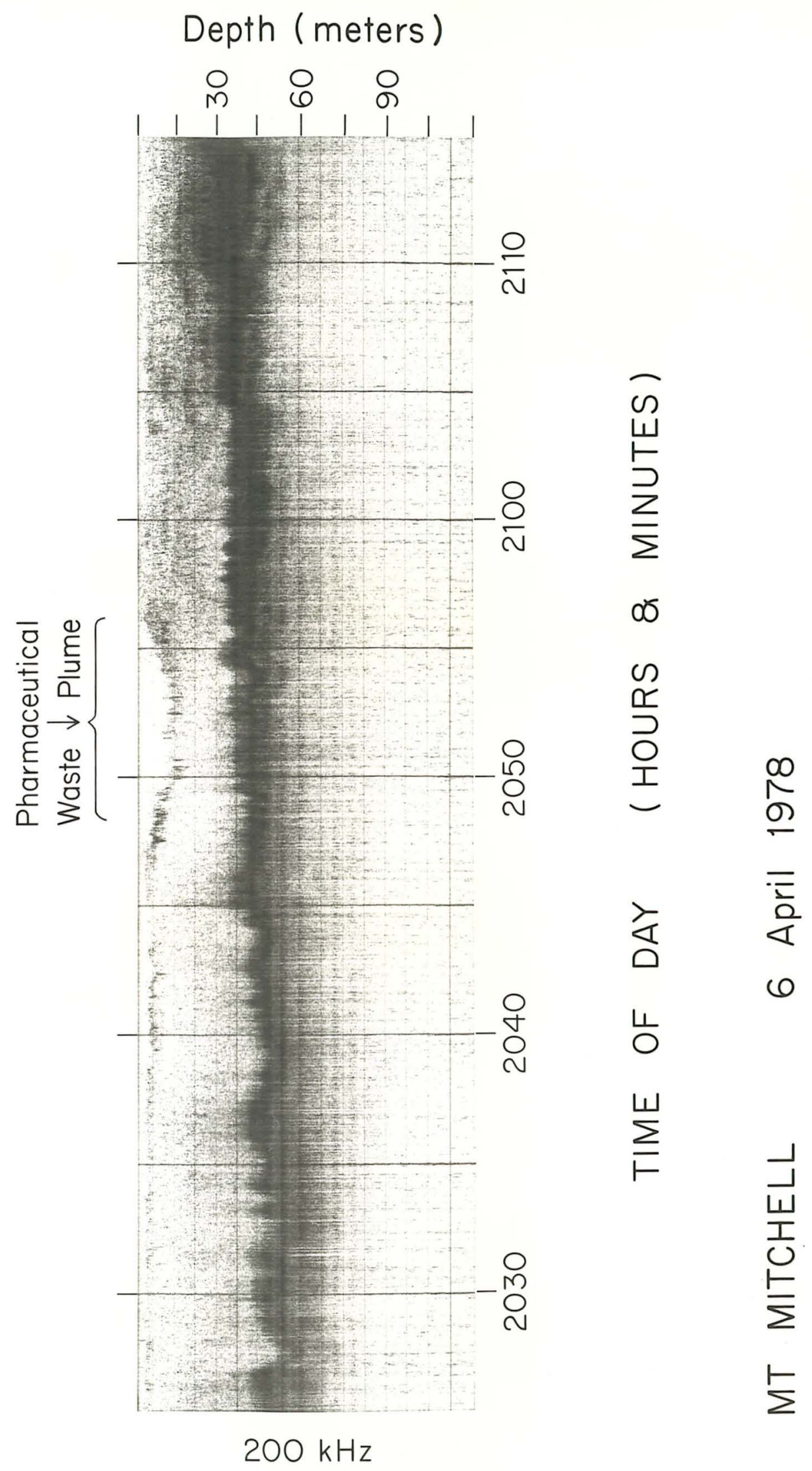




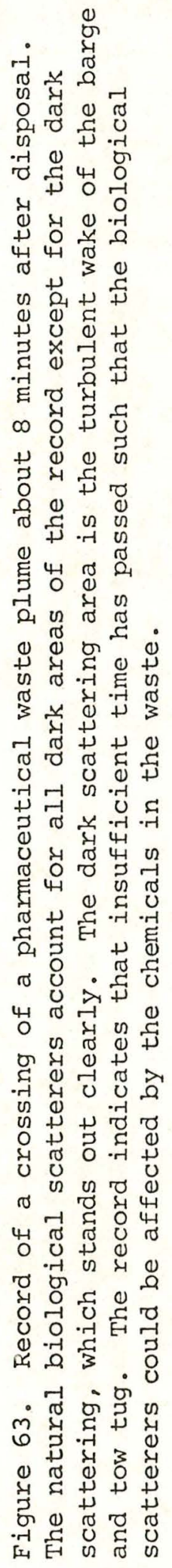




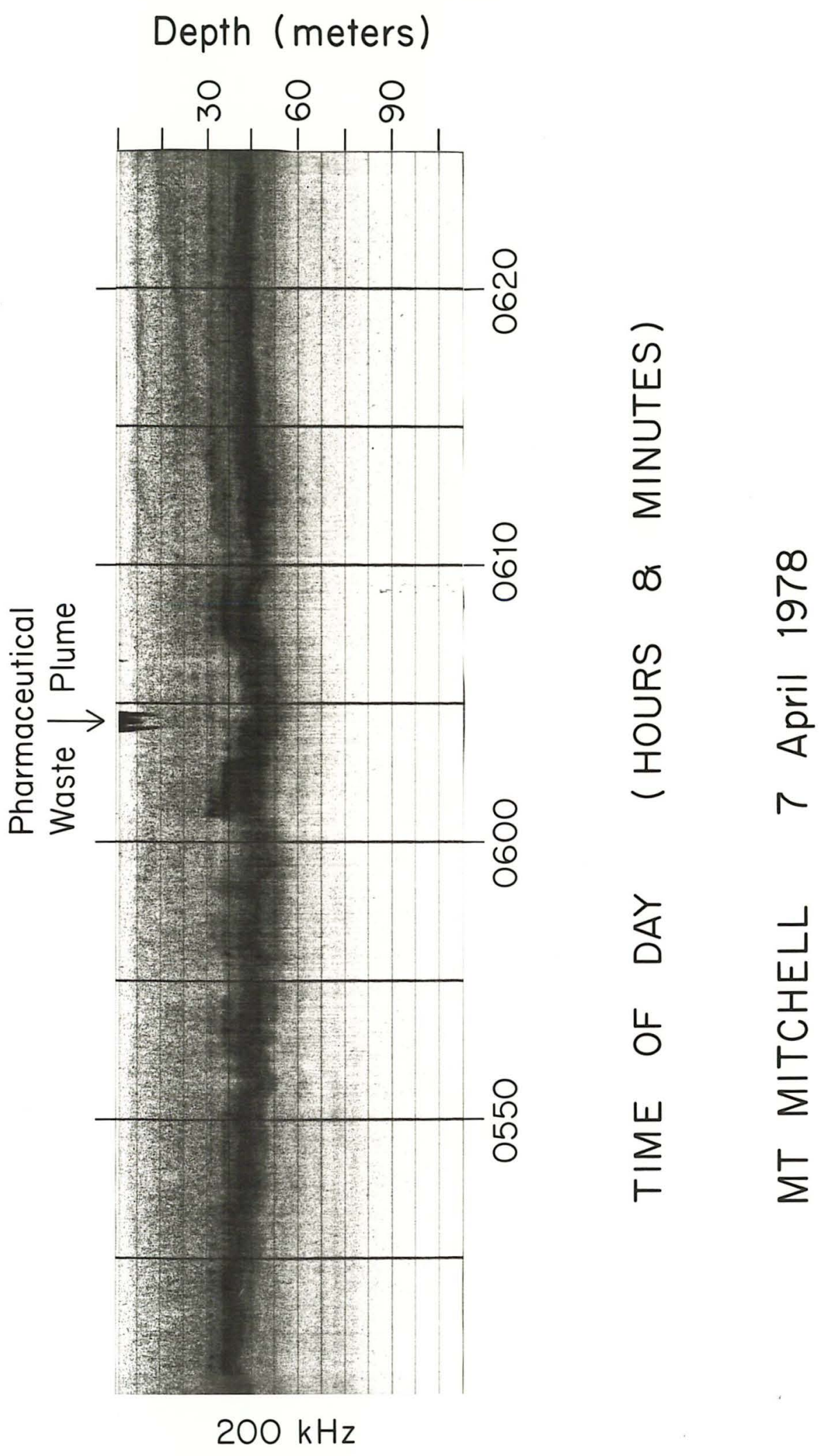




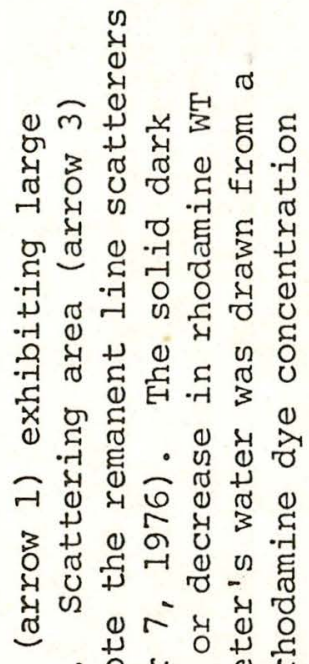

प 0 울 मै

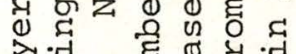
. त 0 ते Oप दे क्ष 兵

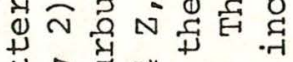

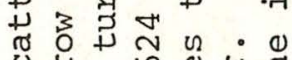

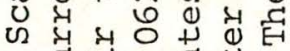
त्व ति 4 मे है 东 त ૬ં

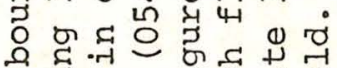
2.

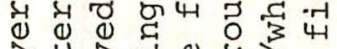
ति क्ष $\rightarrow$ व क थ ष 0 \% E मैं

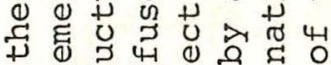
0 मे 4 थ

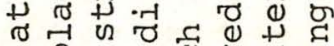

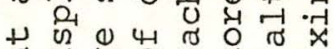

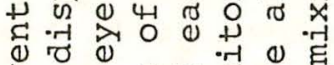

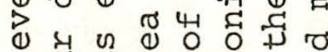
ช . . . . 0 \& 0 \& 0 雪 $\sum \sigma_{-1} D$ है द्व है ० प्र - बि द्व वे क्षे उ 齐

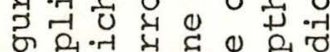

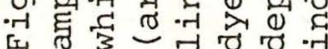



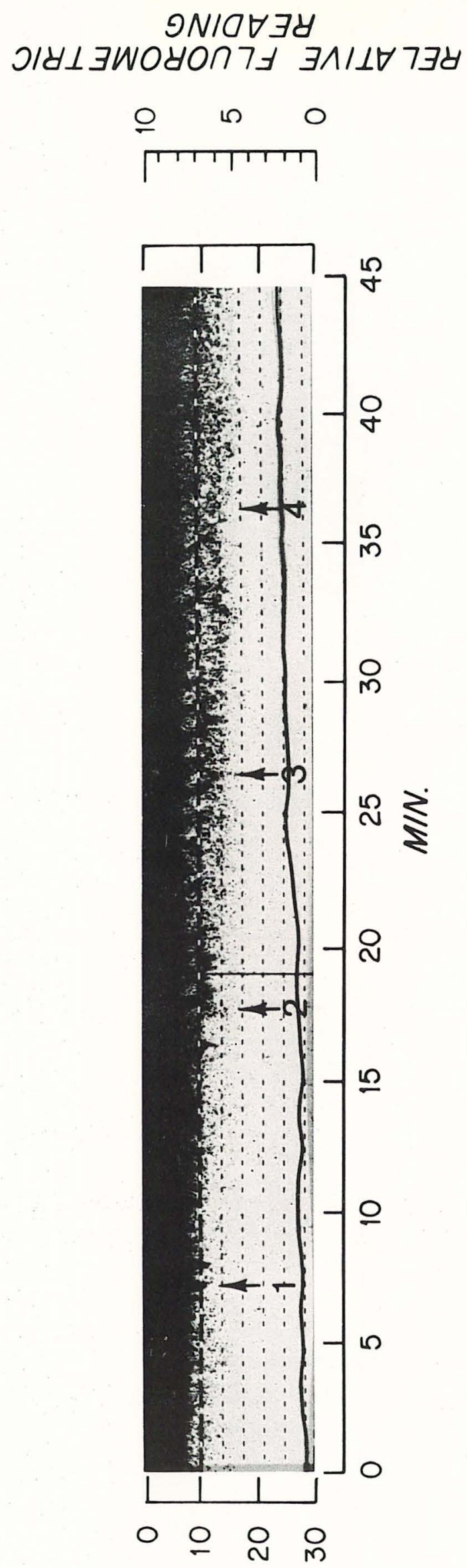

$S \forall \exists \perp \exists W$ 


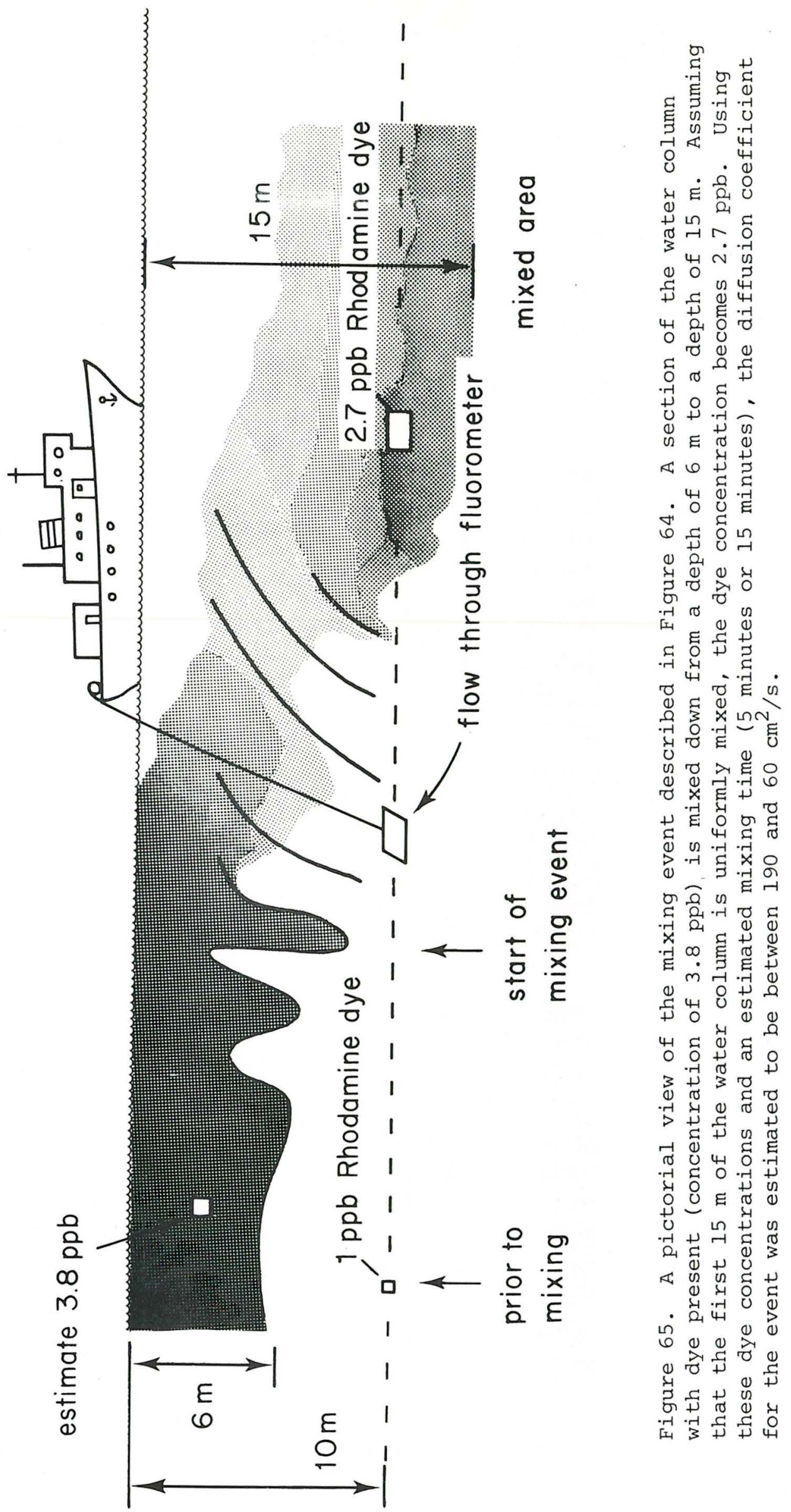


Table I-A: Dispersion Properties of duPont Edge Moor Waste Particulates as a Function of Season - Winter and Spring

Table I-B: Dispersion Properties of duPont Edge Moor Waste Particulates as a Function of Season - Summer, NOAA Ship PEIRCE

Table I-C: Dispersion Properties of duPont Edge Moor Waste Particulates as a Function of Season - Summer, NOAA Ship ALBATROSS IV

Table II: Dispersion Properties of duPont Grasselli Waste Particles as a Function of Season

Table III-A: Dispersion Properties of Sewage Sludge Particulates Summer, NOAA Ship PEIRCE

Table III-B: Dispersion Properties of Sewage Sludge Particulates Summer, NOAA Ship ALBATROSS IV

Table IV: Calculations of Sink Rate of Spheres (Radius $=10^{-1} \mathrm{~cm}$ $(1000 \mu))$ in Sea Water Using Stoke's Law 


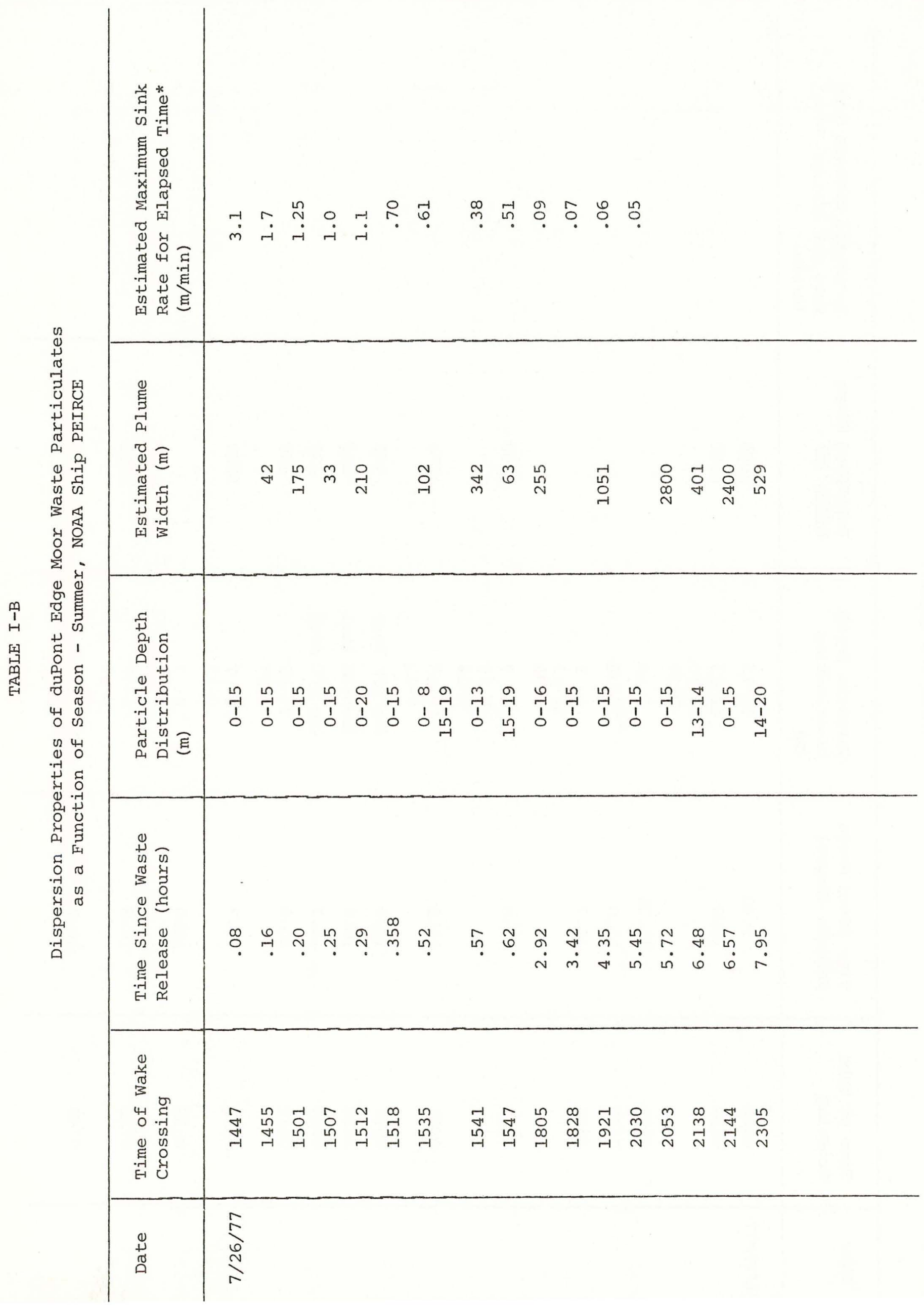




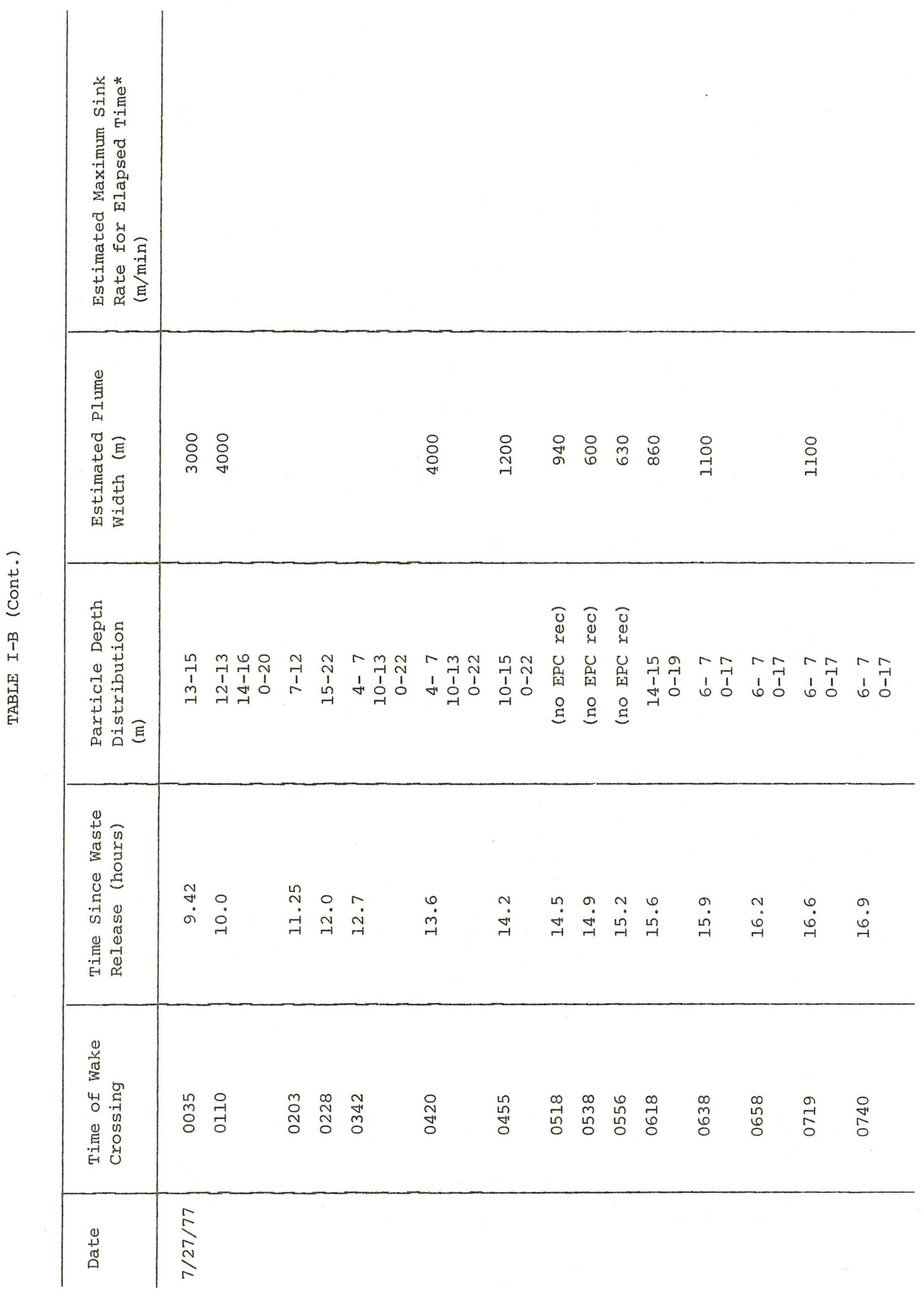




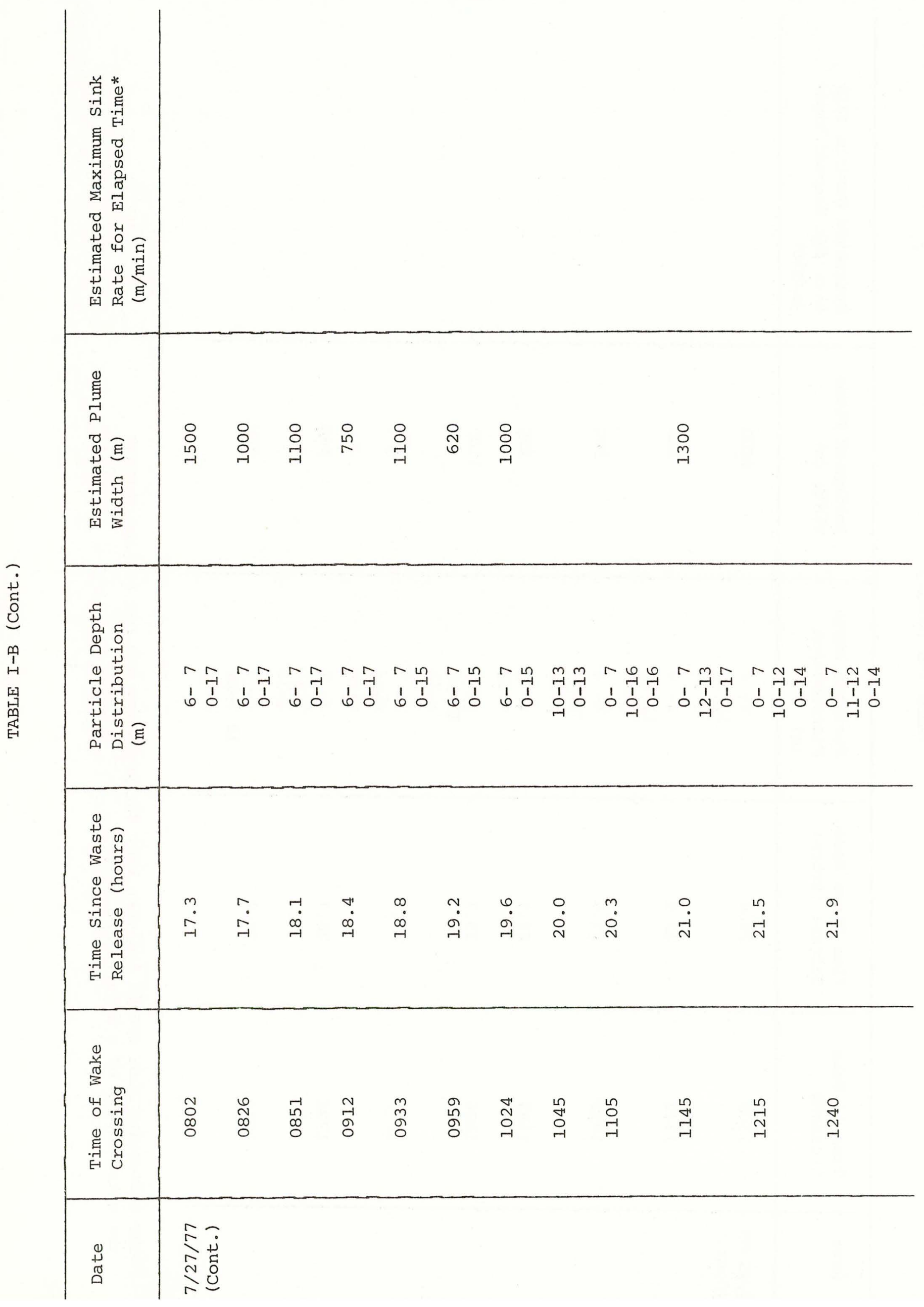




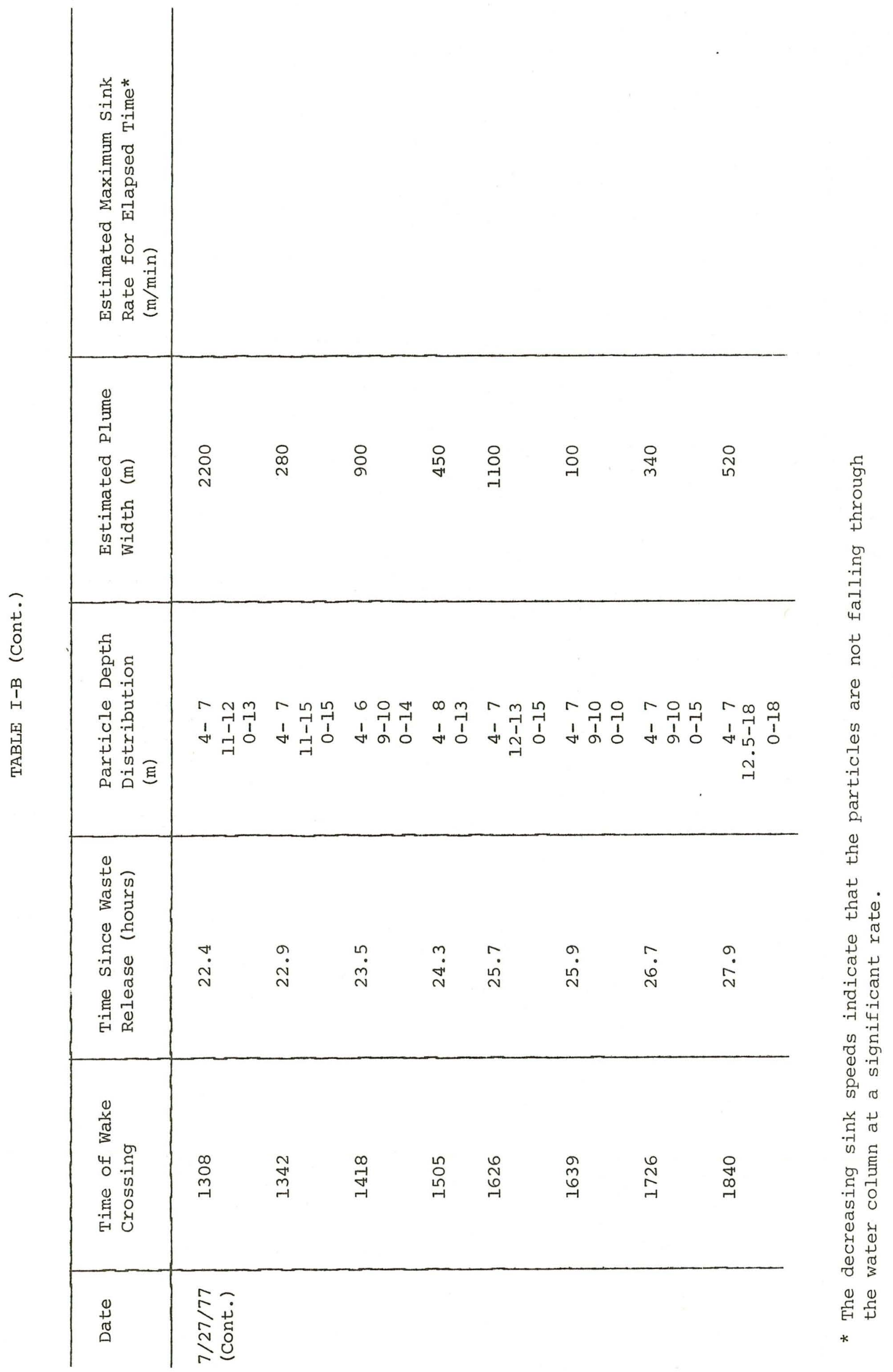




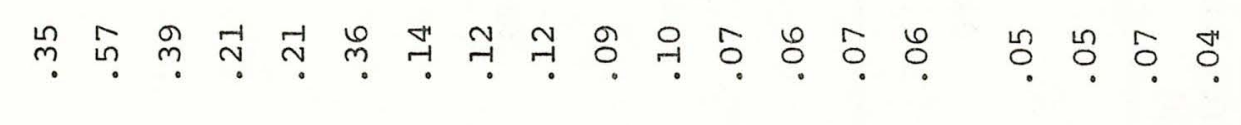

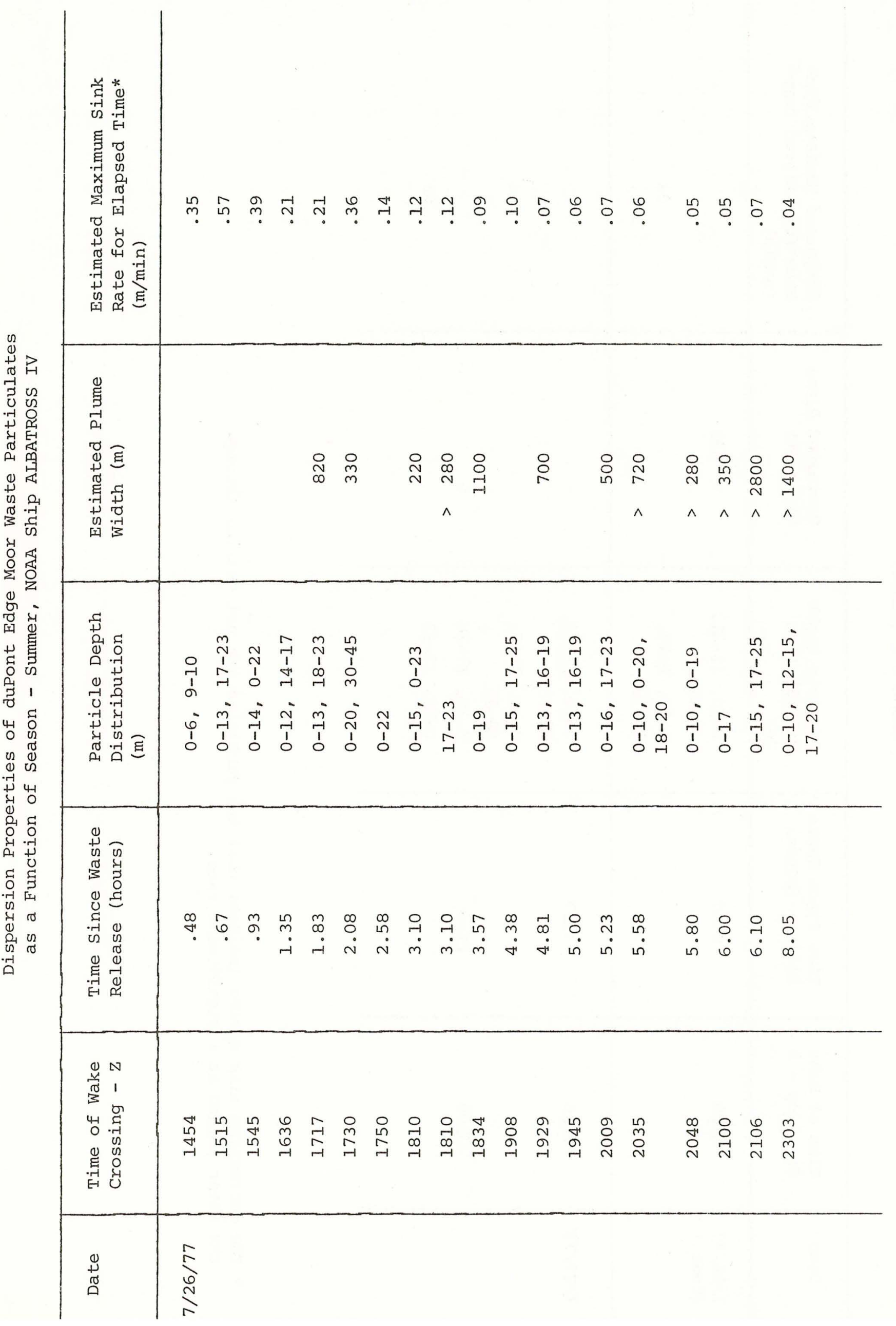


156

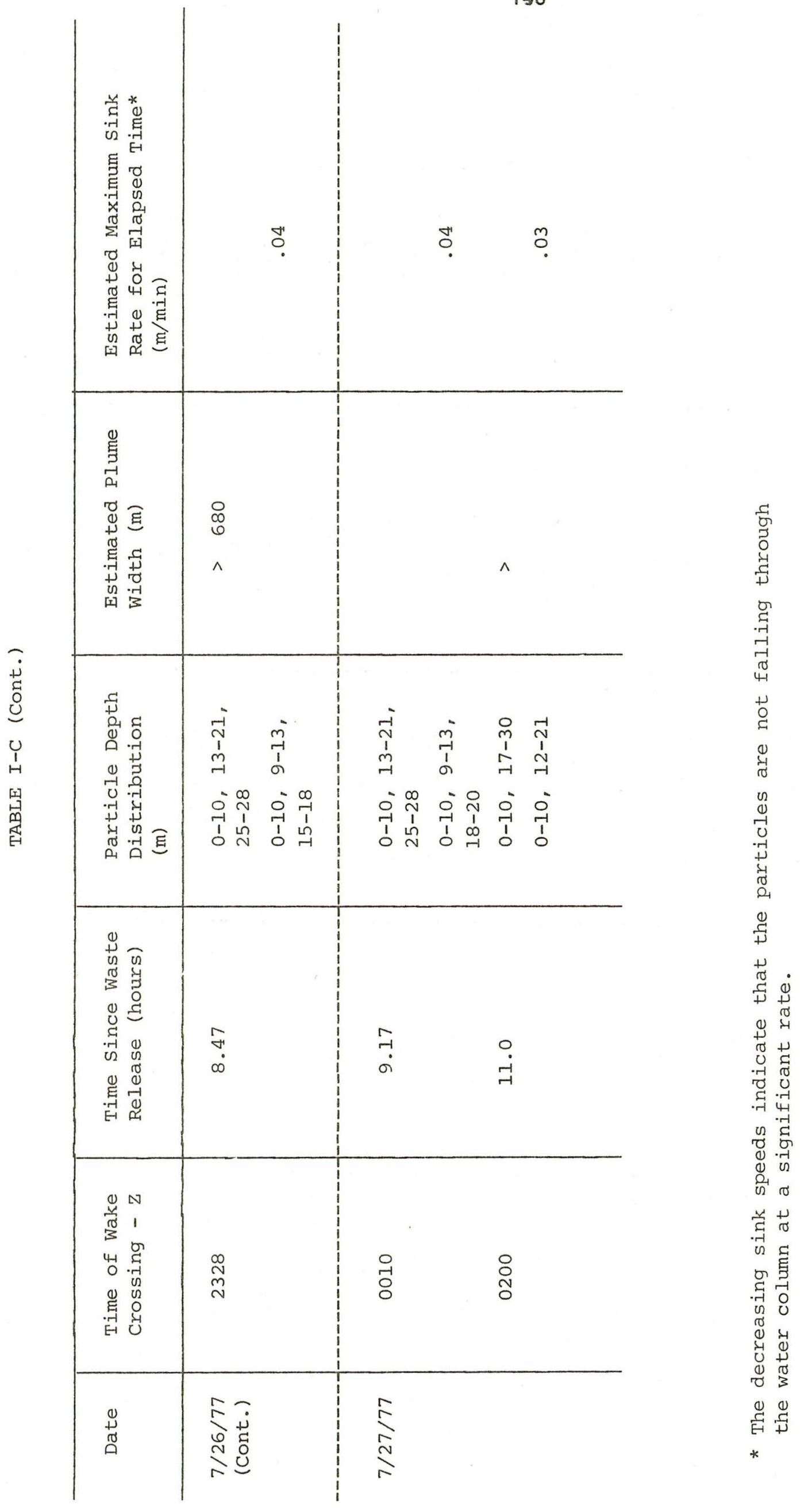




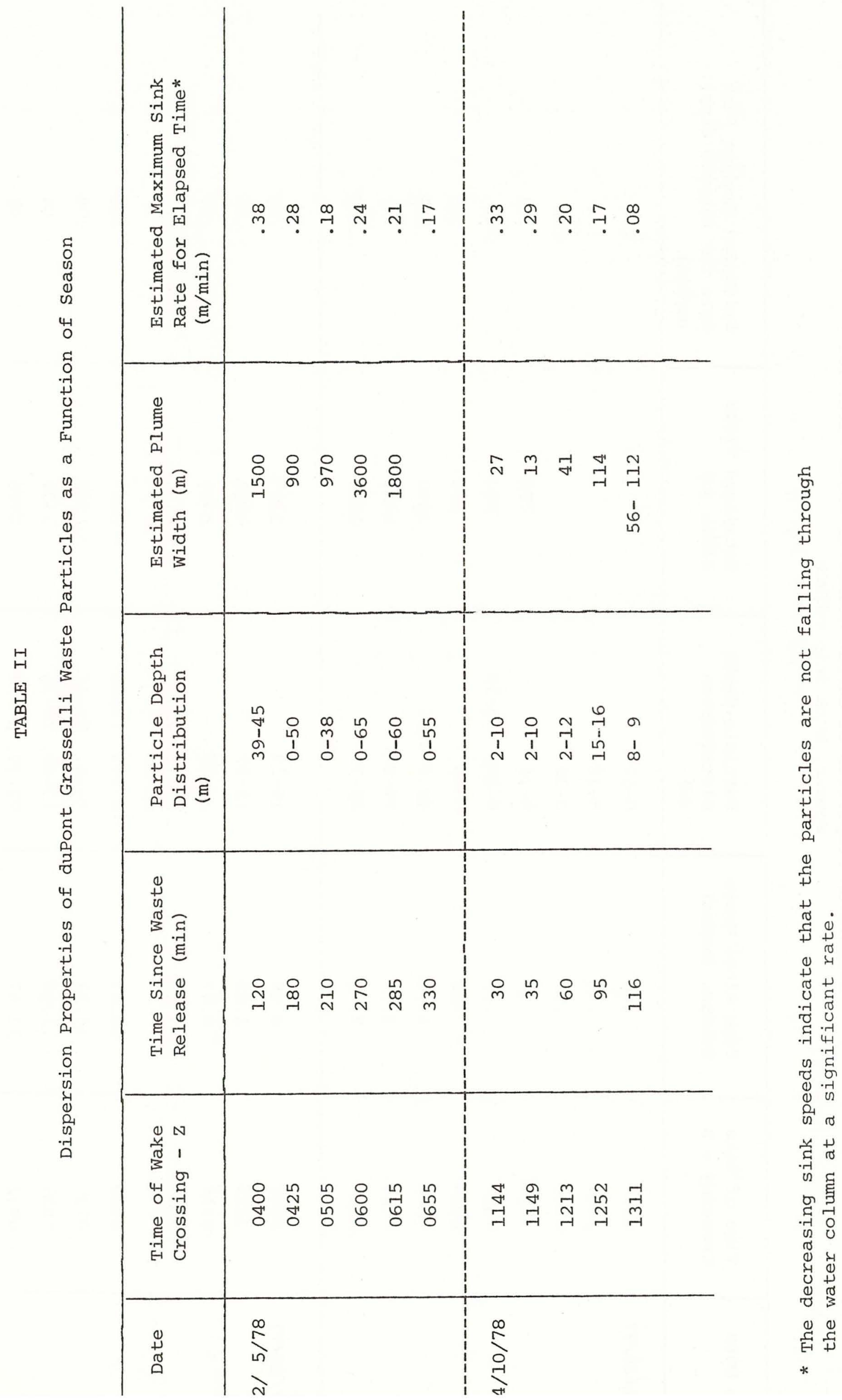




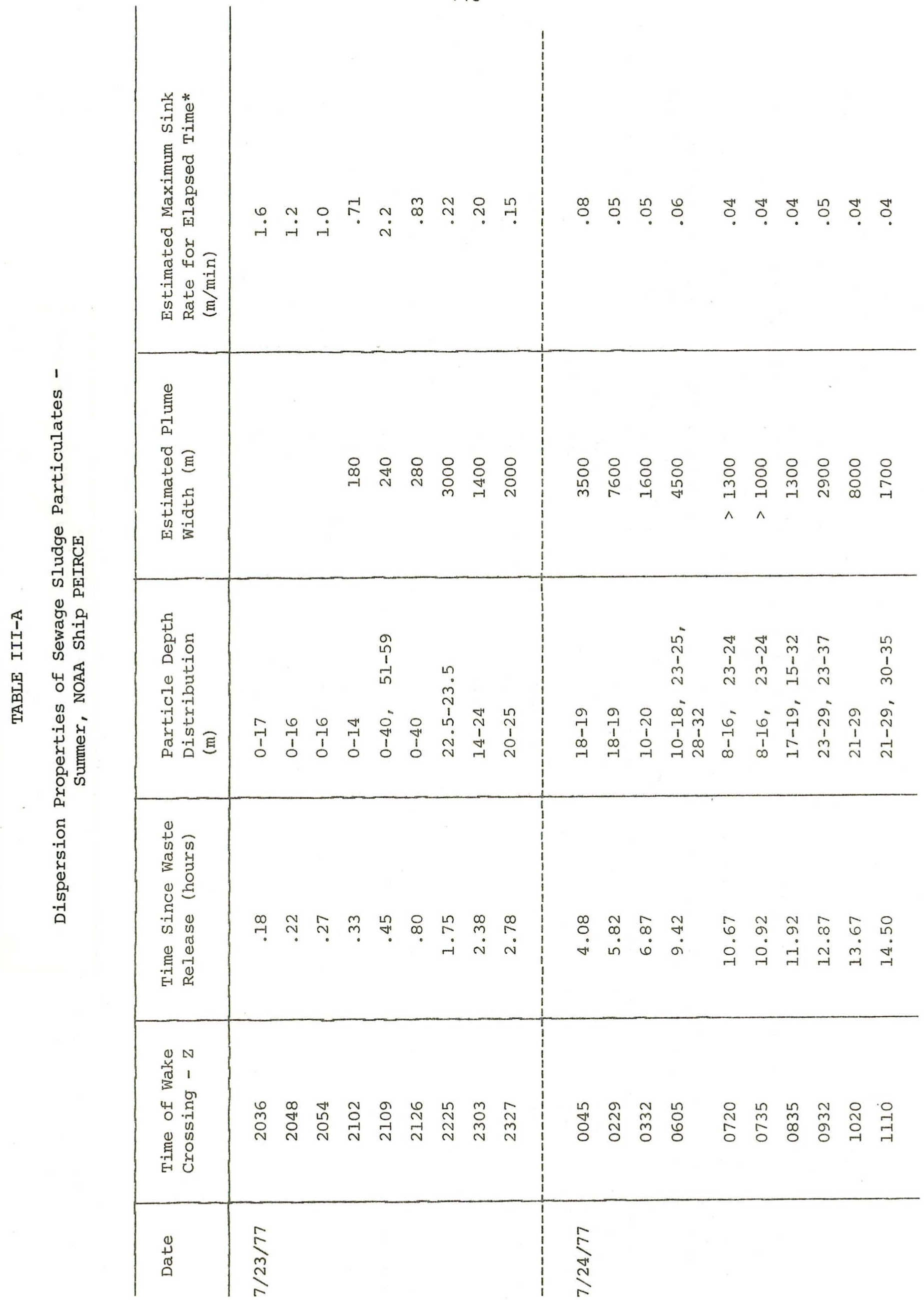




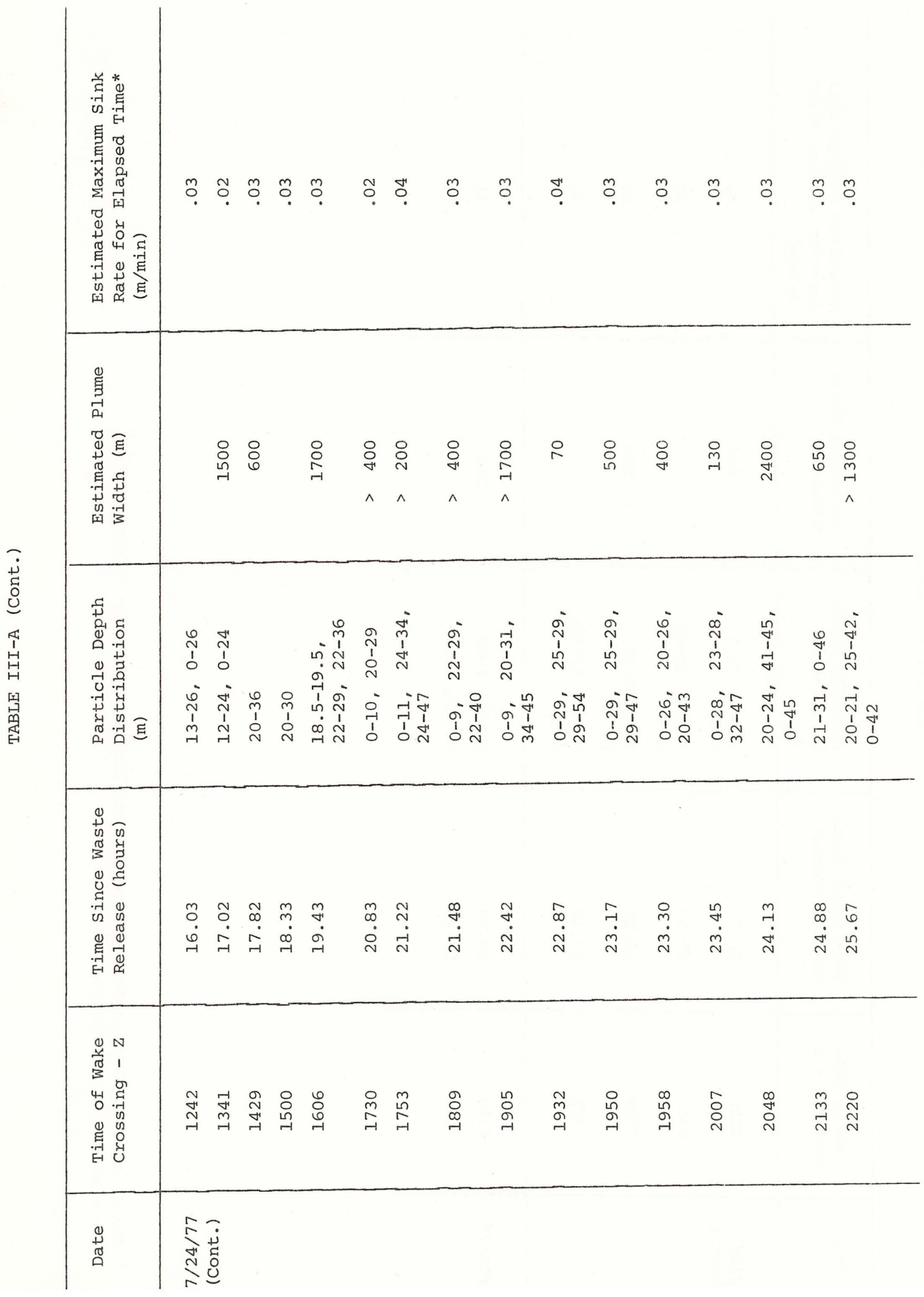




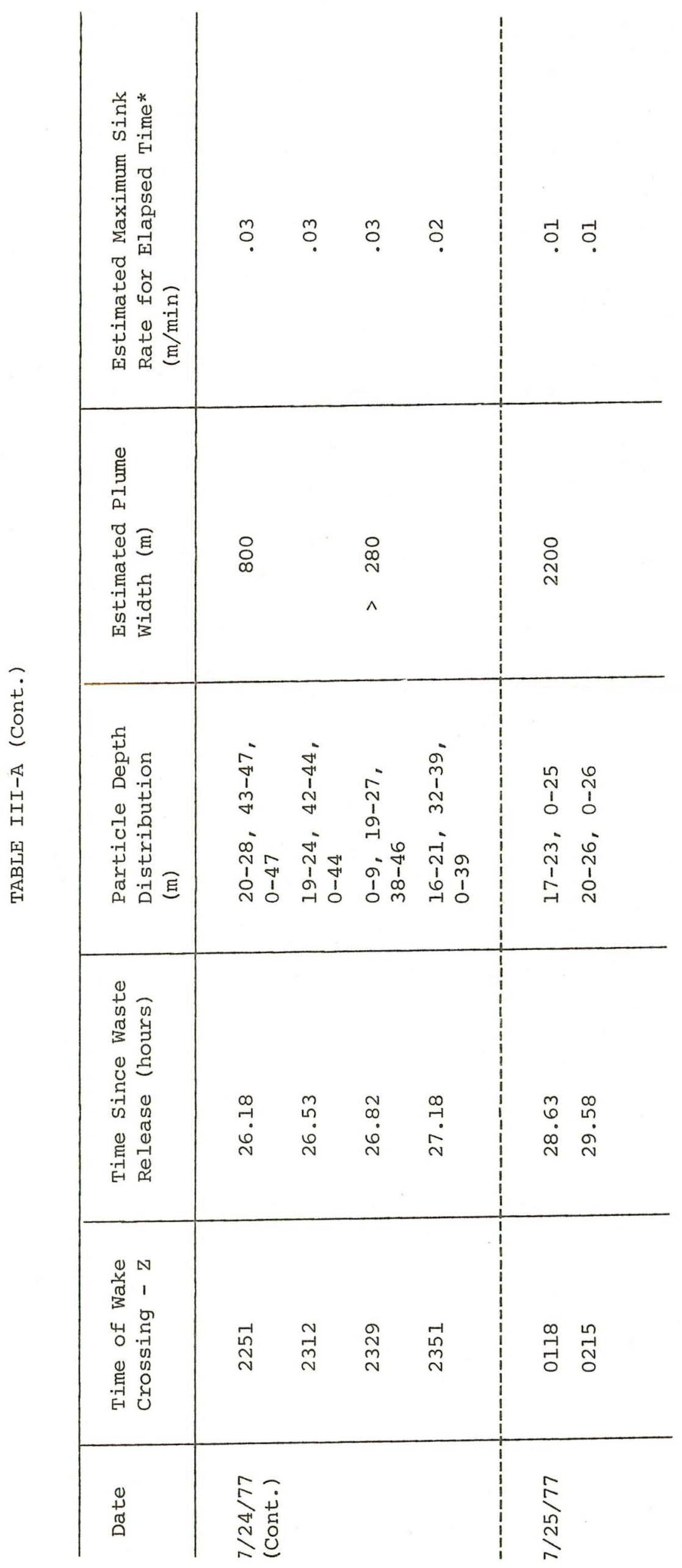




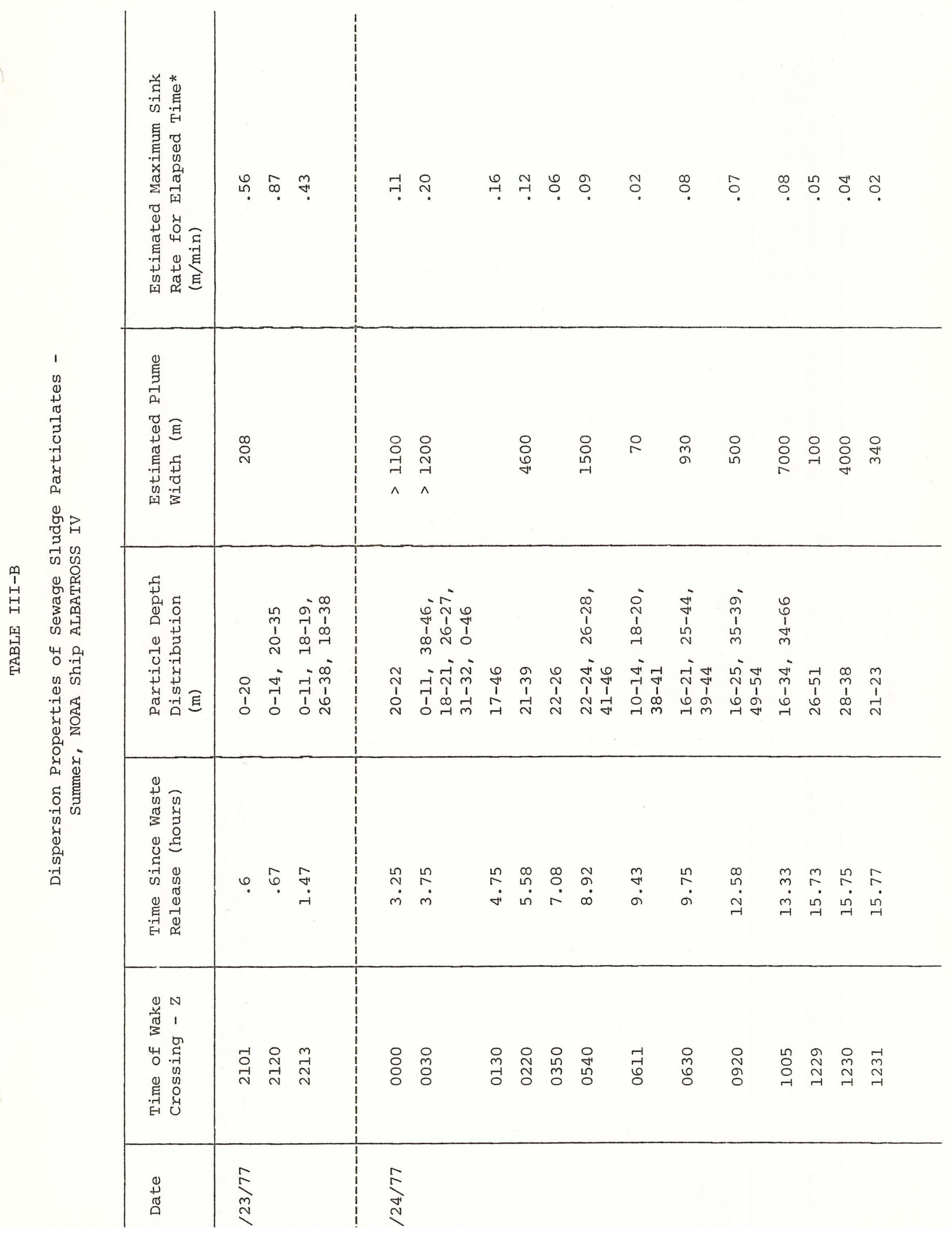



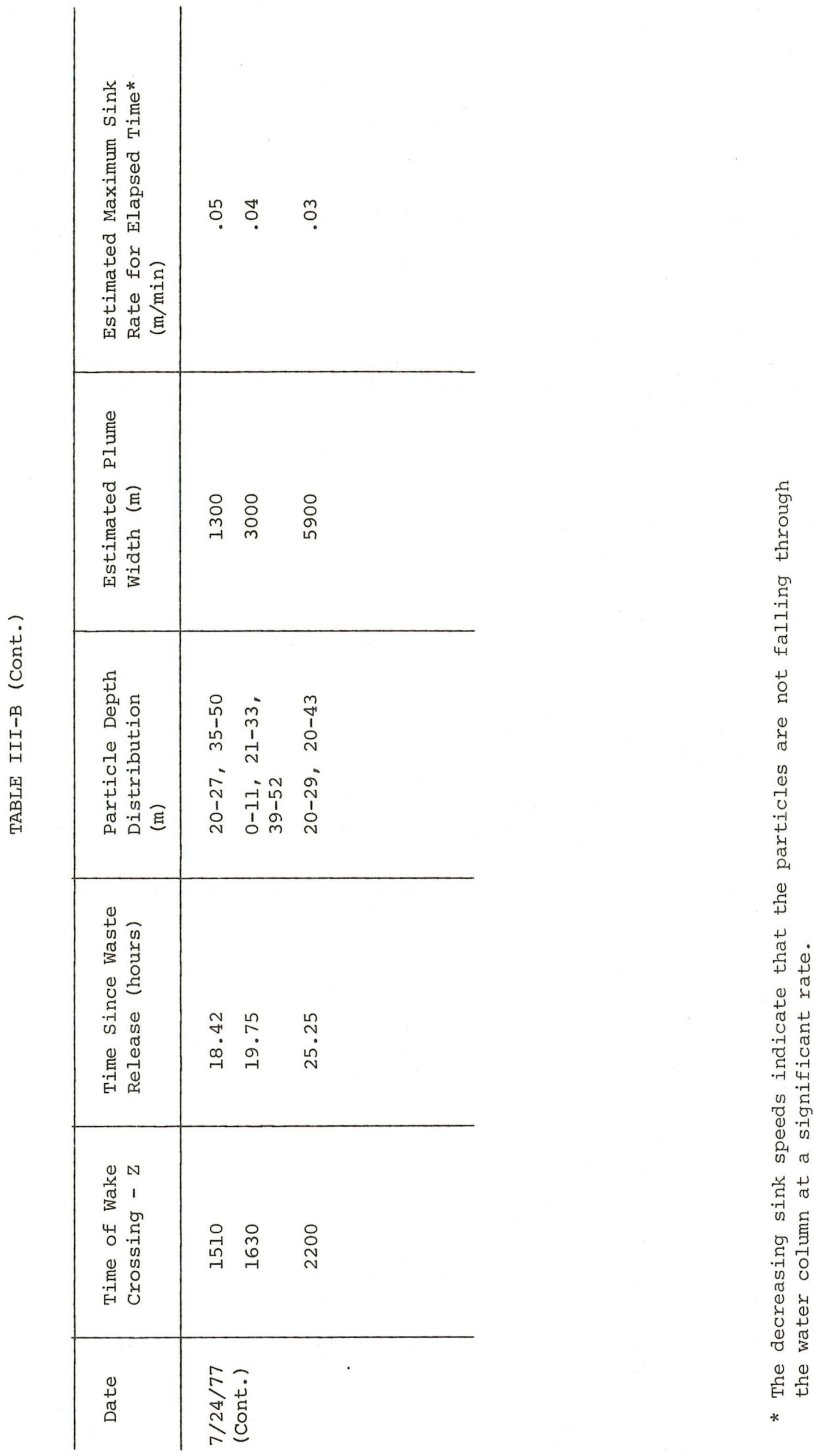
TABLE IV

$$
\begin{gathered}
\text { Calculations of Sink Rate of Spheres (Radius }=10^{-1} \mathrm{~cm} \\
(1000 \mu) \text { ) in Sea Water Using Stoke's Law }
\end{gathered}
$$

\begin{tabular}{c|c|c|c}
\hline $\begin{array}{l}\text { Sphere Density } \\
\mathrm{g} / \mathrm{cm}^{3}\left(\rho_{1}\right)\end{array}$ & $\begin{array}{l}\text { Seawater Density } \\
\mathrm{g} / \mathrm{cm}^{3}\left(\rho_{2}\right)\end{array}$ & $\begin{array}{l}\text { Sinking speed } \\
\mathrm{cm} / \mathrm{s}\end{array}$ & $\mathrm{m} /$ hour \\
\hline 1.03 & 1.024 & 1.304 & 46.9 \\
1.03 & 1.025 & 1.086 & 39.1 \\
1.03 & 1.026 & .869 & 31.2 \\
1.03 & 1.027 & .652 & 23
\end{tabular}




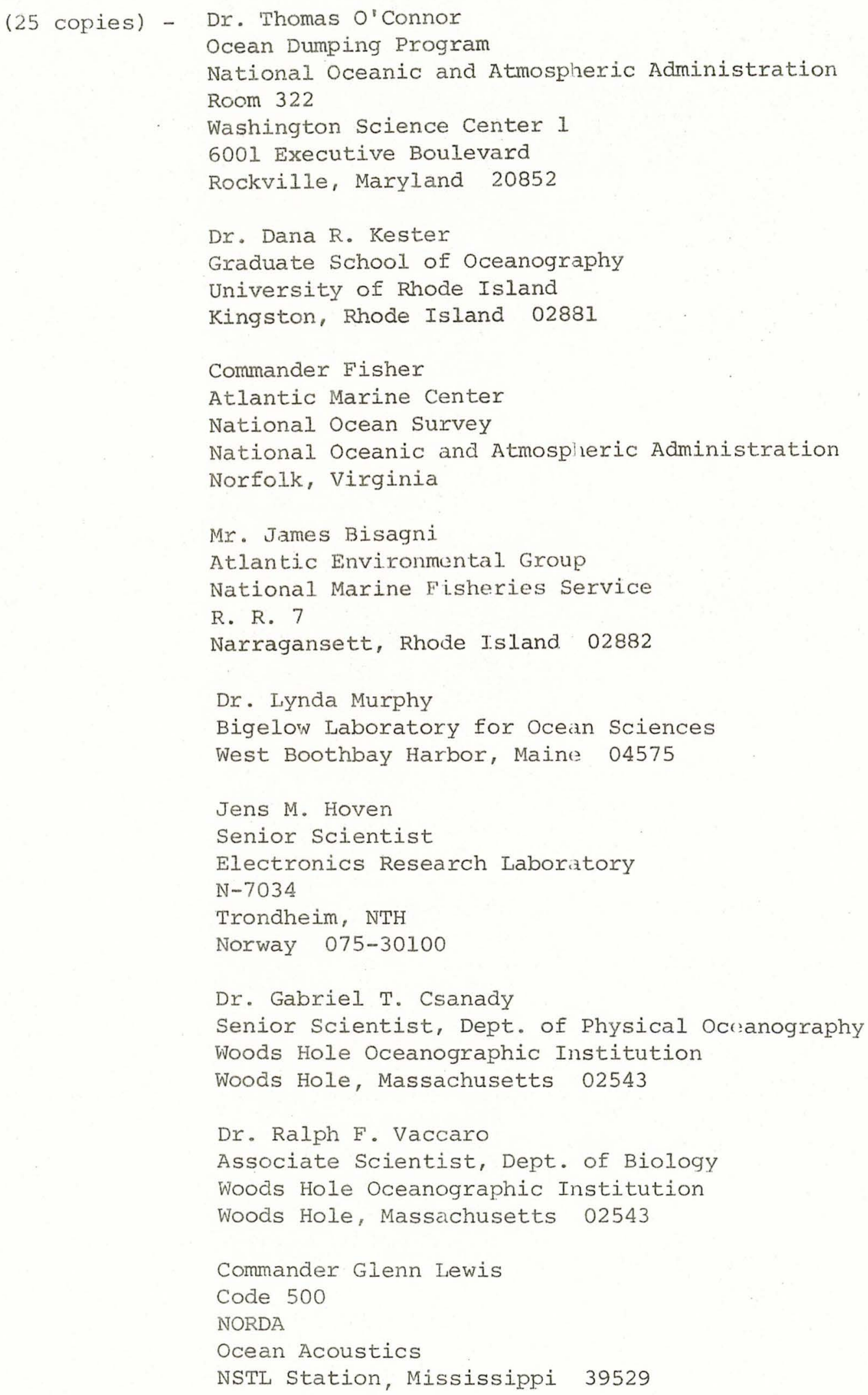




\begin{tabular}{|l|l|l|}
\hline $\begin{array}{l}\text { BIBLIOGRAPHIC DATA } \\
\text { SHEET }\end{array}$ & $\begin{array}{l}\text { 1. Report No. } \\
\text { WHOI-79-38 }\end{array}$ & 3. Recipient's Accession No. \\
\hline $\begin{array}{l}\text { 4. Title and Subtitle } \\
\text { REMOTE ACOUSTIC SENS ING OF THE PARTICULATE PHASE OF INDUS- } \\
\text { TRIAL CHEMICAL WASTES AND SEWAGE SLUDGE }\end{array}$ & $\begin{array}{l}\text { 5. Report Date } \\
\text { January } 1980\end{array}$ \\
\cline { 2 - 3 } $\begin{array}{l}\text { 7. Author(s) } \\
\text { Marshal1 H. Orr, Lincoln Baxter II and Frederick R. Hess }\end{array}$ & $\begin{array}{l}\text { 8. Performing Organization Rept. } \\
\text { No. }\end{array}$ \\
\hline $\begin{array}{l}\text { 9. Performing Organization Name and Address } \\
\text { Woods Hole Oceanographic Institution }\end{array}$ & $\begin{array}{l}\text { 10. Project/Task/Work Unit No. } \\
\text { Woode, MA 02543 }\end{array}$ & $\begin{array}{l}\text { 11. Contract/Grant No. } \\
\text { O4-7-158-44054, NA79AA- } \\
\text { D-00030, 04-8-MOI-43 }\end{array}$ \\
\hline $\begin{array}{l}\text { 12. Sponsoring Organization Name and Address } \\
\text { National Oceanic and Atmospheric Administration } \\
\text { Covered } \\
\text { Technical \& Period }\end{array}$ \\
\hline
\end{tabular}

15. Supplementary Notes

16. Abstracts

The seasonal variability of the dispersion of the particulate phase of industrial chemical waste has been studied with acoustic backscattering techniques at Deep Water Dumpsite 106 (DWD 106). The vertical dispersion of the particulates has been found to be strongly dependent on the depth of the mixed layer and the magnitude of the density gradient associated with the seasonal thermocline. The horizontal dispersion of the particulates as a function of depth has been found to be strongly dependent on the shear present in the water column. Entire waste plumes have been found to be advected out of the dumpsite in less than 24 hours when the area is occupied by a warm core ring.

Simple calculations based upon Stoke's law are presented to reveal the impact of variable oceanic density structure on the sink rate of particles and to indicate

17. Key Words and Document Analysis. 170. Descriptors

1. Acoustic detection of chemical waste particulates at Deep Water Dumpsite 106

2. Dispersion of chemical waste particles in the open ocean

3. Design characteristics of the multifrequency acoustic system

क\% the need for incorporating these considerations into numerical models.

A short discussion is presented on (1) the need to make field measurements on the magnitude of both turbulence and shear in the water column and (2) the need to incorporate shear and turbulence-dependent calculations for the sink rates of particles into those numerical models which may be used to predict the particulate and effluent dispersion rates at DWD 106.

17b. Identifiers/Open-Ended Terms

17e. COSATI Field/Group

\begin{tabular}{|l|l|l|}
\hline 18. Availability Statement & $\begin{array}{l}\text { 19. Security Class (This } \\
\text { Report) } \\
\text { UNCLASSIFIED }\end{array}$ & $\begin{array}{l}\text { 21. No. of Pages } \\
153\end{array}$ \\
$\begin{array}{l}\text { 20. Security Class (This } \\
\text { Page } \\
\text { UNCLASSIFIED }\end{array}$ & \begin{tabular}{l}
22. Price \\
\hline
\end{tabular} \\
\hline
\end{tabular}



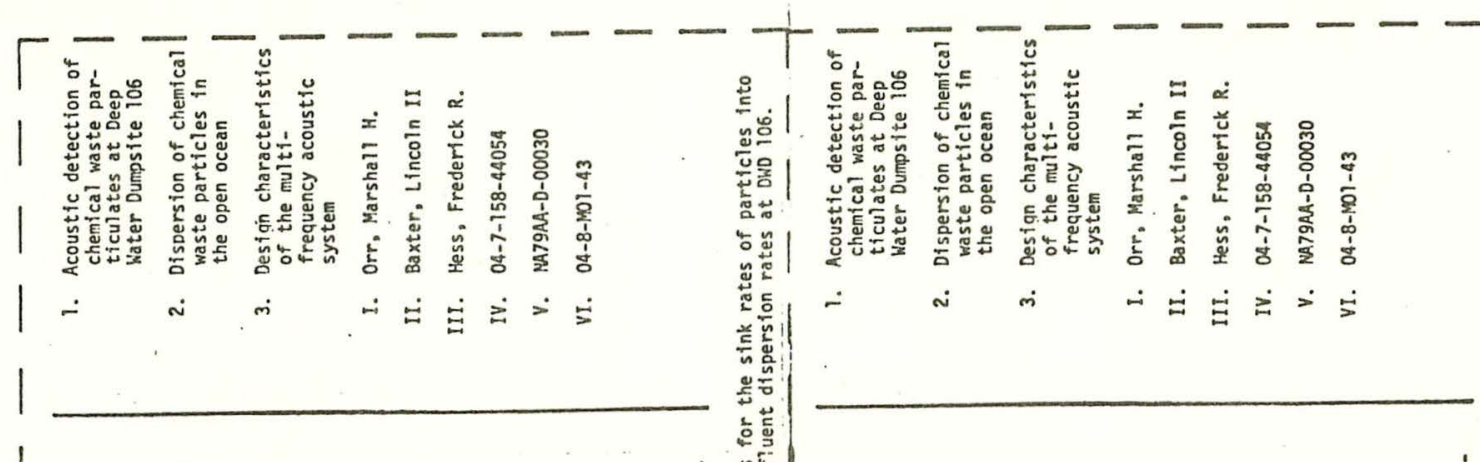

娄

눟울

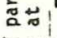

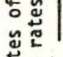

政

ㄴ.

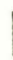

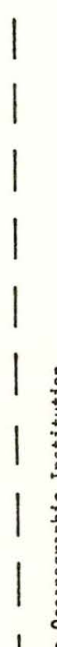

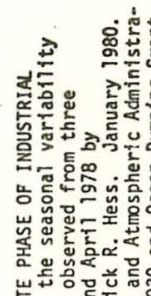

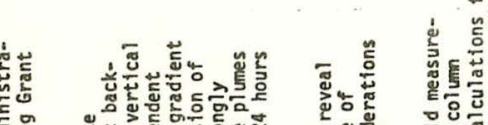

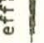

5드의

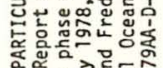

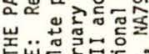

능

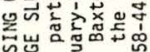

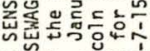

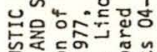

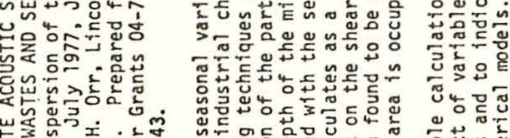

|

윴

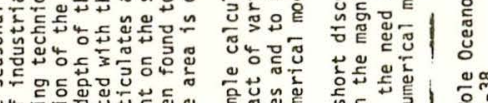

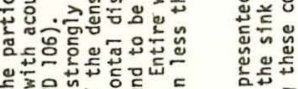

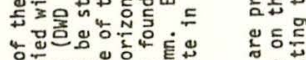

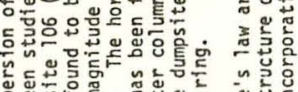

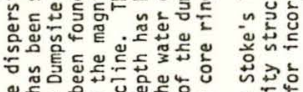

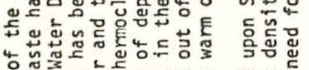

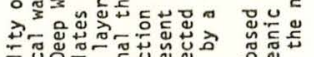

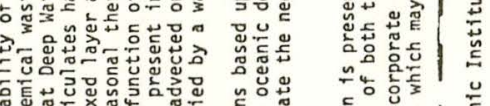

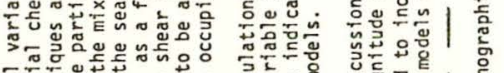

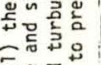

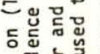

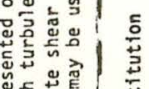

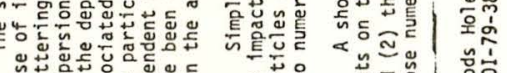

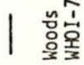

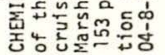

that:

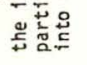

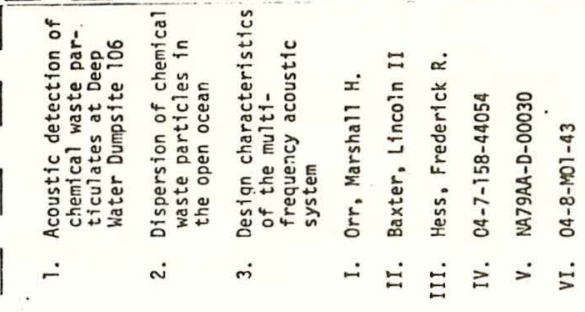

1

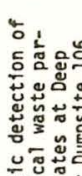

整高

แ。

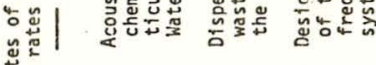

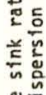

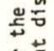

额

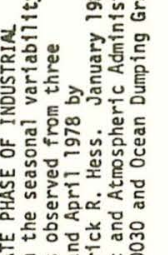

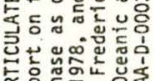

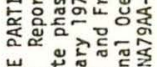

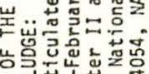

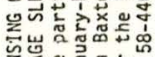

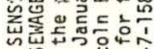

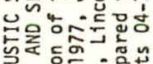

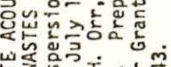

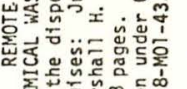

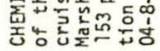

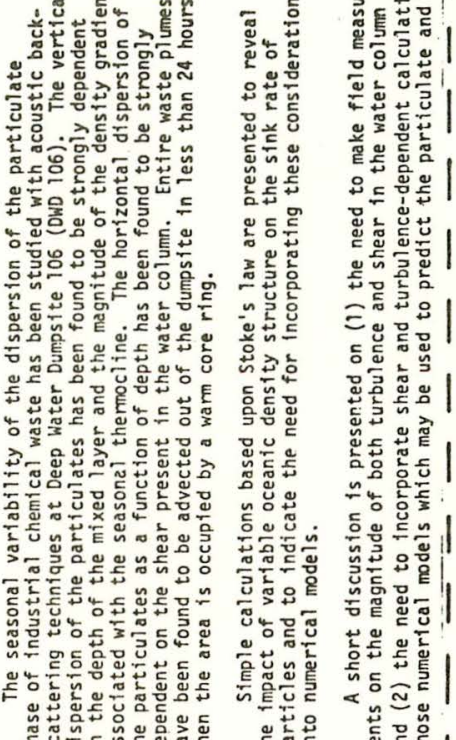

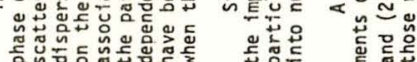

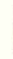

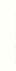

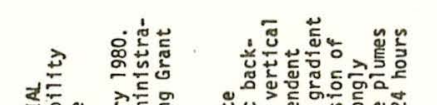

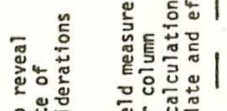

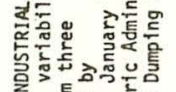

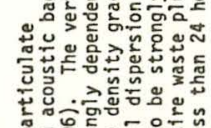

政

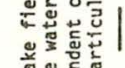

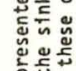

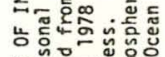

等

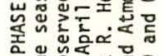

\$o

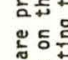

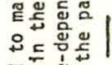

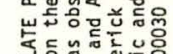

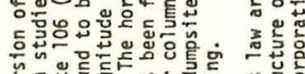

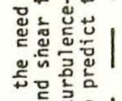

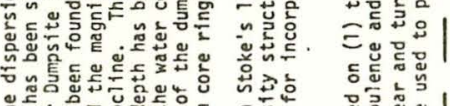

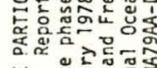

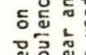

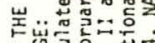

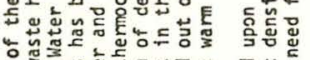

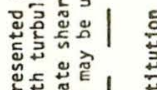

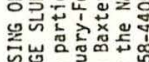

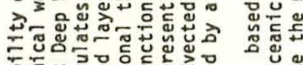

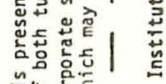

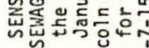

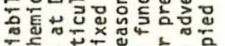

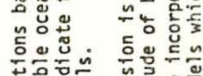

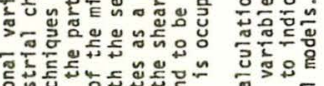

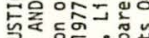

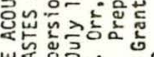

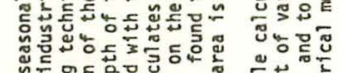

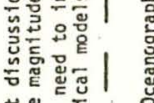

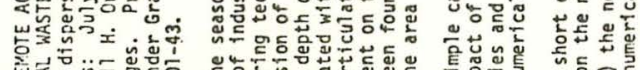

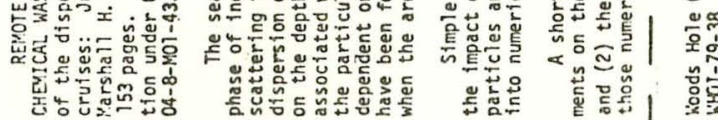

Un:

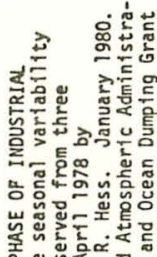

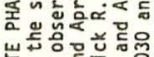

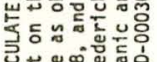

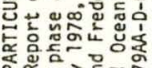

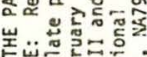

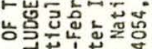

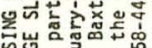

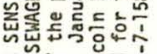

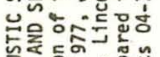

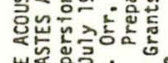

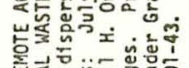

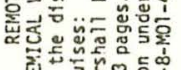

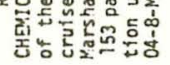

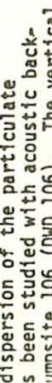

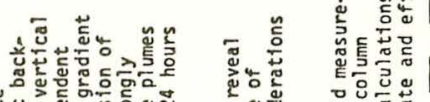

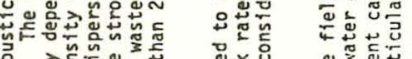

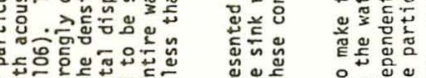

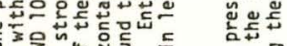

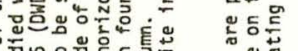

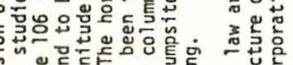

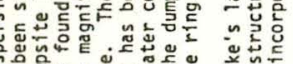

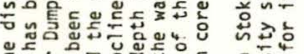

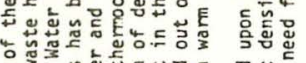

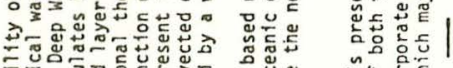

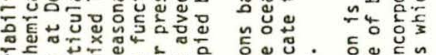

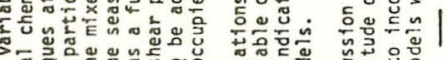

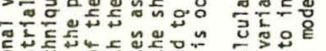

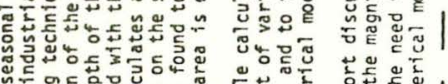

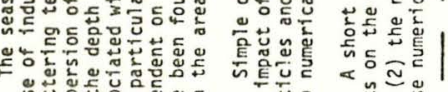

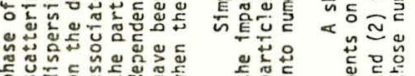

